\title{
Au seuil du monde divin : reflets et passages du dieu d'Ālanturai à Pullamańkai
}

Charlotte Schmid

\section{Citer ce document / Cite this document :}

Schmid Charlotte. Au seuil du monde divin : reflets et passages du dieu d'Ālanturai à Puḷamankkai. In: Bulletin de l'Ecole française d'Extrême-Orient. Tome 92, 2005. pp. 39-157;

doi : https://doi.org/10.3406/befeo.2005.5983

https://www.persee.fr/doc/befeo_0336-1519_2005_num_92_1_5983

Fichier pdf généré le 08/11/2019 


\section{Résumé}

Charlotte Schmid

Au seuil du monde divin : reflets et passages du dieu d'Ālanturai à Puḷ̂amańkai

Cet article présente le temple de Puḷamankai, temple cōla de la fin du IXe ou du début du Xe siècle. L'analyse de l'architecture, du programme iconographique et du corpus épigraphique du temple fait apparaître celui-ci comme un espace de rencontres entre plusieurs mondes, où, à travers des formules iconographiques et littéraires tant shivaïtes que vishnouites bien identifiées, se manifeste une divinité particulière. Ce dieu est le Mahādeva d'Ālanturai, ainsi nommé dans les inscriptions du temple et dans l'hymne que le Tēvāram consacre au site, en une correspondance remarquable. L'étude ici présentée analyse en particulier la relation entre les divinités du temple et les dieux pan-indiens ; elle tente aussi de rendre compte de l'unité du projet iconographique et rituel dont ce temple nous paraît être le résultat. Les frises narratives du soubassement sont disposées de façon à souligner la puissance de Śiva, qui s'avère être ici à l'origine d'un cycle consacré au Rāmāyana. Vișnu, la déesse à qui on offre la tête du buffle et les différentes formes de Siva qui animent les murs du temple ne seraient-elles pas, en définitive, les différentes formes prises par le dieu d'Ālanturai attaché à cet espace où se dresse le temple ?

Les inscriptions forment le second volet de l'étude. Elles sont la marque des fidèles dans l'espace du temple, où ils rendent hommage au dieu en lui donnant des terres qui permettent à la fois à la divinité d'être adorée (grâce au revenu du capital accumulé) et de se constituer en ce monde mortel un territoire spécifique sur lequel régner. La relation entretenue avec le pouvoir central, c'est-à-dire le roi, qu'elle soit artistique, administrative ou financière se révèle changeante au cours des deux siècles où les inscriptions font revivre le temple. Elle confirme ainsi qu'on n'a pas affaire à une fondation royale, hypothèse antérieure qui expliquait le raffinement de la sculpture du temple et l'importance donnée dans l'iconographie à Rāma. La présentation du corpus épigraphique complet du temple que fait le Dr G. Vijayavenugopal nous donne en effet accès à une information précieuse, car nouvelle et très détaillée. Venue du cœur du sanctuaire contenant un linga qui se manifeste aussi sur la face ouest du temple, l'incarnation du dieu s'achève dans ces écrits personnels et datés : ici habite le dieu d'Ālanturai.

\section{Abstract}

Charlotte Schmid

At the doors to the world of the gods: mirrors and windows for the god of Ālanturai at Pullamankai This article presents the temple of Pullamankai, a superb cōla period temple of the end of the 9th or of the beginning of the 10th century. Analysis of its architecture, its iconographical program and of the corpus of inscriptions engraved on this temple reveals it to be a space of encounters between several worlds, where through well identified Shaiva or Vaishnava iconographical and literary formula a particular divinity manifests itself. This divinity is the Mahādeva of Ālanturai, named thus both in the inscriptions of the temple and in the poem devoted to the site that has been anthologised in the Tēvāram, in a remarkable agreement. The study presented here analyzes the relation between the deities of the temple and the pan-Indian gods; it also tries to account for the unit of the iconographic and ritual project of which this temple appears to us to be the result. The narrative friezes of the base are so arranged in order to emphasise the power of Śiva, who proves here to be at the origin of a cycle devoted to the Rāmāyana. All the gods here Vișnu, the Goddess to whom one offers the head of a buffalo and the various forms of Śiva which animate the walls of the temple - are they not, ultimately, the various forms taken by the god of Âlanturai, who is attached to this place where the temple rises?

The inscriptions of the site form the second part of the study. They mark the presence of the devotees in the space of the temple, where they pay homage to the god by giving him lands which make it possible at the same time for him to be worshipped (thanks to the income of the accumulated capital) and to constitute in this mortal world a specific territory over which to reign. The relations maintained with central power, i.e. the cōla kings, wether artistic, administrative or financial appears to change over the course of the two centuries in which inscriptions gave this temple life. The epigraphical record confirms thus that we do not have here a royal foundation, an assumption made earlier to explain the exceptional refinement of the sculpture of the temple and 
the temple which has been prepared and presented by Dr. G. Vijayavenugopal indeed furnishes invaluable information that is both new and very detailed. Radiating from the heart of the sanctuary containing one linga which is echoed by the lingodbhava representation on the western face of the temple, the incarnation of the god reaches even into these personal and dated writings: the god of Ālanturai lives here. 


\title{
Au seuil du monde divin : reflets et passages du dieu d'Ālanturai à Pullamañkai
}

\author{
Charlotte SCHMID
}

«When he [Śiva] following automatically that law of coercive magic, gives a demon a disastrous, world-destroying boon, as he does to Rāvana, Hiranyakasipu, and others, it is Visnu who incarnates himself to save the world - he is the loophole, as Siva is the law. Siva is the contract, but Viṣnu reads the small print. »

\author{
A. K. Ramanujan, "Where Mirrors are windows", Collected Essays of \\ A.K. Ramanujan, Oxford University Press, 1999, p. 21.
}

« La vaillance qui est la tienne,

Toute sans en rien omettre, Tout au fond du cour qui est le mien, Je l'ai représentée en moi $^{1}$ [comme] sur la paroi d'un mur ${ }^{2}$. Pour que se soumette le roi, la hache à la main, Seigneur Rāma, Tu es venu en moi, mon dieu, Maintenant où aller?" Periyālvārtirumoli $i, 5,3,7$. *

\author{
unnutaiya vikkiramam \\ ongru oliyāmal ellām \\ ennutaiya neñcakampāl \\ cuvarvali elutikkontēen \\ man atankka malu valankaik \\ konța irāma nampī \\ ennitai vantu emperumān \\ ini enkup pokingratē?
}

\begin{abstract}
* Remercier ici tous ceux qui m'ont aidée dans l'étude du temple de Pullamańkai est un grand plaisir, et tout d'abord M. Kumar qui a toujours ouvert les portes du sanctuaire où il officie. Je remercie pour l'intérêt manifesté, le savoir dispensé et l'aide apportée toute l'équipe du centre de l'École française d'Extrême-Orient à Pondichéry et mes généreux collègues tamoulisants et historiens, Jean-Luc Chevillard, Emmanuel Francis, Valérie Gillet, T. V. Gopal Iyer ( $\dagger$ ), Dominic Goodall, R. Varada Desikan, G. Vijayavenugopal et Eva Wilden qui ont patiemment lu des textes ou exploré des temples avec moi. Merci à Shanti Rayapoullé de s'être penchée sur les identifications des scènes narratives et à Dominique Soutif pour ses compétences graphiques. J'espère que tous ceux qui m'ont permis une meilleure compréhension du corpus épigraphique, en particulier Emmanuel Francis, Leslie Orr et N. Ramaswamy, dit Babu, retrouveront avec bonheur les suggestions qu'ils ont faites. Cet article est dédié à G. Vijayavenugopal, épigraphiste au centre de l'EFEO à Pondichéry, responsable de l'édition du corpus épigraphique : c'est grâce à lui que les inscriptions du temple de Puḷamańkai ont repris vie.

1. Le substantif elutu, lettre, écriture, peinture, dessin, etc., peut être utilisé pour des inscriptions et pour des représentations. Je le traduis par « représenter » pour conserver la double possibilité. Il me semble cependant qu'il ne peut ici s'agir d'inscriptions, celles-ci n'ayant pas pour habitude de rapporter les hauts faits d'une divinité, au contraire des reliefs ornant les murs des temples pallava et cóla. Par ailleurs, il me semble qu'ici le poète évoque la paroi intérieure de son cœur-sanctuaire (voir la note suivante). Or si les inscriptions sont très rarement gravées sur les parois intérieures des murs des temples, certains épisodes mythiques sont parfois représentés en bas-relief à l'intérieur des temples, comme à Pullamankai.

2. C' est grâce à Jean-Luc Chevillard et à Eva Wilden que j'ai mieux compris cette strophe et je les en remercie. La relation syntaxique de cuvarvali, cuvar le «mur » auquel s'ajoute une particule dénotant un locatif (vali i), avec neñcakampāl, où, si l'on interprète pāl, qui signifie « endroit », "partie », " côté », comme un suffixe de locatif, on a deux, voire trois, indications de lieu qui se succèdent, puisque le «akam » de neñcakam correspond aussi à une indication de lieu (au fond, à l'endroit de) qui est ambiguë. On peut aussi comprendre : « La vaillance [...], au fond de mon coeur et sur le mur », en considérant que les deux termes sont simplement coordonnés ; l'interprétation : « sur la paroi du mur [constituant] la partie intérieure de mon cœur », est aussi possible ; c'est, à mon sens, la plus poétique et la plus en accord avec la conception du neñcam comme sanctuaire du dieu dans le Divyaprabandham. Dans tous les cas, demeure la comparaison du cœur avec un édifice sur les murs duquel on rappelle les hauts faits du dieu, c'est-à-dire un temple, et plus précisément la partie la plus intime, le sanctuaire de ce temple. Peut-être est-ce ainsi qu'il faut comprendre cette succession d'indications de lieu : comme une indication de la profondeur de l'intimité entre le dieu et le poète.
\end{abstract}




\section{Introduction}

Dans le delta de la Kāvēri irriguant le cœur du pays cōla à une dizaine de kilomètres au sud de Kumpakōnam, s'élève à Pull lamańkai un temple d'époque cōlla qu'on appelle aujourd'hui le Brahmāpurīśvara (fig. 1, 2, 3). Rattaché au bourg de Pacupatikōyil, le village ceinture le temple de ses huttes de terre crue ${ }^{3}$. Le corpus dévotionnel shivaïte du Tévāram et les inscriptions du temple désignent la forme de Śiva à laquelle il est consacré comme le dieu d'Ālanturai, « [celui] qui se trouve dans le banian » ou «Celui de l'endroit [où se dresse] le banian ». Les auteurs qui se sont intéressés à ce temple relevant du premier art cōla le considèrent comme une fondation royale ${ }^{4}$. Ils rendent ainsi hommage à la beauté de l'édifice, mais n'en résolvent pas pour autant les énigmes, telles ces frises mythologiques, l'une ornant le soubassement de scènes tirées du Rāmāyana, tandis qu'une autre fait se succéder épisodes mythiques et figures divines, souvent vishnouites, dans un désordre apparent ${ }^{5}$.

Ces récits en images s'avèrent relever d'un programme iconographique précis, qui donne son scns à l'cnscmblc du tcmple, où la place réservée à l'art narratif éclaire les relations entre l'espace sacré shivaïte et les représentations vishnouites. Le corpus épigraphique du temple, largement inédit, tend à confirmer certaines des observations qu'occasionne ce programme iconographique. Mais, affichant des préoccupations humaines sur les murs d'un édifice religieux, il soulève aussi des questions spécifiques. Quelles divinités adorait-on à Pullamañkai ? Celles qui sont représentées sur les murs extérieurs du temple? Celles auxquelles s'adressent les inscriptions? Le dieu loué dans le Tềvāram?

Les relations unissant les hauts-reliefs figurant des dieux, les bas-reliefs représentant hommes et dieux mêlés et les incisions de l'écriture inscrivant les offrandes que les mortels adressent à un autre monde, mettent en valeur l'importance des notions de rencontre et d'échange dans ce sanctuaire. Leur entrelacement dessine le portrait de divinités qui, ancrées dans une histoire et une région particulières, pourraient permettre de mieux comprendre certaines des fonctions du temple durant la première période de son activité.

3. Sur le nom de Pullamankkai, voir la contribution de G. Vijayavenugopal, infra: 107. Les toponymes sont pourvus des signes diacritiques correspondant à leur écriture en tamoul, même s'ils sont, pour tout ou partie, d'origine sanskrite. Nous n'avons pas modifié l'orthographe française usuelle de Tañjore et de Darasuram : outre que ces sites sont très connus, ils ont tous deux été l'objet de publications utilisant cette orthographe dans leurs titres.

4. D. Barrett 1974 : 70 ; D.T. Sanford 1979 : 259 ; G. Hoekveld-Meijer 1982 : 298 ; S. Swaminathan $1998: 202,214$; infra : 48-50.

5. Voir Ch. Schmid 2002. Le cycle narratif correspond sur un temple à la représentation en images, suivant une narration continue, d'un texte narratif. Il est constitué d'une succession d'actions présentées comme des scènes. Les cycles cōla sont, avec les cycles hoysala qui s'en inspirent, les exemples les plus beaux et les plus complets de ce genre, apparu au Iv' siècle de notre ère et lié, me semble-t-il, à l'émergence de la littérature puranique. 


\section{Un temple shivaïte du premier art cōla}

\section{Présentation du temple : petits temples «cōla » et fondations royales ${ }^{6}$}

La datation de la structure actuelle nécessitant une étude comparative des données architecturales et épigraphiques, il est plus prudent de déterminer une fourchette chronologique ${ }^{7}$. James C. Harle $(1958: 6)$ considère la date 918 apparaissant dans l'une des inscriptions comme un terminus ante quem. Douglas Barrett (1974: 70) évoque la même inscription et étudie une série de plans pour déterminer un intervalle probable entre 910 et 920 . Dans son étude sur l'architecture du premier art cōla, Gerda Hoekveld-Meijer ( 1982 : 121) se prononce en faveur de la fin du ix ${ }^{\mathrm{e}}$ siècle, après un examen serré de l'évolution régionale de l'architecture sacrée. Enfin, M. A. Dhaky (Meister-Dhaky 1983 : 165) évoque une inscription qui serait datée de la troisième année du règne de Parāntaka I ${ }^{\text {er }}$ pour préciser une datation basée par ailleurs sur des considérations de style, obtenant la date de 910. L'inscription en question n'apparaît dans aucune publication et nous ne l'avons pas retrouvée sur le bâtiment tel qu'il se présentait entre 2001 et 2005. En l'absence de références plus précises, il paraît donc préférable de ne pas en tenir compte ${ }^{8}$. Il reste que les datations proposées se situent à peu près toutes dans la même fourchette, soit entre la fin du $I X^{\mathrm{e}}$ et le début du $\mathrm{x}^{\mathrm{e}}$ siècle.

Il faut également préciser que l'hymne 1.16 du Têvāram, que Campantar composa à la gloire du dieu Ālanturai de Puḷamañkai, témoignerait en fait de la présence

6. L'utilisation de l'adjectif $c o ̄ l a$ renvoie ici simplement à la période considérée. La datation en années régnales de dirigeants $c \bar{l} l a$ des inscriptions du temple la justifie en partie. Signalons cependant qu'à la lecture des ouvrages majeurs sur le sujet, son usage semble parfois excessif. Les travaux de S. R. Balasubrahmanyam (1963, 1966, 1967a et b, 1969, 1971, etc.) forment en effet la base des études postérieures. Or cet auteur forge ce qu'on pourrait appeler une forme de mythe $c \bar{l} \underline{l} a$ : la grandeur de cette dynastie éclipse, dans ses études, toutes les autres, qu'il s'agisse des Pāntiya ou de ces clans qui occupèrent des territoires moins considérables, comme les Muttaraiyar, les Irukkuvel et les Paluvēttaraiyars dont il sera justement question dans cet article (infra: 88-93). Si l'influence considérable des ouvrages de S. R. Balasubrahmanyam n'a pu occulter entièrement l'importance dans le domaine artistique des autres dynasties, dont font état certains auteurs, comme P. Kaimal (2003), il reste que « cōla » qualifie souvent encore bien des temples dont il n'est pas avéré qu'ils relèvent de la sphère artistique de cette dynastie.

7. Selon G. Hoekveld-Meijer (1982: 216-218), le temple est l'un des plus anciens du delta de la Kāvēri. Il serait antérieur à 890 . En fait cette auteure flotte entre plusieurs datations, se basant principalement sur le type et le nombre des niches ornant les murs extérieurs, et sur le développement de la hauteur du sanctuaire, inhabituelle à Puḷlamańkai, premier temple à trois étages jamais construit sous la dynastie $c \bar{l} \underline{l} a$, du moins dans le corpus que nous connaissons.

8. L'année de règne mentionnée par M. A. Dhaky me fait penser qu'il s'agit de l'inscription $n^{\circ} 14$ du corpus, qui est attribuée dans cet article, comme dans la publication antérieure dans South Indian Inscriptions [SII], à Uttama Cōla. La date de cette inscription est donnée de façon particulière. Elle correspond à la troisième année du règne d'un Parakēcari, titre porté à la fois par Parāntaka I ${ }^{\mathrm{er}}$ et par Uttama Cōla. D'autres éléments, commentés par G. Vijayavenugopal (infra: 7()) vont dans ce sens. Ajoutons que la procédure de vente, particulière, se retrouve dans l'inscription 15, datée du règne de Rājarāja I I ${ }^{\mathrm{er}}$. Tous ces éléments concourent à faire douter fortement de l'attribution de cette inscription 14 au règne de Parāntaka Ier. 


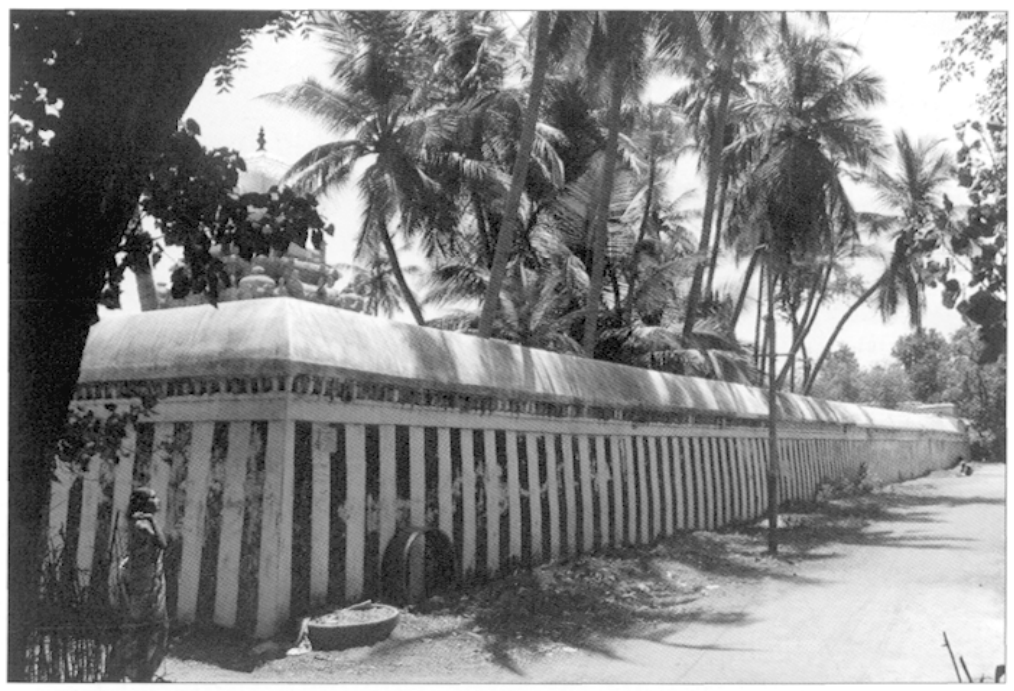

Fig. 1. Le temple derrière l'enceinte moderne, angle sud-ouest.

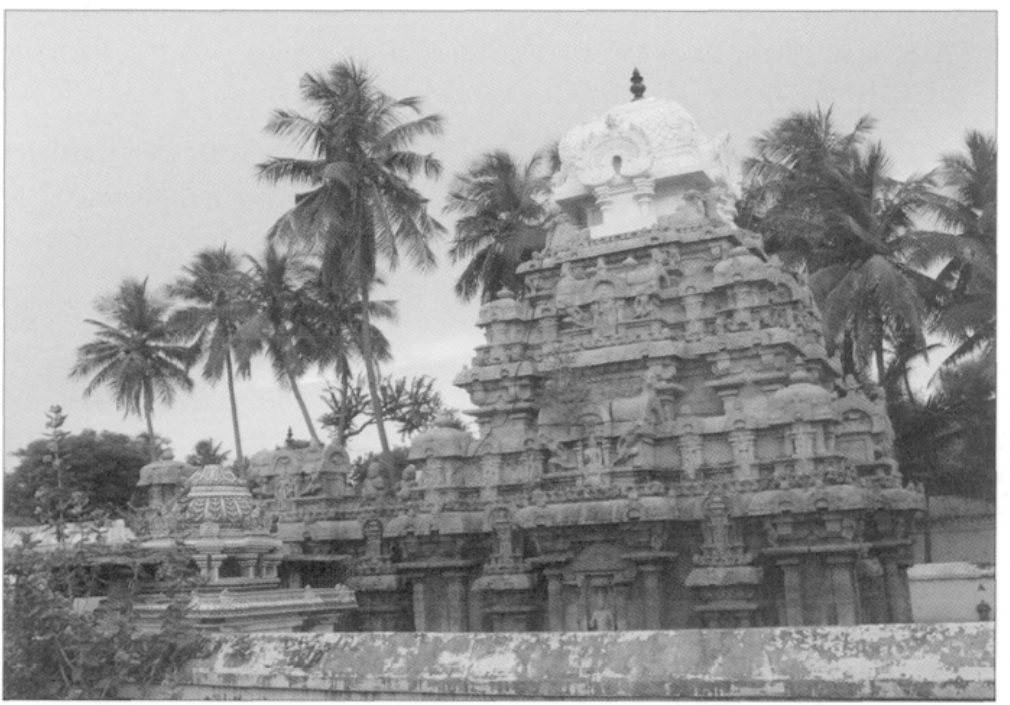

Fig. 2. La face nord du temple, vue de l'extérieur de l'enceinte. Cliché : E. Francis.

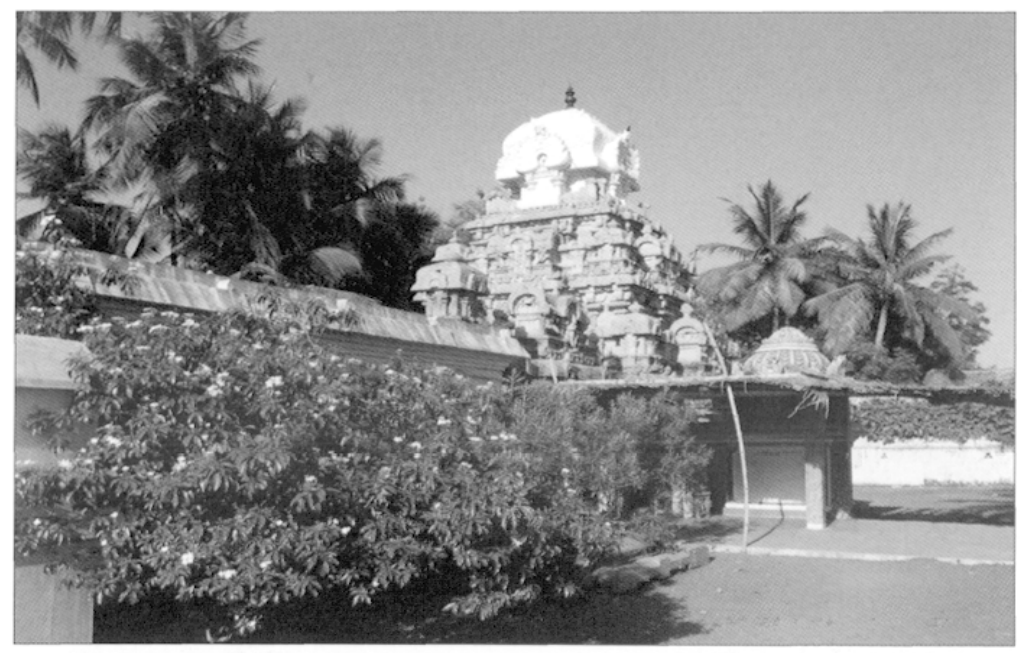

Fig. 3. La face nord du temple, vue de l'intérieur de l'enceinte. Cliché : E. Francis. 


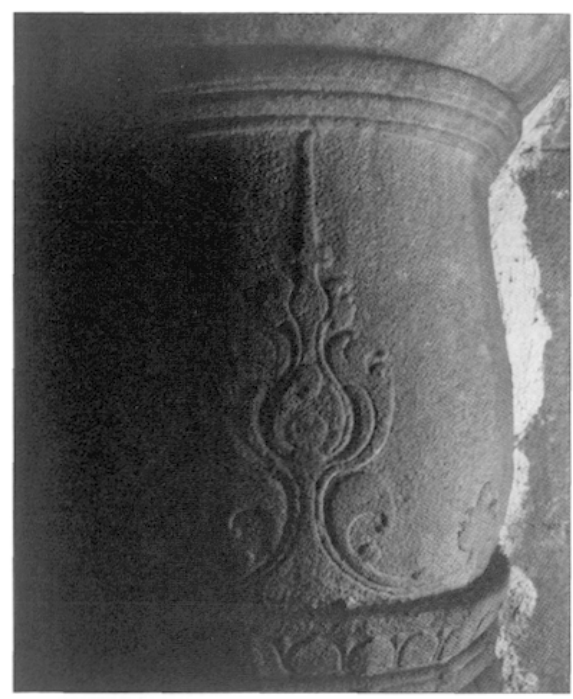

Fig. 4

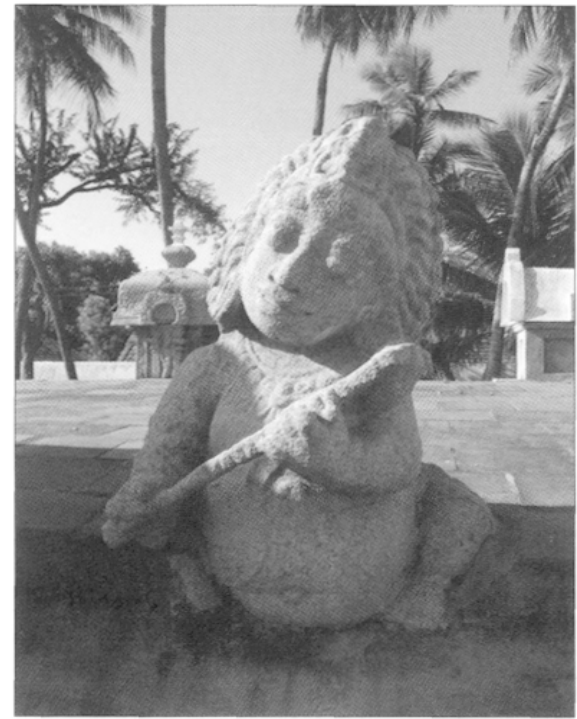

Fig. 6

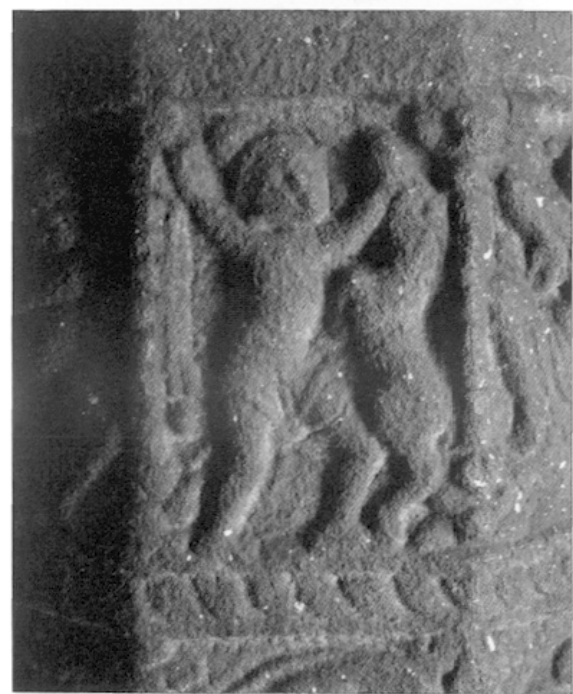

Fig. 7

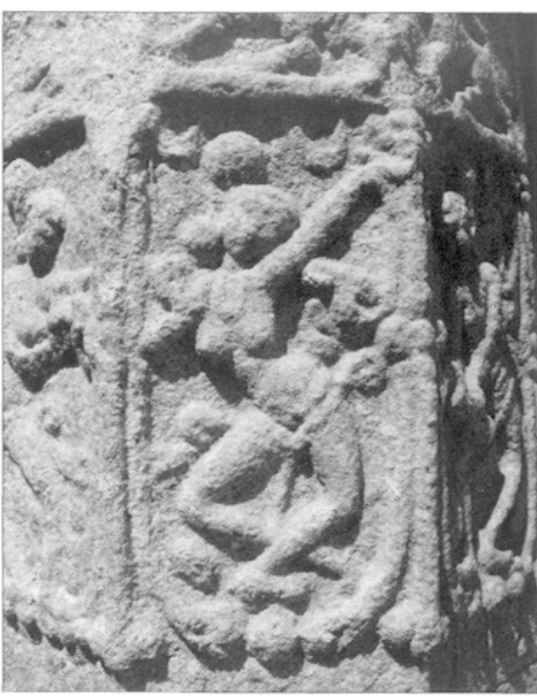

Fig. 5

Fig. 4. Elément de décor sur un pilier intérieur. Cliché : E. Francis.

Fig. 5. Détail du décor d'un pilastre extérieur. Cliché : E. Francis.

Fig. 6. Un gana, ornant le bord du toit du mandapa, (face sud). Cliché : E. Francis.

Fig. 7. Krṣ̣na luttant contre Keśin, décor de pilastre (face sud). Cliché : E. Francis.

Fig. 8. Temple en réduction carré marquant I'angle du mandapa (angle sud-est). Cliché : E. Francis.

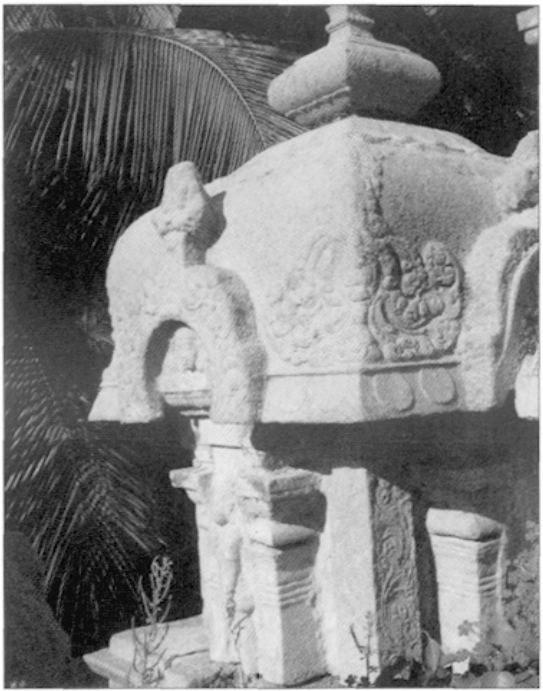

Fig. 8 
d'un sanctuaire antérieur dédié à cette forme de Śiva dans la région ${ }^{9}$. L'hymne atteste l'ancienneté du nom du lieu «Pullamańkalam » et de celui de la divinité «Ālanturai » qui y est attachée. L'édifice visible aujourd'hui pourrait donc avoir succédé à un sanctuaire plus ancien, élevé entre le viI et le $\mathrm{IX}^{\mathrm{e}}$ siècle ${ }^{10}$.

Comme les autres temples du premier art $c \bar{l} \underline{l} a$, celui d'Ālanturai de Puḷamañkai est en pierre et assez petit. La qualité de la décoration sculptée y est exceptionnelle (fig. 4, 5, 6, 7, etc.). Les éléments d'architecture employés dans le décor renforcent le lien entre architecture et décor sculpté, qui est ici particulièrement étroit (fig. 8).

Le Brahmāpurīśvara se dresse dans une enceinte ornée à l'est d'un gopura qui, comme le grand mandapa ouvert joint au mandapa cōla, n'est pas antérieur au $\mathrm{XVI}^{\mathfrak{e}}$ siècle et comporte bien des éléments plus tardifs (fig. 3) ${ }^{11}$. Le prāsāda cōla est parfaitement carré. Contrairement à la majorité des temples du premier art $c \bar{l} \underline{l} a$, aucun élément (couloir, dénivelé du sol) ne marque de séparation intérieure avec le maṇapa. La répétition des mêmes éléments architecturaux du prāsāda au maṇdapa assure la cohésion extérieure : projections centrales creusées par les niches abritant les images (devakoștha), «pañjara» qui les encadrent de leurs niches allongées en hauteur inscrites dans une projection plus faible, et larges projections situées aux angles des deux parties du bâtiment (fig. 10) ${ }^{12}$. Faisant courir les mêmes frises

\footnotetext{
9. Dans son introduction à l'édition du Têvāram établie par T. V. Gopal lyer, François Gros situe le mouvement de bhakti auquel se rattache le texte entre le $\mathrm{VI}^{\mathrm{E}}$ et le $\mathrm{Ix}$ siècle, puis se montre en faveur d'une datation du corpus dans le cours du vil siècle. Je reprends ici cette datation du Têvāram, qui paraît raisonnable. Cependant aucun des arguments avancés ne permet, en définitive, d'exclure une date plus basse. Le phénomène d'ancrage d'un dieu en un lieu précis dont témoignent les inscriptions du temple d'Ālanturai à Pullamanakai (infra: 66-67), correspond au développement du Têvāram, qui fixe un dieu en un lieu auquel s'attachent les hymnes du corpus et une date plus basse, vers la fin du VIII ${ }^{\mathrm{e}}$ siècle, pourrait, me semble-t-il, être proposée. Les correspondances dont François Gros fait état (Ibid. : XVIII-XIX), entre les monuments pallava et le mouvement de bhakti sont ténues, et il me paraît plutôt que l'art pallava, qui connaît au début du vIII ${ }^{\mathrm{e}}$ siècle un bel épanouissement, a peu de relations avec le Tēvāram.
}

10. Le sanctuaire auquel le chant de Campantar était attaché à l'origine peut ne pas s'être élevé exactement au même endroit. J. C. Harle (1958:5) considère que de gros blocs de pierre empilés sans mortier que l'on observe dans une partie du mur d'enceinte au nord du temple témoignent de l'existence d'une structure antérieure. Peut-être a-t-il raison. Cependant les réemplois du vil' siècle sont bien plus nets, par exemple, dans la même région du delta de la Kāvēri, au temple cōla de Tirucennampūnti daté du $x^{c}$ siècle. J.-L. Chevillard (2000) a montré qu'un même hymne du Têvāram peut être rattaché à des structures matérielles se succédant dans le temps sans s'élever au même endroit, même si elles restent proches les unes des autres.

11. Afin de simplifier la lecture, nous utilisons le terme mandapa pour désigner la partie de l'édifice cōla qui constitue, avec le prāsāda contenant le linga, le temple lui-même. D’autres publications désignent cet élément comme ardha-mandapa ou mukha-mandapa, termes qui soulignent sa dépendance par rapport au präsäda mais introduisent parfois une certaine confusion.

12. Le pañjara est une niche allongée en hauteur, de faible relief, couronnée d'un élément architectural en réduction et possédant le plus souvent, comme à Pullamañkai, sa propre base. Je me réfère ici à la définition qu'en donne G. Hoekveld-Meijer (1982:112), correspondant à l'usage que fait également du terme D. Barrett (1974), mais pas au glossaire de M. Meister-M. A. Dhaky (1983 : 292) pour lesquels le pañjara est un fronton, couronnant un pañjarakostha, dont la définition correspond au pañjara de G. Hoekveld-Meijer. C'est la Marīci-sam hitā donnant explicitement le pañjara comme un « édicule en forme de niche " (Marici-samhitā 10.1, 35.1.1, pour le texte et la traduction : Colas 1986: 129, 192), qui me fait préférer la définition de G. Hoekveld-Meijer. 
tout autour du temple, le soubassement assure également l'unité architecturale de l'édifice. Les murs extérieurs du prāsāda et du maṇ̣̂a apparaissent ainsi, de façon exceptionnelle, constitués de la même manière par une succession de projections architecturales, déployées de chaque côté d'une niche centrale abritant une image divine (fig. 19) ${ }^{13}$.

Le prāsāda est marqué par un couronnement exceptionnel, comportant deux étages (fig. 2, 3 et 10). Ce dernier confère à l'édifice une verticalité renforcée par les pañjara qui, naissant en dessous des niches centrales, interrompent l'empilement horizontal du soubassement. Les éléments architecturaux et les élégantes silhouettes qui constituent le couronnement de ces niches particulières marquent une appartenance - à première vue décorative - nouvelle (fig. 11, 12, 13, 14, 15). Les pañjara sont en effet issus de l'art pallava (J. C. Harle 1958 : 9 ; G. Hoekveld-Meijer 1982 : 116), mais où ils abritaient des figures sculptées ${ }^{14}$. Sanctuaires en réduction s'ouvrant sur l'extérieur, les niches centrales sont surmontées d'un temple miniature allongé (fig. 14), qui répond aux quatre «mini-temples » carrés des angles du toit plat du mandapa (fig. 8). Rares dans l'art cōla, ces temples en réduction du toit sont aussi des survivances pallava et marquent, entre autres, l'ancienneté de l'édifice.

Le programme iconographique est celui de la majorité des temples shivaïtes cōl $a$ antérieurs à la période de Rājarāja $\mathrm{I}^{\text {er }}{ }^{15}$. Gaṇeśa occupe la niche sud du

La cohésion de l'édifice de Pullamankai est plus marquée que dans les deux autres sanctuaires relevant du premier art cōlla, Tiruppūranpyam où l'on retrouve des pañjara sur les deux éléments du temple mais ils sont de type différent sur le prāsāda et sur le mandapa, et Karantai, où les pañjara sont certes les mêmes mais composés d'éléments différents de ceux des niches.

13. D. Barrett ( $1974: 40$ ) souligne le caractère exceptionnel des façades « continues » de Pullamańkai : l'organisation des murs extérieurs du maṇạpa et du prāsāda est différente dans les temples du premier art cōla qu'étudie cet auteur. Sur l'ambiguîté qu'implique la cohésion étroite du manḍpa et du prāsāda de certains temples cōla, voir P. Pichard 1995:35-36; on peut interpréter le temple, soit comme une tour précédée d'un corps de bâtiment plus bas, soit comme un bâtiment bas et allongé, surmonté d'une tour à l'une de ses extrémités. Encore les édifices évoqués par P. Pichard présentent-ils un couloir séparant les deux éléments principaux du temple.

14. Le terme pallava se réfère dans cet article à ce qui date de la période pallava dans le territoire que dominait cette dynastie et non spécifiquement aux productions de la dynastie pallava.

15. Même lorsque de nouvelles représentations apparaissent sur les murs extérieurs du temple, ce noyau iconographique tend à perdurer. Dans plusieurs publications (par exemple, $\mathrm{S}$. R. Balasubrahmanyam $1964: 32$; L'Hernault $2002: 1$ ), Viṣnu apparaît comme la représentation la plus courante de la face ouest d'un temple shivaïte relevant du premier art $c \bar{l} l a$, jusqu'au $x^{\mathrm{e}}$ siècle. La réalité paraît plus nuancée. Le Vīrațāneśvíara, temple pallava tardif de Tiruttaṇi daté du viII ${ }^{e}$ siècle est l'unique exemple pallava de ma connaissance (à comparer avec les temples shivaïtes de Kāñcīpuram et le Temple du Rivage de Mahābalipuram qui comportent tous des représentations shivaïtes à l'arrière du temple). La recherche menée dans les temples du premier art cōla donne quelques temples comportant ou susceptibles de comporter un Viṣnu dans la niche ouest : le temple de Nankavaram (Balasubrahmanyam 1971 : 40-43), le temple de Tirumalavāți, dont le premier état, représenté par trois statues, un Viṣnu, un Brahmā et une Mahiṣāsuramardinī, daterait du règne d'Āditya I ${ }^{\mathrm{er}}$ (870-907), et le Sundareśvara de Mēlappaluvūr, datant, probablement, de la deuxième moitié du $x^{e}$ siècle puisqu'il porte une inscription du règne d'Uttama Cōla (969-985). Fncore l'emplacement des Viṣnu dans les trois derniers temples est-il incertain car, dans le premier cas, il s'agit peut-être d'un replacement, et dans le second, le temple a été entièrement reconstruit : la statue de Visnu pourrait aussi venir d'un autre temple ; quant au Sundareśvara, on a simplement retrouvé une statue de Viṣṇu dans le complexe, que S. R. Balasu- 


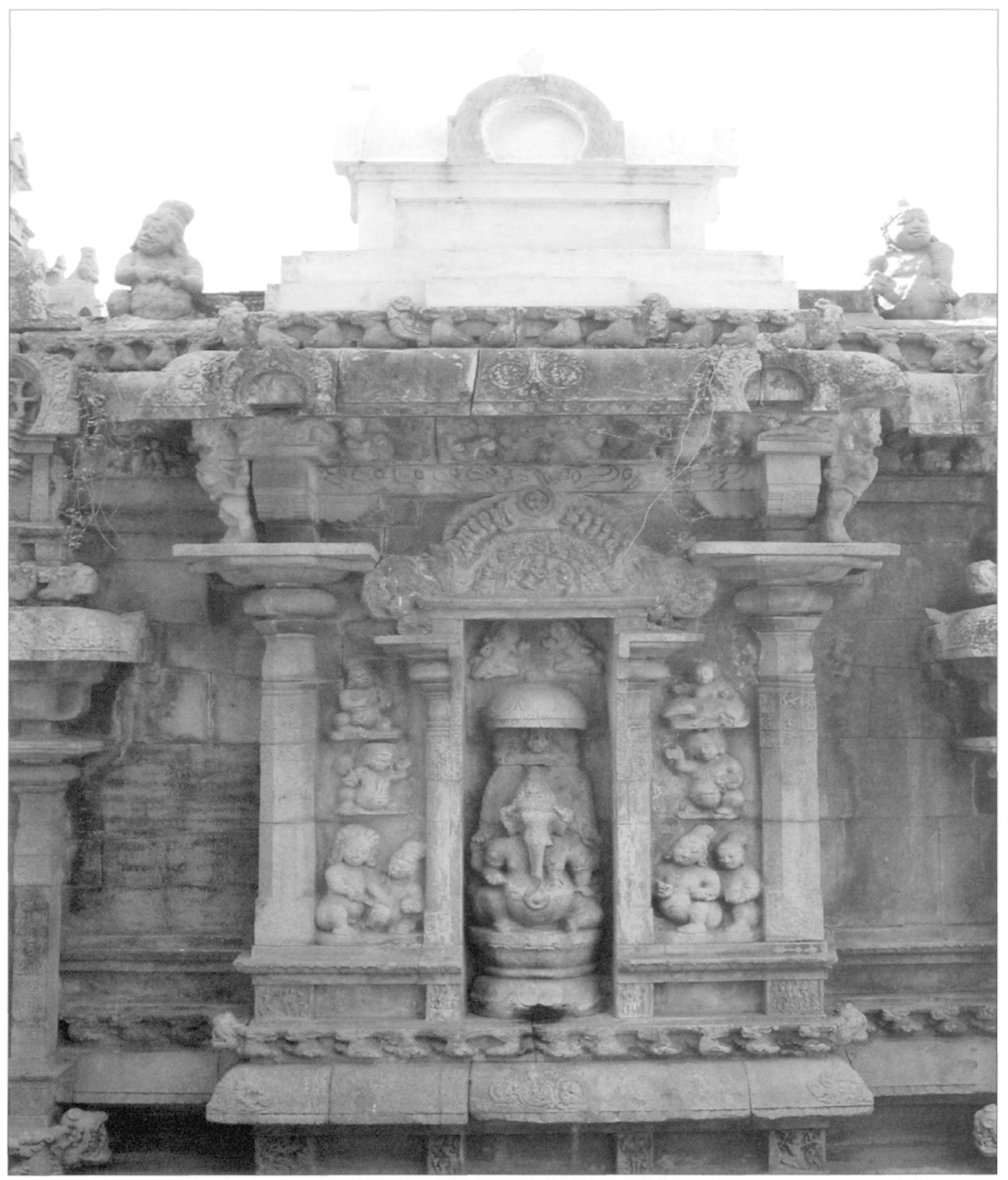

Fig. 9. La face sud du temple : Gaṇeśa et la succession des éléments de décor sur les murs extérieurs. Cliché : E. Francis. 


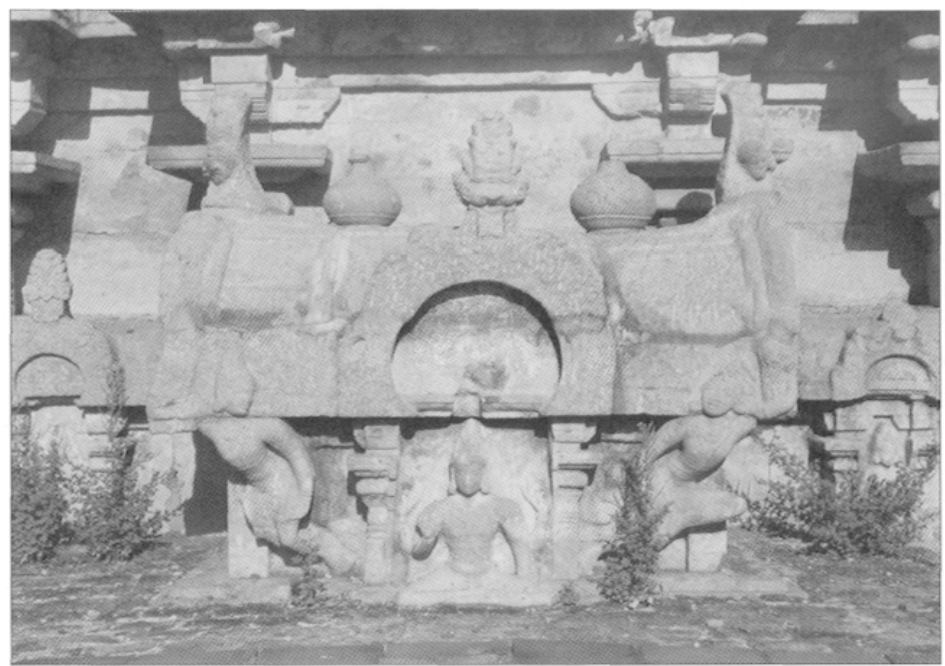

Fig. 11

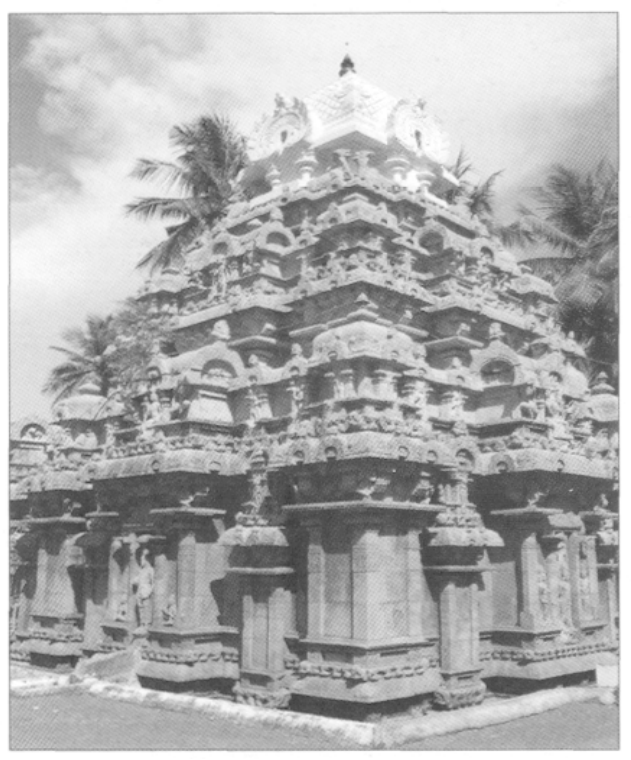

Fig. 11. Śva en posture de méditation, premier étage du couronnement, face est. Cliché : $E$. Francis.

Fig. 10. Le temple, vu de l'angle sud-ouest : on voit se succéder les niches marquant le rythme des murs extérieurs. Cliché : E. Francis.

Fig. 12. Śiva Bhikṣātana, premier étage du couronnement, face sud. Cliché : E. Francis.

Fig. 10

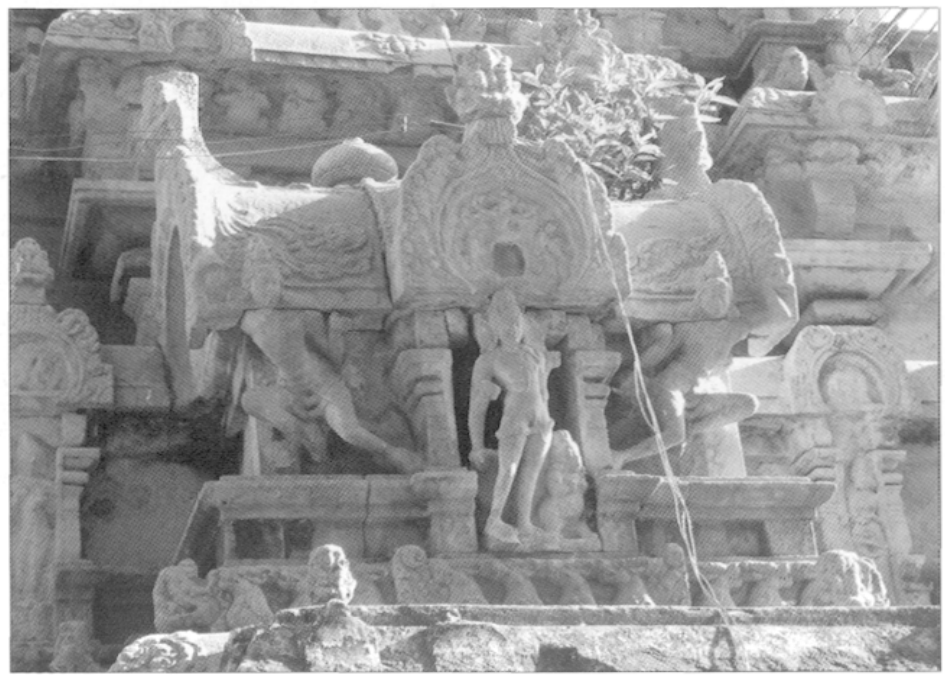

Fig. 12 


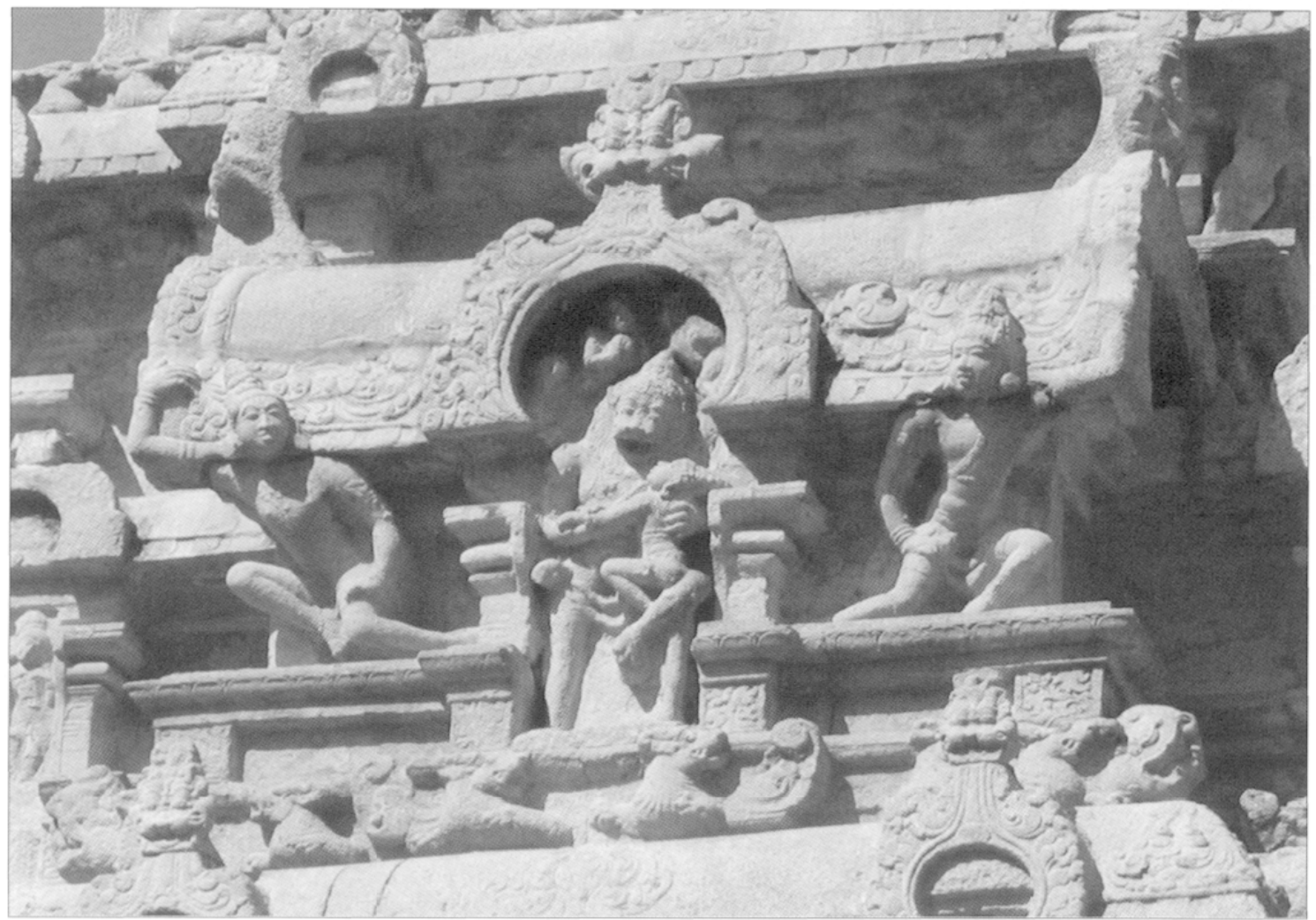

Fig. 14. Narasiṃha, deuxième étage du couronnement, face ouest. Cliché : E. Francis.

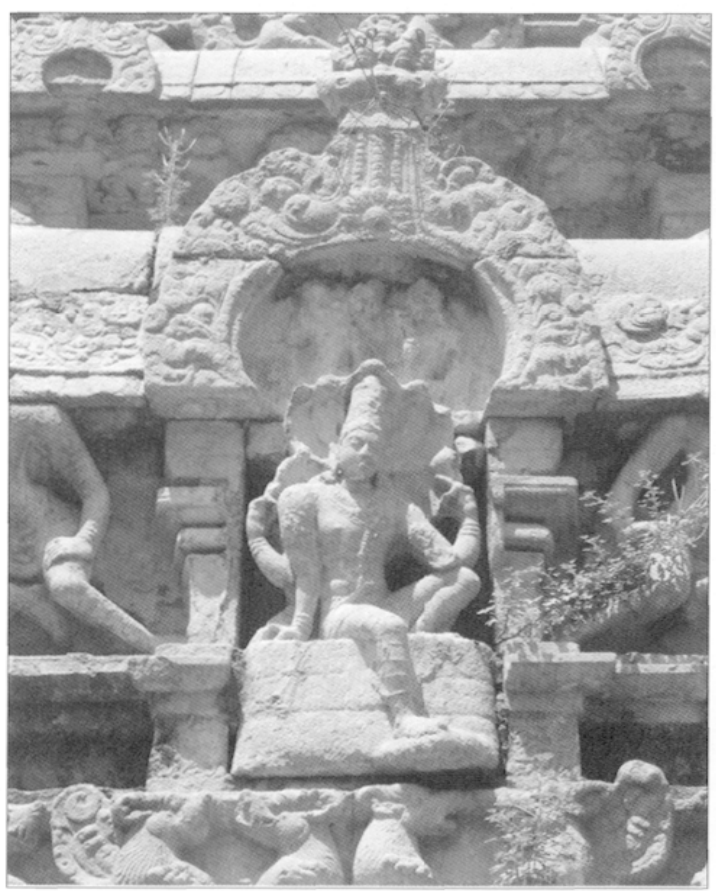

Fig. 13. Viṣnu assis sur le serpent, premier étage du couronnement, face ouest. Cliché : $\mathbf{E}$. Francis.

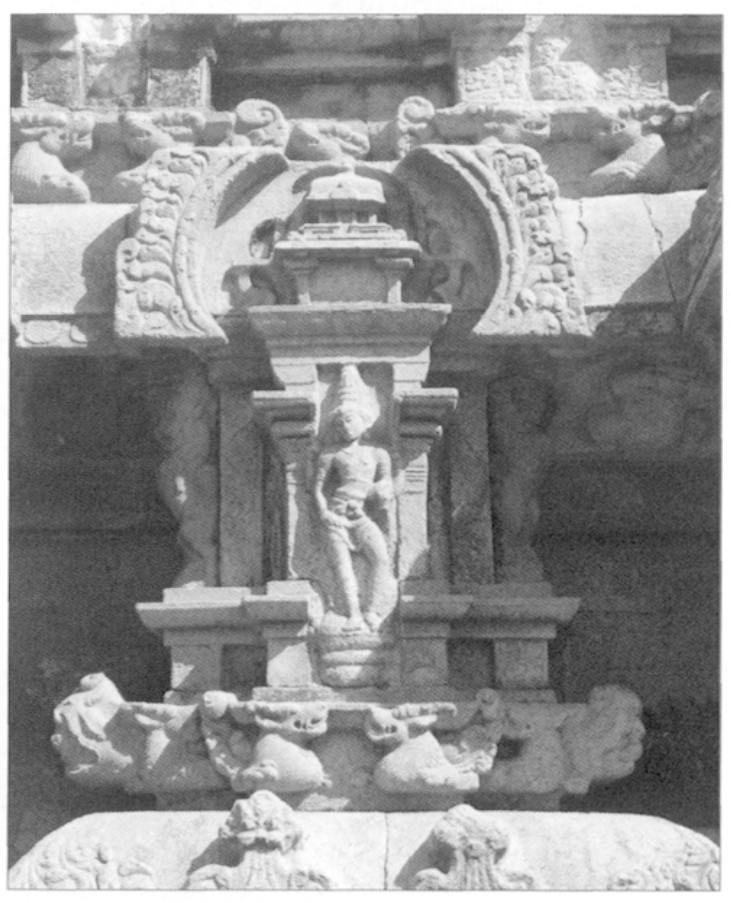

Fig. 15. Rāma et son arc, élément intermédiaire du couronnement, face nord. Cliché : E. Francis. 
mandapa, entre trois niveaux de gana (fig. 9) ; Mahișamardinī se dresse dans la niche nord correspondante, encadrée par ses dévots et ses animaux familiers (fig. 16,17 et 18) ${ }^{16}$; la niche du mur sud du prāsāda a disparu sous le béton d'un sanctuaire dédié à un Dakṣiṇāmūrti originel ; un Brahmā orne toujours la face nord, au-dessus de l'écoulement, entre deux dévots (fig. 19). La face ouest a conservé l'ensemble du dispositif iconographique (fig. 22). Viṣnu et Brahmā y encadrent la niche centrale, ouverte sur l'amande verticale d'un lingodbhava (fig. 23 et 24). Les personnages secondaires représentés de chaque côté de toutes ces niches me paraissent inspirés des dispositifs pallava du $\mathrm{VII}^{\mathrm{e}}$ siècle, où des figures secondaires comparables encadrent souvent les niches centrales du prāsāda. L'étude plus précise de l'iconographie mettra en valeur le caractère alors novateur de ce qui semble constituer a priori un programme classique. D'ores et déjà, la brève présentation de l'édifice qui vient d'être donnée permet de revenir sur certains points des études qui le mentionnent.

Les principales théories portant sur l'évolution de l'architecture cōla ne permettent pas de rendre compte de celle dont témoigne ce petit temple raffiné qui reprend certains éléments pallava. S. R. Balasubrahmanyam fait correspondre un développement graduel de la taille du temple à l'augmentation du nombre et de la taille des niches extérieures, tandis que pour Douglas Barrett, l'architecture se fait plus complexe en fonction de succès politiques ${ }^{17}$. Gerda Hoekveld-Meijer considère pour sa part que le maṇdapa croît avec le développement de l'iconographie, qui nécessite plus de niches extérieures où placer les figures divines. Ces vues sont toutes discutables. À Pullamañkai, il suffit d'ôter les pañjara, ou d'y abriter, comme dans d'autres temples, des formes divines, pour multiplier ces dernières. On aurait aussi pu utiliser les projections des angles. À peu près contemporain de celui de Puñcai, le petit temple de Kōnnnāā, près de Kāñoīpuram, présente un type de temple moins courant mais dont on connaît des exemples. Il ne comporte pas une seule niche, ni une seule grande figure sur les murs extérieurs ${ }^{18}$.

brahmanyam (1963:27), suppose avoir, à l'origine, orné la face ouest du temple. Le Mucukuntesévara de Kotumpālūr comporte bien un Viṣnu à l'ouest (Balasubrahmanyam 1971:24) de même que le Tiruttinatîśsvara de Tintivanam, datant peut-être de la deuxième moitié du $x^{*}$ siècle (Ibid. : 144). Le temple dit Cōlīiśvara à Mēlpāti comporte aussi un Viṣnu dans la niche ouest, mais il date déjà du début du $\mathrm{XI}^{\mathrm{C}}$ siècle. Le couronnement des temples cōla comporte dans la très grande majorité des cas des représentations de Viṣnu à l'ouest, comme c'est d'ailleurs le cas à Pullamańkai.

Dès le $x^{e}$ siècle, bien d'autres temples comportent soit un lingodbhava soit un Hari-Hara à l'ouest. Peut-être l'iconographie du couronnement, dont la face ouest porte souvent, entre le $I^{\mathrm{c}}$ et le $\mathrm{XIII}^{\mathrm{e}}$ siècle, des représentations de Viṣnu, inspira-t-elle cette conception d'un ensemble ouest consacré à Viṣnu. On trouve parfois aussi l'affirmation selon laquelle les temples vishnouites pallava et cōla ouvrent à l'ouest, par opposition à des temples shivaïtes ouvrant à l'est. Les temples shivaiites de Kāñoīpuram ouvrent aussi bien à l'ouest qu'à l'est pourtant, et certains temples vishnouites côla ouvrent à l'est (comme celui de Tiruppuvanai près de Pondichéry), cependant que, par exemple, les deux sanctuaires shivaîtes du temple de Kīlaiyūr, dont l'un est dédié à un «tiruvālanturai mahādeva», s'ouvrent à l'ouest (sur ces deux temples, voir B. Legrand 1987 ; sur le second, le Cōlīśvaram, plus spécifiquement, S. R. Balasubrahmanyam $1963: 20-25)$.

16. Sur la Mahișamardinī de Pullamankai, voir aussi Ch. Schmid à paraître.

17. Dans son article consacré à l'étude du patronage royal cōla aux Ix et $x^{e}$ siècles, P. Kaimal (1996) remet celui-ci en question de façon convaincante : ce faisant, cet auteur fait aussi douter d'un lien fort entre le développement du plan des petits temples et celui de la puissance royale.

18. Le temple de Kōnnnār, par exemple, (voir Ch. Schmid 2002) est un sanctuaire vishnouite ne comportant pas de niches extérieures ; G. Hoekveld-Meijer (1982: 243) signale un autre temple sans niches, «Pennadam ». 
En réalité, ni les niches ni les formes divines ne se multiplient régulièrement. La finesse même des analyses menées par Gerda Hoekveld-Meijer (1982), qui aboutissent presque à créer un type architectural par temple, le montre bien. La taille du mandapa ou le développement de l'iconographie ne peuvent, me semble-t-il, être considérés comme l'explication des dimensions et du nombre de niches dans les murs extérieurs, ou du moins pas systématiquement, et pas dans le cas de l'Ālanturai de Pullamankai. La comparaison avec les données pallava tend également à infirmer un lien entre développement de l'iconographie, dimension des temples et nombre de leurs niches. Les murs extérieurs des temples pallava offrent une iconographie shivaïte plus variée et plus abondante que ces premiers temples cōl ${ }^{19}$. Gerda Hoekveld-Meijer (1982:114) ne sait que faire des pañjara vides de Pullamańkai et doit affirmer à plusieurs reprises que ce temple est une exception à bien des égards. En fait, dans un premier temps, on observe une réduction et non un développement de l'iconographie shivaïte. Ne serait-ce pas plutôt que les auteurs ont tendance à replacer l'architecture religieuse $c \bar{o} \underline{l} a$ par rapport aux grandes fondations royales de Tañjore, de Darasuram et de Gañgaikoṇuacōlapuram ? Entre un petit temple cōla comme celui de Pullamańkai et ces imposants complexes, il est tentant de mettre en valeur développement, agrandissement, multiplication, etc. ${ }^{20}$. Pourtant, les études de Pierre Pichard $(1994 ; 1995)$ ont montré que les grands temples royaux sont de nature radicalement différente. Faut-il tenter de les inclure dans un processus graduel de développement ? On a continué à bâtir des temples de petites dimensions parallèlement aux temples royaux et après ces derniers.

Un autre point a certainement joué en faveur de ce que je serais tentée d'appeler le mythe du patronage royal cōla. Qu'il s'agisse des travaux de S. R. Balasubrahmanyam, de Douglas Barrett ou de Gerda Hoekveld-Meijer, dont la formation est pourtant fort différente, l'art $c \bar{c} l a$ est découpé en tranches correspondant aux règnes des rois connus de cette dynastie. L'utilisation des années régnales cōla dans l'épigraphie pourrait avoir introduit une certaine confusion. Il semble qu'on finisse par supposer souvent que le roi dont l'année de règne constitue une référence chronologique dans l'inscription est le patron du temple sur lequel l'inscription est gravée. L'ensemble des temples construits durant le règne d'Âditya $\mathrm{I}^{\mathrm{er}}$, par exemple, ne doivent pas nécessairement leur existence au patronage qu'exerça ce roi ${ }^{21} \ldots$ Le corpus épigraphique $c \bar{l} \underline{l} a$ tend par ailleurs à se diviser du point de vue de l'intervention royale. Le roi apparaît peu dans les inscriptions des temples des $I X^{\mathrm{e}}$ et $\mathrm{X}^{\mathrm{e}}$ siècles. À partir du règne de Rājarājacōla ${ }^{\mathrm{er}}$, qui fit bâtir Tañjore au début du XI ${ }^{\mathrm{e}}$ siècle,

19. G. Hoekveld-Meijer (1982 : 30) évoque l'expansion importante du panthéon shivaiite. Mais toutes les formes représentées sous les Cōla existaient sous les Pallava, alors que l'inverse n'est pas vrai. L'assertion de cet auteur selon laquelle la forme dite Dakṣināmūrti de Śiva serait apparue à l'âge $c \bar{l} l a$, alors que cette figure est fréquente sur les temples pallava, montre qu'il faut considérer avec précaution tout ce qui relève de l'iconographie dans cet ouvrage.

20. La thèse de G. Hoekveld-Meijer (1982:218,273, 297-298) qui suppose un atelier royal à l'origine du temple de Pullamankai procède certainement de la même idée ; cette auteure affirme aussi (Ibid. : 302) que l'atelier royal qui est à l'origine du Rājarājeśvara de Tañjore a concentré toutes les forces artistiques : aucun tcmple n'aurait ćtć construit durant le règne de Rājarāja I. Mais on n'a aucune preuve de ces deux faits.

21. L'introduction de P. Kaimal 1996 est éclairante à ce sujet. 
le roi se fait bien plus présent dans l'épigraphie des petits temples cōla, comme, d'ailleurs, à Pullamańkai (infra: 73-77). Il me semble qu'en fait les fondations royales, qui entretiennent une relation particulière avec un pouvoir devenu plus directif à la fin du $x^{e}$ siècle, relèvent d'intentions spécifiques. La beauté du temple de Pullamańkai a fait supposer que l'édifice aurait été fondé par un roi. Nous verrons que rien dans les données épigraphiques ne vient étayer cette supposition (infra : 8586). Les études basées sur l'architecture ne peuvent être suffisamment précises pour qu'on puisse avancer des certitudes, mais aucun élément n'y signale que le temple de Pullamankai pourrait s'inscrire dans un processus conduisant aux complexes royaux. Le Brahmāpurīśvara de Puḷamańkai se rapporte plutôt, à mon avis, à une période d'essai architectural, utilisant certains éléments pallava au service d'un projet qui guide architecture et iconographie : illustrer le processus de manifestation de la divinité.

\section{La manifestation divine}

\section{Au seuil de l'invisible}

Lieu où le dieu prend forme, le temple apparaît comme l'un des passages établis par les hommes cherchant à atteindre un invisible divin, auquel les rituels et les textes donnent accès par d'autres biais. C'est là où se manifeste l'Ālanturai de Pullamańkai que le dévot peut chercher à atteindre le dieu. La démarche dont témoigne le temple est ainsi proche de celles de certains textes, indiquant les moyens d'entrer en relation avec la divinité. Pourtant, l'absence de documentation textuelle ou le caractère problématique de celle qui est disponible n'aide guère à comprendre le projet d'ensemble d'un temple comme celui de Pullamańkai. On pourrait dire, à la limite, que ce petit temple cōla se situe entre la doctrine et son incarnation, séparés par autant de contradictions que certains rituels réalisés et les prescriptions censées leur correspondre. Les Āgama n'expliquent ni les plans des sanctuaires ni leurs programmes iconographiques (H. Brunner-Lachaux 1990) ${ }^{22}$. Façonner une image, construire un temple participe dans les Śāstra de l'acte rituel et on peut aller, avec Gérard Colas (1986 : 67-69), jusqu'à évoquer la volonté d'hégémonie des ritualistes

22. Les shivaïtes donnent la préférence à un type symbolique d'image lorsqu'il s'agit de représenter la forme cultuelle. Et les représentations régulières et conformes aux instructions des Àgama relèvent d'un système étranger au culte du sanctuaire et au rituel de consécration du bâtiment. Dans un autre article, Hélène Brunner-Lachaux, s'interroge sur la relation entre jñana, le savoir, et kriyā, l'action, dans l'école du Śaiva-siddhānta. Elle signale entre ces deux termes une tension qui passe inaperçue des tenants de l'école dans le contexte tamoul où ils célèbrent des rituels qui sont, parfois, en contradiction avec les Āgama sur lesquels ils s'appuient — tant ils accordent d'importance à ce jñana par rapport à l'action que constitue le rituel (Brunner-Lachaux 1992). L'étude d'Alexis Sanderson sur la visualisation des divinités du Trika arrive à des conclusions similaires (Sanderson 1990 : 82-83). Les textes donnent aux images une légitimité dans un monde d'abstraction, autre que celui dont elles viennent. 
qui, dans les textes, semblent vouloir réduire l'artiste à l'état d'instrument. Chaque type de document paraît établir sa sphère propre et autosuffisante. C'est pourquoi je privilégie ici la documentation dont je suis certaine qu'elle concerne vraiment ce temple d'Âlanturai, à savoir la structure bâtie ainsi que les représentations et les inscriptions que porte celle-ci. J'y ajoute l'hymne du Tēvāram louant la divinité et son sanctuaire. Même si son utilisation impose des précautions particulières, l'emploi du même nom pour désigner la divinité dans le poème et dans le corpus épigraphique du temple me paraît suffisamment signifiant d'un point de vue historique. Le poème 1. 16 et l'édifice $c \bar{o} \underline{l} a$ participent en outre, à mon sens, d'un même point de vue : approcher cette divinité qu'on appelle le dieu de l'Älanturai de Pullamańkai (hymne du Tềâram) ou de Puḷ!amańkalam (inscriptions).

S'ouvrant sur une niche dont les demi-pilastres encadrent une figure divine, les projections centrales des murs extérieurs dessinent le cadre de divinités à la morphologie essentiellement humaine (fig. 9, 16 et 19). Les demi-pilastres se présentent comme un pilastre fendu en deux sous l'effet d'une poussée intérieure. Sur la face ouest, le linga qui s'ouvre à la verticale pour laisser paraître Śiva leur fait écho (fig. 22). Dans ce double cadre apparaît le dieu habitant l'intérieur du sanctuaire, le mythe du lingodbhava illustrant à sa manière la transition entre dieu manifesté et non-manifesté. Voici « Ālanturai, l'endroit qu'il habite, Lui qui est comme la lumière du soleil levant " chante Campantar en Tévāram, 1. 16, 6, faisant allusion, entre autres, au mythe du lingodbhava, qui réapparaît dans la strophe 1. 16, $9^{23}$. Les niches centrales sont seules pourvues d'images : les sculpteurs ont laissé vides les autres espaces des murs extérieurs, pourtant susceptibles d'accueillir des images. Les niches étirées des pañjara, occupées par des figures ou des éléments décoratifs dans d'autres temples ${ }^{24}$, et les niches des projections des angles offrent à l'œil un cadre plein (fig. 10).

Ces niches me semblent rappeler les fonctions essentielles du temple, à la fois cadre et point de l'espace où se matérialise la divinité, mais aussi représentation de son apparition. L'hymne 1. 16 de Campantar, comme bien d'autres poèmes du Têvāram, le signale. Désigné comme « Álanturaiyatu», c'est-à-dire par la relation entre un pronom démonstratif neutre et le toponyme sacré Ālanturai, le site - ou le temple, car il est difficile et peut-être même peu pertinent de savoir ce qui est exactement désigné dans cet hymne - y matérialise l'essence d'un lieu sacré venue se concentrer en ce point de l'espace. La localisation du lieu de culte est l'une des caractéristiques principales du Tēvāram. Chaque hymne est rattaché à une localité particulière, où se dresse un temple, et la pointe de la péninsule indienne apparaît prise dans le prisme de ce corpus shivaïte recensant les lieux où se manifeste le dieu. À Pullamanakai on retrouve en outre, dans le nom de la divinité, l'importance

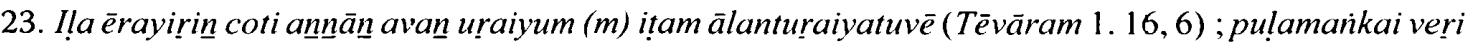

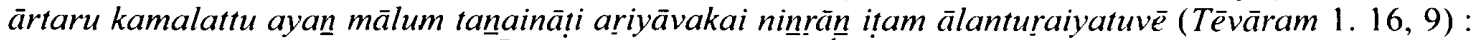
«Pullamañkai, voilà ce qui est d'Ālanturai, l'endroit où Śiva se tient, que ne parviennent à connaître, alors qu'ils le cherchent, ni le [dieu] du lotus (Brahmā), ni Mā! (Viṣnu ). "

24. Outre le Nāgeśvara de Kumpakōnam et les temples pallava, on peut citer certaines niches du Karivarațaperumạ̄ de Dadapuram qui abritent des vases d'où jaillissent des guirlandes, S. R. Balasubramanyam 1969 : fig. 3. 
donnée à l'espace : Âlanturai peut signifier, littéralement «[Celui de] l'endroit de celui de l'arbre banian ». Turai, c'est le « ghat », c'est-à-dire un escalier près d'une rivière, et la proximité de la Kāvēri pourrait être une explication de son emploi ici. Mais il faut plutôt, je pense, lui conserver ici son sens plus général d" «endroit », de «place », ne serait-ce que parce que nous verrons que ce nom apparaît en plusieurs endroits du pays tamoul. À Pullamankai, on se trouve là où réside le dieu, enraciné dans le sol comme un banian, ālam, qui constitue le premier terme du composé et pourrait se référer à d'anciennes croyances associant cet arbre et un dieu, «Celui du banian », qui n'a peut-être pas toujours été une forme de Śiva ${ }^{25}$. En ce lieu donné, l'architecture et l'iconographie du temple donnent à voir la divinité de l'endroit, présentée, me semble-t-il, comme un Śiva manifesté et non manifesté, ou figuré et non figuré. Son apparition dans le temple marque la rencontre avec ses adorateurs en un point où se touchent monde des dieux et univers humain.

En ouvrant sur les murs des niches vides, les projections animant les parois extérieures ne signalent-elles pas, en effet, que l'habitant divin du temple n'a pas toujours de forme ? Dans le Korankanātha de Srinivasanallur et le Nāgeśvara de Kumpakōnam, proches dans le temps et l'espace du temple de Puḷamankai, la forme des niches extérieures, comportant ou non des images, me paraît relever d'une même intention ${ }^{26}$. Au Korankanātha, datant sans doute du règne d'Āditya I ${ }^{\text {er }}$ (870907), alors même que les statues qui occupent les niches étroites étirées en hauteur encadrant les devakoștha ont été sculptées dans un trois-quarts prononcé permettant de réduire leur largeur, il a parfois fallu retailler les niches. La position des statues résout cependant le problème de la faible profondeur des niches, et accentue la ressemblance des figures avec celles qui, au Nāgeśvara de Kumpakōnam, sortent directement du mur. Les solutions adoptées pour insérer les statues du Koranikanātha tendent à faire penser que les niches de ce temple n'avaient pas été prévues pour les accueillir. Celles-ci auraient pu demeurer vides, comme les pañjara de Pullamańkai ${ }^{27}$. Au Nāgeśvara de Kumpakōnam, les personnages, taillés dans le mur même du maṇ̣̂ap, surgissent du temple. Au Korankanātha, il me semble que le procédé utilisé à Kumpakōnam en a recouvert un autre, procédant d'une expression

25. Infra: 93-97.

26. La datation du Korańkanātha est un objet de controverses, voir S. R. Balasubrahmanyam (1967b) et G. Hoekveld-Meijer (1982: 106-109), qui tous deux le datent, avec de bons arguments épigraphiques et stylistiques, de la fin du IX ${ }^{\mathrm{e}}$ siècle. La bibliographie du Nāgeśvara est plus impressionnante. G. Hoekveld-Meijer (1982: 113-114) lie également ces trois temples lorsqu'elle discute de la création et de l'évolution des pañjara, qui seraient dues à un besoin de décorer un mur sans images... On n'est pas loin du concept de manifestation divine invisible que je développe ici et qui rend compte de l'absence d'images dans les pañjara de Pull lamankkai, posant un problème particulier à Gerda HoekveldMeijer à cause de la présence d'images de chaque côté des devakoștha.

27. Si les deux niches du mandapa sont vides, sans doute s'agit-il d'un hasard de l'histoire et devraientelles (S. R. Balasubrahmanyam 1967b : 36), être occupées par un Ganapati, au sud, et une déesse armée, au nord. Il vaut donc mieux se limiter à une comparaison entre les pañjara de Pullamańkai et les niches étroites étirées en hauteur qui encadrent les devakostha du prāsāda à Srinivasanallūr. Cependant pour G. Hoekveld-Meijer (1982: 108), les pañjara vides remplacent les niches vides comme élément décoratif sur le mur du temple. Ibid. : 113, l'auteure évoque les stucateurs et les peintres qui auraient recouvert les plages des murs vides d'image. Mais les inscriptions sont là pour montrer qu'il n'y avait pas d'images là où on a écrit. 
plus architecturale de la présence divine : celui de la niche laissée vide. Face à un mur qui prend figure humaine à Kumpakōnam, les concepteurs de Puḷamańkai, et ceux de Srinivasanallèr à l'origine, auraient mis en place les cadres de l'invisible sur les murs extérieurs du temple d'un dieu qui se manifeste mais, comme venant, justement, du monde non manifesté des divinités.

La composition rayonnante d'une manifestation divine qui fait face à trois directions se double d'une progression symétrique de chaque côté du temple vers le linga de la face ouest : à partir de l'entrée du temple, la représentation du dieu se fait de plus en plus cultuelle, reproduisant, peut-être, le chemin intérieur du fidèle progressant à l'intérieur du mandapa en direction du linga. Là encore, la comparaison avec le temple pallava est instructive. Le mandapa cōla s'étire en longueur devant le prāsāda. Son équivalent pallava était moins long et plus large et l'iconographie des murs extérieurs apparaît ainsi correspondre également à une forme de cheminement dévotionnel. Les niches du mandapa, dieu à tête d'éléphant au sud et déesse au nord, sont les formes les plus éloignées d'une figure «humaine » classique de Śiva. Le Brahmā et le Dakṣināmūrti du prāsāa da sont plus proches du dieu, qui se manifeste dans toute sa gloire à l'ouest dans le lingodbhava.

Disposées en fonction d'un axe de symétrie horizontal dont ce linga de l'ouest est la source, et non selon une pradakṣinā classique commençant à l'entrée (infra: 58-62), les frises sculptées, d'exploits divins (lïlā) qui courent sur le soubassement du temple de Pullamañkai tendent à confirmer qu'on a voulu illustrer une forme de progression dévotionnelle. La manifestation du dieu mais aussi la représentation du culte qu'on lui rend pourraient bien avoir guidé le projet d'un temple où architecture et iconographie sont associées pour exprimer le processus d'apparition d'une divinité : énigme des niches vides, linga symbolique qui se donne à voir sur la face ouest à l'extérieur du temple, et encore figures quasi humaines.

\section{Les formes divines, entre rite et légende}

Quant à l'ensemble du programme iconographique de Puḷamańkai, deux différences essentielles s'imposent par rapport à la période pallava. D'une part, les faces extérieures ne sont pas décorées de grands bas-reliefs. De chaque côté des niches centrales abritant les images s'étendaient des plages vides, pour le plus grand bonheur des lapicides qui les ont recouvertes (fig. 9). D'autre part, l'iconographie est fonction de choix différents. Les mêmes images se retrouvent parfois aux mêmes emplacements que dans les édifices pallava, comme Dakṣiṇāmūrti au centre de la face sud du prāsāda et Mahișāsuramardin̄̄ au nord du temple (fig. 16) ${ }^{28}$. Mais Brahmā (fig. 19), figure très secondaire de l'art pallava, et Ganeśa (fig. 9), apparu au début du $\mathrm{vIII}^{\mathrm{e}}$ siècle seulement dans l'iconographie pallava, où sa fonction est d'abord décorative, se voient attribuer une niche — peut-être, entre autres raisons,

28. La déesse représentée sur les temples construits pallava est accompagnée d'un lion et souvent d'unc antilope, sans être pour autant la forme de la déesse qui tue le buffle. Mais ces deux déesses sont très proches dans l'art pallava (voir Ch. Schmid 2005), et il est clair qu'en plaçant au nord la déesse qui tue le buffle, le temple còla s'inspire de l'emplacement dévolu à cette déesse au lion dans l'art pallava. 


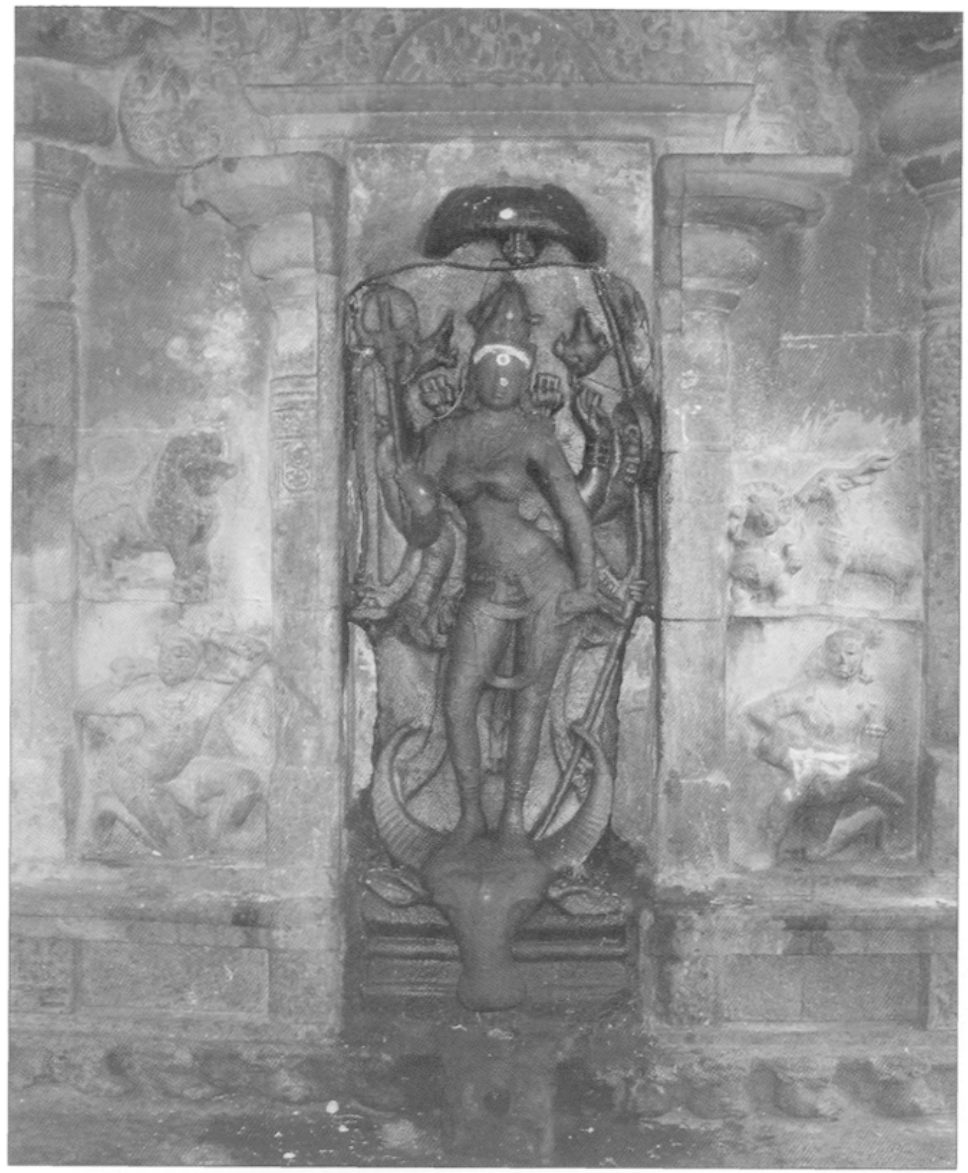

Fig. 16

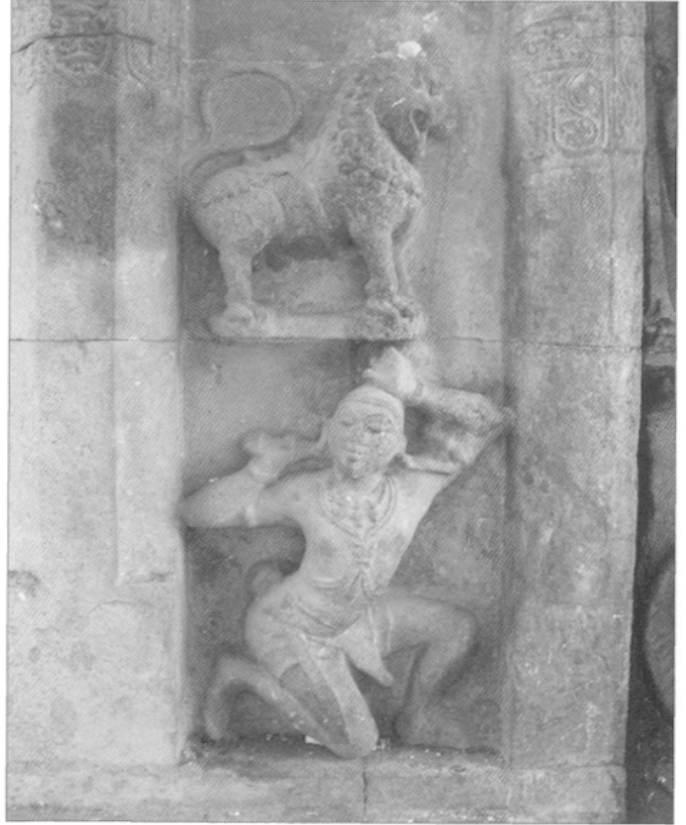

Fig. 17

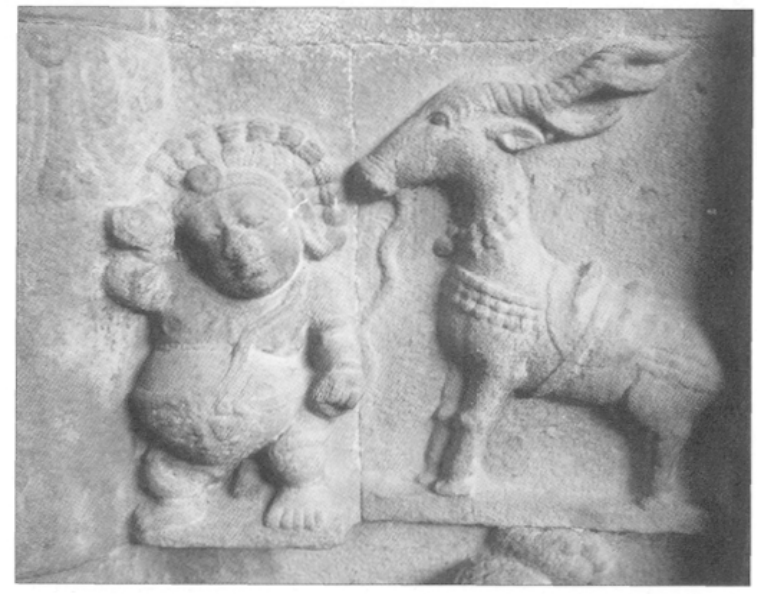

Fig. 18

Fig. 16. La déesse de la face nord. Cliché : E. Francis.

Fig. 17. Un des adorateurs de la déesse, face nord. Cliché : E. Francis.

Fig. 18. Une des montures de la déesse de la face nord : l’antilope. Cliché : E. Francis. 
parce que leurs représentations ne comportaient pas d'élément narratif. Le narratif domine les murs extérieurs pallava, mais les divinités des niches de Pullamankai sont assurément cultuelles. On peut en effet distinguer, aux deux extrémités du spectre iconographique, deux types de reliefs décorant les murs extérieurs : ceux qui présentent le dieu comme héros d'une histoire et ceux qui imitent l'aspect statique de certaines figures cultuelles. Entre ces deux modèles, on rencontre bien des intermédiaires. Grâce à un attribut, une iconographie cultuelle peut faire allusion à un mythe précis. C'est le cas, par exemple, de la tête de buffle sur laquelle se dresse Mahiṣamardinī, la Tueuse du buffle. Les statues de culte des avatāra de Viṣnu comportent toujours des éléments narratifs, etc.

La distinction entre iconographies cultuelle et narrative opère cependant clairement sur les murs extérieurs de Pullamankkai, où toutes les niches qui ont conservé l'iconographie originelle présentent des scènes de culte. Au sud, trois niveaux de personnages secondaires se tournent vers Gaṇeśa, à qui ils offrent friandises et musique ${ }^{29}$ (fig. 9); au nord, Mahișāsuramardinī est debout sur la tête du buffle conformément à l'iconographie cultuelle pallava (fig. 16 ; représentation qui est différente de la représentation, narrative, du mythe lui-même, fig. 30) et deux dévots encadrent sa niche, l'un se tranchant la tête (fig. 17), l'autre se blessant à la cuisse, selon un ritucl d'adoration particulier; sur la même face, deux dévots à genoux offrent des guirlandes à Brahmā; enfin, le lingodbhava du mur ouest - qui est, après les quelques lingodbhava pallava (temples du Kailāsanātha, du Matangeśvara et du Mukteśvara), l'un des premiers connus - illustre la nécessité du culte à rendre à Śiva (fig. 22) ${ }^{30}$. La figure du Śiva est frontale et figée dans une verticalité qui rappelle celle du linga gigantesque dont elle émerge. Viṣnu et Brahmā sont représentés de chaque côté de la niche centrale, la main sur la hanche dans des attitudes dont la symétrie parfaite contribue à l'aspect hiératique de la représentation (fig. 23 et 24).

On voit que, en rupture avec une tradition pallava, le temple de Pullamańkai tend à faire disparaître l'élément narratif des grandes figures des murs extérieurs, qui se déployaient comme une transition entre le monde des hommes et l'espace intérieur où demeure le dieu. Le temple présente d'abord ici une vision cultuelle, qui semble correspondre à l'atmosphère dévotionnelle du Tềvāram, bien illustrée par l'hymne 1. 16, où l'adoration et la prière apparaissent dans sept strophes sur onze ${ }^{31}$ en

29. On ne peut plus savoir quelle était l'esthétique exacte du Dakșināmūrti du mur sud. Cependant l'iconographie de cette forme shivaïte est très stéréotypée : aux pieds de la divinité centrale vers laquelle ils se tournent, les personnages, souvent des sages, lui rendent hommage en l'écoutant.

30. Cette manifestation du dieu est très présente dans le Têvāram où elle constitue près d'un quart des allusions mythologiques à Śiva ; supra, note 23 pour l'hymne qui nous concerne.

31. «Voici Pullamañkai entouré de jardins, où la Kāvēri fait rouler ses flots emplis de vagues, loué dans leurs prières par les érudits connaisseurs des Vedas qui [y] méditent » $(1.16,2 ;[\ldots]$ polil cūl puḷmañkaik / kalaiyāl mali maraiyor avar karutit tolıutu ètta). Le poète enjoint : " priez et adorez les pieds au parfum de fleur du dieu d'Ālanturai entouré de jardins, nù les abeilles ailées, ivres, bourdonnent

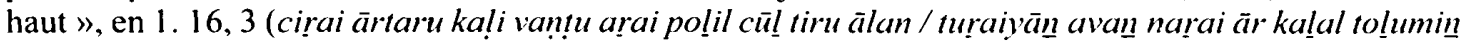
tuticeytē) et "Priez pour que soit enlevé le karman qui est à l'origine du cycle des renaissances" en $1.16,5$ (meyt tannurum vinai tir vakai tolumin $[\ldots]$ ). Il rappelle que « voici Ālanturai, demeure 
ce « Pullamańkai où les dévots prient, les mains jointes, le maître de notre adoration » $(1.16,4)^{32}$. La verticalité exceptionnelle du prāsāda à trois niveaux s'accorde avec la représentation du linga de la face ouest. La divinité qu'on adore se dresse, se tient debout (ningran, Têvāram 1. 16, 9) entre plusieurs mondes, comme sa demeure qui se découpe sur le ciel. La narration n'est pas absente, cependant. Elle pourrait faire partie de cette activité que l'hymne shivaïte désigne avec la racine karutu-tal (« avoir l'intention de, méditer, se rappeler, imaginer... ») utilisée dans la première strophe du poème de Campantar (Têvāram 1. 16, 1): "Si nous imaginons [cet] endroit où le dieu vint pour détruire l'énergie de Kāla... » (kâlan tiral araccạtíya katavul itam karutil). Elle se manifeste ailleurs, sur le couronnement et, surtout, sur la base du temple dans des frises dont le caractère horizontal permet de développer à loisir les épisodes mythiques : si certains thèmes majeurs se retrouvent dans les deux emplacements (comparer les fig. 12 et $35 ; 13$ et 28 , ou encore la fig. 15 , représentant Rāma et l'ensemble de la seconde série narrative), de nombreuses scènes apparaissent seulement sur le soubassement.

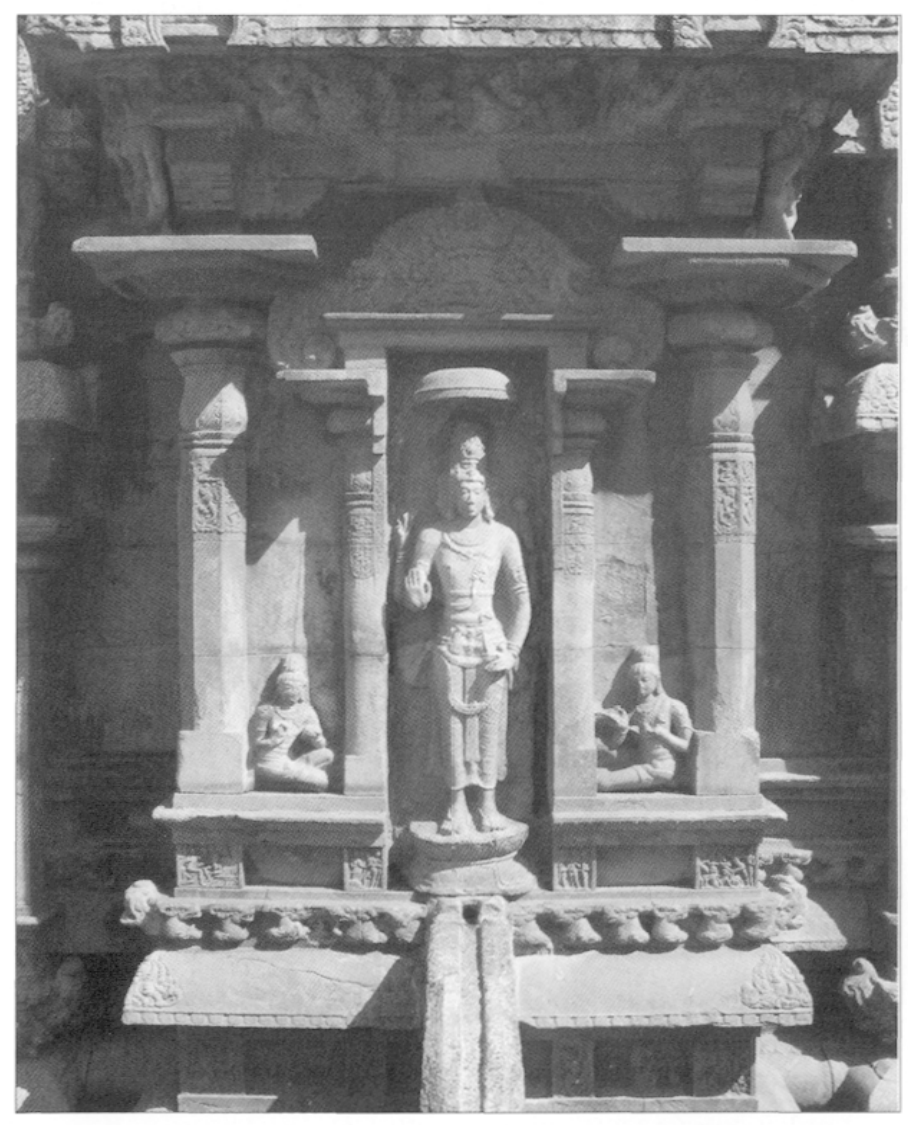

Fig. 19. Brahmā, face nord du prāsāda. Cliché : E. Francis.

de Celui qui est doux pour ses dévots en prière les mains jointes, adorant ses pieds avec de l'eau et des fleurs parfumées ", en 1. 16, 7 (kati âr malar punal kontu tan kalavē tolutu èttum / atiyārramakku

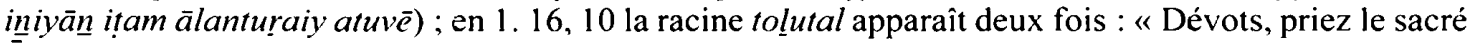
$\bar{\Lambda}$ lanturai en son temple! Vous obticndrez la pric̀re qui cst cclle des immortels de haute naissance "

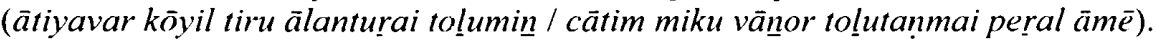

32. [...] em / pani āyavan atìyār tolutu êttum pulamañkai. 
Comme une dizaine de temples cōla anciens au moins, la plupart shivaïtes et situés dans le delta de la Kāvēri, le soubassement de l'Ālanturai porte en effet des séries narratives ${ }^{33}$. Le soubassement du Brahmāpurīśvara est décoré de deux séries de panneaux rectangulaires sculptés en bas-relief (fig. 21). L'iconographie de la première série que l'on rencontre à partir du sol, série 1 par convention, est composite en ce sens qu'on y rencontre aussi bien des feuillages décoratifs que des représentations de dieux et de certains épisodes mythologiques. La deuxième série se trouve à la base des pilastres marquant les niches centrales et les angles du mandapa et du prāsāda, entre la corniche et la frise d'animaux mythiques apparaissant à mi-corps, les yāli. Elle représente les trois premiers livres du Rāmāyana. David T. Sanford (1987) a identifié les panneaux de ces deux séries. En désaccord sur certains points précis avec cet auteur, dont le travail pionnier sur le temple est cependant très utile, je propose une autre identification pour certains d'entre eux - en particulier pour trois des quatre panneaux de la projection centrale ouest. De ces derniers panneaux dépend en effet la compréhension de l'ensemble du dispositif iconographique narratif sur le temple ${ }^{34}$. On se reportera à l'annexe présentant les plans des séries pour l'ensemble des identifications (fig. 57).

\section{Le Rāmāyaṇa issu du lingodbhava}

La relation organique entre la frise de la série 2 et les pilastres des projections centrales est mise en évidence par les dimensions des panneaux, dont la largeur

33. Le Cataiyār de Tirucennampūnti et le Nāgeśvara de Kumpakōnam partagent également des caractéristiques architecturales avec le temple de Pullamankai et il est possible que tous trois constituent un groupe de temples particulier. Les autres temples portant des séries narratives (citons, entre autres et parce que nous avons pu les voir, le Naltuṇaīśvara de Puñcai, le Tirumerratịî́vara de Pāccil, le Sāmavedīśvara de Tirumañgalam, le Saptarṣišsvara de Lālkuti, le Varadarājaperumāl de Tirupuvanai et le petit temple de Kōnnnār, près de Kāñcīpuram) datent des XI-XII' siècles. G. Hoekveld-Meijer (supra : note 20 ) pose l'hypothèse d'un atelier royal opérant à la fin du IX $X^{\mathrm{C}}$ siècle, patronné par Āditya ${ }^{\mathrm{er}}$. Le temple de Pullamankai en serait un produit. Le temple de Kumpakōnam aussi. Cependant cette auteure, tout en signalant les éléments architecturaux communs à Pullamankai et à Tirucennampūnti, ne considère pas ce dernier temple comme relevant du même atelier. La présence de cycles narratifs proches les uns des autres dans les trois temples est pourtant troublante et D. Barrett $(1974: 70-71)$ relève les ressemblances architecturales unissant les édifices de Pullamańkai et de Tirucennampunnti. De plus, on n'a sur aucun de ces temples d'indication épigraphique de l'implication directe d'Âditya i ir dans leur construction ou leur décoration, alors que ce roi se signale, ailleurs, comme un mécène.

34. Quinze des identifications que David T. Sanford propose pour la deuxième série de panneaux me semblent erronées mais je ne peux proposer une identification certaine que pour douze d'entre eux [dans la deuxième série, la traversée de la Yamunā (panneau 7 ; fig. 21 ) ; l'ermitage d'Atri (panneaux 10 et 11 , dont la relation est incertaine chez D. T. Sanford) ; l'entrevue de Rāvaṇa et de Mārīca (panneau 24 ; c'est Surrpanakhā qui accompagne nos deux personnages et non Sītā) ; les commencements du Rāmāyana (panneaux 31, 32 et 33 ; fig. 25, 26, 27 et 28) ; Rāma et Lakṣmana, gardiens du sacrifice de Viśvamitra : ils écoutent les mantra présidant au sacrifice (panneau 42); Viśvamitra, Rāma et Lakmaṇa se dirigeant vers l'ermitage de Gautama (panneau 44) ; le mariage de Māṇụāi avec Bharata, et de Śrutakīrti avec Śatrughna (panneau 50) ; le retour de Daśaratha à Ayodhya (panneau 51 ) ; Rāma tendant l'arc de Paraśurāma (panneau 53) ; le départ de Bharata et de Satrughna accompagné de Yudhajit (panneau 54)]. La face nord du mandapa présente une série de panneaux difficiles à identifier (panneaux 54-57 ; 59-60), mais les propositions de David T. Sanford, pour qui il s'agirait de la scule représentation connue d'épisodes relevant de l'Uttarakānda, ne s'appuient ni sur des passages du texte ni sur un fil narratif continu, qui guide pourtant tout le reste de la série. Elles ne me convainquent donc pas, sans que je puisse proposer une identification qui me satisfasse. En ce qui concerne les identifications de la première série voir, infra, la note 42 . 
varie en fonction de celle de ces pilastres : ils apparaissent comme une sorte de base pour ces derniers. Entre l'espace horizontal du soubassement et le plan vertical du mur, où le décor est disposé en hauteur, la frise narrative forme une transition architecturale (fig. 21). Les panneaux sont séparés les uns des autres par des espaces vides, mais liés par une narration qui donne son sens - signification et direction - à la série, la révélant subordonnée à l'espace vertical, et plus précisément à celui de l'ouest du temple.

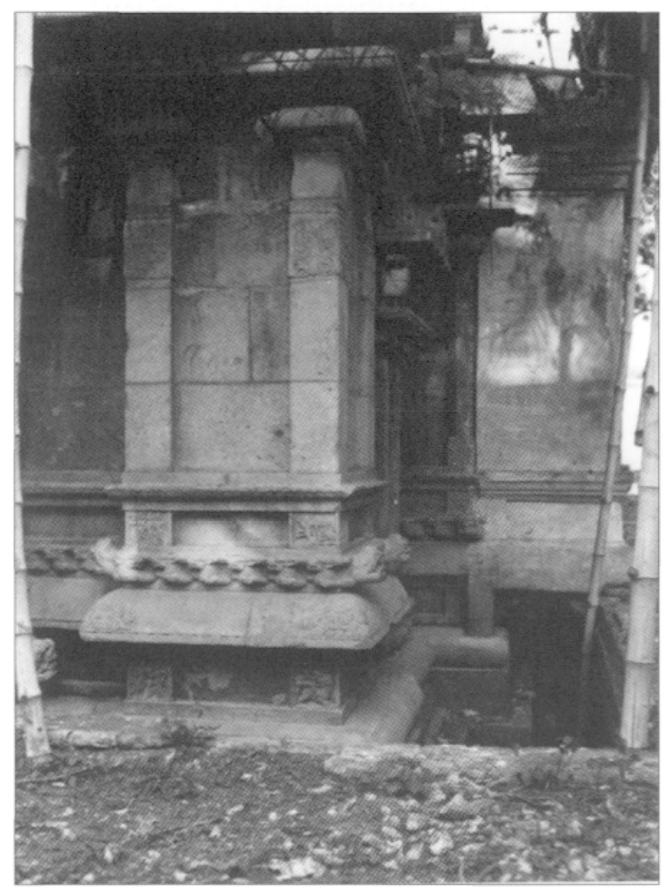

Fig. 20

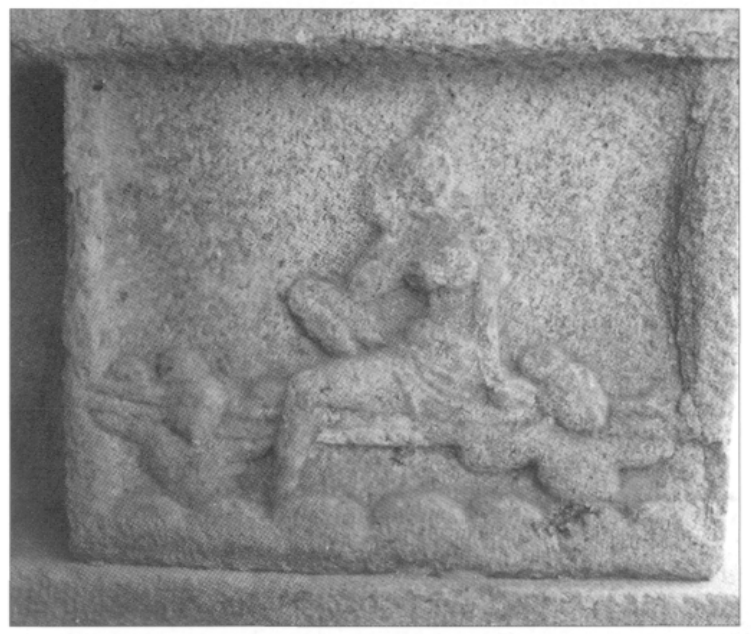

Fig. 21

Fig. 20. Le soubassement portant les séries narratives. Cliché : G. Ravindran.

Fig. 21. La traversée de la Yamunā ; série 2, face sud (emplacement $n^{\circ}$ 7). Cliché : G. Ravindran.

La face ouest est la seule qui corresponde uniquement à l'espace intérieur où se trouve le linga de culte. Elle ne porte qu'une seule inscription, la $n^{\circ} 17$, très particulière (infra: 37-39). Il me semble qu'elle se révèle en ceci plus « divine » que les autres. Sa composition, liée avec la disposition narrative du Rāmāyaṇa, met en valeur le lingodbhava qui marque, en effet, les débuts de la représentation de l'épopée, se déroulant ensuite suivant le chemin de la pradakṣinā pour s'achever au sud de la niche centrale ouest, avec la mort du démon Kabandha (Āranyakāṇạa $65,22-23$ et $66,5-6 ; 69,35-36$ et $70,8-9)^{35}$. La manifestation du linga de feu est représentée comme source de l'incarnation de Viṣnu. La mise en scène du lien, délicat, entre le lingodbhava et le Rāmāyana ordonne la composition de la projection centrale ouest (fig. 22).

35. Les références données sont celles des vers qui correspondent le plus étroitement à la scène représentée. Les références des éditions sont données avant la présentation de la liste des panneaux, objet d'une annexe de cet article, infra: 150. La recherche de correspondances avec le Rämäyana de Kampan a été décevante et je ne peux donner de références précises à cette œuvre. 
Figurés chacun quatre fois sur la projection, Brahmā et Viṣnu unissent l'image verticale du linga et la série horizontale du Rāmāyaṇa. Dans la niche centrale, Brahmā vole au-dessus et à gauche de l'apparition de Śiva tandis qu'un Viṣnu à tête de sanglier creuse la base du linga, le corps déporté vers la droite. À gauche de cette niche, un Brahmā debout à quatre bras et trois têtes se tourne vers le Śiva émergeant du linga ; à droite, un Viṣnu à quatre bras lui répond (fig. 24). Sous ces deux figures, de chaque côté de la niche, se situent quatre panneaux de la série 2 , deux à droite sous la partie du mur consacrée à Viṣnu, et deux à gauche sous la partie dévolue à Brahmā (fig. 25-28).

Ils représentent successivement, en partant de la droite «vishnouite», des dieux s'assemblant autour de Brahmā assis sur un trône de lotus pour comploter la mort de Rāvaṇa dans le premier panneau (fig. 25 ; Bālakāṇḍa 14, 5 -15 ; 15, 415) ; Brahmā et deux dieux se dirigeant vers la gauche demander l'aide de Viṣnu dans le deuxième (fig. 26) ; l'apparition de Viṣnu s'appuyant sur Garuḍa dans le troisième (fig. 27 ; Bālakāṇụa 14, 16-21 et $15,1-7$; 15, 15-21 et 16,1-8) ; et, dans le quatrième, Viṣnu allongé sur le serpent, symbolisant le processus d'incarnation (fig. 28). Le cinquième panneau de la série, invisible lorsqu'on fait face à la projection ouest puisqu'il se trouve sur le côté, représente le sacrifice offert par Daśaratha pour obtenir des fils (fig. 29). Le personnage au milieu du feu, les figures l'encerclant et la comparaison avec les autres cycles représentant les débuts du Rāmāyana, comme à Kumpakōnam (où cette scène est représentée sur la face sud), rendent certaine l'identification du panneau illustré dans la figure 29. Il semble donc marquer les débuts du Rāmāyaṇa ${ }^{36}$. En réalité, les quatre panneaux de la projection centrale ont une double fonction.

On peut en effet interpréter l'iconographie de la projection ouest sans recourir au Rāmāyaṇa. Les représentations de Viṣnu et de Brahmā se comprennent dans le cadre du lingodbhava. Chacun de ces dieux est l'objet principal de deux panneaux. Brahmā apparaît dans les deux de droite, sous le grand Viṣnu associé au lingodbhava, et sous le grand Brahmã correspondant, Viṣnu apparaît dans les deux panneaux de gauche. Entre les figures du mur et celles de la frise, il n'y a qu'une différence d'échelle. La disposition des personnages sur les deux panneaux correspondant aux demipilastres de la niche centrale accentue l'ambiguïté. En effet, les paires de panneaux placées à la base des demi-pilastres des niches illustrent souvent une même scène divisée en deux panneaux. Sur la face sud du temple, par exemple, de chaque côté de Gaṇeśa on a représenté l'arrivée de Rāma, Lakṣmaṇa et Sītā dans l'ermitage d'Atri : dans le panneau de droite les trois héros, dans celui de gauche les sages qui les accueillent (fig. 9).

Sur la face ouest, celle qui nous occupe, on a affaire au même type de disposition : à droite, Brahmā et les dieux marchent vers Viṣnu, qui les accueille dans le panneau de gauche. Mais Viṣnu tourné vers le Brahmā de droite pourrait tout aussi bien être tourné vers le linga dont la base occupe l'espace séparant les deux panneaux. Quant à Brahmā, s'avançant dans la direction de Viṣnu, il se tourne aussi vers le linga.

36. Pour David T. Sanford, le Rāmāyana commence avec cette scène de sacrifice : le dispositif iconographique de la projection ouest échappe alors et cet auteur donne du programme iconographique du temple, qui serait partagé en deux moitiés suivant la course ascendante et descendante du soleil, illustrée par certains livres du Rãmāyaña, une interprétation qui me semble étrange. 
Les divinités de ces deux panneaux apparaissent donc aussi comme des adorants du linga, renforçant la majesté de sa représentation. Et les deux panneaux des extrémités de la projection dupliquent les représentations divines : à droite, encore un Brahmā - assis, dans ce cas, sur un lotus - à gauche, encore un Viṣnu, couché cette fois sur le serpent d'éternité. Ces deux représentations s'intègrent dans la série du Rāmāyaña mais correspondent aussi à une iconographie autonome. Tēvāram 1. 16 évoque le Brahmā du lingodbhava comme une figure assise sur un lotus (kamalattu ayan), ce qu'il n'est pas dans la niche ni sur la projection centrale, mais dans ce panneau du soubassement. De son côté, Viṣnu couché sur un serpent est une forme cultuelle du dieu, en même temps qu'il rappelle un lien avec l'assise du monde qu'évoque également la forme du sanglier (Ch. Schmid 2004b). Il s'agit donc là encore de représentations susceptibles d'une double interprétation, dans le cadre d'un culte rendu à Śiva, ou dans celui d'une épopée vishnouite.

La série 1 comporte des panneaux de type décoratif - feuillages ou autres - et des panneaux mythologiques. Les deux panneaux les plus proches du lingodbhava sont ornés de feuillages et les deux autres de figures de Śiva (porteur de son linga, au sud, et décorant son dévot Candeśa d'une guirlande, au nord). Or les figures de Śiva sont minoritaires dans la série 1 (comme dans la série 2 mais, dans ce dernier cas, pour des raisons évidentes). Leur omniprésence à l'ouest tend à confirmer que le dispositif iconographique de cette face du temple met l'accent sur les manifestations de Śiva. Peut-on aller jusqu'à dire que le Rāmāyana apparaît ici organisé autour du linga de feu?

Chacun connaît le Rāmāyana et cet horizon d'attente est manipulé à travers la multiplication des figures de Viṣnu et de Brahmā. Les louanges de Viṣnu deviennent un hymne à la puissance de Śiva. Il s'agit d'un procédé courant dans les textes indiens, où un mythe connu est remis en perspective, ne serait-ce que par son insertion dans un texte à la gloire d'une autre divinité, quand ce n'est pas l'identité même du héros divin qui est changée. Rāma ne serait-il pas ici l'une des formes de Śiva ? Le grand nombre de représentations de cet avatāra vishnouite sur des temples shivaïtes a fait naître l'idée de la représentation du roi sur le temple. Modèle du roi, Rāma permettrait au souverain terrestre d'être figuré sur la demeure du dieu. Mais la quasi-absence du roi dans les inscriptions avant le $\mathrm{xI}^{\mathrm{e}}$ siècle suggère d'écarter cette hypothèse dans le cas de Pullamañkai, où le dieu est, en revanche, très présent dans le corpus épigraphique ${ }^{37}$. Il me semble qu'on a affaire ici à une

37. Rappelons que pour David T. Sanford (1974), Āditya ${ }^{\text {er }}$ serait responsable de la construction du temple ; le patronage royal expliquerait le nombre de scènes vishnouites. Les noms de ce roi l'associent spécifiquement avec Rāma (Ibid. : 16, 259), ce qui expliquerait la place importante du Rāmāyāna dans le temple. Mais on n'a aucune trace d'une participation quelconque d'Āditya Ier à la construction du temple. De plus les frises consacrées au Rāmāyana sont également importantes dans d'autres temples shivaïtes, sans qu'on puisse jamais établir un lien spécifique entre l'un de ces temples et un roi. En fait, comme l'a démontré Padma Kaimal (1996), ce patronage royal est lui-même un mythe contemporain. Sheldon I. Pollock (1996) a par ailleurs posé l'hypothèse du caractère relativement récent de l'utilisation politique du Rāmāyaṇa, qui n'apparaîtrait pas avant le xíc siècle. Sans ètre nécessairement d'accord avec toutes les conclusions de son article, remarquons que dans le Tamil Nad où fleurit un art pallava qui glorifie roi et fonction royale, on connaît une seule représentation pallava de Rāma (sur l'Olakkaneśvara de Mahābalipuram). L'association de la glorification du roi avec la figure de Rāma ne peut donc, en tout cas, se prévaloir d'une tradition antérieure aux Cōla. Sheldon Pollock traite avec 


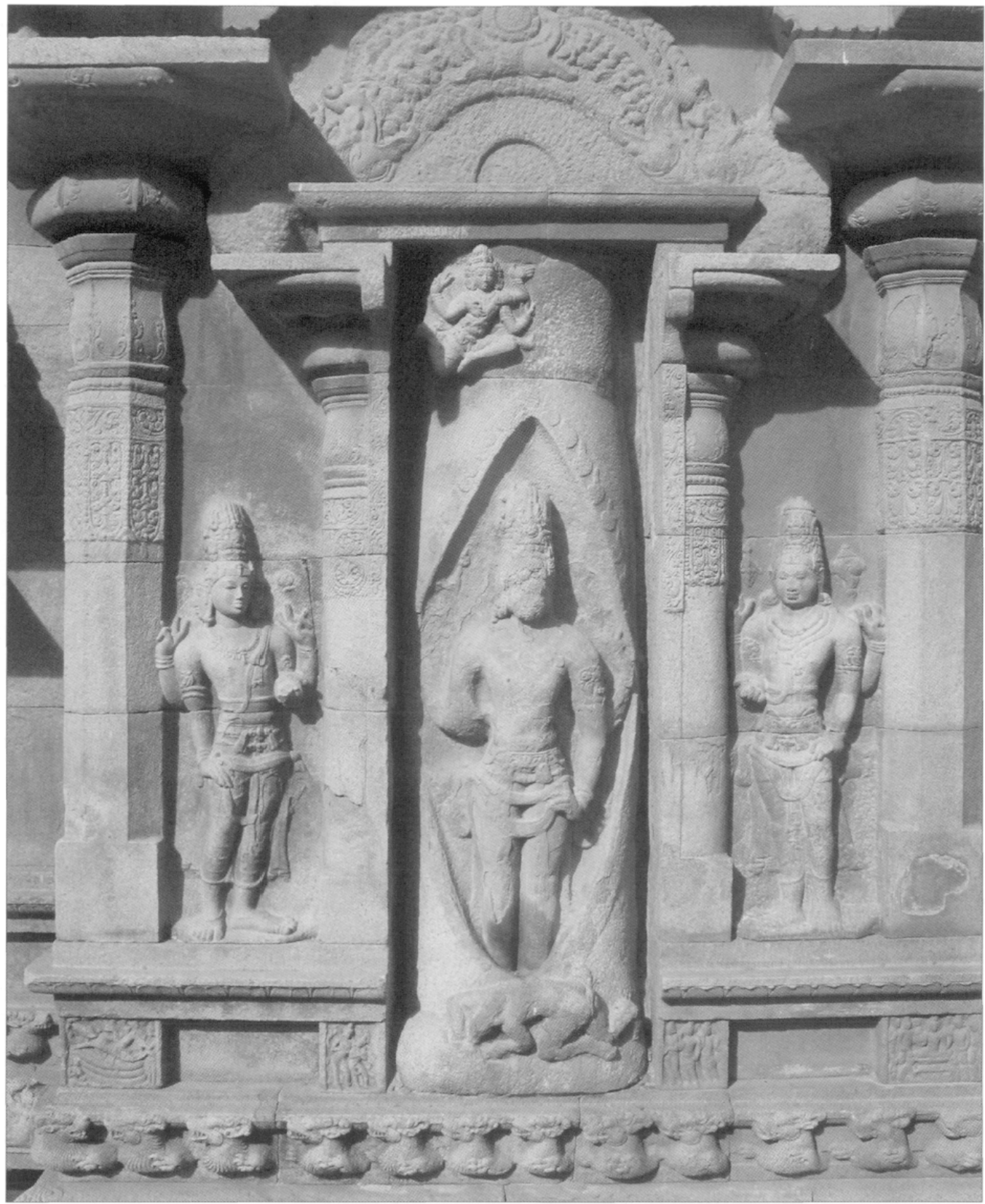

Fig. 22

Fig. 22. Le dispositif iconographique de la face ouest. Cliché : E. Francis.

Fig. 29. Le sacrifice de Daśaratha ; série 2, face ouest (emplacement $\left.n^{\circ} 35\right)$. Cliché : G. Ravindran.

Fig. 28. Vị̣nu couché sur le serpent ; série

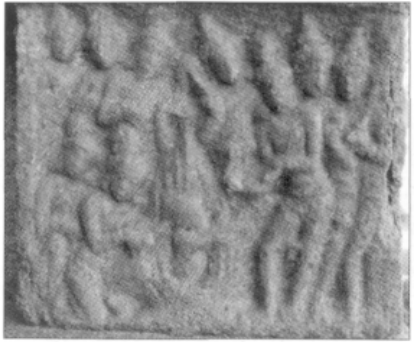

Fig. 29

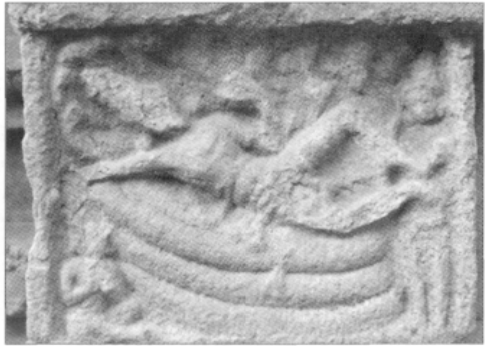

Fig. 28

2 , face ouest (emplacement $n^{\circ} 34$ ). Cliché :

G. Ravindran. 


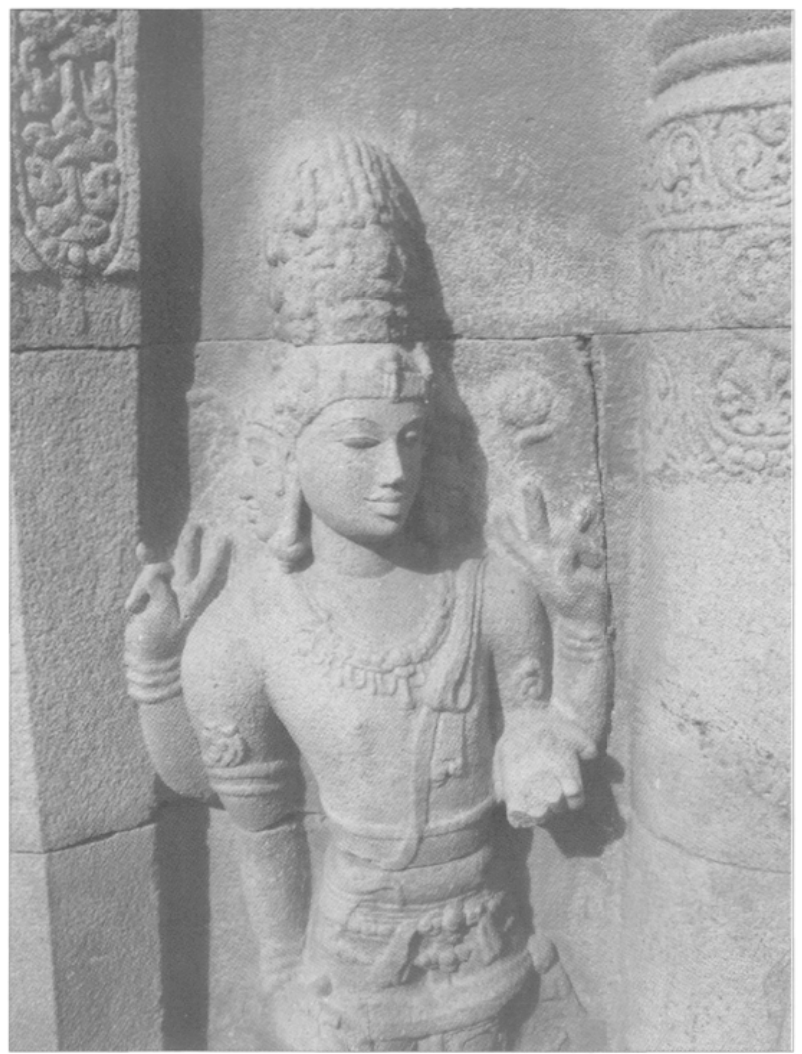

Fig. 23

Fig. 23. Le Brahmā de la face ouest. Cliché : E. Francis.

Fig. 24. Le Viṣṇu de la face ouest. Cliché : E. Francis.

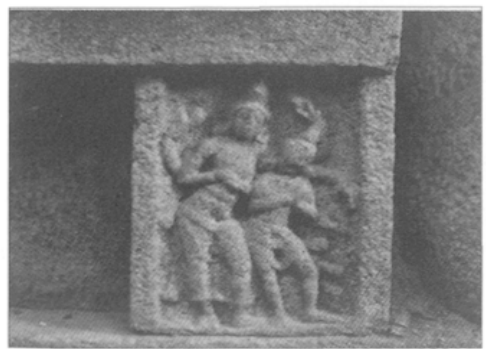

Fig. 27

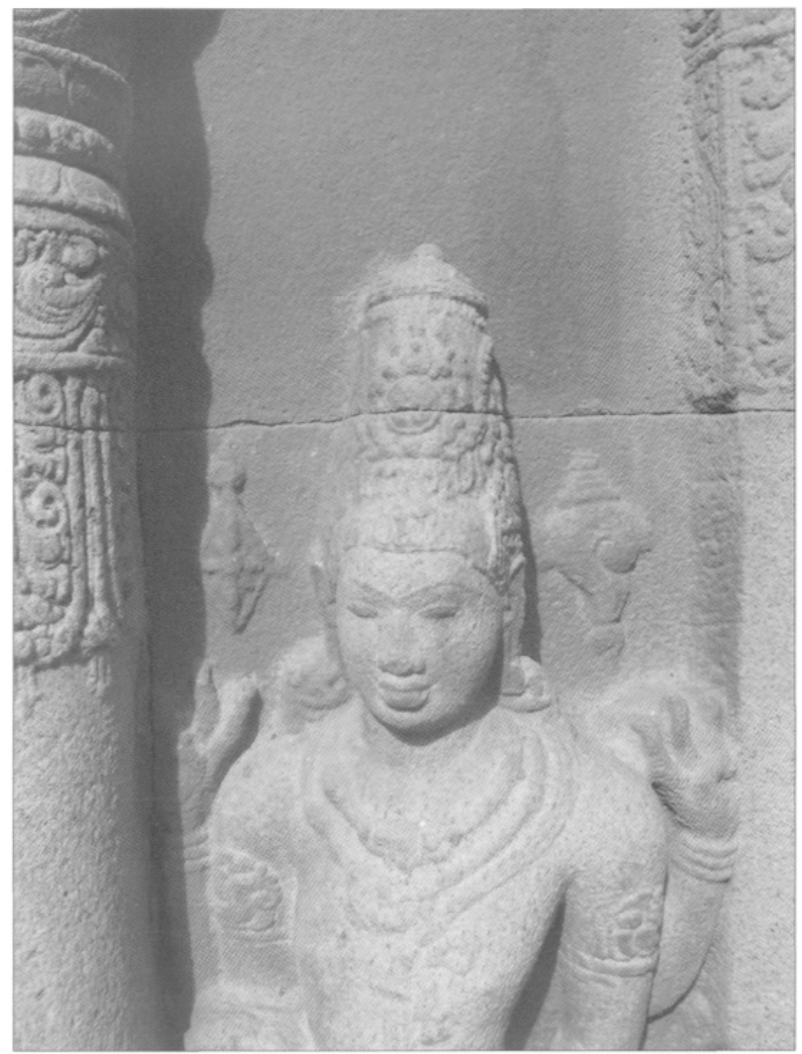

Fig. 24

Fig. 27. Viṣṇu appuyé sur Garuḍa écoute les dieux ; série 2, face ouest (emplacement $n^{\circ} 33$ ). Cliché : G. Ravindran.

Fig. 26. La députation des dieux auprès de Viṣnu ; série 2, face ouest (emplacement $n^{\circ} 32$ ). Cliché : G. Ravindran.

Fig. 25. Brahmā assis sur le lotus ; série 2, face ouest (emplacement $n^{\circ} 31$ ). Cliché : G. Ravindran.

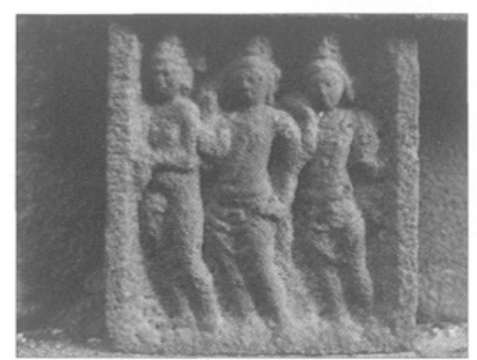

Fig. 26

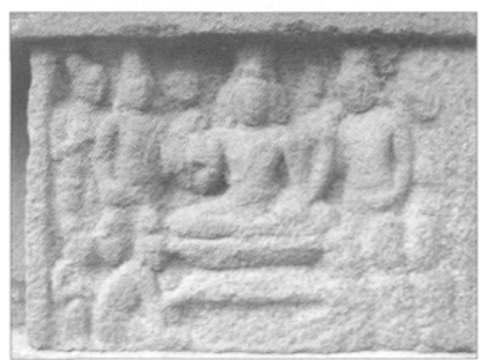

Fig. 25 
mise en perspective particulière du Rāmäyaṇa, un texte qui s'est prêté à de multiples adaptations culturelles.

Rappelons que le statut du Rāmāyaṇa en Inde du Sud, tel qu'il apparaît à la fois dans les représentations ( $\mathrm{Ch}$. Schmid 2002) et dans un phénomène comme celui de la version tamoule qu'en écrivit Kampan, sans doute au XII ${ }^{\mathrm{e}}$ siècle, est loin d'être sectaire. La légende veut que le Rāmāyana de Kampan fut tout d'abord rejeté par la tradition śrivaiṣnava de Śrīrankam. Ce texte, comme l'a rappelé Norman Cutler (2003 :303), n'a pas joué un rôle dévotionnel comparable à celui du Divyaprabandham, l'anthologie des Ālvāra prisée par les Śrīvaisnava et récitée régulièrement dans les temples vishnouites. Les représentations de Pullamankai semblent montrer que, plus d'un siècle avant l'apparition de Kampan, le Rāmāyana avait un statut ambigu, moralisant peut-être, qu'on observe ultérieurement. Du temps de Cāminātaiyar, cette épopée faisait partie des textes enseignés dans le monastère shivaïte de Tiruvāvatuturai. On le retrouve même en contexte musulman ${ }^{38}$. Le caractère épique des aventures de l'avatāra de Viṣnu lui vaut de s'intégrer parfaitement dans des contextes fortement shivaïsés. Le peu qu'on sait des Pāśupata de cette époque, associant parfois les légendes vishnouites à des corpus shivaïtes, correspond d'ailleurs à l'esprit du temple de Pullamañkai. Enfin, on a ici affaire à l'un des premiers lingodbhava cōl $a^{39}$, auquel on a vu que le dispositif iconographique donne en outre une grande importance. Représentation de la manifestation de la divinité, le lingodbhava correspond à la problématique mise en valeur plus haut en confrontant données de l'architecture et hymne du Têvāram.

Enfin, l'iconographie des temples cōla fait de la face ouest le lieu de rencontre de plusieurs divinités: c'est là qu'on représente Ardhanārīśvara et Hari-Hara, mais aussi Viṣnu dans les premiers temples $c \bar{o} \underline{l} a$, une divinité qu'on retrouve ici dans le couronnement de la face ouest (fig. 13,14 et 15$)^{40}$. La rencontre prend ici une forme particulière, présentant Viṣnu et Brahmā dominés par un Śiva auquel les représentations des autres divinités sont par ailleurs clairement subordonnées, comme, peut-être, d'autres formes du même dieu.

La comparaison avec les autres temples présentant des frises narratives continues souligne le caractère exceptionnel du Brahmāpurīśvara. Tous ces édifices portent des représentations du Rāmāyana, mais l'épopée commence sur les faces est ou

précaution des temples cōla construits durant le règne d'Āditya I ${ }^{\mathrm{er}}$, qui lui apparaissent comme une exception possible étant donné le titre de Kōdaṇ̣a Rāma porté par ce roi. Mais aucun lien entre le temple de Pullamankai et ce roi ne peut être établi.

38. Voir V. Narayanan 2000 qui évoque la tradition d'érudition musulmane du Rāmāyana à travers les deux figures emblématiques d'Umaru Pulavar (c. 1665-1773), auteur d'une biographie du prophète modelée en partie sur le Rämāyana de Kampan, et de Justice M. M. Ismail, qui a publié à la fin du $\mathrm{XX}^{\mathrm{e}}$ siècle plusieurs articles en tamoul sur le Rāmāyana tant tamoul que sanskrit ou hindi.

39. Sur la présence du lingodbhava à l'arrière du temple, voir S. R. Balasubrahmanyam $1966: 257$. Pour D. Barrett (1974: 70), il s'agirait de la première représentation connue d'un lingodbhava à l'arrière d'un temple côla. Cependant le lingodbhava apparaît à l'époque pallava sur la face arrière de plusieurs temples et les premiers temples cōla qui ont conservé leur iconographie me semblent trop rares pour qu'on puisse confirmer, ou infirmer, l'opinion de cet auteur.

40. Supra, note 15. 
sud à Puñcai, à Kumpakōṇam, à Tirupuvanai et à Kōnnn̄ār, correspondant donc à la

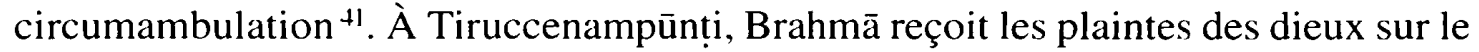
deuxième panneau de la face ouest en suivant la pradaksina $\bar{a}$; le panneau précédent est vide et la niche centrale ouest occupée par un lingodbhava. Le mauvais état de conservation du temple rend impossible l'étude de l'ensemble de la frise, mais il me semble qu'on y retrouve une partie de la structure iconographique de Pul!amańkai. Dans quelques autres temples apparaît le Viṣnu couché sur le serpent, mais Brahmā n'est jamais le sujet central d'un panneau voisin ${ }^{42}$. Le dispositif de Pullamańkai, l'un des temples les plus anciens de ce corpus, semble donc sinon unique, du moins rare, peut-être parce que la subtilité de la disposition iconographique n'était pas facile à imiter, ou même n'a pas toujours été comprise.

\section{Le concept narratif et le temple}

L'emplacement réservé aux formes narratives des dieux - un soubassement - et ses faibles dimensions - des panneaux de dix centimètres sur douze en moyenne marquent une subordination de l'aspect narratif aux formes cultuelles, qui s'exprime également par d'autres biais. Dans la série 1, on retrouve quelques scènes tirées du Rāmāyana. Ellcs sont alors disposées en paires symétriques de chaque côté du temple, au mépris de toute logique narrative. La mise à mort du démon Virādha est insérée entre un Kirātārjunīya et Hari-Hara, sur l'angle est de la projection centrale sud du mandapa (emplacement 9, a ; fig. 31), et son apparition se trouve sur l'emplacement correspondant au nord (emplacement 56, a), entre l'incarnation de Viṣnu en nain et un combat d'un éléphant contre un cheval (fig. 32). Si les deux panneaux du même sujet se succèdent selon la logique narrative dans la série 2 (sur l'angle est de la projection centrale nord du präsāda, emplacements 12 et 14 , b; fig. 33 et 34), la première série apparaît ainsi organisée parfois suivant un principe de symétrie, qui distribue des scènes choisies, entre autres, pour leur valeur esthétique.

Les figures divines de la première série sont par ailleurs courantes et faciles à identifier; seules deux des identifications proposées par D. T. Sanford me paraissent devoir être remises en question ${ }^{43}$. Les représentations de Śiva peuvent

41. À Puñcai, le Rãmāyana commence sur l'angle sud-est du prāsāda. Peut-être là aussi, cet emplacement fut-il choisi en partie au moins pour sa valeur symbolique : là où commence le prāsāda, commence le Rāmāyaña. À Tirumangalam, le Rāmāyaṇa commence sur la face nord et se poursuit dans le sens inverse de la circumambulation.

42. Le panneau de l'angle sud-est du temple de Tirupuvanai, daté du début du $\mathrm{xI}^{\mathrm{C}}$ siècle, porte un Viṣnu couché sur le serpent marquant le début des représentations du Rāmāyana, voir Ch. Schmid 2003.

43. Les désaccords portent cette fois sur deux scènes typiques de l'Inde du Sud. La première est une représentation de Kṛ̣na au milieu des bouviers, que l'on retrouve dans la plupart des autres temples portant des séries narratives (panneau 49 de la première série). Quant à la seconde (panneau 46 de la deuxième série ; fig. 37), j'avoue ne pas même savoir s'il s'agit d'une scène shivaïte ou vishnouite. À première vue, on pourrait penser qu'il s'agit d'un Śiva Tripurāntaka, avec le dieu représenté au bord de son chariot. Mais le dieu tient un disque, dont la présence n'est pas si facile à expliquer en contexte shivaïte. La même scène est représentée au premier étage du Vaikuntha Perumāl pallava, où toutes les scènes identifiées sont vishnouites. Pour compliquer encore les choses, le Vaikuntha-perumāl présente plusieurs bas-reliefs qui sont des réinterprétations vishnouites de scènes shivaïtes (un Krṣna Govardhanadhara représenté comme un Śiva Gañgādhara, un Viṣnu entremêlant une guirlande dans les cheveux 
relever d'une iconographie cultuelle (Ardhanārîśvara, Śiva porteur de son linga et formes associées à celles de Viṣnu), ou bien avoir un caractère narratif. En dehors du Kirātārjunīya, Śiva est Bhiksāạtanamūrti (fig. 35), reçoit la Gañgā sur sa tête, tue le démon éléphant (fig. 36), détruit Kāma, orne la tête de son dévot Candeśa d'une guirlande et, peut-être, détruit la ville de Tripura (fig. 37) ${ }^{44}$. À trois reprises, il est représenté dansant (fig. 38 et 39). L'ensemble du répertoire shivaïte n'est pas utilisé. Le meurtre de Kāla et le soulèvement du Kailāsa par Rāvaṇa, représentés dans l'art pallava et auxquels la première et la huitième strophe de l'hymne consacré au dieu d'Ālanturai dans le Tévăram font respectivement allusion (comme tous les hymnes de Campantar), ne sont pas figurés. La première série apparaît donc rassembler plusieurs types d'images, en prenant en compte leur aspect décoratif et en sélectionnant dans l'iconographie vishnouite un aspect narratif qu'on retrouve moins du côté shivaïte. Cette série hésite, me semble-t-il, entre une iconographie shivaïte cultuelle et le narratif qui domine le soubassement.

Les représentations divines du soubassement adoptent en effet rarement une iconographie cultuelle. Dans la deuxième série consacrée au Rāmāyaṇa, il ne serait pas facile d'insérer des figures cultuelles. Mais alors même que la première série fait appel aux ressources classiques de l'iconographie tant shivaïte que vishnouite, elle en comporte peu. Aucune des grandes figures des murs extérieurs ne se retrouve parmi les panneaux. Cette première série offrait quatre-vingt-quatre emplacements (les soixante-quatre emplacements qu'on trouve sur le plan de l'annexe, auxquels s'ajoutent les panneaux décorant la base des pañjara). Le total de ceux qui sont restés vides, de ceux qui ont été recouverts par des additions, et des nombreux panneaux décorés d'un feuillage s'élève à quarante-six ; les trente-huit autres sont occupés par, au moins, une figure humaine. La série du Rāmāyana nous est actuellement connue par quarante-deux panneaux sur les soixante-quatre qui étaient disponibles (en dehors de la base des pañjara). Mais plutôt que de reproduire un Dakșināmūrti, un Gaṇeśa, un lingodbhava ou même un Brahmā sur les panneaux de la première série ornant le soubassement, on a laissé le panneau vide ou on l'a orné d'un feuillage. Les avatāra de Viṣnu, formes narratives par essence, ont bien leur place, en revanche, dans la série 1, alors qu'ils n'apparaissent pas sur les murs du temple.

En définitive, sur les quatre-vingt-huit panneaux des deux séries offrant, aujourd'hui, des figures, soixante-deux mettent en scène uniquement des formes de Viṣnu, trois offrent des représentations impliquant à la fois Śiva et Viṣnu (HariHara, Śiva et Viṣnu, Kirātārjunīya, si on considère Arjuna comme le dévot de Viṣnu) et douze des représentations de Śiva ${ }^{45}$. Enfin, dans la première série, les épisodes

d'un dévot agenouillé, tel Śiva honorant Caṇdeśa, etc.) et ce panneau pourrait aussi correspondre à l'une d'elles. Le Harivamśa place la destruction de Tripura par «Bhava » au beau milieu d'une liste d'incarnations de Viṣnu $(65,38)$ et le Divyaprabandham fait parfois du dieu détruisant les trois villes une forme de Viṣnu. Aurait-on ici affaire à un Viṣnu Tripurāntaka ? Voir, dans ce même BEFEO, Francis-Gillet-Schmid, Chronique des études pallava, p. 579-601.

44. Voir, supra, note précédente.

45. Les autres panneaux sont occupés par des scènes non identifiées, d'autres qui n'ont pas d'identification précise comme des combats d'animaux et de cavaliers et, enfin, des scènes se rapportant à la mythologie de la déesse. 
du Rāmāyaṇa sont traités en continuité avec l'iconographie shivaïte : Rāma, comme d'autres manifestations de Viṣnu, apparaît comme l'une des expressions de la divinité du temple.

En fait, si le Rāmāyana est présenté comme issu de Śiva, dont les formes se mélangent à celles de Viṣṇu, force est de constater que les scènes vishnouites dominent les séries du soubassement. En plus de Rāma, Krș̣na (cinq scènes), Varāha, Narasiṃha, Trivikrama et Arjuna sont représentés. La contradiction entre la prééminence shivaïte apparente du temple et ces séries narratives majoritairement vishnouites se dissout dans une grille d'analyse autre, séparant formes divines narratives et formes cultuelles, comme je l'ai expliqué ailleurs : le statut particulier du narratif rend compte du grand nombre des scènes vishnouites en contexte shivaïte (Ch. Schmid 2002). Encore Pullamankai est-il plus «shivaïte » que les temples pratiquement contemporains de Kumpakōṇam et de Tiruccennampūṇti et ceux, plus tardifs, de Tirumańkalam, de Paccil et de Puñcai, où le pourcentage de panneaux consacrés à Śiva est encore inférieur.

En effet, Śiva ne se manifeste pas facilement comme héros d'une histoire. Les formes vishnouites se pressent dans un soubassement dont le caractère horizontal se prête au narratif. Les quelques représentations de la déesse trouvent place dans le même dispositif, sur la série 1 (emplacements $n^{\text {os }} 25$ et 41 ; fig. 40 ). Du côté nord où se trouve la niche de la Tueuse du Buffle, on a représenté le combat contre le démon (fig. 30). Vue de profil et l'arc tiré, la déesse montée sur le lion met en fuite un être à tête de buffle dans un panneau rempli de figures secondaires aux poses énergiques. L'iconographie s'inspire du bas-relief monumental de la grotte pallava de Mahiṣamardinī à Mahābalipuram, en subissant une drastique réduction d'échelle. Pourtant, la Mahișamardinī cultuelle occupant la niche nord du mandapa est à peu près de mêmes dimensions que les figures équivalentes pallava ${ }^{46}$. Deux autres combats de la déesse se répondent presque, dans deux petits panneaux au nord et au sud du soubassement du temple (fig. 40). Entre formes shivaïtes et avatāra de Viṣnu, les représentations de la déesse confirment donc une forme de scission entre iconographies cultuelle et narrative.

Les représentations narratives paraissent ainsi correspondre à un Śiva proche du monde des humains - autant que les incarnations de Viṣnu et de la déesse ${ }^{47}$, descendus en ce monde pour combattre les démons - , proche aussi des musiciens et danseurs, qui sont nombreux dans la première série. Tout comme ces derniers, les épisodes mythologiques tendent parfois vers un décoratif qui leur retire sans

46. La représentation est si proche de celle de la grotte pallava de Mahābalipuram dite grotte de Mahișāsuramardinī qu'on peut supposer une influence directe de la représentation pallava, qu'on retrouve dans d'autres temples portant des séries narratives (Paccil, Kumpakōnam). Sur les déesses tueuses de buffle du Sud, Ch. Schmid 2004a, et à paraître, et sur les représentations de divinités féminines à Mahābalipuram, V. Dehejia-G.M. Tartakov 1984 et Ch. Schmid 2005.

47. La déesse est aussi représentée, presque symétriquement par rapport à la Mahiṣāsuramardinī du mur nord, dans le panneau de la face sud (emplacement $\left.n^{\circ} 25\right)$ transperçant un démon dans une scène que l'on peut mettre en relation avec plusieurs épisodes du Devi-Mähätmya (fig. 40). Sur la proximité du statut des avatāra de Viṣnu et de certaines manifestations de la décsse, Ch. Schmid 2004a. Enfin, l'une des premières listes des manifestations de Viṣnu dans le Harivamśa mentionne Śiva, supra, note 43. Il ne s'agit pas pour autant nécessairement d'un avatāra de Viṣnu, mais d'une manifestation du dieu qui prend forme pour combattre un démon. 


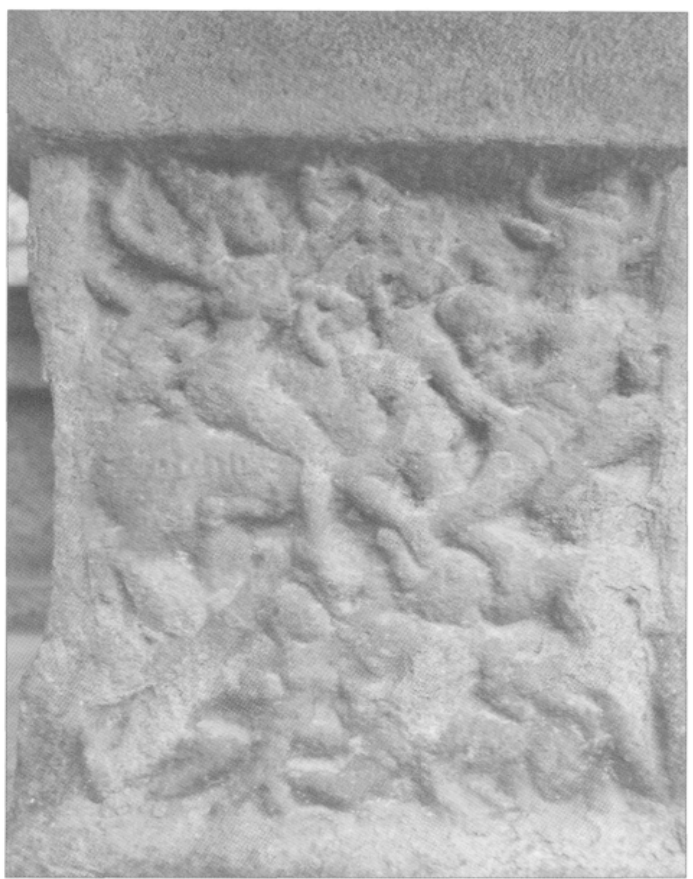

Fig. 30. Mahișamardin̄̄ ; série 1, face nord (emplacement $n^{\circ}$ 50). Cliché : G. Ravindran.

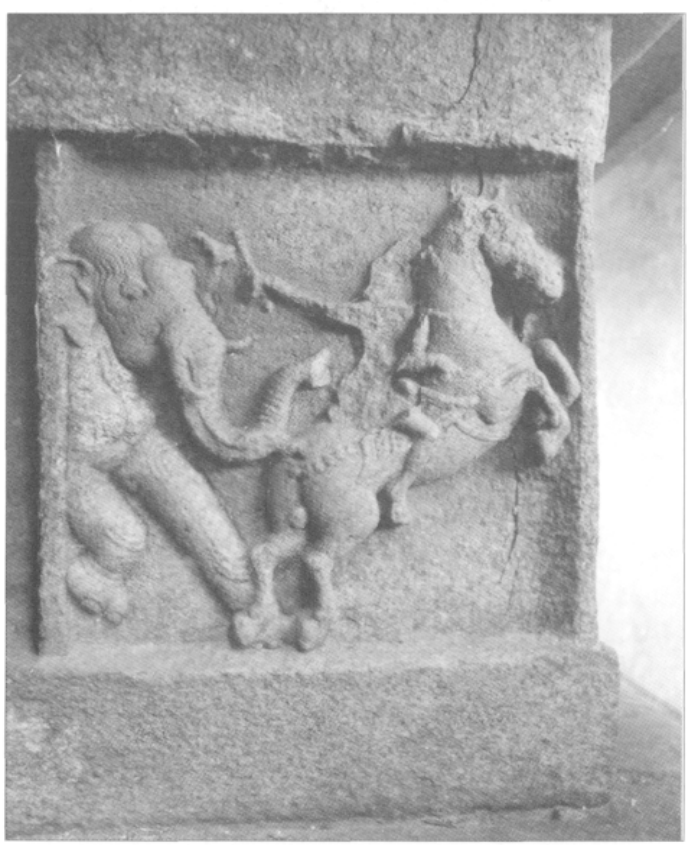

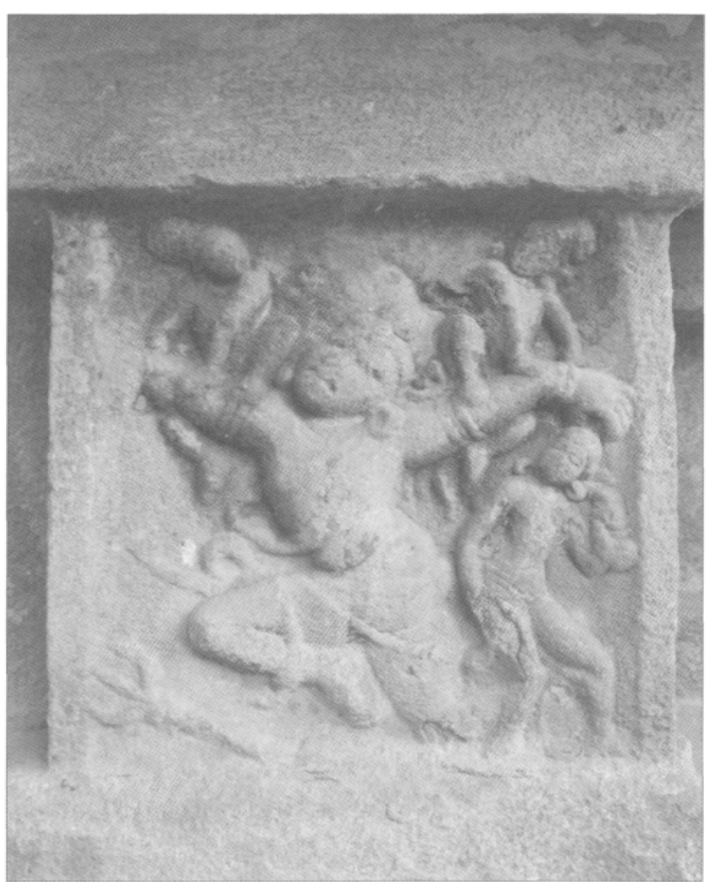

Fig. 31. La mort de Virādha ; série 1, face sud (emplacement $n^{\circ} 9$ ). Cliché : G. Ravindran.

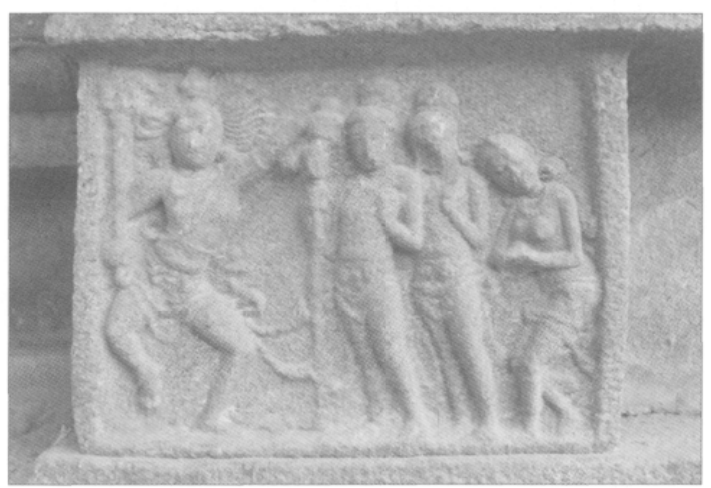

Fig. 33. L'apparition de Virādha ; série 2, face sud (emplacement $n^{\circ}$ 12). Cliché : G. Ravindran.

Fig. 32. Le combat d'un éléphant et d'un cheval ; série 1 , face nord (emplacement $n^{\circ} 57$ ). Cliché : E. Francis.

Fig. 32 


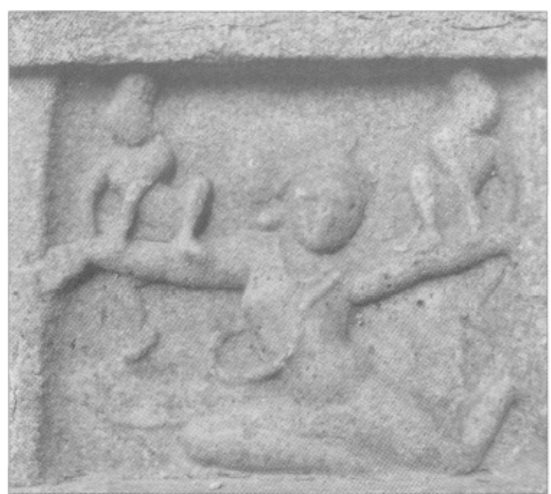

Fig. 34

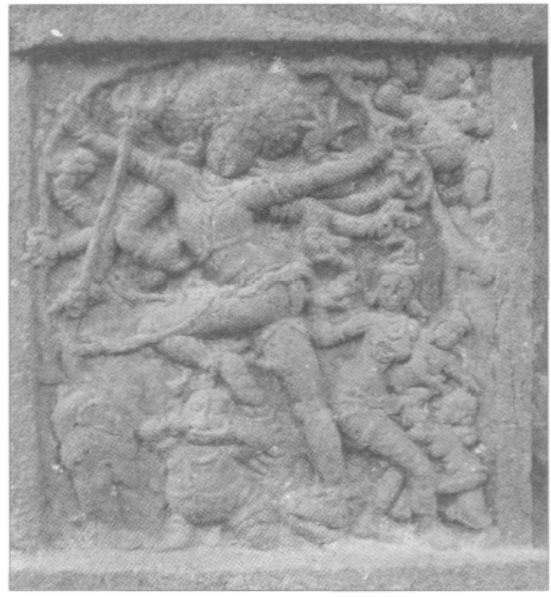

Fig. 36

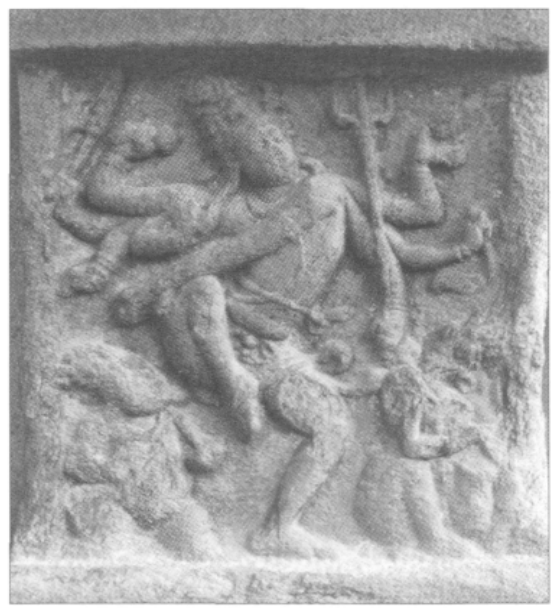

Fig. 38. Śiva dansant ; série 1, face nord (emplacement $n^{\circ} 43$ ). Cliché : G. Ravindran.

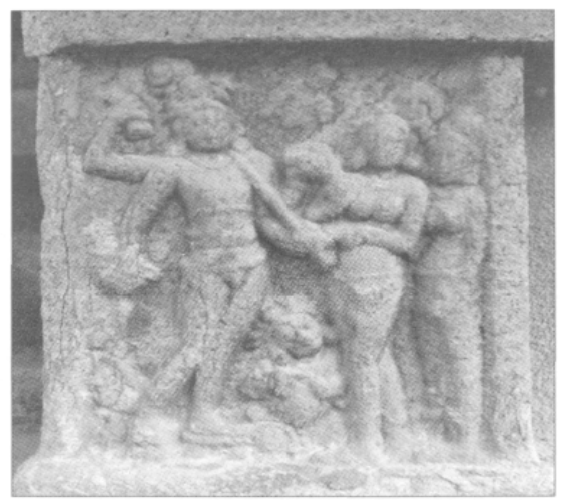

Fig. 35

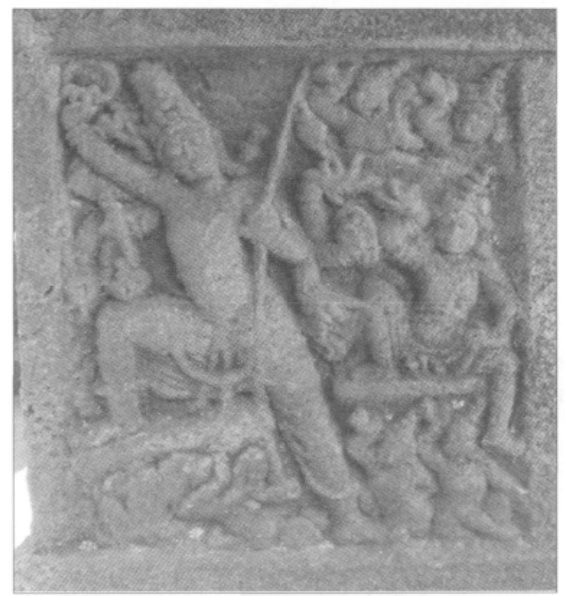

Fig. 37

Fig. 34. La mort de Virādha ; série 2, face sud (emplacement $n^{\circ}$ 14). Cliché : G. Ravindran.

Fig. 35. Śiva mendiant ; série 1 , face sud (emplacement $\left.n^{\circ} 16\right)$. Cliché : G. Ravindran.

Fig. 36. Śiva tue le démon éléphant ; série 1, face sud (emplacement n²6). Cliché : G. Ravindran.

Fig. 37. Śiva Tripurāntaka ; série 1 , face nord (emplacement $n^{\circ} 46$ ). Cliché : G. Ravindran. 


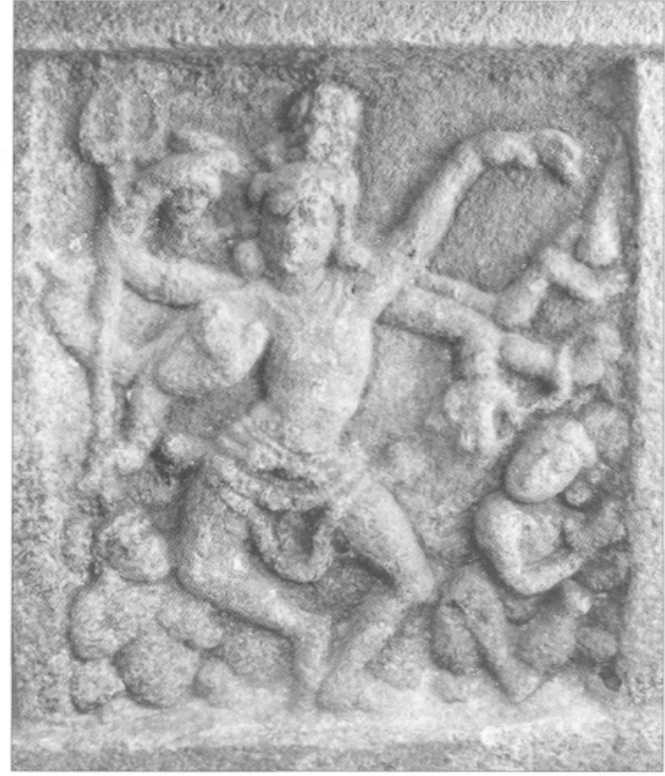

Fig. 39

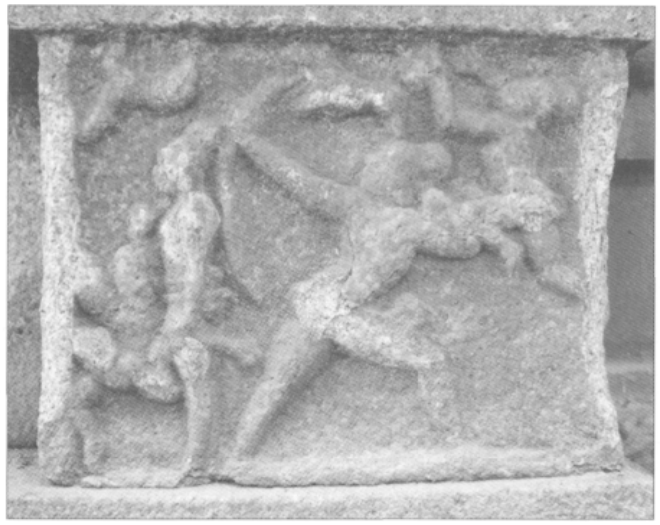

Fig. 41

Fig. 41. Le panneau consacré à la poursuite de Mārīca ; série 2, face sud (emplacement $n^{\circ}$ 25). Cliché : G. Ravindran.

Fig. 42. L'enseignement de la science de l'arc; série 2, face nord (emplacement $n^{\circ}$ 38). Cliché : G. Ravindran.
Fig. 39. Śiva dansant ; série 1, face sud (emplacement $n^{\circ} 15$ ). Cliché : G. Ravindran.

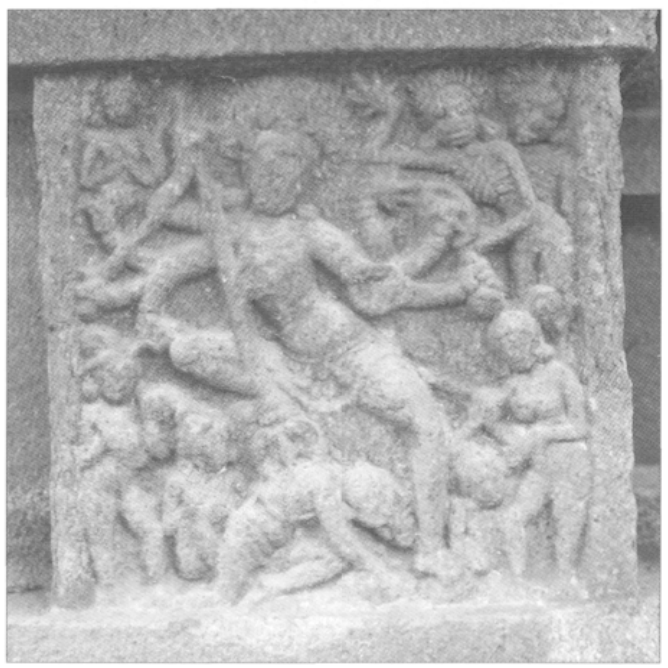

Fig. 40

Fig. 40. Déesse échevelée plongeant son trident dans le corps d'un démon; série 1 , face sud (emplacement $n^{\circ} 25$ ). Cliché : G. Ravindran.

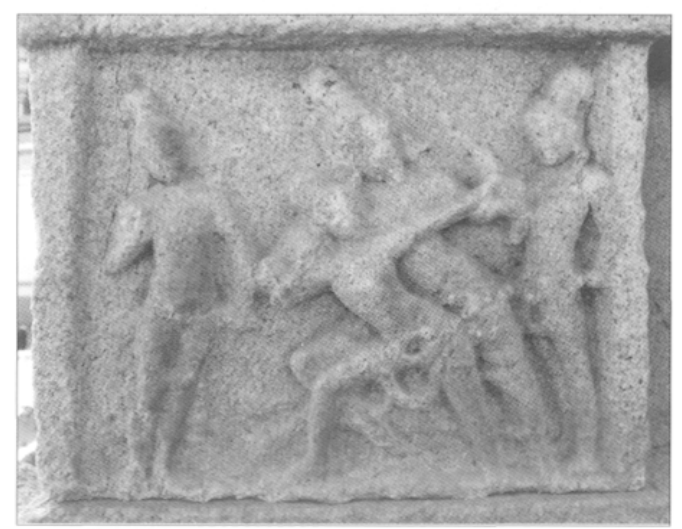

Fig. 42 
doute une partie de leur force divine. Trois des combats de Kṛ̣na s’intègrent dans l'une des bandes de feuillages et de fleurs d'un pilastre de la face sud du mandapa (fig. 7) ${ }^{48}$. À Tirucennampūṇti, la gueule d'un yāli s'ouvre sur un Varāha. Jamais une iconographie shivaïte n'apparaît dans un cadre aussi décoratif, et si la multiplication des figures de Viṣnu s'accompagne parfois clairement d'une déperdition de leur caractère divin, ce type d'affaiblissement pourrait être sous-jacent dans d'autres cas.

\section{Les inscriptions : le dieu, le lieu, les hommes}

Face à un programme iconographique précis, qui distribue les emplacements des images, on ne peut évoquer un programme épigraphique. Et pourtant, à Pullamañkai, il apparaît que la disposition des inscriptions joue parfois aussi un rôle de nature symbolique. On y retrouve l'importance donnée au dieu, et plus précisément à son culte, même si ce peut être dans une perspective assez différente.

Les emplacements libérés par la disparition des grands bas-reliefs pallava sont ici, comme dans bien d'autres petits temples cōla, occupés par l'écrit, qui marque sur le temple le déroulement de la période $c \bar{l} \underline{l} a$. Dix-sept des vingt-deux inscriptions de l'Ālanturai ont fait l'objet de publications partielles; aucune n'avait jamais été traduite $^{49}$. Le professeur G. Vijayavenugopal, assisté par R. Sathyanarayanan, N. Ramaswamy et E. Francis, a, pour la première fois, établi le corpus épigraphique du temple, qu'il s'est aussi chargé de présenter et de traduire. Les quelques analyses qui suivent ne prétendent pas résoudre tous les problèmes que soulève un tel corpus. En l'absence de publication d'ensemble de l'épigraphie médiévale tamoule, dont la moitié au moins est inédite et les traductions rares, pouvoir avancer des hypothèses est un premier pas. La prise en compte de la disposition des inscriptions, rendue possible par un travail de terrain attentif à l'inscription comme objet archéologique autant que comme texte, amène, à mon sens, à les mettre en relation dans deux cas précis avec le programme iconographique du temple. La comparaison des inscriptions de Pullamańkai avec les inscriptions connues par ailleurs amène à des réflexions plus générales sur le rôle de l'épigraphie dans un petit temple cōla, et plus précisément sur la relation entre le dieu et son dévot dont elle témoigne.

\section{Emplacement des inscriptions}

Les inscriptions ne sont pas réparties sur le temple de façon uniforme (fig. 55 et 56). Le couronnement n'est pas inscrit. Portant quinze inscriptions sur vingt-deux, dont onze entières (c'est-à-dire commençant et finissant à cet endroit) alors qu'il constitue seulement environ $20 \%$ de l'espace extérieur du temple (sans prendre en compte le couronnement), le soubassement apparaît favorisé. Le caractère horizontal

48. Kṛ̣na luttant contre Keśin (épisode représenté dans la première série sur la face nord, panneau 45), soulevant le mont Govardhana et passant entre les arbres dits arjuna.

49. Sur les publications antérieures, voir la mise au point de G. Vijayavenugopal : aucune photographie, aucun estampage, aucune traduction (en dehors de celle de l'inscription $n^{\circ} 6$ ) n'avaient jamais été publiés (infria: 107-111). 
du soubassement a pu jouer un rôle dans son importance en tant que support épigraphique. Mais les inscriptions concernées (sur la face sud, inscriptions 2, 3, 4, 5,11 , une partie de l'inscription 15 [fig.47-48] et une grande partie de l'inscription 16 [fig. 53] ; au nord, le début de l'inscription 19 et les inscriptions 7, 8, 13, 20 et 22 [fig. 54]) sont aussi, en général, plus anciennes. Peut-être l'importance ici donnée à la base du temple vient-elle de la période pallava, où les inscriptions étaient gravées de préférence sur les soubassements?

Le caractère lisible des emplacements a, en tout cas, sans doute joué un rôle dans leur choix. Si les fidèles accomplissant la circumambulation n'étaient certes pas tous capables de lire les inscriptions, tous pouvaient les voir - même s'il est parfois difficile d'en distinguer certaines lignes situées très bas ou assez haut sur les murs extérieurs (fig. 46). L'Arjuna ratha de Mahābalipuram étant le seul monument pallava connu portant des inscriptions invisibles - elles sont gravées sur le couronnement - les emplacements des inscriptions de Pullamankai semblent s'inspirer de la tradition pallava dans ce qu'elle avait de lisible et de pratique. Dans un premier temps, on peut dire qu'on a affaire à des informations disponibles ou, en tout cas, se présentant comme telles.

Mais, à Pullamañkai, à partir de la fin du $\mathrm{x}^{\mathrm{e}}$ siècle, les inscriptions sont également gravées sur les murs extérieurs, qui, à la différence de ceux des temples pallava, offrent des plages libres. Et l'on s'aperçoit que la répartition des emplacements des inscriptions est surprenante. Elle est inégale d'une partie du temple à l'autre. Tout d'abord, le mandapa comporte 18 inscriptions, dont 14 prenant place uniquement sur cette partie du temple; le prāsāda ne compte que 6 inscriptions, dont 2 se partagent entre maṇdapa et prāsāda ${ }^{50}$. Les inscriptions du maṇapa sont en outre plus anciennes. On ne trouve pas une seule des inscriptions de Parāntaka ${ }^{\mathrm{er}}$, dont le règne occupe une grande partie du $\mathrm{x}^{\mathrm{e}}$ siècle, sur le prāsāda, où l'inscription la plus ancienne $\left(n^{\circ} 12\right)$, est datée de 969.

Par ailleurs, la face sud du temple porte plus d'inscriptions que les trois autres. Les faces ouest et nord du prāsāda ne portent qu'une inscription et demie. Avec cinq inscriptions complètes et une partie de deux autres, le soubassement sud du mandapa - soit environ $5 \%$ de la surface disponible de l'espace extérieur apparaît comme l'emplacement favorisé par les premiers graveurs. Enfin, après l'inscription $\mathrm{n}^{\circ} 12$, les inscriptions gravées uniquement sur le prāsāda constituent un groupe défini, celui de l'épigraphie du règne de Rājarāja ${ }^{\text {er. }}$.

Si aucun programme d'ensemble ne commande les emplacements des inscriptions, l'étude de la disposition d'inscriptions qui, d'abord confinées sur le soubassement, gagnent peu à peu une grande partie du temple, s'impose. L'analyse se concentrera ici sur deux points importants dans cette perspective : l'intervention du roi et le lien privilégié entre la face sud et l'épigraphie.

50. Je reprends dans cette note la numérotation des inscriptions donnée dans l'annexe de cet article (voir les fig. 55 et 56). Les inscriptions $12,15,17$ et 19 se trouvent sur le prāsāda et les inscriptions 1 , $2,3,4,5,6,7,8,9,10,11,13,18,20,21$, et 22 sur le mandapa; les numéros 14 et 16 prennent place sur les deux parties du temple. La face est porte une inscription de chaque côté de l'entrée du temple (9 et 10). La face ouest porte l'inscription 17 et une partie de la 19 qui est répartie sur les faces nord et ouest. 


\section{Les inscriptions et les rois}

Deux rois apparaissent dans les inscriptions de Pullamañkai : Parāntaka I ${ }^{\mathrm{er}}$ qui, dans la dix-huitième année de son règne, en 925 donc, fait une donation au temple si l'on en croit l'inscription $n^{\circ} 6$ (fig. 44), et Rājarāja I ${ }^{\text {er }}$ qui, en 997 et en 1006, intervient dans l'organisation des taxes de l'ür (inscriptions nos 15 et 17, fig. 49), peut-être dans l'organisation religieuse du brahmadey ${ }^{51}$. L'inscription de Parāntaka I Ir est courte (fig. 44). Comme les autres inscriptions utilisant ici le comput de ce roi, elle se limite aux détails matériels ; le roi a donné tant de terre et d'or dans tel but, la terre a tel statut et correspond à tel territoire. Rien ne semble distinguer cette inscription où le roi est donateur du tout-venant des inscriptions de l'époque. Les deux inscriptions évoquant Rājarāja I ${ }^{\text {er }}$ sont en revanche plus longues et plus individualisées que celles qui les précèdent dans le temps. Elles ne s'adressent pas à la divinité du temple, tandis que toutes les inscriptions du règne de Parāntaka Irer enregistrent des dons au dieu d'Âlanturai, ou, dans un cas, à un dieu qui danse. Enfin, l'une des inscriptions mentionnant Rājarāja I ${ }^{\text {er }}$ présente le seul éloge royal (meykkīrtti) du temple. Ces trois inscriptions « royales », les $\mathrm{n}^{\mathrm{os}} 6,15$ et 17 , ont pourtant une caractéristique commune : le caractère exceptionnel de leur emplacement (fig. 44 et 49).

La première inscription de Rājarāja $\mathrm{I}^{\mathrm{er}}\left(\mathrm{n}^{\circ} 15\right)$ commence en effet tout à gauche de la face sud, sur le premier espace alors disponible sur le prāsāda (fig. 47 et 48). Elle court ensuite sur le mur extérieur de cette partie du prāsāda, avant la niche de Dakṣināmūrti, puis sur le soubassement correspondant, pour s'achever sur le soubassement de la niche du dieu. Elle est donc très visible. De plus, elle est gravée seulement sur le prāsāda, dont elle recouvre entièrement la face sud, selon une logique complexe qui a égaré les épigraphistes du début du siècle et indique clairement que cette inscription devait être gravée sur le prāsāda uniquement ${ }^{52}$. Les inscriptions 6 et 17 sont elles aussi très visibles. Isolée du reste du corpus de la

\footnotetext{
51. L'expression iv vīr, «ce village », est employée à plusieurs reprises alors que le brahmadeya de Pullamankalam est la seule unité territoriale précédant le démonstratif. C'est ainsi qu'elle apparaît dans l'inscription $15(1.10,13,16$, etc.) où comprendre le complément ivvūrppāl brahmadeyam nilamarika[la .. ] (1. 16) n'est pas si facile. Un brahmadeya dépendant d'un autre, plus vaste "' Un a ici l'impression d'une équivalence de l'ür et du brahmadeya de Pullamankalam, difficile à concilier avec l'usage fait des deux termes dans la littérature secondaire pour qui, en général, ür et brahmadeya correspondent à des communautés villageoises différentes, voir Y. Subbarayalu (1973: 89), N. Karashima 200la et b (surtout le chapitre intitulé "Village Communities : Myth or Reality? »). Selon Y. Subbarayalu (1973: 91) et R. Champakalakshmi (2001: 67), pāl est employé pour désigner un hameau. Il reste que le hameau dont il est question ici serait lui-même un brahmadeya, étant donné la finale -mankkalam dont il est pourvu. Peut-être l'ūr dont il est ici question est-il le territoire administratif originel dans lequel se situe Puḷamankkai. Voir, à ce sujet l'étude des inscriptions d'Uttaramerūr par François Gros (Gros-Nagaswamy 1970 : 104-107), qui pose une assemblée se substituant peu à peu à une organisation territoriale originelle, l'ùr, pour résoudre la difficulté que constitue l'équivalence apparente, dans certaines inscriptions, des termes $\bar{u} r \bar{o} m$ et sabhā ou mahāsabhā. Il semble que dans notre petit corpus, l'assemblée de brahmanes qui se réunit à Puḷamankai, désignée par les termes $s a$ bha ou mahāsabha, contrôle les terres de tout ce qui est brahmadeya, y compris d'autres brahmadeya que celui de Pullamankai, dans un territoire plus vaste. C'est ce dernier territoire qui est appelé $\bar{u} r$. Il fait lui-même partie d'un nătu, placé sous le contrôle d'autres autorités que celle de l'assemblée de brahmanes, voir aussi, infra, note 100 .
}

52. On peut suivre sur la fig. 55 et dans le corpus la logique d'occupation de l'espace de cette inscription; le transcrit réalisé en 1921 est composé de certains de ses morceaux seulement. 


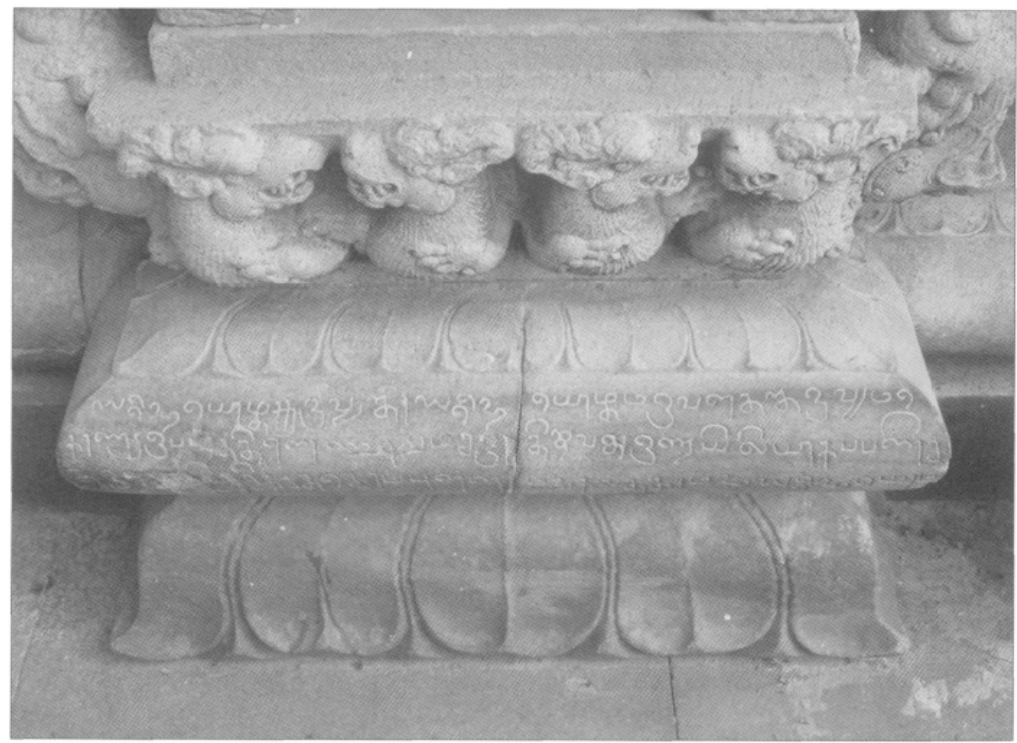

Fig. 43. Inscription $n^{\circ}$ 16, I. 34-36. Cliché : E. Francis.

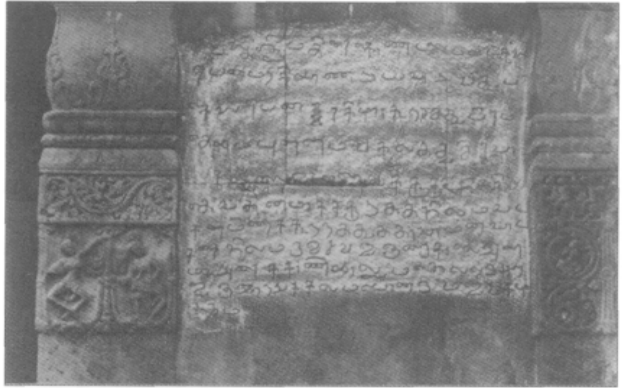

Fig. 44. Inscription $n^{\circ}$ 6. Cliché : G. Ravindran.

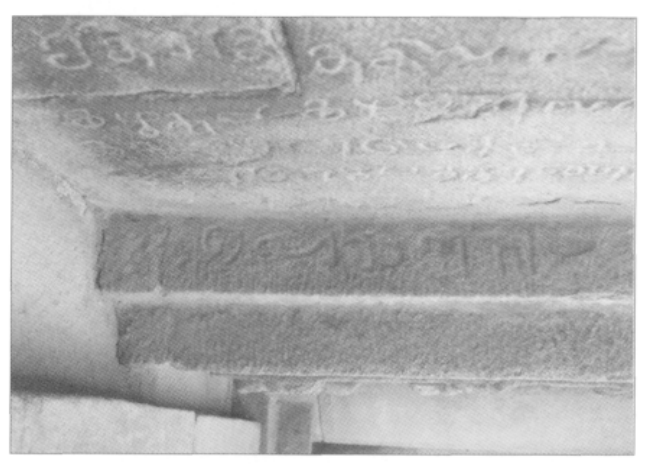

Fig. 46. Détail de l'inscription $n^{\circ} 18:$ « les lettres invisibles ». Cliché : E. Francis.

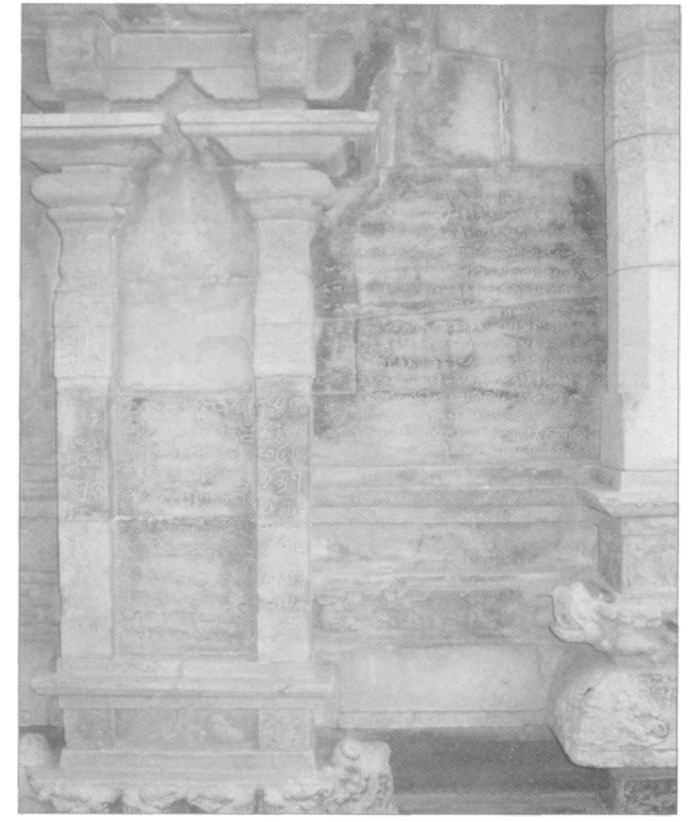

Fig. 45. Inscription $n^{\circ}$ 18. Cliché : E. Francis. 
face sud, l'inscription 6 se détache solitaire, en haut de la première portion du mur extérieur sud, alors que toutes les autres inscriptions de la face sud datées du règne de Parāntaka $\mathrm{I}^{\mathrm{er}}$ se trouvent sur le soubassement. Quant à la $\mathrm{n}^{\circ} 17$, elle est l'unique inscription de la face ouest du temple, aux côtés du lingodbhava (fig. 10 et 49). Elle place le nom de Rājarāja I $^{\text {er }}$ et le seul éloge royal complet du temple aux côtés de la manifestation par excellence de Śiva.

Cette disposition de l'écrit par rapport aux images recoupe le contenu épigraphique. À partir de l'inscription 15 , le roi est présenté comme une autorité proche de celle d'un dieu auquel il semble se considérer lui-même associé. Deux des trois inscriptions du règne de Rājarāja ${ }^{\text {er }}$ font en effet intervenir directement le roi. Cette observation tend à confirmer celles que l'on peut faire sur le corpus du territoire des inscriptions de Pondichéry (Kuppusamy-Vijayavenugopal 2006), seul autre corpus exhaustif sur une région du Tamil Nad où, comme ici, le rôle du souverain cōla - et notamment son pouvoir d'intervention dans l'économie des régions - se fait plus apparent à partir de Rājarāja $I^{\text {er }}$. Avant le règne de ce dernier roi, le souverain cōla est peu mentionné dans l'épigraphie, en dehors de l'année régnale qui a pour fonction de dater l'inscription. Mais dans le corpus daté du règne de Rājarāja ${ }^{\text {er }}$, les inscriptions où le roi lui-même apparaît se font bien plus nombreuses et il est parfois présenté comme un intervenant quasi direct dans la vie locale, par l'intermédiaire des ordres royaux qu'il envoie.

Dans l'inscription 15 de notre corpus, l'assemblée a ainsi reçu un ordre royal enjoignant de vendre les terres d'un certain Nākan Kali ; ces terres doivent être dorénavant contrôlées par Pāntịulācañi Mārān. L'assemblée achète ces terres et les donne afin que leurs revenus rémunèrent des récitants du Sāma-veda et du $R g$-veda ${ }^{53}$. Un accord est donc passé avec Pāṇtikulācani, qui use, en l'occurrence, d'une autorité qu'indique le terme difficile à traduire de $k \bar{o} c$-ceyya, où l'on retrouve l'action $(c \bar{e} y a)$ d'une autorité $(k \bar{o})$ qui semble proche du roi $(k \bar{o} \underline{n})$. Peut-être le terme dénote-t-il le fait d'agir au nom du roi ${ }^{54}$. Les terres sont données sans taxes. Neuf ans plus tard, l'inscription 17 fait état d'un autre ordre royal. Le roi, est-il dit, impose les terres car il n'y a pas de récitants du Sāma-veda et du Rg-veda dans le village. Les efforts pour instaurer des récitations védiques paraissent donc avoir été vains. On peut aussi penser qu'il s'agissait, dans l'inscription 15, d'une manœuvre de l'assemblée pour échapper à certains impôts ou, en tout cas, pour éviter que les terres relevant

53. Peut-être faut-il rapprocher ces récitants de textes védiques des connaisseurs des Veda qu'on trouve en 1. 16, 8 dans l'hymne dédié à Ālanturai ([...] -vètam payinaru èttip / pulankal tamai veñrār pukalavar vāl pulamarikai ; «Puḷ!amañkai où vivent les célèbres [maîtres] qui ont vaincu leurs sens, psalmodiant le Veda en prières continues »).

54. G. Vijayavenugopal serait enclin à considérer que $k \bar{o} c$-ceyya connote une manifestation forte de l'autorité royale; il pense qu'il s'agit parfois de tortures imposées à l'assemblée et que le terme fait au moins allusion à une forme de punition. Ce type d'action semble induit par le tantal, dérivant du danda sanskrit et symbolisant, semble-t-il, l'autorité que le roi confère à ce personnage aux lignes 2324 , dans le śrimukam, l'ordre royal cité. Il me semble que le personnage possédant le tantal est celui qui a autorité pour régler les affaires dépendant de l'ür, et non d'un brahmadeya (supra: note 51), sans qu'il faille nécessairement aller jusqu'à supposer que son autorité s'exerce de façon aussi tyrannique. Il me semble qu'il correspond à peu près à ce que Burton Stein (1999: 282-283) définit comme le "chieftain», avec lequel le roi interagit et qui fut, pour des raisons idéologiques, à peu près ignoré de l'historiographie $c \bar{l} l a$ traditionnelle. 


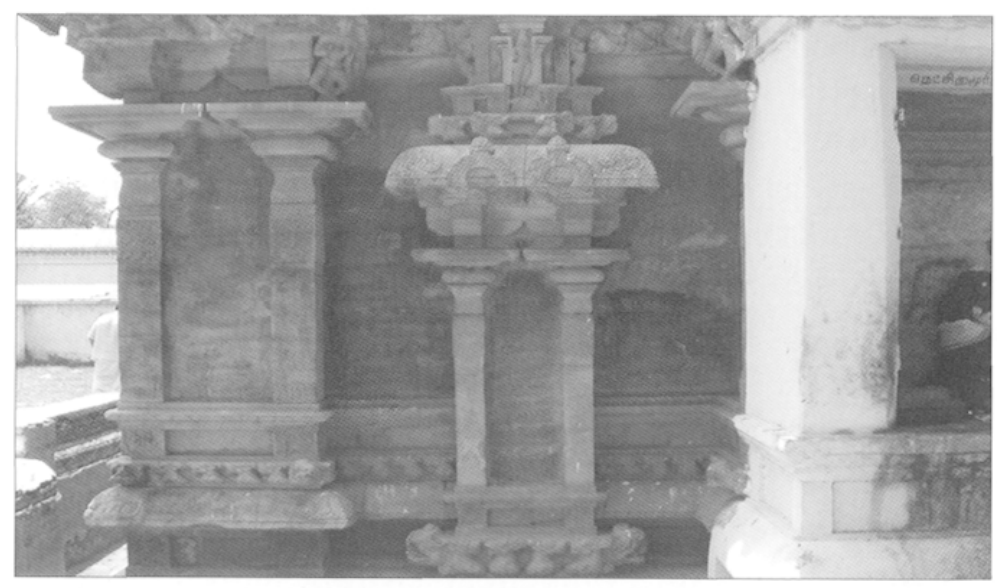

Fig. 47. Inscription $n^{\circ} 15$. Cliché : Ch. Schmid.

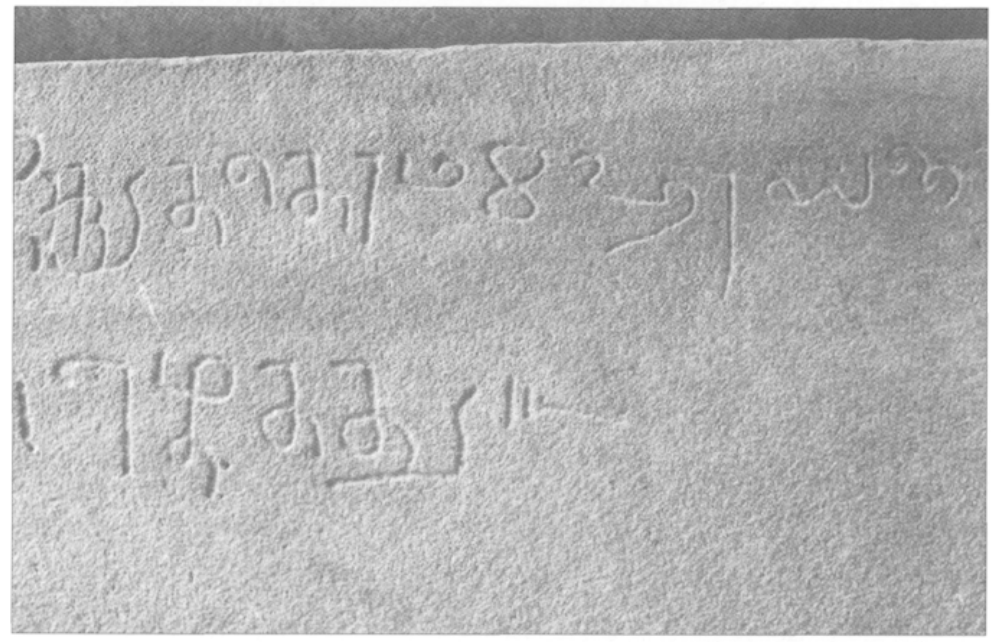

Fig. 48. Inscription $n^{\circ} 15$, détail : fin de l'inscription. Cliché : E. Francis.

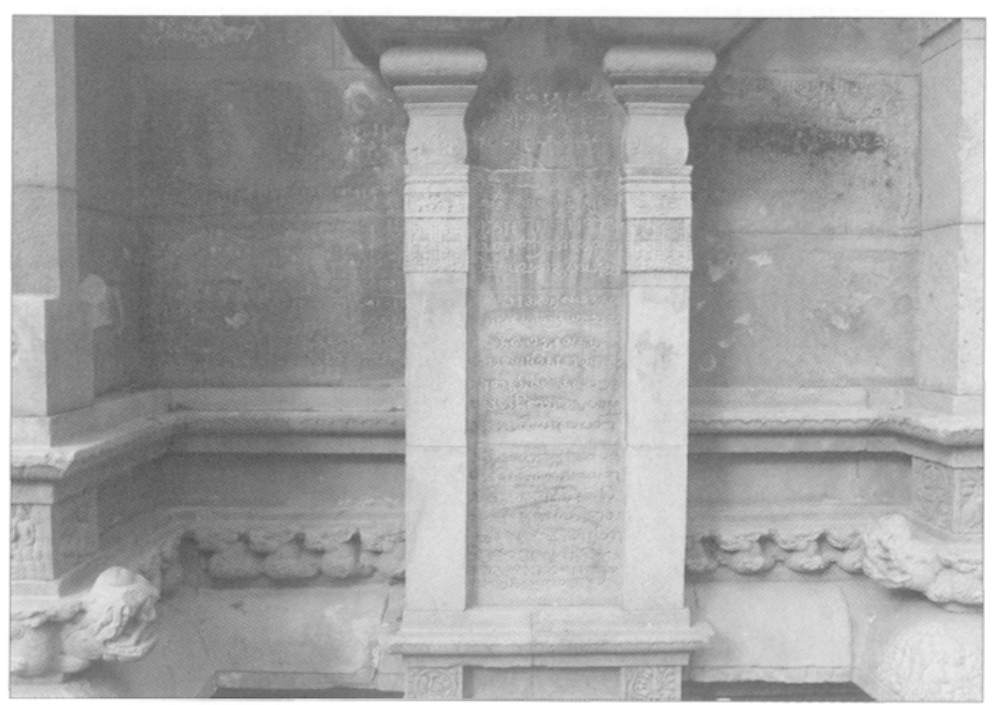

Fig. 49. Inscription $n^{\circ}$ 17. Cliché : Ch. Schmid. 
d'un brahmadeya, et donc placées sous le contrôle de l'assemblée de brahmanes de Pullamańkai, ne dépendent dorénavant d'autres autorités. Le but de la donation va dans ce sens. On remarque en effet que rémunérer des brahmanes récitant les textes védiques est un des appanages du roi, selon un modèle brahmanique qui subordonne le roi au brahmane. Le don fait par le roi aux brahmanes relève du processus de légitimation royale dans les textes normatifs (Lois de Manu I, 88-89). L'initiative de l'assemblée de Pullamańkai pourrait se lire comme l'une des manifestations d'un désir d'auto-suffisance brahmanique, qui cherche à se passer du roi, ou à contraindre ce dernier à faire un don, celui des taxes auxquelles il renonce. Mais d'autres interprétations sont possibles. Pour Leslie Orr, la liste nominative qui achève cette inscription exprime la fierté de l'assemblée qui mentionne un ordre royal de façon répétitive et en utilisant des termes différents pour évoquer la parole du roi ${ }^{55}$.

L'ordre en question permet en effet de mentionner le monarque, donnant ainsi de l'importance à un village brahmane dont la tentative avortée d'organiser des récitations védiques montre, en tout cas, qu'il tend à se présenter comme plus considérable qu'il n'est. La mention de l'ordre royal, la gravure de l'éloge du roi, la position donnée à l'inscription sont peut-être autant de tentatives de grossir le rôle des brahmanes de Pullamańkai. L'assemblée doit finalement indiquer que ces terres sont imposables, se soumettant donc à une autorité fiscale centrale et on peut trouver surprenant qu'en douze années le brahmadeya n'ait pas réussi à trouver des récitants védiques.

Quelle que soit la raison pour laquelle les chants védiques ne s'élèvent pas dans le Pullamańkalam du début du $\mathrm{XI}^{\mathrm{e}}$ siècle, la succession des inscriptions 15,16 et 17 témoigne, à mon avis, des difficultés de l'assemblée de brahmanes pour résister à une pression royale qui se manifeste, entre autres, par une fiscalité de plus en plus importante. La mention dans l'inscription 17 d'une nouvelle division territoriale, Nittavinōtavalanātṭu va dans ce sens. Cette division administrative du territoire cōla n'est pas attestée avant 1002 dans l'épigraphie (Subbarayalu 1973 : 58). Datée de 1006, l'inscription 17 fait déjà état de cette nouvelle unité territoriale et Rājarāja $\mathrm{I}^{\mathrm{er}}$ semble bien contrôler plus étroitement que ses prédécesseurs le brahmadeya de Pullamankkai. La position des inscriptions le mentionnant dans le temple, et surtout celle où on utilise son éloge royal, manifeste le pouvoir qu'il représente ici au début du $\mathrm{XI}^{\mathrm{e}}$ siècle. L'absence, étonnante, de svasti śrī au début de l'inscription 17 pourrait dénoter, à mon sens, le peu d'habitude qu'avait l'assemblée de mentionner le roi et plus encore d'utiliser un éloge royal comportant des éléments étranges qu'on ne retrouve pas ailleurs ${ }^{56}$. Qu'on interprète ce manque d'habitude comme

55. Je remercie vivement Leslie Orr d'avoir longuement discuté du contenu l'inscription $n^{\circ} 17$ avec moi : c'est son interprétation de la situation que je reproduis, avec son autorisation, dans cette seconde hypothèse qui fait la part moins belle à l'autorité royale. Leslie Orr doute fortement que le pouvoir royal ait exercé une influence bien considérable, voir sa très convaincante introduction au corpus des inscriptions du territoire de Pondichéry dans Kuppusamy-Vijayavenugopal 2006 : XVII-XIX. La remise en question de la nature de l'autorité royale est nécessaire.

56. Il ne paraît pas possible de traduire cet éloge royal. Il est très abîmé et donc difficilement lisible. Nous l'avons reconstitué à partir des versions publiées du roi et des aksara que l'on distingue encore. Il est clair que nombre de termes ne correspondent pas aux versions publiées, sans qu'on puisse savoir si le texte avait un sens, s'il s'agissait d'une copie mal comprise d'une version connue par ailleurs de l'éloge royal, ou s'il s'agit d'une version différente de celles que l'on connaît. 
expression de la résistance de l'assemblée locale au pouvoir du roi ou comme le désir de cette assemblée de se faire valoir en mentionnant le roi, on doit constater que les manifestations du pouvoir royal, si maladroites qu'elles soient, se font plus nombreuses sous le règne de Rājarāja I ${ }^{\mathrm{er}}$.

Inscrite aux côtés du lingodbhava, faisant de Rājarāja I'er l'égal d'un Śiva que prient les divinités, l'inscription 17 permet, me semble-t-il, de mieux comprendre l'emplacement de l'inscription 6, qui fait de Parāntaka $I^{\text {er }}$ un donateur. Cette inscription est placée bien loin du linga et sa syntaxe, le nom du roi se trouvant placé avant la mention géographique, unique dans le corpus. On peut douter de l'implication personnelle de Parantāka $I^{\text {er }}$ dans une donation, par ailleurs peu considérable. Il reste que comme l'inscription 17 , mais selon des modalités très différentes, elle se distingue de l'ensemble de l'épigraphie de Puḷamañkai. La relation avec le pouvoir central semble s'être modifiée entre le règne de Parāntaka $I^{\text {er }}$ et celui de Rājarāja I ${ }^{\text {er. }}$. Mais, d'une période à l'autre, la gravure d'une inscription mentionnant un roi occupe un emplacement spécifique. Les inscriptions de type royal ne sont pas seulement visibles. Elles se montrent.

Net dans le cas des inscriptions où un roi apparaît en personne, le caractère symbolique de l'emplacement des inscriptions de ce temple apparaît pour d'autres groupes d'inscriptions. Première face longue et dégagée que rencontre un dévot accomplissant la circumambulation, la face sud du temple est aussi celle qui s'est le mieux conservée au fil du temps. Ces deux caractéristiques suffisent-elles cependant à rendre compte de la très importante concentration épigraphique dont elle fut l'objet ? La thématique symbolique attribuée à cette direction dans l'iconographie joue là, à mon avis, un rôle aussi important que les considérations d'ordre pratique.

\section{Du sud au nord, les inscriptions et le programme iconographique}

Depuis plus d'un siècle, lorsqu'on bâtit le temple de Puḷamañkai, la face sud se trouve, en Inde méridionale, associée aux formes enseignantes de Śiva, occupant la niche sud du prāsāda ${ }^{57}$. Après les quelques variations que l'on observe dans les temples d'époque cōla les plus anciens, ces formes, Dakṣināmūrti, ou Vīṇādhara dans les régions contrôlées par les Irukkuveḷ, s'imposent ${ }^{58}$. Par ailleurs, Ganeśa

57. Sur le développement de l'image du Śiva enseignant et son lien avec la direction du sud, voir le travail de Valérie Gillet (2006) et, dans ce même volume du BEFEO, Francis-Gillet-Schmid, Chronique des études pallava, p. 579-601.

58. La forme que S. R. Balasubrahmanyam appelle Vīnādhara-Dakșināmūrti (1966: 36, pl. 23a) se trouve, par exemple, à Muvarkōyil. La niche sud du Nāgeśvara de Kumpakōṇam est occupée par un Bhikṣạtanamūrti (qu'on voit aussi à Vīralūr, temple de l'époque de Vijalayala ${ }^{\text {er }}$ dans la niche nord). D'après S. R. Balasubramanyam (1967a : 17-18), on trouve aussi un Bhikṣātanamūrti dans la niche sud du temple de Lalkuṭī (district de Trichy). Dans le temple de Tirukkattalai (district de Trichy), daté du règne d'Āditya I ${ }^{\mathrm{e}}$, on trouverait un Tripurāntaka dans la niche sud et un Rsabhavāhanadeva dans celle de Tiruccenturai (district de Trichy). Il faut noter que dans le Vīrațāneśvara de Tïruttani, daté de la $18^{\circ}$ année d'Aparajita Pallava, on a déjà un programme qu'on retrouve dans plusieurs temples du $x^{\complement}$ siècle, c'est-à-dire cinq niches occupées par Gaṇeśa, Dakṣiṇāmūrti, Viṣnu, Brahmā et la déesse armée. 
se fixe dans la niche sud du mandapa, dans le courant du vill ${ }^{\mathrm{e}}$ siècle $^{59}$. La place de Ganeśa dans le programme iconographique n'a guère soulevé d'intérêt. Pourtant, dans la mise en place d'un programme l'impliquant, au sud, c'est toute l'organisation symbolique du temple qui est concernée. Or la répartition des inscriptions dans l'Ālanturai de Pullamanakai met en lumière le rôle particulier que joue ici le dieu, nous permettant peut-être alors de mieux comprendre aussi le fonctionnement symbolique des directions nord et ouest.

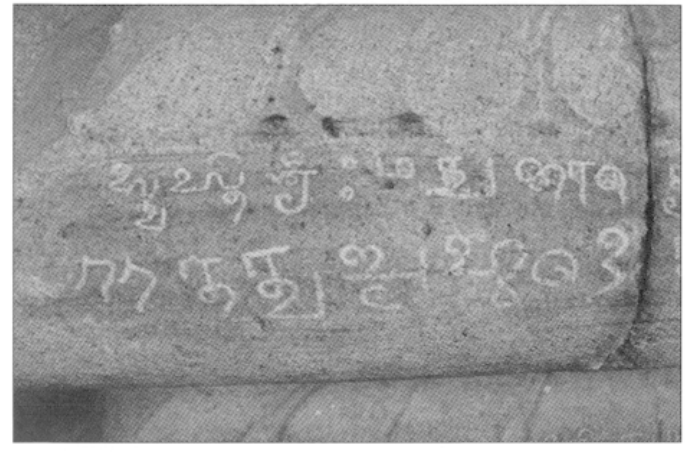

Fig. 50. Inscription $n^{\circ} 19$, détail : début de l'inscription. Cliché : E. Francis.

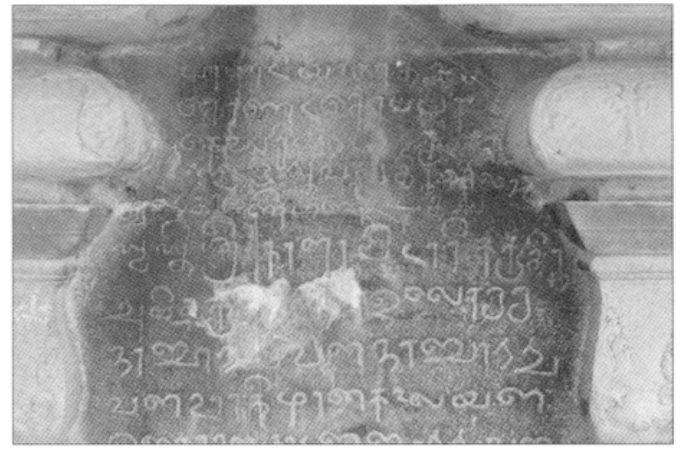

Fig. 51. Inscription $n^{\circ} 12$, début de l'inscription. Cliché : E. Francis.

Gaṇeśa est considéré comme un intercesseur et un dieu qui enlève les obstacles. En tant que tel, il a sa place au début de la pradakșină. Mais il faut aussi, je crois, le considérer comme lié aux formes du savoir, et cela d'autant plus qu'au moment de son apparition sur des temples qui, pour certains, ouvrent à l'ouest, sa place au sud n'en fait pas nécessairement une figure d'introduction à la circumambulation. Le programme iconographique qui apparaît dans le cours du vIII siècle, annoncé en partie sans doute par le mur sud du Kailāsanātha de Kāñcīpuram au début de ce même siècle, comprend un Śiva enseignant dit Dakṣināmūrti, parfois remplacé par un Vīnādhara, Gaṇeśa et, sur certains temples, Agastya. Tous trois sont liés d'une façon ou d'une autre à l'enseignement, à la langue et à l'écrit. Nul besoin de le détailler dans le cas d'un Dakșināmūrti qu'écoutent attentivement ses disciples ; le dieu musicien semble constituer une autre figure de l'enseignant à travers la notion de sabda, de son, voix ou musique, faisant sens ${ }^{60}$. Entre autres hauts faits littéraires,

59. À ma connaissance, c'est à l'Iravāttāneśvara de Kāñcīpuram qu'on rencontre pour la première fois Ganeśa sur la face sud du temple. Il est ici en outre couplé avec une déesse au lion sur la face nord du même temple, comme il l'est toujours durant la période $c \bar{l} l a$. L'Iravāttāneśvara est daté du VIII siècle.

60. Sur Dakșin̄āmūrti, la forme enseignante du dieu et son lien avec la face sud, infra: 93-97. Pour Bruce Long (1971), il s'agit d'une tentative, réussie, de pacification d'une face liée à la mort. Valérie Gillet lie ce choix directionnel à la fois aux rivalités avec les bouddhistes qui sont, à l'évidence, au moins en partie, à l'origine de la constitution de l'image et à un lien spécifique, à mon avis plus contestable, entre Śiva et le sud de l'Inde. En ce qui concerne Vinnādhara, l'interprétation qu'en fait l'Inde méridionale, où le dieu musicien se fait figure de l'enseignement, alors qu'il apparaît plus souvent en Inde du Nord aux $\mathrm{v}-\mathrm{vI}^{\mathfrak{e}}$ siècles comme un Ardhanārīśvara, est particulière et demanderait des recherches approfondies. 
Agastya est crédité d'une grammaire tamoule ${ }^{61}$. Assise un manuscrit à la main, au centre du la face sud du mandapa du Śrī Viṣamañgaleśvara de Turaiyūr, qu'on peut dater de la fin du $x^{\mathrm{e}}$ siècle (d'après son corpus épigraphique), Sarasvatī, la déesse du savoir, tend à confirmer cette orientation spécifique de la face sud.

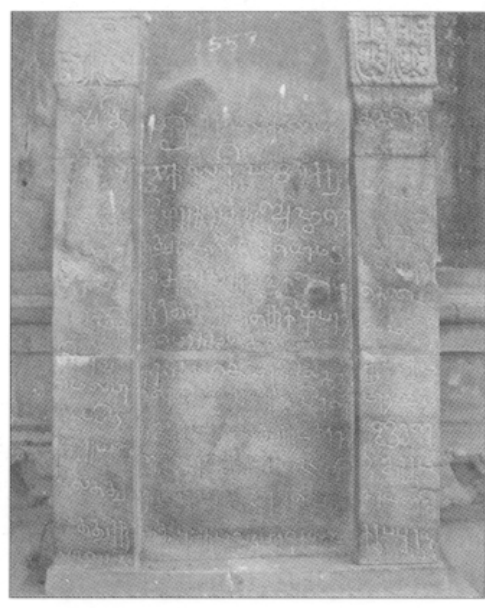

Fig. 52

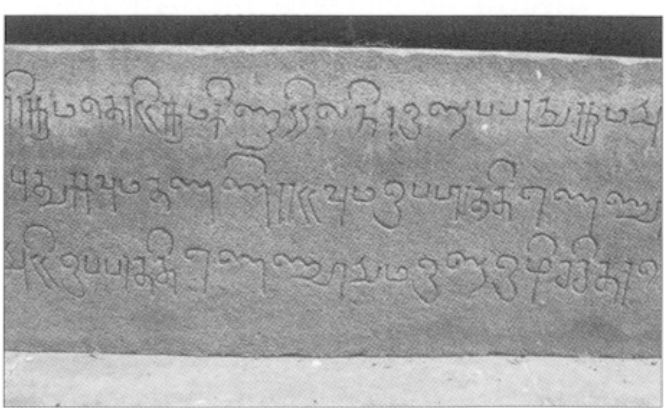

Fig. 53. Inscription $n^{\circ} 16$, détail. Cliché : E. Francis.

Fig. 52. Inscription $n^{\circ} 16$, détail : début de l’inscription. Cliché : E. Francis.

L'association de Ganeśa et de la direction méridionale pourrait ainsi, me semblet-il, se rattacher à ses fonctions de scribe. À ses pieds, deux inscriptions et une partie d'une autre (inscriptions 2 et 5, inscription 16, fig. 9, 43, 52, 53) occupent tout l'espace disponible. Ganeśa l'intercesseur, tenant à la main la défense qui fut son stylet, coucha par écrit les épopées, dont le Rāmāyaṇa figuré juste en dessous de lui. Le dieu éléphant paraît avoir attiré, en quelque sorte, une majorité de ces « archives » épigraphiques. Il est l'une des figures animant une face consacrée à la transmission des connaissances. Unissant les termes disparates de l'animal et de l'humain, il incarne la rencontre entre plusieurs mondes ${ }^{62}$. Maître de l'écriture à corps d'homme et chef d'éléphant, il semble résumer les intentions qui ont présidé à l'organisation d'un échange prenant place sur la face sud du temple, sous la forme d'un enseignement divin donné aux mortels.

Pourtant, associée dans les textes védiques et la littérature sanskrite classique, entre autres, avec les morts, la direction du sud y semble considérée comme néfaste. Comment envisager alors qu'elle se présente comme porteuse de savoir et lieu de rencontre entre hommes et dieux ? Plusieurs considérations ont, à mon sens, joué. L'association, forte et antérieure à l'arrivée de Ganeśa en Inde méridionale, du dieu

61. Voir, par exemple, l'éloge d'Agastya que fait le Rämāyana de Kampan, Äranyakānda 3. 36 et 3. 41 , où le sage est présenté comme celui qui donna le tamoul aux humains. En ce qui concerne les représentations, il serait hasardeux de donner des dates trop précises. Agastya appartient déjà au programme iconographique du temple de Tiruvatutturai, portant une inscription de la deuxième année du règne de Parāntaka I Irr (907-955). Il se trouve aussi au Kailāsanātha de Kāñcīpuram, mais dans le petit prākāra, c'est-à-dire sans doute dans le deuxième tiers du vIII' siècle, et face au nord, alors qu'on le trouve donc ultérieurement sur la face sud du temple.

62. C'est bien ainsi que Gaṇeśa apparaît dans certains développements philosophiques, comme ceux qu'expose le Mugdala-purāna (Granoff 1997). Ce dieu est métaphore du processus de manifestation du monde comme unissant des stades différents de la réalité. 
à tête d'éléphant et de la déesse Tueuse du Buffle serait l'une des plus considérables. La face nord et la face sud du temple entretiennent une correspondance, que l'analyse de la disposition des panneaux à l'intérieur de la frise dite frise 1 a bien mise en valeur. Au nord du temple, la déesse dressée sur la tête coupée du buffle correspond au Ganeśa de la face sud. Aux pieds de la divinité féminine, on a représenté deux dévots agenouillés, l'un se coupant la tête, l'autre offrant chair et sang de son corps. Dans les ensembles gupta, comme à Udayagiri dans le Madhya Pradesh par exemple, la déesse et Ganeśa se répondent de chaque côté d'un axe de symétrie. Dans les temples cōla, les deux divinités se font systématiquement pendant, au sud et au nord du temple.

Cette disposition appelle deux remarques. Tout d'abord si l'on prend en compte, les premières apparitions de l'association de ces deux divinités, à Udayagiri donc, et le Pañcārthabhāşya sur le sūtra 1.9 des Päśupatasūtra, l'appariement de Ganeśa et de «Durgā » fait d'eux des dvārapāla, des gardiens de porte. Représentée dans la tradition agamique par un passage du Sarvajñānottara, selon lequel Vighnavināyaka (Ganeśa) et Durgā doivent être placés à l'extérieur du temple, à l'emplacement des portes, une telle conception me semble s'incarner ultérieurement dans le programme iconographique le plus courant des temples sud-indiens ${ }^{63}$. À Udayagiri, Gaṇeśa, qui connaît là ses premières représentations, se trouve à la gauche de la porte et Mahișamardinī à droite. On retrouve le même schéma sur les temples méridionaux, où les façades des sanctuaires excavés du Madhya Pradesh semblent avoir été écartés pour former les murs latéraux du maṇapa précédant le sanctuaire, un maṇapa qui possède ses propres dvārapāla. La fonction originelle de gardiens de porte a certainement joué un rôle dans le positionnement de part et d'autre du sanctuaire de deux divinités dans lesquelles on retrouve en outre les caractères traditionnellement opposés des $d v a \bar{r}$ rapāla - l'un bénin, Gạ̣eśa, et l'autre terrible, la déesse armée.

Il faut par ailleurs aussi replacer le dieu éléphant et la fière déesse dans l'ensemble des faces du temple où ils se trouvent. Or le suicide rituel, ici représenté au nord du temple par un homme se tranchant la tête devant la déesse (fig. 16 et 17), implique, dans la littérature du Cańkam, que le dévot se tourne vers le nord ${ }^{64}$. L'association du suicide avec cette direction est si étroite que l'expression « se placer au nord » (vatakkiruttal) signifie en tamoul «se donner la mort de façon rituelle » (jeûne ou mort violente). Dans le cadre pallava, la déesse sous ses formes armées, qu'il s'agisse de Mahișamardinī ou d'une déesse en armes accompagnée ou non d'un lion, est placée au nord des temples construits ${ }^{65}$. La position de ces déesses armées

63. Le passage en question est cité par Dominic Goodall dans son édition du Pañcāvaranastava (p. 97 ) ; il s'agit d'un texte non publié dont il existe un manuscrit, N1, et un transcrit, T. 334, à l'Institut français de Pondichéry.

64. On trouvera dans Filliozat $1967: 75$, deux références au Puranān̄ūru $(65,9-11$ et 66, 5-8) et une à l'Akanānuru $(55,9-12)$.

65. Plusieurs formes peuvent être qualifiées de terribles dans le cadre pallava: déesses debout sur la tête du buffle et déesses au lion, devant lesquelles sont représentés les dévots se tranchant la tête ou offrant leur sang, comme ceux de la déesse au lion du Temple du rivage de Mahābalipuram. Il vaut mieux sans doute, à la suite de J. C. Harle 1963 et avec Emmanuel Francis (en cours), considérer ces figures essentiellement sous l'angle de la victoire qu'elles conféreraient, les déesses au lion n'apparaissant pas comme sanglantes lorsque la paire de dévots ne les accompagne pas. Par ailleurs, les déesses à qui 
se fixe dans ce qu'on pourrait appeler une deuxième phase de l'art pallava. Ganeśa, lorsqu'il est alors figuré, lui répond au sud ${ }^{66}$. Il apparaît donc que c'est à ce moment précis de l'art pallava que les deux directions du nord et du sud acquièrent les caractéristiques iconographiques qui resteront les leurs dans le cadre cōla.

Un symbolisme particulier s'attache, à l'évidence, à de telles caractéristiques. Face au sud, la divinité enseignante et le scribe assurent le lien entre le monde des hommes et celui des dieux, dont témoigne, à Puḷamańkai, l'abondance des inscriptions sur les murs sud; face au nord, l'humain cherche à atteindre le svarga où règne Brahmā et auquel le sacrifice de lui-même qu'il fait à la déesse lui donne accès. Un tel ensemble symbolique ne s'oppose pas à la tradition dont témoignent les textes d'origine nord-indienne, où l'association des morts et de la direction du sud se manifeste, entre autres, par l'intermédiaire du culte aux ancêtres (pitr) : la direction du sud est la direction des mortels, avant toutes les autres. Lorsque le temple s'ouvre à l'est, la façade sud est la première étape de la circumambulation et un certain accord s'établit entre l'association du sud avec le monde mortel et le premier contact du dévot humain avec la demeure divine. Or il est vrai que c'est au moment où, au Tamil Nad, l'ouverture des temples vers l'est devient plus commune, que se met en place le programme iconographique dont nous essayons de retrouver la cohérence symbolique. Le mur sud des temples semble alors considéré comme lieu d'une rencontre, représentée par la figure d'une divinité à la fois gardienne et intercesseur sur le prélude des mandapa.

Gaṇeśa, ou Sarasvatī, et Dakṣināmūrti, ces divinités ne seraient-elles pas des figures du savoir parce que celui-ci est le point de contact par excellence entre l'univers des humains et celui des dieux ? Les ancêtres eux aussi sont à la frontière entre deux mondes, en même temps qu'ils participent du processus de connaissance. Ni hommes ni dieux, ils composent une chaîne rattachant le mortel à un univers invisible qui l'a précédé, et qui est l'une des origines du savoir. En même temps que la śruti de Dakṣiṇāmūrti, leur univers de smṛti participe d'une forme d'enseignement. La concentration épigraphique de la face sud du temple de Pullamanankai s'inscrit ainsi, à mon sens, dans une thématique du contact avec le monde des dieux qui prend la forme de cette rencontre durable avec le divin qu'est le savoir. L'association du sud et de l'échange s'inscrit d'ailleurs dans la tradition védique de la daksina — le salaire versé aux brahmanes à la conclusion d' un sacrifice —, qui est investie, déjà, du symbolisme de la direction méridionale que nous avons tenté de mettre en valeur (Malamoud 1976 : 173-174). Cette daksināa et l'adjectif dakșina, qualifiant le sud, notamment dans le composé dakșināmūrti qui désigne la forme enseignante du dieu dans l'Inde méridionale, dérivent de la même racine DAKȘ-,

l'on fait des offrandes sanglantes, comprenant éventuellement la tête du dévot, font face à l'ouest dans les monuments excavés de Mahābalipuram (grotte de Varāha, grotte d'Ādivarāha, ratha de Draupadī). Les contraintes techniques auxquelles obéissent les monuments excavés font qu'on peut douter de l'attribution précise de la direction de l'ouest dans un premier temps.

66. Gaṇeśa et une déesse au lion forment pendant au sud et au nord du maṇ̣apa du Kailāsanātha de Kāñcīpuram, comme à l'Iravāttāpeśvara, au Mukteśvara et au Tripurāntakéśvara. Dans la grotte de Paṇaimalai, Ganeśa est également couplé avec la déesse. Sur d'autres sanctuaires, notons la présence de Gajalakṣmī (grottes de Varāha et d'Ādivarāha de Mahābalipuram ; Piravātānneśvara de Kāñcīpuram), et de Bhikṣātana (Airāvateśvara de Kāñcīpuram). 
« agir habilement, avec compétence ». La dakșinā se trouve au cœur d'un processus sacrificiel qui constitue une série d'échanges dont elle assure la conclusion (ibid. : 177-178) : c'est entre un monde des ancêtres et la tradition de l'échange qu'il faut, me semble-t-il, situer le mur sud couvert d'inscriptions de ce temple shivaïte consacré au savoir et à ses maîtres divins.

Il se situe sans doute aussi dans des traditions historiquement plus proches de ce temple. On sait que les Śaiva-siddhānta sud-indiens entretenaient une relation spécifique avec le savoir. Le temple de Puḷamañkai n'était pas nécessairement un temple śaiva-siddhānta; on n'a guère de moyens de savoir aujourd'hui dans quel type de mouvance shivaïte il s'inscrivait. Cependant, les textes saiva-siddhānta nous permettent de mieux comprendre ce temple, dans des passages qui ne sont pas forcément les plus originaux du mouvement mais participent, au contraire, d'une attitude d'esprit générale. Certains passages des Āgama donnent le savoir, parfois associé au rituel, comme moyen d'atteindre le dieu et la libération. Le Śivajñāna a pour origine première la bouche du dieu et l'Ajitāgama 18. 3-4 le pose comme le seul moyen d'atteindre la libération ${ }^{67}$. Dans la triade rite, foi, connaissance qui tisse le lien avec un dieu, qu'on adore parfois sous sa forme d'incarnation de la connaissance, le savoir apparaît à la fois comme moyen d'obtenir le dieu et comme ce qu'on obtient de lui. Lumière qui détruit les ténèbres de l'ignorance, l'enseignement que donne le dieu à travers les Āgama permet au dévot de voir les choses telles qu'elles sont ${ }^{68}$. L'illumination qu'illustre le lingodbhava est proche et le programme iconographique de Puḷamańkai, qui fait se succéder, dans l'ordre de la pradakșină, un Ganeśa, un Śiva enseignant porteur de lumière (la torche) et un linga de feu où le dieu se manifeste, se conforme à ces conceptions agamiques. Le dévot est d'abord, au sud, en contact avec un enseignement qui lui ouvre l'esprit, lui permettant de voir le dieu sur la face ouest et d'atteindre ainsi un autre monde, au nord du temple. Ce parcours dévotionnel paraît, en définitive, rejoindre celui que proposent les Brāhmaṇa lorsqu'elles envisagent la montée au ciel du sacrifiant à travers trois mondes successifs : la terre, l'atmosphère et les régions de l'air (Lévi 1898 : 91-92). L'élément feu, qui se trouve au centre du sacrifice védique, est devenu métaphore de la lumière du savoir qu'apporte l'incarnation du dieu.

Éloignées dans le temps et l'espace, l'ensemble des références qui précèdent montrent assez, il me semble, que le parcours proposé participe d'une logique intuitive traçant des passages entre terre et ciel. Représentant de l'importance du savoir dans le cadre dévotionnel et rituel, le dieu à tête d'éléphant introduit au monde des dieux. Tournant le dos au Ganeśa d'une face sud recouverte par les inscriptions, Mahișamardin̄ĩ est, au nord, le symbole d'une mort rituelle qui permet de rejoindre les divinités. La disposition des inscriptions nous aide ainsi à élucider la formation du programme iconographique des temples shivaïtes cōla dans ce temple

67. Le Śaivaparibhāṣā de Śivāgrayogin (311-314), compare l'alliance de la connaissance et du rituel aux deux ailes de l'oiseau permettant de voler vers la libération. Les deux passages sont cités, en traduction anglaise, par Richard H. Davis $2000: 29-31 ; 34-38 ; 73$, qui explore les liens du Śaivasiddhānta et de la connaissance.

68. «When the light consisting of the sound [of these texts] shines, no longer will the worlds be covered in thick darkness and ignorance ", Ajitägama 1. 33-35, cité par Richard H. Davis (2000:30). 
du tout début du $\mathrm{x}^{\mathrm{e}}$ siècle, où la transmission du savoir, dont l'épigraphie est l'une des formes, apparaît jouer un rôle considérable. Nous reviendrons sur ce point lors d'un essai de définition de la divinité principale du temple, qui renvoie dos à dos Dakṣināāūrti et Brahmā (infra : 93-97). Mais pour ce faire, il nous faut tout d'abord considérer l'évolution, entre autres rituelle, dont témoigne le corpus épigraphique.

\section{Inscriptions du règne de Paräntaka $I^{e r}$ : des dates et des copies}

\section{Premières inscriptions et fondation du temple}

Les inscriptions du règne de Parāntaka I ${ }^{\text {er }}$ forment un groupe homogène qui, comprenant les onze premières inscriptions, est le plus important du temple du point de vue numérique. Signalons qu'il est en outre probable que les inscriptions 20,21 et 22 , offrant le même type de composition quasi stéréotypée que ces premières inscriptions et situées, comme elles, sur le soubassement, appartiennent également

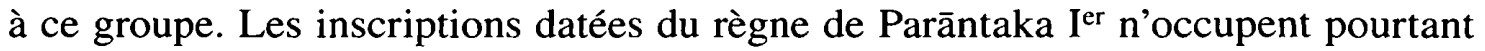
pas la majorité de l'espace inscrit puisqu'elles ne dépassent pas, pour la plupart, une quarantaine de mots. Certaines sont brisées ou recouvertes par des constructions postérieures, mais aucune ne devait être très longue à l'origine.

L'inscription la plus ancienne nous paraît être la $\mathrm{n}^{\circ} 1$, mentionnée dans l' $A R$ de 1921 et publiée dans $S I I$ XIX. Elle n'est prise en compte dans aucun des travaux où l'on date le temple, dans lesquels c'est l'inscription 5, datant de 918, qui est, en général, considérée comme la plus ancienne du temple. Pourtant, datée de l'année 5 du règne de Parāntaka ${ }^{\mathrm{I} r}$, l'inscription 1 du corpus atteste une construction antérieure à 912 . Sa description permettra de mettre en place des caractéristiques générales du corpus.

Comme toutes les inscriptions de ce groupe et comme la majorité de celles du temple, la $\mathrm{n}^{\circ} 1$ commence par se situer dans un espace brahmanique : on est à Puḷamañkalam, un brahmadeya de Kị lār Kürram. On rapporte ensuite un don au dieu appelé le «Mahādeva Tiruvālanturai », objet de treize sur vingt-deux des inscriptions, auxquelles on peut ajouter les inscriptions 9 et 22, qui évoquent un don à un acteur (cakkai) jouant dans le festival dédié à ce dieu. La correspondance avec le Têvāram vaut d'être relevée. Comme dans la plupart des hymnes, les deux premières strophes de 1.16 définissent le cadre du poème. On se trouve à Pullamańkai, lieu entouré d'un espace arboré (polil, dans les deux strophes) où vivent les brahmanes « d'une valeur égale à celle de Brahmā » (piramañ tān pōlum tiralavar vāltarum [str. 1]), où ils prient et adorent le dieu (kalaiyāl mali maraiyor avar karutit tolntu êtat), qui est celui d'Ālanturai. La grande majorité des dons consignés dans les inscriptions consistent en terres, dont les revenus serviront à faire brûler des lampes en l'honneur du dieu ${ }^{69}$. Dans cette région et à cette époque, les dons de terres sont majoritaires. Sous les règnes suivants, d'autres raisons d'inscrire apparaissent, d'autres divinités, et d'autres types de dons. On peut se demander si l'on n'a pas affaire, pendant cette première période épigraphique, à un enregistrement de l'établissement du territoire de la divinité du temple.

69. Je remercie Leslie Orr de m'avoir signalé qu'il s'agissait là d'une caractéristique remarquable, qu'on ne retrouvait pas à la même époque dans d'autres régions. 
Sous le même règne de Parāntaka $\mathrm{I}^{\mathrm{er}}$, on grave des inscriptions en $913\left(\mathrm{n}^{\circ} 2\right), 914$ $\left(n^{\circ} 3\right), 915\left(n^{\circ} 4\right), 918\left(n^{\circ} 5\right), 925\left(n^{\circ} 7\right)$ et $926\left(n^{\circ} 8\right)$. La structure que l'on connaît ne semble donc pas tellement antérieure à 912, puisque les inscriptions se succèdent rapidement à partir de cette date. Il est aussi possible que la première inscription gravée marque le début d'un processus, les caractéristiques architecturales et iconographiques du temple tendant à se rapporter à la décennie antérieure ${ }^{70}$. Les inscriptions amènent en tout cas à dater le temple de Pullamañkai du tout début du règne de Parāntaka ${ }^{\mathrm{er}}$, dans les premières années du $\mathrm{x}^{\mathrm{e}}$ siècle, une datation qui $s$ 'inscrit dans la fourchette chronologique déterminée plus haut (supra: 41), mais soulève certaines difficultés, l'une relative au contenu de l'une des inscriptions, l'autre au problème plus général, soulevé par G. Vijayavenugopal, des copies d'inscriptions (infra: 109).

Datée de 913, l'inscription $n^{\circ} 2$ est l'objet d'une controverse. Appelé « Cempiyan Magāvali Vānarāyar », le donataire porte ce qui est considéré dans la littérature secondaire comme un titre donné par Parāntaka Ir à un feudataire gangga, Pṛthivipati II, pour l'aide apportée contre le rāṣtrakūta Kṛ̣ṇa III ${ }^{71}$. L'appellation « Bānāādhirāja » apparaît dans l'inscription sanskrite dite de Cōlańkipuram, datant de 916 (EI IV : 221-225). Selon Nilakanta Sastri (1955: 125-126), elle fut conférée après 909 , car jusqu'à cette date le territoirc Baṇa n'était pas sous le contrôle de Parāntaka ${ }^{\text {er }}$. Cependant, pour l'auteur du résumé de l'inscription paru dans SII XIX, ce n'est pas avant la neuvième année de son règne que Parāntaka I ${ }^{\text {er }}$ a donné ce titre, et l'inscription de Pullamankai étant datée de la sixième année de son règne, le Cempiyan Magāvali Vānarāyar de Puḷamañkai ne peut pas être le feudataire gañga.

Malheureusement, ce dernier auteur ne justifie pas son opinion et les références qu'il donne sont fausses. Peut-être prend-il l'inscription de Cōlankipuram comme

70. Pour M. A. Dhaky 1971 : 266, note 12 (auquel se réfère G. Hoekveld-Meijer $1982: 5$ ), épigraphistes et historiens devraient suivre les indications données par l'histoire de l'art et non l'inverse : les inscriptions ne peuvent servir seules de base à la datation du temple. Ici cependant, à mon sens, on n'a affaire à aucun des éléments, parfois importants, qui jettent le doute sur une datation à partir des inscriptions (utilisation d'inscriptions retrouvées ailleurs que sur le temple, copies d'inscriptions antérieures, réemplois supprimant les dates, identification erronée du roi à partir de ses titres, absence de l'habitude de graver des inscriptions pour mémoriser des dons, absence d'inscription de fondation). Les inscriptions se trouvent sur le temple en suffisamment grand nombre et rien n'indique, à mon sens, de réemplois ou de copies (infra: 87 ; contra, la contribution de G. Vijayavanugopal : 71 ). L'absence d'inscription de fondation doit être, entre autres, liée au statut provincial ou régional d'un temple peu lié à la fonction royale. Les titres des rois sont trompeurs il est vrai, mais l'étude de G. Vijayavenugopal use de beaucoup des précautions dont il fait lui-même état. Enfin, G. Hoekveld-Meijer elle-même explique (1982:15) qu'elle a choisi les temples de ses études architecturales sur des bases épigraphiques, sans réaliser, me semble-t-il, à quel point les données épigraphiques publiées étaient partielles et parfois fausses - ce qui constitue un problème bien plus préoccupant.

71. Pour D. Barrett ( 1970 : 70), l'implication de Prthivipati II est évidente. D. T. Sanford (1979 : 175 , 229-232) évoque la controverse, née de l'éditeur d'EI XXVI (113-114; contra l'éditeur de SII XIX : 85 , renvoyant à $S I I$ III : 376, 381). Il signale des ressemblances architecturales entre un temple situé en territoire ganga, Narasamañgalam, au sud du Karṇātaka, daté des IX- $\mathrm{x}^{\mathrm{e}}$ siècles, et l'Ālanturai de Pullamañkai (un kapota en moulure de soubassement et des pañjara très marqués). Considérer le Gańga comme l'un des fondateurs du temple apparaît ainsi séduisant. Mais aucune autre donnée ne confirme cette hypothèse et on voit mal pourquoi, s'il était le fondateur du temple, Pṛthīvapati II ne le signalerait pas au lieu de se présenter seulement comme un donateur. 
terminus a quo de la conquête alors qu'il s'agit seulement d'un ad quem. D'un simple point de vue chronologique, le titre de Cempiyan Magāvali Vānarāyar peut avoir été décerné entre 909 et 916 . Mais l'hypothèse implique qu'en 913, peu de temps après la construction du temple, un Ganga de rang royal ait fait une donation au temple d'Ālanturai. Deux difficultés se présentent alors. Tout d'abord, on se souvient de l'emplacement particulier de l'inscription $6:$ une donation faite par un personnage fameux tend à bénéficier d'une position particulière. Il n'en est rien ici. Souvenonsnous par ailleurs du contenu de cette inscription 6, enregistrant une donation du même type que celle de l'inscription 2. Dans les deux cas, la donation est peu importante et ne semble pas correspondre au rang réel ou supposé des donateurs. En ce qui concerne Parāntaka I ${ }^{\text {er }}$, elle fait penser que c'est au niveau local qu'on a voulu donner de l'importance à une donation peu impressionnante, mais qui conférait un certain prestige au temple étant donné le caractère royal d'un donateur connu par ailleurs pour son patronage ${ }^{72}$; en ce qui concerne l'inscription 2 , elle fait douter qu'on ait affaire à un personnage important. Le titre mentionné dans l'inscription de Cōlan̉kipuram apparaît en sanskrit et ne correspond pas exactement à la désignation de l'inscription tamoule de Puḷamankai, qui lui ajoute Cempiyan : s'agit-il bien d'un même titre ? Et si tel est le cas, la correspondance est-elle si concluante qu'elle établisse un licn cntrc le temple de Pullamañkai et le personnage qui apparaît dans l'inscription de Cōlańkipuram ? Le titre pouvait apparaître ailleurs. L'hypothèse implique en outre que le temple ait été assez célèbre pour que des personnages de rang royal y fassent des donations. Après avoir fait remarquer le peu d'importance de la donation mentionnée dans l'inscription 6 , il faut constater que nous n'en avons, en définitive, aucune autre.

Les inscriptions 2 et 6 renforcent les doutes pesant sur l'hypothèse d'une fondation royale. Pourquoi Parāntaka ${ }^{\mathrm{er}}$, s'il avait été le fondateur du temple, ne l'aurait-il pas signalé ? L'assemblée locale aurait pu, tout au moins, faire état de ce glorieux patronage. Mais elle ne le mentionne pas plus que celui du Ganga, dont la donation n'a rien de considérable. Enfin, nous allons voir que, loin de correspondre à ce qu'on s'attendrait à trouver sur une fondation liée au pouvoir central $c \bar{l} \underline{l} a$, les inscriptions du $x^{\mathfrak{e}}$ siècle témoignent de l'autonomie du temple, inscrit dans la vie locale.

\section{Les fonctions de la première épigraphie du temple}

Les inscriptions 9 et 10 ont été gravées, la même année, de chaque côté de l'entrée originelle du temple, sur la face est. L'inscription 10 est difficile à lire car elle est très érodée. La 9, inédite, en est le pendant. L'année régnale est suffisamment élevée pour qu'on puisse être certain que le parakesarin dont il est ici question est Parāntaka ${ }^{\text {er. }}$ Il s'agit des dernières inscriptions du groupe de Parāntaka ${ }^{\text {er }}$.

72. Les donations faites par divers membres de la famille royale de Parāntaka Ier au temple de Tiruvorriyūr, sont d'un montant de trente et de soixante kalañcu, et celle que fit Kătupatțikal Nantippōttaraiyar dans la $4^{c}$ année du règne d'un Parakēcarivarman qui doit être Parāntaka ler au temple de Tiruvitaimarutūr de soixante kalañcu d'or, c'est-à-dire douze fois la donation royalc de Pullamañkai (SII III, n 104-105 (p. 236-239); n 124 (p. 260-261). Il ne s'agit là que d'exemples et des donations de ce montant ne sont pas exceptionnelles sous le règne de Parāntaka ler, qui a fait construire le temple Ādityeśvara à Toṇṭaimānad en 941 , terminer le temple de Gōmuktīśvara à Tiruvātutturai avant 945 et dorer le toit de la citrasabhā de Chidambaram. 
Ces deux inscriptions ont plusieurs caractères communs, qui les différencient

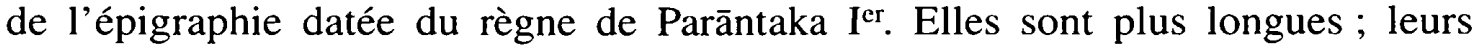
emplacements sont symétriques. Leur disposition et leur taille tendent à confirmer que, d'un point de vue visuel tout au moins, les emplacements n'étaient pas choisis au hasard. La longueur de ces deux inscriptions indique par ailleurs quelques changements dans la fonction symbolique de l'épigraphie, ce que confirme le groupe suivant ainsi, à mon sens, que l'apparition, dans l'inscription 10, des «Panmāheśvara » veillant au bon déroulement de la donation. Ce groupe de dévots n'apparaissait pas jusqu'ici, mais il est peut-être lié au fait que c'est l'assemblée ellemême qui apparaît ici en tant que donateur. C'est aussi à la nature de ce donateur particulier que se rapporte, à mon sens, le choix des emplacements situés à l'entrée du temple.

On voit qu'à l'exception de l'inscription $n^{\circ} 5$, dédiée à un autre dieu, toutes les inscriptions datées du règne de Parāntaka $I^{\text {er }}$ sont bâties suivant un même modèle. Dans les deux premières lignes, l'année mentionnée constitue souvent le seul changement. Mentions scrupuleuses de l'actant officiel qu'est la grande assemblée du village (mahāsabha, inscriptions 4, 5, 7, 9 et 10), et précision des mesures (dimensions des terres, poids du ghi, du grain ou de l'or, etc.) confirment lc rôle d'archives administratives de ces inscriptions, rapportant des transactions d'un type particulier. Ce premier groupe est, en effet, uniquement constitué de donations au profit de divinités, à savoir le dieu d'Ālanturai et «kūttap perumāl », le dieu qui danse ${ }^{73}$, alors qu'apparaissent ultérieurement des motifs d'inscrire plus variés. Lampes (inscriptions $1,3,4,7,8$ et 10), riz ( $\mathrm{n}^{\circ} 2$ et 11$)$, āryakkūttu, une forme de spectacle acrobatique populaire $\left(n^{\circ} 7\right)$, sont offerts à Ālanturai. On donne dans l'inscription 5 de quoi nourrir Kūttapperumāl.

De nos jours, les mêmes types de transaction sont exposés dans la cour des temples, sur des panneaux peints qui en font des objets publics. Cependant, les inscriptions cōla de Pullamankai ne sont sans doute pas de véritables archives administratives et financières, ou, en tout cas, pas seulement. Toutes les transactions ne sont pas inscrites et le bornage des terres n'est pas toujours suffisamment précis pour servir de référent (surtout quand on les compare à d'autres inscriptions, où toutes les limites des terres sont mentionnées). Ce ne sont pas des problèmes matériels qui ont arrêté les scribes. Dans tous les cas, il reste de la place pour rédiger une plus longue inscription. On a du mal à croire qu'il s'agisse d'un souci financier, ou uniquement financier, alors que les inscriptions se succèdent à un rythme assez soutenu. Il semble que le premier groupe chronologique d'inscriptions illustre aussi à sa façon simplement l'une des fonctions symboliques de l'épigraphie. L'acte dont il est question doit être gravé sur le temple ; il doit y être visible. Mais ce n'est pas à l'inscription qu'on se rapporte en ce qui concerne le contenu, disponible par ailleurs, manuscrit sur ôle par exemple.

73. Ce nom pourrait correspondre à un Natarāja, Śiva roi de la danse adoré à Cidambaram, auquel la dynastie cōla est plus spécifiquement liée. Krṣnna danse aussi mais il paraît plus probable qu'il s'agisse d'une divinité shivaïte. Le titre perumāl qu'on a tendance à associer à une divinité vishnouite ne l'est pas toujours dans les inscriptions médiévales, infra: 92. 
On peut aussi rendre compte de la brièveté de ces inscriptions en les considérant comme des copies partielles d'inscriptions plus anciennes. C'est ce que fait G. Vijayavenugopal, se fondant essentiellement sur le caractère incomplet des inscriptions. À un moment donné, on aurait rénové le temple et regravé sur l'édifice les inscriptions les plus importantes, sans les reprendre nécessairement en entier. Ce phénomène de copie est connu par des inscriptions qui le mentionnent explicitement et le font soupçonner ailleurs. Mais les inscriptions du règne de Parāntaka ${ }^{\text {er }}$ à Puḷamañkai ont été gravées par des mains différentes et les emplacements occupés ne semblent pas résulter d'un plan d'ensemble. De plus, la date de l'édifice actuel devrait être modifiée s'il s'agit bien de copies. Postérieur au moins à la dernière des inscriptions de Parāntaka I ${ }^{\mathrm{er}}$, le temple aurait été bâti après 946 . Or les caractéristiques stylistiques de l'édifice ne sont pas celles de la deuxième moitié du $x^{c}$ siècle. Enfin, soulignons que nombre d'inscriptions du règne de Parāntaka ${ }^{\mathrm{er}}$, qu'on trouve dans d'autres temples, ne sont pas davantage «complètes » ${ }^{74}$. Dans l'état actuel de la question, il me semble qu'aucun indice ne suggère que nous sommes en présence de copies d'inscription.

\section{Le rite et l'épigraphie : l'éternité d'Ālanturai à Pullamañkalam}

Copie ou non, l'inscription qui grave dans la pierre le don fait au dieu, donne accès à une forme de permanence, à laquelle le contenu épigraphique fait sans cesse référence. Chaque jour (nicatam), les lampes éternelles (nontāa) brûlent nuit (iravum) et jour (pakalum), durant ce que durent la lune et le soleil (cantirāticcaval). Les moutons offerts ne vieillissent pas et ne meurent pas (cāvamuvāperatu). Les rites célébrés sont quotidiens. Gravé, l'acte s'inscrit dans l'éternité du dieu, évoquée en Têvāram 1. 16, 10: « [Dévots], priez Ālanturai dans le temple de l'Originel, à Pullamańkai. » Quant aux modalités d'adoration, elles n'évoquent pas les rituels agamiques. Offrandes de lumière, de nourriture et d'eau (bain), allusions à un service du matin (sandhipuja, inscription 2), il s'agit de rites simples et quotidiens, proches de Têvāram 1. 16, où l'on offre de l'eau et des fleurs à un dieu de lumière, qu'on prie sans cesse. Enfin, on peut se demander si la donation qui forme le sujet exclusif du premier groupe d'inscriptions est ici présentée, archivée ou mise en acte. Le « $\bar{a} k a$ » utilisé dans nombre de ces inscriptions au moment où on définit les limites du terrain peut être considéré comme injonctif : « que les limites [de la terre donnée] soient... » L'inscription donne à voir sur le temple ce qui est donné et l'acte même de donner. Représentation du don, la gravure d'une inscription apparaît ainsi comme un rituel d'offrande en lui-même adressé au dieu d'Ālanturai.

Gravées dans la pierre du temple, il me semble donc que ces premières inscriptions participent ainsi, à leur façon, au culte dont le dieu est l'objet. Le mur extérieur semble constitué comme un espace particulier où hommes et dieux

74. Si on se reporte aux inscriptions considérées comme datant du règne de Parāntaka I ${ }^{\text {er }}$ dans SII III (pages 227-245), on voit que toutes ne comprennent pas les imprécations censées marquer la fin de l'inscription. Il me semble que la mention des panmāheśvara en particulier intervient dans les inscriptions qui devaient être plus soignées parce qu'elles nommaient des personnages importants ou des donations considérables, etc. Ici c'est l'assemblée elle-même qui est, pour la première fois, le donateur. On peut faire l'hypothèse d'une absence d'imprécation dans l'inscription $n^{\circ} 6$ parce que l'autorité du nom du roi suffisait à faire respecter ses donations. 
communiquent par le biais d'un échange «économique », dont l'un des termes n'est pas toujours précisé. Le donateur donne au grand dieu Ālanturai de Puḷamañkalam, Pullamañkalattu tiruvālanturai mahādeva. Mais que reçoit-il ? D'approcher la divinité, peut-être. Tandis que les formes divines y apparaissent comme surgies de l'intérieur du temple, l'homme vient graver son nom aux côtés de celui du dieu, répété comme un leitmotiv d'une inscription à l'autre.

L'importance donnée ainsi au nom divin ne doit pas être sous-estimée. Le corpus médiéval tamoul ne comporte pratiquement pas de stèles. Les inscriptions sont liées à un lieu précis, d'un dieu précis se manifestant en un temple particulier, comme à Puḷamañkai. Dans les « pullamañkalattu tiruvālanturai mahādeva » qui apparaissent sous différentes formes dans les inscriptions gravées sur les murs du temple, on retrouve un phénomène d'enracinement du dieu en un lieu, proche de celui que représente le Têvāram. L'épigraphie et l'architecture du Tamil Nad des $\mathrm{IX}^{\mathrm{e}}-\mathrm{XII}^{\mathrm{e}}$ siècles se développent en parallèle dans un mouvement qui fixe la divinité en un espace précis. Le temple apparaît marqué par le nom divin qu'on répète d'une inscription à l'autre, comme on le psalmodie dans les hymnes. Qui est cette divinité dont l'onomastique souligne la filiation géographique ? Le mahādeva du saint Ālanturai, est, dans la majorité des cas, le dédicataire des inscriptions - dans tous les cads, en ce qui concerne les inscriptions datées du règne de Parāntaka $\mathrm{I}^{\mathrm{er}}$. De tels écrits devraient permettre d'en préciser quelque peu le profil.

\section{Lieu, temple, dieux}

\section{Siva et le toponyme sacré Ālanturai}

Nous nous attacherons d'abord à l'analyse du nom même du dieu, le pullamañkalattu tiruvālanturai mahādeva des inscriptions ${ }^{75}$. Tout neutre qu'il puisse sembler, le mahādeva («grand dieu ») ne s'applique qu'à Śiva dans les textes indiens, littéraires et épigraphiques, et son emploi paraît indiquer qu'on a affaire à une forme de Śiva. L'iconographie d'obédience shivaïte du temple confirme ce point. On peut cependant remarquer que le nom même de Śiva n'est employé dans aucune des inscriptions, pas plus qu'aucun des nombreux autres noms du dieu. N'est-ce pas à sa neutralité que mahādeva devrait d'être ici utilisé ? L'importance ainsi donnée aux deux toponymes, Pullamañkalam et Ālanturai, est grande, en effet, et le caractère vénérable que le préfixe tiru confère au second d'entre eux vient la renforcer. Le Śiva du temple qui nous occupe est avant tout celui d'un lieu.

La correspondance avec le Tēvāram est remarquable. Le nom de Śiva est rare dans ce corpus dévotionnel identifiant le dieu dont il parle comme celui qui agit en tel ou tel lieu. En outre, les lieux évoqués portent presque exactement les mêmes noms dans le corpus épigraphique et dans le Tévāram, "Pullamańkai » étant simplement remplacé par « Pullamańkalam ». Des inscriptions à l'hymne 1. 16, on retrouve donc une double détermination géographique qui ancre le dieu en un lieu. La divinité qui hante cet espace est l'objet de l'hymne et vient habiter le temple. Sur les murs du temple, le nom du dieu est répété inlassablement, marquant d'un

75. Nous remercions Jean-Luc Chevillard de nous avoir guidée dans ce travail. 
sceau de propriétaire la demeure divine, mais aussi signalant la présence du dieu en ce lieu, ou encore, me semble-t-il, l'y enracinant. "Pu!llamarikalattu tiruvālanturai mahādeva » se manifeste là où un hymne et un temple le fixent.

On pourrait adopter un autre point de vue, considérant que l'hymne et le temple viennent se rattacher à un lieu sacré par ailleurs. Il est bien possible qu'un tel schéma rende compte de nombre de temples auxquels sont attachés les hymnes du Têvāram, le site possédant une force - sacrée - qui lui est propre et demeure indépendante des manifestations que sont temples et textes ${ }^{76}$. Cependant, nous allons voir que le cas du dieu d'Ālanturai est particulier.

La confrontation du double toponyme avec les autres données dont on dispose, tant dans le corpus épigraphique - toute limitée qu'en soit la publication - et dans le plus accessible Têvāram, confirme en effet la spécificité de l'association de toponymes. Le dieu d'un lieu est, le plus souvent, divinité d'un seul lieu. La succession de deux toponymes, l'un déterminant l'autre, se rencontre cependant dans le cas d'Ālanturai, attaché à d'autres lieux que Pullamañkai, dans des inscriptions d'époque cōla et dans des hymnes du Têvāram.

Un temple dédié au «mahādeva » ou au maître («ălvār ») de Tiruvālanturai se dresse dans l'actuel Kīlappaluvūr, dont le nom ancien est Ciruppaluvūr, «le petit $(c i r u)$ village $(\bar{u} r)$ du banian (pallu) », où l'on retrouve mention de l'arbre lié à Ālanturai. Le nom du village s'oppose à celui de Perumpaluvūr, « le grand village du banian », qui participa, avec une autre unité appelée Paluvūr dans les inscriptions, à la constitution du bourg appelé aujourd'hui Kīlaiyūr-Mēlappalıuvūr ${ }^{77}$. Daté par S. R. Balasubrahmanyam (1963: 30-32) du début du règne de Parāntaka I ${ }^{\text {er }}$ (907955), le temple de Kīlappaluvūr serait quasi contemporain de celui de l’Ālanturai de Pullamankkai ${ }^{78}$. Il a subi de nombreux remaniements mais présente encore un lingodbhava sur la face ouest (Barrett 1974 : fig. 62).

À une quarantaine de kilomètres au nord de Kịlappaluvūr se trouve un troisième Ālanturai, appelé « anpil utaiyār tiruvālanturai utaiyanāyañar » dans les inscriptions du site et « anpilälanturaikōn » ou « anpilälanturaiyār » dans les deux hymnes du Tềäram rattachés au site (Têvāram 1.33 et 5.80$)^{79}$. Lors de notre mission de terrain d'août 2005, G. Vijayavenugopal a retrouvé une mention ancienne de ce dieu du banian dans une inscription gravée sur une pierre isolée en réemploi dans le dallage

76. Voir, à ce sujet, la note 35 de François Gros dans Gopal lyer 1984, p. XXVI.

77. Les inscriptions du temple toujours appelé celui de Tiruvālanturai mahātēvār, c'est-à-dire le seul des temples consacrés au dieu d'Ālanturai à avoir gardé un nom originel, apparaissent en $A R$ 1926, $n^{\circ}$ 225-250; les numéros 251-261 enregistrent des inscriptions se trouvant sur des parties du temple postérieures à l'âge $c \bar{l} \underline{l} a$.

78. Dans sa monographie sur le temple voisin de Kịlaiyūr, Blandine Legrand (1987: 21) donne la même date pour ce sanctuaire. Cependant pour D. Barrett (1974: 97), il daterait de 984. Notons que c'est à ce temple qu'on rattache l'hymne de Paluvūr du Têvāram (2. 34), alors même que le temple est dédié à un dieu d'Âlanturai qui n'apparaît nulle part dans l'hymne, ce qui paraît curieux. Là encore on peut s'interroger sur le processus de mise en relation d'un hymne et d'un temple, quand bien même lorsque le temple remonte au $x^{c}$ siècle, comme c'est le cas ici.

79. Les inscriptions mentionnant le dieu d'Anpil sont éditées dans SII VIII, n $192-195$ ( $A R$ 1902, $\mathrm{n}^{\circ}$ 595-598). Il s'agit d'inscriptions longues, qui se trouvent actuellement sur un gopura, peut-être en réemploi. Pour deux d'entre elles, la date est donnée en règne pānțiya. 
surélevé séparant le temple actuel, postérieur au XIII siècle, et le jardin qui l'entoure. Le fragment rapporte une donation faite par Cempiyan Mahādevī, épouse de Ganḍarāditya, qui régna dans la deuxième moitié du $x^{\mathrm{e}}$ siècle, au dieu Tiruvālanturai d'Anpil. Plus au sud, on retrouve un Tiruvālanturai à Antavanallūr : tiruvālanturai parameśvarar ou tiruvālanturai perumāl, en l'honneur duquel un Irukkuvel a construit un temple avant la dixième année du règne de Parāntaka ${ }^{\mathrm{er}}{ }^{80}$. Les statues qui ornaient le temple à l'origine ne sont plus en place mais les inscriptions sont encore lisibles pour la plupart. Enfin, beaucoup plus au nord, un cinquième dieu d'Ālanturai, tiruvālanturai utaiya paramasvāmin ou tiruvālanturai ălvār , ou encore tiruvālanturai nāyañār, apparaît au Vēdapurīśvara à Ēmappērūr, dans le district du South Arcot (taluk de Tirukkōyilūr) ${ }^{81}$. Le programme iconographique n'est pas le même qu'à Puḷamañkai. Notons pour finir que l'épigraphie du temple du Mahādeva d'Ālanturai de Kịlappaluvūr mentionne un lieu nommé « Tiruvālanturainallūr », « le village d'Ālanturai » $\left(A R \text { 1926, } n^{\text {os }} 249-250\right)^{82}$ — nom porté par une unité appelée par ailleurs « Pūtarkuṭi » —, et que ce toponyme est toujours en cours dans le Tamil Nad d'aujourd'hui.

Une divinité de Tiruvālanturai est donc attestée dans cinq sites et l'état de publication du corpus épigraphique permet de supposer qu'il existe, ailleurs dans le Tamil Nad, d'autres dieux de Tiruvālanturai. Le caractère particulier du toponyme Ālanturai se dessine. Il est toujours accompagné du préfixe tiru et d'un autre toponyme. À Anpil, les données recoupent, comme à Pullamañkai, celles du Têvāram. Ce dieu est attesté dans l'épigraphie dès la deuxième moitié du $\mathrm{IX}^{\mathrm{e}}$ siècle.

Le double ancrage géographique signifie qu'Ālanturai désigne une divinité qu'il particularise et permet d'identifier, dans plusieurs espaces. Il ne s'agit pas de désigner le lieu où l'on se trouve, ce que fait l'autre toponyme, Puḷamankai ou Anpil, mais le lieu d'origine. Le dieu d'Ālanturai est d'ailleurs mentionné dans un quatrième hymne du Tềvāram, l'hymne 6.71, qui relève des hymnes dits potu, énumérant les lieux où l'on adore Śiva, sans être eux-mêmes rattachés à un lieu précis (Têvāram 6. 71, 11). Le dieu d'Ālanturai se constitue donc comme une divinité qui a une histoire car doté d'une origine et d'une diffusion géographique. Quant à savoir lesquelles, quoique lacunaires et difficiles d'interprétation, les quelques documents à notre disposition permettent de tenter de préciser nos interrogations.

Il semble qu' «Ālanturai » n'entretienne pas la même relation syntaxique avec son environnement dans les quatre hymnes du Tévāram où il apparaît. Dans les deux hymnes dédiés à l' Ālanturai d'Anpil, anpil ne porte aucune marque de cas, alors que

80. $A R$ 1903, $\mathrm{n}^{\circ} 348-369$, SII III, $\mathrm{n}^{\circ} 285$, SII VIII, $\mathrm{n}^{\circ} 657-673$; l'inscription mentionnant que Cempiyan Irukkuvel dit « Putiparāñtakan » fonda le temple est la $n^{\circ} 668$ ( $A R$ 1903, $\left.\mathrm{n}^{\circ} 359\right)$.

81. Les inscriptions retrouvées à Ēmappērūr sont enregistrées dans $A R$ 1921, n 513-533 (elles ne concernent pas toutes le dieu du temple); deux d'entre elles sont éditées, SII XIII, n ${ }^{\circ} 94$ et 263 . Lors de la mission d'août $2005, \mathrm{~N}$. Ramaswamy a retrouvé une inscription datant du règne de Parāntaka $I^{\text {er }}$ en réemploi à l'intérieur du temple actuel qui porte des inscriptions datant de la fin du $x^{\mathfrak{c}}$ siècle au plus tôt. Un temple se dressait donc là dans la première moitié du $\mathrm{x}^{\mathrm{e}}$ siècle.

82. Signalons que les rapports sur ces inscriptions copiées en 1926 sont rééditées dans l'AR 1922 1925. Les deux inscriptions sont situées en pendant de chaque côté de l'ouverture du sanctuaire, à l'est. Cette disposition, très particulière puisqu'il s'agit des seules inscriptions gravées sur la face est d'un temple dont vingt-six inscriptions sont enregistrées, donne plus d'importance à ce toponyme. 
l'hymne 1.16 et les inscriptions du temple de Pullamankai indiquent clairement que Puḷlamańkalam/Pullamañkai est le déterminant d'Ālanturai. La position d' « Anpil », placé avant Ālanturai dans les hymnes 1.33 et 5.80 , peut suffire à indiquer le même type de relation entre les deux toponymes. Mais l'absence de cas autorise aussi à considérer qu'il y a formation d'un composé Anpil-Ālanturai, où la relation entre les deux termes reste à déterminer. Dans l'hymne 1. 16, Ālanturai et Pullamañkai sont séparés et qualifiés par des termes différents dès la première strophe, où Puḷamańkai est encerclé de bosquets et où se trouve le lieu, itam, d'Ālanturai, tandis que Pullamankalam est pourvu d'un suffixe de cas oblique dans les inscriptions. Dans les hymnes d'Anppil, Ālanturai est immédiatement précédé d'Anpil et les deux toponymes sont qualifiés par les mêmes mots ou membres de phrase. Si «Anpil » apparaît bien comme un toponyme indépendant en 5. 80,11, Ālanturai ne se sépare jamais d'Anpil dans les hymnes consacrés à ce dieu — ou à ce site. À Pullamañkai se trouve un Ālanturai ; il existe aussi, ailleurs, un Anpilālanturai.

Dans les inscriptions de Ciruppaluvūr, le dieu d'Ālanturai est appelé mahādevar, comme à Puḷamańkai, mais aussi ālvār $\left(A R\right.$ 1926, $\left.{ }^{\circ} 227\right)$ et tiruvālanturai utaiya paramasvamikal, mâ̂tre suprême du saint Ālanturai de Ciruppaluvūr. Mais il est èmappērūr tiruvālanturai alvārr, maître du saint Ālanturai à Ēmappērūr, tandis qu'à Anpil, il est anpil utaiyār tiruvālanturai utaiyanāyañar, le maître du saint Ālanturai d'Anppil. Dans les trois sites, la relation entre tiruvālanturai et Ēmappērūr ou Anpil paraît bien être celle d'un complément de nom, qu'indique, dans deux des cas, l'usage d'utaiya. L'épigraphie semble donc présenter une situation plus simple que celle du Tévāram : Âlanturai y est toujours un toponyme sacré, précédé d'un autre toponyme le déterminant et suivi d'un terme qui en fait le dieu de tel endroit situé dans tel espace. Le lien avec le shivaïsme ne se laisse pas toujours immédiatement déceler, puisque le terme ălvār désigne les adorateurs de Viṣnu d'une façon quasi canonique dans le corpus vishnouite dévotionnel ${ }^{83}$, et que le perumāl parfois employé se rencontre le plus souvent dans le corpus vishnouite ${ }^{84}$. Le corpus épigraphique est plus récent que le Têvāram, si l'on admet pour ce dernier la date du $\mathrm{VII}^{\mathrm{e}}$ siècle (supra: note 9). Le statut du dieu d'Ālanturai se serait-il précisé d'une période à l'autre comme étant celui d'un lieu avant tout? La nature des documents peut aussi avoir joué. Les inscriptions enregistrent les dons faits au dieu du temple et, en tant que telles, s'inscrivent dans une tradition de localisation plus limitée que le Têvāram, dont les hymnes se rattachent à des temples répartis sur toute la pointe de la péninsule indienne.

La localisation de ces inscriptions apporte un autre type d'informations. Quatre des sites sont regroupés dans un rayon d'une quarantaine de kilomètres autour de Puḷamańkai. Cette région correspond par ailleurs à une dynastie particulière, qui entretient avec le Kerala des liens vagues mais certains. À Anpil, en effet, on a retrouvé des tablettes de donation royales de Cuntara Cōla, qui signalent que

83. L'article récent de S. Palaniappan (2004) qui reprend l'histoire du terme vishnouite montre qu' " $a \underline{l} \underline{v} \bar{a} r »$ résulte d'une hypercorrection de $\bar{a} l v a \bar{r}$, et qu'on a bâti une étymologie dévotionnelle pour ce terme : il s'agit en fait d'un équivalent de nāyanāar, dont l'opposition traditionnelle en tant que terme à connotation shivaïte face à un ălvār vishnouite n'est donc pas originelle. C'est bien ce qu'on observe ici.

84. En ce qui concerne l'emploi du terme perumāl pour désigner Viṣnu, on le rencontre, par exemple, sur le Vēdapurīśvara de Kīlaiyūr qui est bien un temple vishnouite, voir SII XIII, nº 67. 
Ciruppaluvūr est le fief des Paluvēttaraiyar, d'origine kéralaise. Ce dernier terme est difficilement traduisible mais il associe des rois (raiyar) au banian (palu), l'arbre du dieu d' « Âlanturai ». Les Paluvēttaraiyar apparaissent dans le Tamil Nad à la fin du $\mathrm{IX}^{\mathrm{e}}$ siècle. Ils sont très présents dans l'épigraphie du temple consacré au Mahādeva de Tiruvālanturai de Ciruppaluvūr ${ }^{85}$, de même que dans l'épigraphie du proche Mēlappaluvūr. Ciruppaluvūr se rattache lui-même à un groupe de villages où l'on retrouve le composé palluvūr, « le village du banian », comme dans Perumpaluvūr. L'un des hymnes de Campantar, l'auteur de Tēvāram 1. 16, est dédié au dieu de Paluvūr, sans qu'on sache aujourd'hui auquel des temples de ce groupe de villages il faut rattacher l'hymne en question (2. 34 ; supra: note 78 ). Les prêtres mentionnés dans cet hymne sont des Malayalis, ce qui rappelle l'origine kéralaise des Paluvētțaraiyar ${ }^{86}$. Par ailleurs, S. R. Balasubrahmanyam (1963:28) signale qu'à Kīlappaluvūr, les légendes locales mettent en scène Paraśurāma, l'avatāra de Viṣnu que sa légende crédite d'avoir créé le Kerala, découvrant un svayambhu linga dans un banian.

Ce faisceau de données peut se résumer de la façon suivante. Une dynastie entretenant des liens avec le Kerala est par ailleurs liée au dieu du Saint (Lieu) Ālanturai. Ses attestations épigraphiques se situent dans la même région que celle de ce dieu. Leur association aurait pu se faire par l'intermédiaire du thème du banian, qui, outre le rôle tenu dans une légende locale, apparaît dans le nom du dieu, celui de la dynastie et celui de nombre des villages où l'épigraphie atteste sa présence. Qu'en est-il d'un lien avec le dieu qui nous occupe à Puḷlamańkai ?

À Puḷamañkai, l'inscription 13 pourrait contenir le mot «paluve[*e]țtaraiyar ». Mais elle est à la fois très mal gravée et assez abîmée : on ne peut donc être certain que les Paluvêtțaraiyar aient jamais été précisément associés à Pullamañkai. La proximité géographique de leur fief et de ce village, la similitude du programme iconographique et des noms donnés aux divinités des deux temples de Ciruppaluvūr et de Pullamankkai laissent cependant supposer un lien entre eux. Enfin, le dieu du temple de Pullaman̉kai apparaît, pour le moment, être une forme de Śiva mais dans laquelle l'élément shivaïte pourrait être secondaire, puisque le toponyme Ālanturai n'est pas toujours associé à des désignations shivaïtes claires et ne l'est jamais à un nom de Śiva. Ce pourrait être le nom du dieu d'un lieu qui aurait pris suffisamment d'importance pour s'implanter dans d'autres espaces que celui de son lieu d'origine, situé dans la région assez délimitée où l'on rencontre ce nom. L'origine pourrait aussi être plus lointaine, dans ce Kerala des Paluvētțaraiyar qui auraient apporté, en quelque sorte, avec eux un dieu du banian, l'implantant dans la région qu'ils contrôlaient.

85. «Paluvētṭaraiyan Maravan Kantan » le fit bâtir dans la $15^{\mathrm{e}}$ année du règne d'un Parakēcarivarman ( $A R$ 1926, $\mathrm{n}^{\circ}$ 245). Dans l'une des inscriptions au moins (le corpus reste largement non publié), l'une des donatrices est une Paluvēttaraiyar (SII XIII, n $171 ; A R$ 1926, $\mathrm{n}^{\circ} 226$ ).

86. Antanārkal āna malaiyālar avar èttum pantam malikingra palıvūr aranai $(2.34,11)$. Sur le temple d'Ālanturai à K̄ilappaluvūr une inscription $\left(A R\right.$ 1926, $\left.n^{\circ} 231\right)$, datée de la douzième année du règne de Parāntaka $I^{\mathrm{er}}$, rapporte une donation destinée à faire brûler une lampe dans le temple de Tiruvālanturai mahādeva de Cirupaluvūr à Kuñrakkurram, afin de célébrer la victoire de Paluvētțaraiyan Kantan Amutanār contre les Pāṇtiya et les Cinghalais. Elle recoupe les informations données par les tablettes d'Anpil sur les Palıvēttaraiyar. Sur ce temple et sur l'Agatyeśvara de Mēlappaluvūr, des inscriptions mentionnent Ațikal paluvețaraiyan maravan Kañ $\tan \bar{a} r\left(A R 1924, \mathrm{n}^{\circ} 365,367\right.$ et 370$)$. Sur cette dynastie voir, $A R 1924, \S 10 ; I d .1926, \S 20, \mathrm{n}^{\circ} 226 ; 29, \S 28$; Blandine Legrand (1987) offre un appendice regroupant les références et donnant un résumé des inscriptions de deux temples du site. 
La disparition à peu près concomitante des mentions de ce dieu et de celles des Paluvēttaraiyar dans les inscriptions va dans le sens de cette dernière hypothèse. Cependant, l'association entre Paluvētțaraiyar et Ālanturai n'est vraiment claire qu'à Ciruppaluvūr. En outre, la divinité à laquelle se rapporte la désignation de mahādeva tiruvālanturai, «grand dieu du site sacré du banian », pourrait aussi relever d'une tradition d'association avec cet arbre dont on trouve trace dans la littérature tamoule ancienne et qui fait considérer les origines de ce dieu sous un autre angle.

\section{Le dieu du banian}

Dans le contexte tamoul, l'association d'un dieu et d'un banian évoque en effet la forme enseignante de Śiva, dite Dakṣināmūrti, représentée assise sous un banian. Le Dakṣināamūrti de la face sud du temple n'a cependant sans doute pas ici plus d'importance qu'une autre des images de Śiva, même s'il faut tenir compte de la dévotion spécifique dont cette forme est l'objet dans le Tamil Nad, à Puḷlamańkai comme ailleurs. Et « Âlan-turai » ne signifie pas assis sous un banian, mais lié à un banian. La divinité à laquelle se rapporte ce composé pourrait, pourtant, s'avérer liée à l'histoire conceptuelle et iconographique - mystérieuse - de « Dakṣiṇāmūrti », à travers des traditions sud-indiennes dont on trouve trace dans la littérature tamoule ancienne. Rappelons que le terme Dakṣināmūrti est une dénomination tardive apparaissant dans certains Āgama utilisés par ces textes et par la littérature secondaire pour désigner un type de figure représentant un Śiva enseignant assis sous un banian, apparu sans doute à la fin du $\mathrm{VII}^{\mathrm{e}}$ siècle, dans l'Inde méridionale ${ }^{87}$.

La représentation précède dans le temps la dénomination agamique et l'apparition de l'une comme de l'autre soulève bien des interrogations. On peut considérer que le terme enregistre en quelque sorte un état de fait, selon une procédure courante dans les Ägama. L'invention de la forme iconographique n'en est pas résolue pour autant et Hans Bakker (2004), qui a beaucoup étudié l'apparition de Dakṣināmūrti, met en relation la forme et le nom. Pour cet auteur, il faudrait replacer « Dakṣiṇāmūrti » dans la mouvance de textes védiques qui font du guru enseignant une incarnation de Śiva. L'indication de la position du disciple par rapport au maître aurait été qualifiée de «dakșinā », de «droite », c'est-à-dire de « correcte », et finalement comprise comme une indication de la position de la forme enseignante du dieu par rapport à ses disciples. Le dieu du Sud se trouvant placé à la droite (dakșina $\bar{a}$ ) du linga que renferme le sanctuaire, il est au sud — troisième signification de daksinga lorsque le sanctuaire ouvre à l'est. La symbolique de la face sud signalée plus haut (supra: 78-82) trouve dans cette hypothèse une forme de confirmation de l'association de la direction du sud et du savoir, mais une confirmation qui ne doit pas faire oublier que la moitié des premiers temples shivaïtes sud-indiens où l'on figure « Dakṣiṇāmūrti » ouvrent à l'ouest. La forme enseignante demeure alors au sud, mais ne se trouve plus à la droite du linga. Lors de l'apparition de Dakṣināmūrti, l'association avec la direction méridionale prime sur la position par rapport au linga et par rapport à la circumambulation. L'orientation absolue de l'image doit donc, me

87. Sur l'apparition de Dakșināmūrti, voir dans ce même BEFEO, Francis-Gillet-Schmid, Chronique des études pallava, p. 579-60i et le travail de Valérie Gillet (2006). 
semble-t-il, être prise en compte pour rendre compte de sa signification. La tradition sanskrite ancienne n'y fait pas allusion et il faut se tourner vers d'autres textes pour comprendre Dakṣināmūrti.

Dans la littérature tamoule ancienne, l'interprétation des rares mentions d'un Śiva associé au banian est cependant délicate. Je renvoie ici à l'étude de Valérie Gillet, qui a travaillé avec T. V. Gopal Iyer, au Centre de l'EFEO à Pondichéry, à retrouver dans la littérature du Cañkam les attestations d'une divinité au banian ${ }^{88}$. Dans le Tirumurukkarruppatai, un hymne à la gloire de Murukan qui serait antérieur au $v^{e}$ siècle de notre ère, les vers 256-257 louent Skanda-Murukan en tant que «alkelu kațavut putalvan », c'est-à-dire fils (ou disciple) du dieu (ou du précepteur) qui brille dans le banian. Le double sens de fils et de disciple, se rapportant à un père ou à un maître, rappelle le concept présidant à la représentation dite « Dakṣināmūrti ». Le terme kellu, qui dénote ici l'association avec le banian, est difficile à traduire ${ }^{89}$. Le substantif kellu signifiant « couleur et lumière », " luminosité », peut-être s'agitil de décrire l'apparition lumineuse d'une divinité qui donne un certain éclat à l'arbre banian. Elle pourrait, alors, se rapprocher du mythe du lingodbhava, où Śiva se manifeste comme une colonne de feu, ou dans cette colonne de feu qui est un linga. Mais kelu est aussi un auxiliaire de sens assez neutre : on pourrait avoir affaire à une simple notation d'un lien avec le banian. Aucune trace ici, en tout cas, d'une association avec la direction du sud, qui apparaît en revanche dans l'épopée tamoule du Cilappatikäram (23, 90-95), qu'on date entre le IVe et le $\mathrm{VI}^{\mathrm{e}}$ siècle et où le personnage de Vārttikan prie « celui qui est au sud lui-même » et a un fils récitant les Veda, qui prend le titre d'āl-amar celvan, «celui qui est associé au banian ${ }^{90}$. On retrouve dans la relation entre Vārttikan et son fils le lien de filiation des textes précédents, qui apparaît par ailleurs déjà dans le texte sans doute plus ancien du Kalittokkai $(83,12-15)$. Correspondant dans le Cilappatikäram à un lien de maître à disciple, il suggère que la notion d'enseignement pourrait avoir pris la forme du lien de filiation entre Śiva et Skanda dans un Tamil Nad où, comme l'a démontré Françoise L'Hernault (1978), Murukan est spécifiquement considéré comme maître de la connaissance. Dans le Manimēkalai (3, 144-145), daté comme le Cilappatikāram entre le $\mathrm{Iv}^{\mathrm{e}}$ et le $\mathrm{vI}^{\mathrm{e}}$ siècle, Murukan est aussi le fils de celui qui est associé au banian (älamar celvan makañ).

88. Valérie Gillet a traduit en français certains passages de la littérature du Cankam avec l'aide de T. V. Gopal Iyer et d'Eva Wilden. Ce sont ses traductions que je reprends ici. Le Cilappatikäram évoque ainsi le dieu associé au banian à propos d'un sage : « le fils du célèbre Vārttikan a grandi en prenant le nom de celui qui est associé à l'arbre banian. Devant ceux qui sentaient le lait et avaient des bouches rouges et qui n'avaient pas appris, pendant qu'il récitait les Veda convenablement, son esprit se remplissait de joie, sans dévier le discours des textes secrets. Le Grand Vārttikan a prié celui qui est au sud lui-même, et lui a donné un cordon sacré fait de perles, de brillants joyaux, des bracelets et des boucles d'oreille. » (Cilappatikāram chapitre 23, 1. 90-95), voir aussi ibid. chapitre 24, 1. 2-3 : « Le fils du dieu associé au banian est venu avec des joyaux éclatants sur un animal ayant des ailes bleues. »

89. Les traductions disponibles, J. V. Chelliah 1985 (traduction accompagnée du texte), et N. Raghunathan 1978, traduisant " sits beneath the banyan tree » et " sits under the banyan tree ", voient, à l'évidence, un Dakṣinămūrti dans le dieu du banian.

90. Supra, note 88 . 
Le caractère guerrier du dieu au banian apparaît également dans ces quelques passages, et dans d'autres. Kalittokkai, 81, 7-10, évoque « la grande et belle victoire du dieu de l'arbre banian » et le Tirumurukarrupatai appelle Skanda, fils du dieu au banian, «mort de tes adversaires », cependant que le poète de Purañānūru, 198, 9-10, voit «l'illustre personne, éclatante, portant la lance et tes richesses comme le seigneur associé à l'arbre banian». Cet aspect guerrier pourrait expliquer certaines particularités iconographiques de Dakṣiṇāmūrti, dont la seule notion de divinité enseignante ne peut guère rendre compte. Les Dakșiṇāmūrti ont souvent un petit crâne humain dans la coiffure, renforçant l'aspect marginal, ascétique, mais violent aussi, de leurs chevelures libres. Le premier Dakṣināmūrti connu, celui du Kailāsanātha de Kāñcīpuram, porte des crocs. Si nombre des figures de Śiva dans ce temple sont pourvues de proéminentes canines, il reste que ces dernières ne se justifient pas dans un contexte d'enseignement, sauf s'il s'agit d'un enseignement donné par une divinité qui est, ailleurs, dieu de violence et de guerre, ce que le programme iconographique du Kailāsanātha rappelle tout à loisir ${ }^{91}$.

La littérature du Cańkam connaît donc un dieu au banian; celui-ci pourrait avoir été l'une des sources d'inspiration d'un Dakșiṇāmūrti, dont les origines iconographiques sont aussi mystérieuses que les origines textuelles ${ }^{92}$. Or, bien antérieures aux représentations de Dakṣiṇāmūrti, les bas-reliefs du Bouduha prononçant son premier sermon comportent trop d'éléments communs avec ces dernières pour ne pas avoir été l'un de leurs modèles. On y retrouve le personnage assis enseignant sous un arbre, les disciples représentés en pendants de chaque côté de la figure principale et les animaux, gazelle et lion, écoutant la parole du maître. De tels reliefs constituent, à l'évidence, l'un des intermédiaires unissant le dieu au banian de la littérature tamoule - le maître des textes recensés par $\mathrm{H}$. Bakker — et la figure du Śiva enseignant qui orne la face sud des temples de l'Inde méridionale. La connotation enseignante de l'image bouddhique empruntée n'aurait-elle pas rencontré le concept de ce maître shivaïte dont $\mathrm{H}$. Bakker retrace l'histoire dans la littérature sanskrite ? Elle a pu lui fournir une image, un support matériel où s'exprimer dans une Inde du Sud habitée par une divinité au banian parfois terrible et qui, ayant pour fils le dieu de connaissance du Tamil Nad, serait un Śiva où domine l'aspect de maître spirituel. L'association de la direction du sud avec l'enseignement a pu jouer un rôle dans le placement de cette image, enregistré par la suite dans des Āgama dont les auteurs ont même pu avoir tendance à accentuer l'aspect enseignant d'une divinité dont ils ne comprenaient plus les origines. Si semblables qu'ils soient d'un point de vue iconographique, les Dakṣināmūrti pallava et cōla ne correspondent sans doute pas exactement au même concept religieux. L'interprétation qui fait du dieu assis une forme d'enseignant correspond certes à nombre de détails de la représentation,

91. C'est sans doute ainsi qu'il faut comprendre Kuruntokai 87 : « The dreadful god in the Māram tree of the village common torments the faithless ones, they say » (traduction de Eva Wilden, citée par V. Gillet (2006: 64). L'arbre de la place commune au centre du village est un banian, habité par une divinité dont le caractère terrible se manifeste parfois, vis-à-vis de ces gens sans foi, proches du concept d'ennemi dans une guerre.

92. L'article de Pierre-Sylvain Filliozat (2004) sur la conscience et le caractère divin des arbres tels qu'ils se présentent dans les textes sanskrits montre assez qu'on conçoit dans le nord de l'Inde aussi qu'un arbre puisse être habité par un dieu. 
mais elle a pu être adoptée sous l'influence des textes postérieurs. Le dieu au banian d'un temple royal pallava n'a certainement pas la même signification qu'un dieu au banian d'un sanctuaire local d'époque cōla : ils s'inscrivent d'ailleurs dans des programmes iconographiques qui présentent des différences significatives.

Il paraît difficile, dans l'état actuel de la question, de supposer un dieu indigène en quelque sorte, antérieur à Śiva : les témoignages qu'on possède sont, de même que les études qui leur sont consacrées, trop rares. Le titre donné au dieu du temple de Puḷamankkai me paraît, cependant, témoigner qu'il subsistait à l'époque $c \bar{l} \underline{l} a$, à un moment où l'iconographie de Dakṣiṇāmūrti était déjà bien en place, des traces du dieu au banian dont la littérature tamoule atteste l'existence à une période plus ancienne et que le Tēvāram dessine clairement comme figure enseignante. Quant à savoir si le Têvāram précède, accompagne ou reflète l'importance prise par cette forme de Śiva sur les temples du Tamil Nad, il est impossible, me semble-t-il, d'en décider. Il pourrait s'agir, à l'origine, d'un dieu de l'arbre, un esprit du banian, qui aurait pris plus d'importance que d'autres divinités locales et aurait essaimé en dehors de son territoire d'origine, pour des raisons qui restent hypothétiques. Le prestige des nombreux banians du Tamil Nad n'a-t-il pu faciliter cette expansion, l'implantation du dieu en question ou même l'assimilation d'un dieu à un autre s'opérant par l'intermédiaire de l'arbre « habité »?

On voit que le dieu d'Ālanturai reste secret encore en son sanctuaire shivaïte. Il n'y est pas seul : l'épigraphie mentionne une déesse, et l'iconographie représente une divinité féminine. Cette «Kālappitāri », déesse du temps ou déesse noire, qui est-elle?

\section{Kạlāppitāari ${ }^{93}$, une déesse entre deux mondes}

Une divinité féminine apparaît dans les deux inscriptions 12 et 14 , qui présentent des caractéristiques formelles particulières. Leur contenu est aussi singulier ; il attire l'attention sur une déesse, mystérieuse tant dans le corpus de Pullamankai que dans l'ensemble d'un corpus épigraphique pallava et cōla, où apparaît parfois le nom qu'on lit à Puḷamañkai : Kālāpppițāri ${ }^{94}$.

Par leur position et leur longueur, les inscriptions 12 et 14 apparaissent comme des intermédiaires entre les groupes épigraphiques des règnes de Parāntaka $I^{\text {er }}$ et de Rājarāja I ${ }^{\mathrm{er}}$. Les inscriptions gravées sous ce dernier règne sont bien plus longues, on l'a vu, et certaines prennent place sur le prāsāda. L'inscription 12 est la première à se situer sur le prāsāda, dont elle occupe la première partie disponible en suivant la pradakșinā, l'angle est de la face sud. L'inscription 14 est la seule qui soit inscrite

93. L'orthographe n'est pas fixée dans les inscriptions où le premier terme de composé peut s'écrire Kālā, Kạ̣ā ou Kạ̣a.

94. La dénomination de « Kạ̣āpitāri » se retrouve dans d'autres inscriptions que celles de Pullamañkai, sans que la divinité désignée soit jamais précisément identifiée dans la littérature secondaire (Orr 2005 : 28-31). La note 38 du chapitre 2 de N. Karashima 2001 a est précise : « Kālā-piḍāri is the same as Durgā ", mais elle n'est guère explicative. On peut se demander qui est Durgā et pourquoi, s'il s'agit des mêmes divinités, des noms aussi divers sont donnés aux sanctuaires (il s'agit de l'analyse des données des inscriptions de Rājarāja Ier à Tañjore) : Kạlāâ-piḍarī śrīkōyil, Pị̣āri-śrīkōyil, Piḍāri-kōyil et Durgaiyār-kōyil. 
à la fois sur le mandapa et le prāsāda. Elle forme ainsi comme une transition entre le groupe épigraphique de Parāntaka, gravé uniquement sur le maṇdapa, et celui de Rājarāja, qui prend place essentiellement sur le prāsāda.

Les inscriptions considérées jusqu'ici sont assez courtes. Mais la $\mathrm{n}^{\circ} 12$ et la $\mathrm{n}^{\circ} 14$ sont longues, la première parce qu'apparaissent plus de quatre-vingt donateurs et la seconde, entre autres raisons, parce qu'on y rapporte des modalités officielles de l'enregistrement du don, jusque-là inconnues : elle marque en effet l'apparition de certaines conventions qu'on retrouve dans toutes les inscriptions du règne de Rājarāja I ${ }^{\text {er }}$. La donation est située dans le temps de façon beaucoup plus précise : « Un mardi, alors que [l'étoile] Avittam se trouvait dans le mois de mina, (du poisson), de cette année ». Son caractère officiel est plus marqué : on bat le tambour devant le temple et on y fait graver ce qui constitue une sorte de sentence. Faute, protagoniste, jugement, l'ensemble du processus judiciaire est rapporté, dont plusieurs témoins individualisés se portent garants à la fin d'une inscription qui est bien plus qu'un simple acte d'enregistrement d'une donation. Aucun de ces caractères n'apparaît sur le temple avant cette inscription 14.

De telles conventions évoquent, en revanche, le pouvoir royal qui se fait plus apparent, car plus directif, à partir de l'inscription 15 (supra : 73-77). Si l'on n'est pas encore dans le cadre de l'épigraphie royale, on n'est plus dans un cadre uniquement villageois. La très longue liste de donateurs de l'inscription 12 tendrait à le confirmer. Le temple s'inscrit dans un espace social plus vaste. Et si le temple royal de Tañjore offre plusieurs occurrences des termes controversés pitāri et kälappițāri, nom que porte la déesse de l'Ālanturai, ce n'est peut-être pas par hasard.

Le terme kälāpitāari (inscription 12), ou kalapitāari (inscription 14) désigne une divinité féminine. En tamoul contemporain et en malayalam, le second terme de ce composé signifie déesse de village, et c'est ainsi que l'on a, longtemps, considéré cette entité dans la littérature secondaire (Venkayya 1916 : 40-41, S. R. Balasubrahmanyam 1966 : 1-2). Pourtant, son emploi dans le corpus épigraphique tamoul montre que ce sens de déesse de village dérive de l'une des significations originelles de «pitāri », qui en avait plusieurs autres. L'étymologie même du terme l'indique : il remonte au sanskrit bhattar, transcrit pitär en tamoul, et dérivé de bhattāra, dont le premier sens est « orgueil, fierté, arrogance » et le second, « grandeur ». "Pițāri » constitue la transcription tamoule de bhattārikă, la forme féminine du terme, comme le confirme, du moins pour l'usage du $x^{\mathrm{e}}$ siècle, l'inscription 14 de Pullamańkai, qui utilise les termes pițāri (kalā pițār[ikku], 1. 12) et bhāttari (bhātāriyārkku, 1. 54) pour désigner la même déesse. La transcription tamoule apparaît en contexte sanskrit, au XIII $^{\mathfrak{e}}$ siècle, dans l'un des surnoms royaux d'un Yadavaraya, gravé sur le premier gopura du temple Tirumā! de Tirupati : pitharadēvi-labdha-varaprasāada, «celui qui reçoit de Pitharadēvī l'accomplissement de ses souhaits ${ }^{95}$. Le va-et-vient entre les deux langues a produit cet hybride, dont la signification exacte aux $\mathrm{x}^{\mathrm{c}}-\mathrm{XI}^{\mathrm{e}}$ siècles reste à cerner ${ }^{96}$.

95. Tirupati Devasthanam Inscriptions 1931, p. 101-104, $\mathrm{n}^{\circ} 81$.

96. Dans les dictionnaires médicaux contemporains, ainsi que dans le dictionnaire de Mousset et Dupuis (1938), pitäran dérive de visahara, autre composé sanskrit, signifiant celui qui attrape les serpents, un 
Dans les inscriptions tamoules médiévales, le terme pitāri apparaît parfois comme l'équivalent d'un titre, indiquant le haut statut de la personne concernée. Il peut, par exemple, désigner une donatrice de haut rang. Mais T. N. Subrahmaniam (1958 : 94-95) mentionne une inscription faisant état d'un temple à une «Padāri » rattaché à un temple bouddhique et Leslie Orr (2005:28-31) a montré que le mot bhattărakiyār désigne des déesses dans des inscriptions jaïnes, dès le $\mathrm{IX}^{\mathrm{e}}$ siècle. On pourrait alors, me semble-t-il, le traduire par «maîtresse » ou « dame », ce qui correspond à la signification du terme en sanskrit ${ }^{97}$. À partir du $x^{\mathrm{e}}$ siècle, le terme se rencontre aussi pour des divinités féminines pan-indiennes en contexte hindou, comme la bhațtārakiyār Umā de Tiruvițaimaruțūr, mentionnée en l'an 993 (Orr 2005 : 30 ${ }^{98}$. Les inscriptions de Pullamańkai sont vraisemblablement antérieures d'une vingtaine d'années à cette inscription. La forme bien tamoule adoptée à deux reprises sur ce temple serait-elle associée à une forme de divinité plus «locale »? Encore proche du sanskrit, le bhätāriyār de l'inscription 14 incite à la prudence sur ce point. On peut aussi se demander comment une divinité adorée sur un territoire précis est désignée, adorée et représentée. Peut-être est-elle assimilée à une déesse de tendance pan-indienne, c'est-à-dire dont le profil cultuel, mythologique et iconographique se laisse reconnaître sur un territoire plus large. La mystérieuse divinité du Saint Ālanturai est représentée par une iconographie et une mythologic shivaïtes des plus formulaires. Dans le même complexe cultuel, il paraît possible que les procédés de représentation de la divinité féminine offrent des traits similaires. La prise en compte du premier terme du composé désignant la déesse et l'analyse du contenu des deux inscriptions qui l'évoquent vont dans ce sens.

Nous n'avons pas affaire en effet à une simple pitạri mais à une «Kāla/āa-p-pitāiri ». Ce composé apparaît dans d'autres inscriptions tamoules. Le premier terme en est, généralement, mis en relation avec la forme shivaiite terrible bien connue de la déesse Kālī, dont Kāla-piṭāri serait l'équivalent tamoul. Cet équivalent est-il uniquement ou principalement linguistique, ou bien la divinité désignée estelle cette même Kālì dont les images nord-indiennes et la littérature sanskrite nous donnent l'idée assez précise d'une déesse d'aspect terrifiant ? Dans les inscriptions du Rajarajeśvara de Tañjore, de peu postérieures et localisées dans la même aire géographique, on rencontre des « Kāḷappitâri ». Sur un pilier de l'enceinte sud, un

médecin, un homme de la caste des Kuravar et, enfin, un musicien. Dans les proverbes tamouls, pitāari apparaît comme une diablesse, voir H. Jensen 1897, $\mathrm{n}^{\circ} 2961$ : « comme il était anxieux de fonder une famille, il s'est marié avec une diablesse (pitāri) "; le sens de divinité et non pas seulement divinité de village est clair dans le proverbe $n^{\circ} 925$ (Ibid. : 100) : " comme la déesse (pitäri) qui vint et expulsa la déesse de village (ūlar pitāri) ", où on ajoute $\bar{u}$ lar pour faire la distinction entre les deux types de déesses. À une pitāri semblent donc s'attacher certains pouvoirs, éventuellement démoniques. Il semble que partant du sens, et de la fonction, de maîtresse, grande dame devenant une déesse de village, on ait attribué des pouvoirs de guérison de venin du serpent aux pitâri (EI XIII : 135). L'étymologie bâtie à partir de viṣa-hara est secondaire, visant à justifier un statut acquis ultérieurement.

97. Monier-Williams donne « venerable ».

98. SII XXIII, $\mathrm{n}^{\circ} 278$, sur un pilier de Tiruvitaimarutūr, dans le district de Tañjore. 
officier de Rājarājadeva fit installer une représentation en bronze de Kāḷāpitāari ${ }^{99}$. La déesse a quatre bras, un piédestal (pitham) et une auréole (prabhai). L'iconographie de cette divinité peut donc être cultuelle ; son statut est suffisamment important pour qu'elle apparaisse en bronze dans un temple royal. Dans le même temple de Tañjore, deux Kālappitạari sont mentionnées dans la longue inscription 5, très instructive, ne serait-ce que parce qu'elle utilise également plusieurs fois le simple « pitāari ».

Cette inscription se trouve au nord du prāsāda du temple, sur le tiers supérieur. Gravée après l'année 1014, d'après son éditeur (SII II, $1: 53$ ), elle donne une liste de villages devant redevance au temple de Rājarājadeva; ces villages comportent des temples, dont certains de «pițāri» et de «Kālappițāri » (Mākāṇikuṭi et Turaiyūr). Elle est proche de l'inscription 4 du même temple, qui mentionne les sanctuaires $(k \overline{o y} y i)$ de deux pitări apparaissant dans le même genre de liste (seconde section, 1. 5 ; septième section, 1. 7) et rattachées aux villages ( $\bar{u} r)$ d'Ārappār et de Maṇarkālappa!̣i. Dans l'inscription 5 de Tañjore, on peut donc supposer que les kāla pitāari des villages de Mākāṇikuṭi et de Turaiyūr ne sont pas de même nature que ces pitāri «simples » de l'inscription 4 de ce temple, ou que celles de l'inscription 5 elle-même, qui en mentionne sept. Une pitäri apparaît dans la section consacrée à Turaiyūr, et la preuve semble ainsi faite d'une différence entre piṭāri et Kālapitạari. On pense à une forme particulière de pitāari, qui serait terriblc, ćtant donnćc la relation avec le nom sanskrit Kālī.

En réalité, la section de Turaiyūr est particulière. Les sanctuaires aux déesses y sont nombreux. Trois pițāri y apparaissent, différenciées les unes des autres par des dénominations se rapportant à des territoires, selon toute vraisemblance ceux qui leur sont rattachés : piṭāri « Punnnaitturai-nankai », la Dame de Punnnaitturai ; pițāri « Potuva[k]ai-ūr uṭaiyāl », la Dame de Potuvakaiyūr ; et pițāri « Kuturaivaț̣am uṭaiyāl », la Dame de Kuturaivațtam. En l'occurrence, les pițāri semblent bien constituer des déesses de ces territoires. Kālappițāri, à qui aucune onomastique géographique précise n'est ici associée, serait une divinité de plus considérable influence, plus proche d'une divinité pan-indienne donc. Cependant il est bien précisé dans les deux cas qu'il s'agit de la Kạlappițari « de ce village » (ivvūr kạlar pițāriyār).

L'analyse de ces occurrences amène à conclure que Kālappițāri serait une forme de divinité pan-indienne qui connaîtrait, parfois, des incarnations particulières dans certains villages, du moins dans la région de Tañjore. Ces quelques indications amènent à poser l'hypothèse d'une forme de déesse que je qualifierais, dans un premier temps, d'intermédiaire entre un temple de dimensions locales comme celui de Puḷamańkai et le temple royal de Tañjore. Ce type de divinité permettrait d'établir un lien entre une déesse, sinon dynastique, du moins régionale comme celle de Tañjore, adorée par un officier de l'armée du roi dans un complexe royal, et une divinité dont le territoire se limite habituellement au «village» (ür) sur lequel elle règne. Certains détails des deux inscriptions de Puḷamańkai mentionnant la déesse tendent, à mon sens, à confirmer l'hypothèse d'une déesse « intermédiaire » — qualificatif déjà employé à propos de certaines caractéristiques formelles des inscriptions 12 et 14 . 
Territoire et attributions de la divinité à laquelle se réfèrent ces inscriptions sont incertains. Dans l'inscription 12, Kālāppitāri est une divinité rattachée au beau mandapa d'Ālanturai (tiruvālanturai tirumanimantapattu svasti śrī kālāpitāârikku) ; dans l'inscription 14, il semble qu'il s'agit apparemment de la divinité qui a un beau mandapa à Natuvirccēri, localité elle-même rattachée à l'ūr, un terme dont il est difficile de savoir ce qu'il désigne exactement, mais qui en l'occurrence pourrait désigner simplement le brahmadeya de Puḷamañkalam en tant qu'unité territoriale (ivvūr națvirceri tiruma[ni]mantakamutaiya kală pițār[ikku]) ${ }^{100}$. Dans cette seconde inscription, le territoire de la déesse considérée paraît plus limité que dans la première. Le beau mandapa est l'un des éléments communs des attributs donnés à la déesse dans les deux inscriptions. Il est aussi possible que, ne comportant pas de marque de cas, le natuvirceri de l'inscription 14 soit l'équivalent d'un ablatif désignant le village comme donateur. C'est le rôle des officiels de Natuvirccēri plus bas dans la même inscription, où le toponyme est alors accompagné de la particule itai. L'ordre des mots adopté aux lignes 10-12 permet cette interprétation. De toute façon, la Kālappițāri de l'inscription 14 reste une déesse située dans l'unité religieuse que constitue Pullamankalam. Mais les contours du territoire dans lequel elle se situe, c'est-à-dire en définitive les limites de son pouvoir, apparaissent imprécis.

Son statut cultuel semble bien être, lui aussi, imprécis. L'inscription 14 rapporte la faute commise pendant le culte qu'on lui rend, sans que l'on sache exactement laquelle. Deux manquements graves se sont produits. Aimpattunālvan, du village de Națuvirccēri, «n'a pas pu montrer les comptes » et « a commis le crime de permettre à ses frères de prendre le contrôle des opérations ». Ces fautes donnent lieu à une sorte d'amende que doivent verser les comptables (karanattār) de Națuvircceri pour réparer la faute du responsable des comptes (ivvūrk kaṇakkuc ceyvān).

Si une telle faute a été commise, on peut supposer que les règles à suivre lors de l'adoration à la déesse étaient beaucoup moins claires que, par exemple, la façon dont on adore une divinité comme le Mahādeva de Tiruvālanturai. Aucun manquement

100. La terre passe d'une main à l'autre selon un processus compliqué. Les comptables officiels de Natuvirccēri ont donné $25 k \bar{c} c u$ à l'assemblée et donnent une terre à la déesse. Par aillcurs c'cst l'assemblée qui, dit-elle, donne cette terre après ce qui est désigné par virrru, c'est-à-dire une vente. La terre donnée est celle d'un comptable qui a commis des malversations. Pourquoi donner de l'argent à l'assemblée ? Est-ce une amende ou une forme de taxe sur le don fait ? Ce serait alors cette taxe qui serait ici désignée par le terme virru : après avoir reçu de l'argent correspondant à cette terre, l'assemblée accepte de la remettre à la déesse. Les termes employés pour désigner les actants n'aident guère à comprendre. On est dans le brahmadeya de Pullamankalam puis dans un ür pourvu du démonstratif $i$, désignant ce qui est proche. Peut-être $i v v \bar{r}$ est-il redondant par rapport à Natuvirccēri, peut-être désigne-t-il une unité villageoise plus vaste dans laquelle Natuvirccēri s'insère (sur cette question, supra, note 51). Il semble plausible que le démonstratif signale que l'ūr dont il est question est celui qui s'étendrait autour du brahmadeya de Pullamańkalam. Il serait constitué de plusieurs hameaux ou autres unités, dont Națuirccēri. L'intervention de l'assemblée serait due au fait que la terre donnée relève d'un brahmadeya, donc de l'assemblée de brahmanes de Pullamańkai ; mais la relation entre $\bar{u} r$ et mahāsabhā est peut-être plus complexe, supra, note 51. F. Gros (1970:110) signale que l'assemblée d'Uttaramerur peut percevoir les amendes ; l'hypothèse selon laquelle la sabhä hérita de certaines des fonctions du manram (Ibid. : 101-102) fait de l'assemblée une forme de "siège de justice " et l'établissement des amendes, ou des compensations (comme celle que mentionne l'inscription 18 du corpus) rentre tout naturellement dans ses attributions. En tout état de cause, ces transactions financières établissent un lien étroit entre une déesse qu'on qualifie habituellement de déesse de village (ür), et le temple brahmanique de Tiruvālanturai à Puḷamańkai. 
envers la divinité masculine du temple n'est évoqué. Kālappitāia a par ailleurs reçu de l'assemblée du brahmadeya de l'or, du grain, etc. (inscription 14). Elle semble donc relever - adoptons une formulation prudente - d'une sphère financière placée sous le contrôle d'une assemblée de brahmanes. C'est bien à son propos qu'apparaissent des éléments de codification sociale inconnus jusqu'ici. Il semble qu'on cherche en quelque sorte à rendre officielle une divinité. C'est alors qu'il faut tenir compte du caractère vraiment étrange de l'inscription 12. Les premières lignes de cette inscription ont été ajoutées (fig. 51). La paléographie est la même mais les lettres des cinq premières lignes sont bien plus petites et les lignes bien plus serrées que les suivantes. La formule d'invocation (svasti śr $\vec{\imath}$ ) qui marque le début d'une inscription apparaît au début de la ligne 6. L'inscription 12 eut donc dans la première période de son existence, qui fut sans doute brève, un caractère intemporel. Elle n'était pas datée, ce qui constitue un fait unique dans le corpus. Kālappițāri n'était pas non plus cette déesse au beau mandapa d'Ālanturai. Elle n'était située ni dans le temps, ni dans l'espace, ni à un quelconque niveau cultuel. On a ajouté des détails qui sont finalement apparus indispensables, ou simplement commodes, par la suite, sans doute après avoir gravé cette longue inscription de donation à Kālappitāri, ou bien au moment où on gravait une seconde inscription de donation à la déesse, l'inscription 14.

Tous ces éléments dessinent la figure d'une déesse au statut ambigu. Est-elle ou n'est-elle pas divinité de Puḷamankkalam ? Dépend-elle ou non du brahmadeya? Quelles relations entretient-elle avec le dieu d'Ālanturai lui-même, et avec son temple? L'inscription 14 semble témoigner que nous ne soyons pas les seuls à nous être posé ces questions. L'analyse d'autres occurrences de « piṭāri » et « Kālappițāri » dans le corpus épigraphique tamoul permet cependant, à mon sens, de mieux cerner la personnalité divine de la déesse de Puḷamankkalam.

Dans EI XIII, K. V. Subrahmanya Aiyer commente l'emploi du terme patāari, qui revient dans plusieurs inscriptions retrouvées à Centalai, localité qui se situe dans le même district de Tañjore que Puḷamańkai. L'un des poètes qui composa les inscriptions des piliers de Centalai est originaire de Kīlāar Kurram, la division territoriale dans laquelle est situé le temple d'Ālanturai, comme le signalent presque toutes les inscriptions de ce temple (inscriptions $1,2,3,4,5,6,8,9,14,15,16$, 17, 18 et 19). Sans aller jusqu'à considérer que l'on a affaire à la même déesse, la proximité géographique incline à considérer ces témoignages comme assez précieux pour comprendre la divinité de Puḷamankalam.

La plus ancienne des inscriptions de Centalai rapporte la fondation d'un temple à pițāri. Pour comprendre qui est cette divinité, l'auteur se réfère à deux autres inscriptions du $\mathrm{XI}^{\mathfrak{e}}$ siècle, retrouvées dans un temple d'Ālampākkam $(A R \quad 1909$, $\mathrm{n}^{\mathrm{os}}$ 704-706) et dans un temple de Vēlaccēri, près de Madras. Pour lui, pitāari et kāla bhatāari sont souvent équivalents, désignant la collectivité de déesses appelées mātrkā ${ }^{101}$; piṭāri employé seul désignerait parfois de simples divinités

101. Pour l'inscription originaire de Vēlaccēri, voir SII XIX : $n^{\circ} 97$, rapportant une donation de terre faite en tant que « mañjikam » (traduit par « common property » dans l'index de $S I I$ ) par l'assemblée de Vēlaccēri, à Puliyūrkōtțam pour maintenir une lampe perpétuelle et de quoi nourrir deux fois la 
de village. Les hypothèses de ce type, anciennes, ne paraissent plus guère crédibles (Orr 2005: 30). On peut ajouter que le portrait de la divinité de Centalai ne correspond guère à celui d'une divinité de village.

La patâri de Centalai apparaît guerrière. Après l'exposé de sa généalogie royale, le souverain qui fonda son temple fait conter ses conquêtes, se vantant d'avoir fait chanceler la beauté d'une déesse au visage de lune dont les flèches mettent à mort les soldats (EI XIII : 144). Sur les même piliers que cette inscription mentionnant la fondation du temple de pitāari — gravée sur quatre piliers —, plusieurs inscriptions postérieures rapportent des dons qui lui sont faits. Le dédicataire peut être un roi victorieux, tels ce Nantippōttaraiyar (Nandivarman III) en $858^{102}$ et Ilańkomuttaraiyar, un chef muttaraiyar, sans doute au début du $1 x^{e}$ siècle ${ }^{103}$. En 889 (sous le règne du cōlla Rājakēcarivarman, c'est-à-dire Āditya I ${ }^{e r}$ ), Mārampavai fait aussi une donation à cette déesse ${ }^{104}$, et sous le règne du Pāṇtiya Mārañcaṭaiyan ${ }^{105}$ on enregistre la donation d'un serviteur de la famille des Mutttaraiyar. Notons qu'un «Māran » apparaît dans la liste de donateurs de l'inscription 12 (1. 16) et que plusieurs occurrences de ce nom appartiennent à l'épigraphie du groupe de Paluvūr. La pitāari à laquelle s'adressent tous ces donateurs semble une divinité non pas dynastique - les dynasties changent tandis qu' « Elle » demeure —, mais une déesse qui accorde la victoire au combat. C'cst sans doutc cette valeur gucrrière qui lui vaut d'être liée aux rois de façon constante au fil du temps.

L'ensemble de ces indications, internes dans le corpus de Pullamankai et externes dans le corpus publié, dessinent une figure qui ne correspond pas exactement à celle d'une divinité de village - même si elle se rattache parfois à un territoire précis -, mais serait une divinité de statut intermédiaire, entre l'échelon local et une aire géographique plus étendue, entre le brahmanique et le guerrier, voire entre d'autres espaces ou catégories religieuses encore. Le māran utilisé pour composer le nom d'un donateur de l'inscription 12 se retrouve ailleurs dans l'épigraphie de la région. La Kālappitāari de Puḷamańkai pourrait être celle qu'on invoque lorsqu'on cherche à élargir peu ou prou le territoire d'une unité religieuse, dans une perspective guerrière ou simplement idéologique, une déesse des contacts avec l'extérieur en quelque sorte. Identifier des représentations de cette divinité nous aiderait à la cerner. Or il me semble possible de proposer une identification de la déesse de Pullamañkai dans les représentations du temple. Le grand dieu d'Ālanturai est représenté par une iconographie hindoue classique ; les procédés utilisés dans le cas de Kālappițāri pourraient être similaires.

kālābhatāri de cette inscription. Rien n'indique ici que Kālabhatāri serait une mātrkā. Rappelons en outre que Leslie Orr (2005: 24) a démontré que les mātrkā du Tamil Nadu n'entretenaient guère de relations avec des enfants. Il s'agit bien, comme ailleurs, de collectivités de déesses, mais pas de déesses-mères. Rien dans l'inscription de Vēlaccēri n'indique que ces pitāari seraient des mātrkāa, sinon leur nombre (sept).

102. SII VI, n 447, p. 185 ; Mahalingam 1988, vol. I, n $125: 386-387$; Id. 1992 : $\mathrm{n}^{\circ} 2616$, p. 593.

103. SII VI, $n^{\circ} 448$, p. 185 ; Mahalingam 1992, vol. VII, $\mathrm{n}^{\circ} 2622$, p. 594-595.

104. SII VI, n 449, p. 186 ; Mahalingam 1992, vol. VII, n² 2619, p. 594.

105. SII VI, $\mathrm{n}^{\circ} 446$, p. 185 ; Mahalingam 1992, vol. VII, ${ }^{\circ} 2614$, p. 592. 
La très belle femme qui se dresse debout sur la tête d'un buffle, une Mahișamardinī donc, à qui un dévot offre sa tête et un autre la chair de sa cuisse sur la face nord du temple, pourrait, me paraît-il, constituer la représentation de la Kālappițāri du temple (fig. 16). L'inscription de Mallām (SII XII : no 106, p. 50, ill. pl. VI), où un personnage offre sa chair et sa tête à une «bhatāā » et est figuré en tant que tel à côté de l'inscription, prouve amplement que les bhațārī/pitâri peuvent être sanguinaires. Les représentations méridionales de Mahiṣamardinī possèdent, dès leurs premières représentations, des caractères proprement sud-indiens, qui signalent très clairement qu'on n'a pas affaire à la même déesse dans le Nord et dans le Sud de l'Inde : la présence d'une antilope et l'importance donnée aux têtes coupées dans l'iconographie de la Mahișamardinī méridionale y font reconnaître la part de la Korravai de la littérature du Cankam, rapide comme l'antilope et que l'on adore dans des sanctuaires ornés de têtes coupées (Ch. Schmid 2005).

Korravai est la «Victorieuse ». On retrouve à Pullamańkai comme dans d'autres temples cōla (J. C. Harle 1963), l'iconographie inaugurée au viI ${ }^{\mathrm{e}}$ siècle à Mahābalipuram, où l'on figure une déesse debout sur la tête d'un buffle, entre un lion et une antilope, et à qui deux dévots offrent qui sa tête, qui son sang. Déesse de la victoire qu'on remporte au combat, divinité à qui on offre le buffle des divinités de village mais aussi des consécrations royales, et située sur le maṇapa certes beau du temple du dieu d'Ālanturai, la Mahișamardin̄̄ du mur nord du Brahmāpurīśvara ne pourrait-elle représenter la pitâri des inscriptions des murs sud et nord du temple du dieu d'Ālanturai ? Ajoutons qu'à partir de Rājarāja $\mathrm{I}^{\mathrm{er}}$, les meykkīrtti cōla $a$ font état d'une déesse particulière, $p \bar{o} r$-c-ceya, la déesse qui donne la victoire au combat. Le temple de Pullamankai n'est pas une fondation royale, mais les inscriptions mentionnant la déesse sont déjà représentatives de la mouvance épigraphique du règne de Rājarāja $I^{\mathrm{er}}$. Comme certaines des inscriptions de Rājarāja $\mathrm{I}^{\mathrm{er}}$, celles de Pullamańkai pourraient témoigner de l'importance prise alors par une déesse de la victoire, inspirée certainement en partie par la Korravai des épopées tamoules et à laquelle les images de Mahișamardin̄i fournissent un support iconographique. Rappelons, enfin, que les premières apparitions de la Noire Kālī dans les textes, qu'il s'agisse de Mahābhārata XII, 98 ou du Devi-Māhātmya, où elle vient offrir les têtes coupées de ce qu'elle qualifie elle-même de victimes sacrificielles (DeviMāhātmya 7, 25) font d'elles une exécutante du sacrifice géant qu'est la guerre. Celle à qui on offre têtes et chair des victimes du sacrifice est bien proche de cette divinité qui tranche têtes et membres tant des humains que des animaux sur les champs de bataille - Kālī, Kālappițarī, Mahișamardin̄in, Korravai, quel que soit le nom qu'on veuille lui donner.

Les indications épigraphiques et l'analyse de l'iconographie, si rapidement qu'elle ait été ici menée, conduisent donc, à mon sens, à poser l'hypothèse de représentations de pitāari, et plus précisément de Kālappiṭāri, en Mahiṣamardinīī ${ }^{106}$.

106. Cette hypothèse ne s'oppose pas nécessairement à V. Venkayya (note 1 p. 41 de son introduction au vol. II, I-II des SII ; soutenu par H. Krishna Sastri 1974: 224, note 3) et R. Nagaswamy (1977), qui pensent reconnaître dans des déesses assises sur des sièges où sont représentés des personnages humains en position de vaincus, et pourvues d'une auréole flammée les images des pitâri (quoique V. Venkayya ne donne aucune référence à la description très précise qu'il fait de l'iconographie de pitāari). Ces images sont plus courantes à l'époque vijayanagar, rares à l'époque côla et inconnues dans l'art pallava. 
L'évolution du terme pițāri comme de l'iconographie de la Tueuse du Buffle dans le Sud de l'Inde semblent parallèles, utilisant des acquis apparaissant dans la littérature sanskrite pour représenter une réalité méridionale que les quelques documents dont nous disposons laissent deviner plus diverse que les termes et les images utilisés pour la représenter dans des cadres codifiés. La relation entre représentations et corpus textuel, inscriptions et Têvāram, permet de mieux comprendre le lien tissé par des divinités qualifiées de locales, de régionales, ou encore de dynastiques et des divinités pan-indiennes comme Śiva ou Mahiṣamardin̄i. Ces figures hindoues de très haute importance connaissent des incarnations « locales » par un jeu d'échanges si profond qu'il n'est pas possible d'opérer une distinction claire entre le concept global du dieu et ces manifestations concrètes, enracinées dans le temps et l'espace. Si, tant dans ses représentations que dans les louanges composées à sa gloire, ou encore dans les inscriptions rapportant les dons qu'on lui fait, le grand dieu d'Ālanturai et Śiva se confondent, faut-il chercher à les distinguer l'un de l'autre ? Kālappitāâri et Mahișamardinī participent de même à la constitution d'une divinité, connaissant ici une représentation, qui pourrait correspondre à d'autres déesses encore. Lorsqu'il est impossible de séparer les dieux, de dessiner des différences, il n'est peut-être pas non plus utile, ni même pertinent, de le faire.

\section{Conclusion}

L'hypothèse d'une fondation royale, qui expliquerait le raffinement du temple de Puḷamańkai et l'importance donnée à Rāma dans un temple shivaïte où cette incarnation de Viṣnu serait une figure idéale du roi, ne résiste guère à l'analyse. Même l'implication de la dynastie mineure des Paluvēttararaiyar demeure très hypothétique. Le plan, l'élévation et le programme iconographique tendent à illustrer la diversité des manifestations du dieu lorsqu'il apparaît aux hommes ainsi que le culte dont il est l'objet : le dieu d'Ālanturai est représenté comme un Śiva dont Viṣnu n'est que l'une des nombreuses formes. Comme d'autres temples $c \bar{o} \underline{l} a$, mais aussi plus que d'autres, le Brahmāpurīśvara donne par ailleurs corps à des concepts abstraits, telles que la non-manifestation du dieu en ses niches vides et l'importance de la dévotion, s'élevant de la terre vers le ciel en une tour-sanctuaire exceptionnellement haute.

L'influence nord-indienne croise dans ce temple une dévotion originaire du pays tamoul. Selon l'hymne du Tềväram et le corpus épigraphique de Pullamankkai, l'édifice est la demeure du grand dieu du lieu sacré Ālanturai, dont le lien avec le banian demeure difficile à préciser. Les formules utilisées pour le représenter - mythes d'origine septentrionale qui se répètent d'un chant à l'autre du Têvāram, iconographie shivaïte qui plonge souvent ses racines dans la littérature sanskrite et qui se fixe de temple en temple — sont l'un des aspects

La large acception du terme pitāri permet de l'appliquer sans doute à bien des images, mais aussi, et plus précisément à Pullamańkai, à celle qu'on désigne communément comme Mahișāsuramardinī. Le mythe du combat contre le buffle apparait d'ailleurs toujours dans une geste comportant une lutte contre deux autres démons, Śumbha et Niśumbha, qu'on dit parfois être représentés sur le piédestal des " pitāiri » assises sur des humains. Il s'agirait donc de la même déesse mais représentée dans deux mythes différents. Toutefois, je ne connais pas de représentations de dévots se tranchant la tête devant ces divinités assises, et l'inscription de Mallām prouve qu'on tranche bien sa tête devant « bhațārī ». 
d'une réalité dont l'épigraphie nous rappelle qu'elle en a bien d'autres. Qui sont-ils, ce dieu d'Ālanturai et la déesse dite Kạlappitạani du corpus épigraphique ? Un dieu de Tiruvālanturai apparaît dans les inscriptions de plusieurs sites du Tamil Nad, dessinant un territoire circonscrit mais vaste qui constitue cette divinité comme ayant une histoire et une implantation géographique spécifiques. Les premières mentions épigraphiques datent $\mathrm{du} I \mathrm{X}^{\mathrm{e}}$ siècle, un siècle environ après les premières images d'un Śiva au banian que les Āgama appellent Dakṣināmūrti et dont la littérature du Cańkam atteste, peut-être, l'existence dès le $\mathrm{vI}^{\mathfrak{e}}$ siècle.

Mais s'il s'avère impossible, dans l'état actuel des recherches, de distinguer précisément les éléments dont le dieu de Pullamańkai forme une synthèse, peutêtre est-ce l'une des grandes réussites de cette bhakti tamoule, dont le Têvāram semble être à la fois acteur et témoin. Comme ce dernier corpus, le temple de Pullamankkai puise dans un répertoire de figures dont le caractère formulaire permet de rattacher le dieu et la déesse du temple à des réseaux pan-indiens - autres temples correspondant aux hymnes du Tēvāram, Tēvāram lui-même mais aussi, par exemple, le réseau que tissent les représentations du Rāmāyana et les textes qui les inspirent. À Pullamańkai, de tels réseaux semblent d'abord s'organiser en dehors d'un pouvoir politique, $c \bar{l} \underline{l} a$ ou autre, qui n'apparaît guère dans l'épigraphie du temple durant le $\mathrm{X}^{\mathfrak{e}}$ siècle, puis se fait plus présent à la toute fin du même siècle.

Et ce sont certains des interlocuteurs du programme iconographique qui, en introduisant leur humanité à travers des écrits témoignant d'une relation individuelle avec des dieux particuliers, font de ce temple un espace unique. Le dieu qui se manifeste dans ce temple s'y nomme Puḷamańkalattu Tiruvālanturai Mahādeva, en cet espace nommé Pullamańkai où le grand dieu de l'entour du banian donne accès à lui-même et où l'on figure une déesse qui, recevant le don rituel de sang et de chair, vous ouvre les portes d'un autre monde. Miroir tendu au dieu pour qu'on l'y reconnaisse, passage construit entre l'univers divin et celui des hommes, le temple matérialise l'essence d'une rencontre avec la divinité d'Ālanturai.

Ses murs portent toujours les traces de rencontres particulières qui prirent place entre le $x^{\mathfrak{e}}$ et le $\mathrm{XII}^{\mathfrak{e}}$ siècle. Le corpus suivant invite à les découvrir.

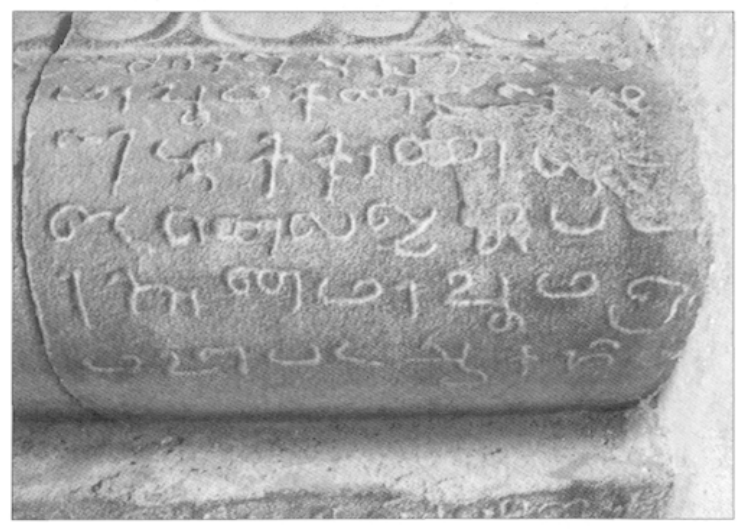

Fig. 54. Inscription $n^{\circ} 22$, détail : l'inscription est en partie prise sous le ciment. Cliché : $E$. Francis. 


\section{Les inscriptions du Brahmāpurīśvara de Puḷ!amañkai}

par le $\mathrm{D}^{\mathrm{r}} \mathrm{G}$. Vijayavenugopal*

\section{Introduction au corpus}

Le corpus épigraphique appelle le village de Pullamańkai « Puḷamańkalam ». Terme d'origine sanskrite, le tamoul mankalam signifie littéralement « de bon augure ». Il est utilisé comme une forme de suffixe dans les toponymes pour indiquer qu'on a affaire à un village donné à des brahmanes connaisseurs des Veda. On le rencontre souvent, alors, sous la forme «caturvedimarikalam». Quant à pulla-, ce pourrait être un dérivé d'un nom propre, Puḷan. Mais aucun Pullạn n'apparaît dans les témoignages dont on dispose.

L'élégant temple qui se dresse dans ce village porte actuellement, comme beaucoup d'autres temples d'autres villages, le nom de Brahmāpuríśvara. Mais les inscriptions gravées sur les murs du temple l'appellent le temple (kōyil) de Tiruvālanturai Mahādeva.

\section{Publications antérieures}

En 1921, on copia quatorze inscriptions dans ce temple. Elles furent l'objet de brefs rapports dans l'Annual Report of the Epigraphist, Madras, de l'Archaeological Survey of India, qui leur donna les numéros 546 à $559^{107}$. Seules six d'entre ces inscriptions furent publiées par la suite : la $\mathrm{n}^{\circ}$ 548/1921 dans South Indian Inscriptions [SII] III, sous le $\mathrm{n}^{\circ} 257$; la $\mathrm{n}^{\circ} 549 / 1921$ dans SII XIX, sous le $\mathrm{n}^{\circ} 63$; la $\mathrm{n}^{\circ} 546 / 1921$ dans $S I I$ XIX, sous le $\mathrm{n}^{\circ} 138$; la $\mathrm{n}^{\circ} 559 / 1921$ dans SII XIX, sous le $\mathrm{n}^{\circ} 168$; et la $\mathrm{n}^{\circ} 551 / 1921$ dans SII XIX, sous le $n^{\circ} 188$. L'inscription $\mathrm{n}^{\circ} 555 / 1921$ a été publiée dans une annexe de l'ouvrage sur l'art cōla de S. Swaminathan (1998). Le bureau de l'Archaeological Survey à Mysore a fourni le texte de sept des huit inscriptions restantes, à savoir les $\mathrm{n}^{\text {os }} 547 / 1921,550 / 1921,552 / 1921,553 / 1921$, $554 / 1921,557 / 1921$ et 558/1921. Le texte de l'inscription alors copiée sous le numéro $556 / 1921$ n'a pas été retrouvé ; certains des éléments publiés correspondent avec l'inscription 12 , d'autres en diffèrent ${ }^{108}$. Six inscriptions ( ${ }^{\circ s} 3,5,10,17,20$ et 21 du présent corpus) ont depuis été publiées dans le périodique Varalāru; cinq d'entre elles étaient entièrement inédites, mais la $n^{\circ} 20$, que l'édition de Varalāru présente comme nouvelle, correspond en réalité à celle qui est enregistrée en $A R 1921$ sous le $n^{\circ}$ 547. Enfin, la liste de T. V. Mahalingam fait état de cinq inscriptions dont nous n'avons pas trouvé trace. Trois d'entre elles sont datées du règne de Kulōttunka II

\footnotetext{
* Maître de recherches, centre de l'École française d'Extrême-Orient, Pondichéry. Je remercie Charlotte Schmid qui m'a incité à éditer les inscriptions du temple de Pullamankai et à rédiger cette présentation, et qui en a ensuite assuré la traduction en français. Nous remercions aussi vivement $R$. Satyanarayanan, M. Ramaswamy (Babu) et Emmanuel Francis qui nous ont accompagné dans le travail de lecture des inscriptions, ainsi que Mme Shanti Rayapoullé du centre de l'Ecole française d'Extrême-Orient à Pondichéry qui nous a aidé dans cette recherche et a participé à la frappe du manuscrit anglais.
}

107. Les Annual Reports of the Epigraphist, ont fait l'objet de la réimpression citée en bibliographie sous le titre "Annual Report on Indian Epigraphy».

108. Il faut préciser que les transcrits d'inscriptions publiées ne sont plus disponibles par principe semble-t-il. Le cas de l'inscription 556/1921 est curieux puisqu'on ne retrouve pas le transcrit mais qu'on ne trouve pas non plus sur le temple aucune inscription qui corresponde au contenu indiqué dans le rapport publié. Peut-être s'agissait-il d'une erreur de classement des inscriptions par site. 
ou III Cōla, dont aucune inscription n'est identifiée sur le temple : peut-être ces inscriptions plus tardives que l'ensemble du corpus se trouvaient-elles sur des blocs de pierre indépendants du temple et qui ont disparu ${ }^{109}$.

Nos propres investigations nous ont fait découvrir trois nouvelles inscriptions, portant ici les $n^{\text {os }} 9$, 10 et 11 ; l'inscription $n^{\circ} 12$ est peut-être nouvelle. Deux fragments contenant seulement la formule marquant le début d'une inscription, à savoir «svasti śrī koparakēcari », n’ont pas été introduits dans le corpus.

\section{Dater les inscriptions : difficultés et hypothèses}

Durant le règne des premiers Cōla, les rois (Āditya I ${ }^{\mathrm{er}}$, Parāntaka I ${ }^{\mathrm{er}}$, Āditya II, etc.) sont identifiés par un surnom qu'ils présentent en alternance, Rājakēcari et Parakēcari. Si le père porte le surnom de Rājakēcari, son successeur (en principe, son fils aîné) porte celui de Parakēcari. Il est donc parfois difficile de savoir à quel règne on a affaire. Les historiens ont cependant déterminé des critères qui doivent conduire à plus de certitude. La longueur du règne de Parāntaka $\mathrm{I}^{\mathrm{er}}$, qu'on situe entre 907 et 955, permet, en général, de dire qu'un Parakēcari accompagné d'une année de règne importante (telles les années 31,33 , etc. dans notre corpus), correspond à Parāntaka $\mathrm{I}^{\mathrm{er}}$. On considère en fait souvent que le titre Parakēcari utilisé seul désigne Parāntaka I ${ }^{\mathrm{er}}$. Mais l'identification reste délicate puisque le surnom est aussi celui, par exemple, d'Uttama Cōla, qui régna à partir de 970 . S. R. Balasubrahmanyam a ainsi identifié l'inscription 14 ( $\left.A R 1921, \mathrm{n}^{\circ} 549\right)$ comme étant de Parāntaka ${ }^{\text {er }}$ parce que le surnom Parakēcari y figure isolément. Mais la méthode utilisée pour la date - l'addition des chiffres 2 et 1 pour indiquer le chiffre 3 - est plus souvent employée dans des inscriptions pāntiya que dans celles de Parāntaka I ${ }^{\mathrm{er}}$. De plus, cette inscription mentionne le mois, le jour et l'étoile particulière qui se trouvait dans le ciel au moment où on a gravé l'inscription. Ce type de détails ne se rencontre pas dans les inscriptions de la première moitié du $x^{\mathrm{e}}$ siècle. Enfin, l'un des donateurs mentionnés dans l'inscription porte le nom de Cuntaracōla Muttaraiyar. Or les rois donnaient habituellement aux personnages officiels qui les représentaient des noms dérivant de leur propre nom et il est donc probable que ce Cuntaracōla Muttaraiyar soit lié d'une manière ou d'une autre à Cuntaracōla, lequel régna après Parāntaka I ${ }^{\mathrm{er}}$, de 956 à $970{ }^{110}$. Il nous semble donc qu'il faut identifier le Parakēcari de cette inscription $n^{\circ} 14$ avec le roi qui suivit immédiatement Cuntaracōla, à savoir Uttama Cōla. C'est d'ailleurs ce que fait l'éditeur de SII XIX, où l'inscription est publiée ${ }^{11 !}$.

Les symboles utilisés pour transcrire les chiffres sont une autre source d'erreurs. Les chiffres 3 et 9 d'une part, et 4 et 6 d'autre part, s'écrivent parfois de façon

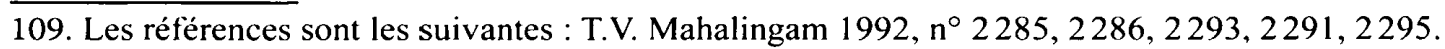

110. Ce nom n'apparaît d'ailleurs jamais dans les inscriptions publiées de Parāntaka I'r.

111. Ce type de controverses a des conséquences importantes pour la datation de l'évolution architecturale. En effet, se basant sur les travaux de S. R. Balasubrahmanyam, Gerda Hoekveld-Meijer écrit : " the year 910 is that of the oldest inscription on the Brahmāpurīśvara at Pullamangai » (1982: 102). Puis, l'auteure précise que ce temple est « the earliest known example of a complex vimanna without lateral niches in the recesses " (Ibid.). Mais l'inscription évoquée est cette $n^{\circ} 14$, qui date, nous semble-t-il, de 973 et non de 910 . 
similaire et peuvent donc être confondus. En outre, le chiffre 1 est souvent peu clair. C'est pourquoi nous avons indiqué une double datation dans certains cas : nous ne pouvons nous décider sans incertitude, surtout dans les cas où une publication antérieure indique un chiffre qui ne correspond pas à celui que nous lisons. C'est ce qui s'est produit dans le cas de notre inscription $n^{\circ} 4$, datée de 11 dans Varaläru, alors que nous lisons 31 . En revanche, en ce qui concerne l'inscription $n^{\circ} 5$, le chiffre 11 nous paraît très clair et nous corrigeons donc la date donnée dans l'édition antérieure. Parfois, seuls les chiffres des dizaines sont lisibles, sans qu'on puisse préciser l'unité 112 .

\section{Des inscriptions incomplètes}

Le caractère incomplet des inscriptions nous paraît être également source d'erreurs. Le centre de l'inscription 22 est recouvert par un bloc de ciment et l'extrémité de certaines des inscriptions se trouvant sur la base du temple, comme la $n^{\circ} 3$, n'est plus lisible, car elle a été englobée dans des constructions postérieures (fig. 54). Cependant, nombre d'inscriptions sont aussi incomplètes parce qu'elles n’ont jamais été terminées. Il y manque l'imprécation finale, et, souvent, le prix payé, comme dans l'inscription $n^{\circ} 1$ du corpus. On peut imaginer que ces inscriptions ont été recopiées sur les murs du temple, une fois celui-ci bâti en pierre. Auparavant, les informations n'auraient été gravées que sur ôles ou, parfois, sur de plus onéreuses tablettes. Il semble que les documents faisaient parfois l'objet d'une double copie : sur tablettes de cuivre et sur les murs d'un temple. Un document comme un ordre royal, tels ceux qui sont mentionnés dans les inscriptions $\mathrm{n}^{\mathrm{os}} 15$ et 17 , parvenait d'abord dans le village sous forme d'une ôle écrite. Il est possible que ceux qui ont gravé les premières inscriptions du temple aient recopié des documents qu'ils ne comprenaient pas.

Enfin, paradoxalement, les transcrits ont rendu difficile la constitution du texte des inscriptions 15 et 16. Ces deux inscriptions avaient fait l'objet de rapports basés sur les transcrits réalisés en 1921, mais elles avaient été mal recopiées en raison de la complexité de leur disposition dans l'espace, qui adapte le texte à une architecture qu'il finit par recouvrir selon une logique particulière ${ }^{113}$. Certaines portions de ces inscriptions n'avaient pas été copiées du tout, et il était impossible de les comprendre à partir des transcrits que l'Epigraphical Survey a eu l'amabilité de mettre à notre disposition à Mysore.

\section{Présentation du corpus}

L'ordre donné ici aux inscriptions correspond à la succession des règnes des rois $c \bar{c} \underline{l} a$, qui forment une première catégorie, à l'intérieur de laquelle les inscriptions sont ensuite ordonnées en fonction de l'année de règne mentionnée. Les inscriptions

112. D'autres types d'erreurs peuvent se produire, lorsqu'on se base sur les publications antérieures, qui ne comportent pas le texte des inscriptions mais en font un bref résumé. Se basant sur le rapport $A R$ $1921, n^{\circ} 556$, S. R. Balasubrahmanyam précise que cette inscription enregistre un don pour une lampe. En réalité, soit cette inscription appartient à un autre temple, soit il s'agit de l'inscription 12 de notre corpus, qui mentionne un don pour une offrande de nourriture.

113. Sur le caractère symbolique de la disposition des inscriptions, supra: $71-84$. 
dont nous ne sommes pas parvenus à identifier le roi se trouvent en fin de corpus (inscriptions $n^{\text {os }} 19-22$ ). Nous donnons le nom du roi, l'année de règne mentionnée dans l'inscription et son équivalent en ère chrétienne. La bibliographie de chaque inscription est également donnée avant le texte de l'inscription. Le texte est basé sur la lecture faite in situ. Si les lectures diffèrent de celles des éditions, voire des transcrits antérieurs, nous le signalons en note. Pour certains termes très courants, nous avons finalement décidé de conserver l'orthographe qui se présentait dans les inscriptions, sans corriger leur texte par rapport à une norme grammaticale qui n'était pas nécessairement celle de l'épigraphie médiévale ${ }^{114}$.

C'est ainsi que les longueurs des voyelles, pour ces mots fréquemment utilisés ici et très connus par ailleurs, ne sont pas rétablies ${ }^{115}$ : rappelons que $k o$ vaut $k \bar{o}$ ( $k o$ parakecari... 1, 1;2, $1 ; 3$, 1, etc., koyil en 5, 2, etc.), kecari, kēcari (1, 1;2, 1, etc.), mekkum, mērkkum $(1,5 ; 9,10 ; 14,16$, etc. $)$, etc. De même, le $\bar{e}$ et le $\bar{o}$ des premières personnes du singulier et du pluriel ne sont pas corrigés et ariveñ vaut arivēn (XIV, 55, 59, 66-67, etc.) comme kututtom équivaut à kuṭuttōm (IV, 4-5 ; IX, 27 ; IX, 12, etc.) et mahāsabhaiyom, à mahāsabhaiyōm (IV, 5 ; VII, 4 ; IX, 5, etc.). Les voyelles longues de termes issus du sanskrit (comme deva devenant têva en tamoul) n'étant jamais notées, elles ne sont pas indiquées. Lorsque nous proposons des restitutions, nous respectons cette graphie habituelle des inscriptions de Pullamańkai.

Rappelons que $r / \underline{r}$ devant une consonne est souvent noté par le doublement de ladite consonne, comme dans panmakku, qui se présente aussi sous la forme panmakku, toutes deux plus courantes que panmark $\bar{u}(1,1 ; 2,1 ; 3,1 \text {, etc. })^{116}$; dans mekkum qui vaut mērkum $(1,5 ; 9,11 ; 14,16$, etc.) ; dans tekkum qui vaut terkum ( 1 , $7 ; 9,15-16$, etc.) ; dans mahādevakku $(1,2 ; 2,2 ; 3,2$, etc.) qui vaut mahādēvarku, qu'on rencontre aussi. Mais notons qu'on observe aussi $r / \underline{r}$ devant un $\mathrm{k}$ doublé, comme dans le cas des datifs teñpārrkkellai (ou pārkkellai/pārkellai), melpārkkellai, vatapārkkellai, kīlpārkkellai, etc. $(15,35,38,50,53$, etc.) et devarkku (17, 10, etc.). Là encore, nous n'avons pas corrigé le très courant $r$ en $r$, qu'on rencontre aussi. On voit que le $k$ est doublé de façon quasi systématique dans le cas des finales de datif, signalant sans doute que le $-k u$ du datif est encore conçu comme une particule séparée dont le rattachement au mot précédent occasionne un samdhi. À l'inverse, on constate que le $n$ initial de l'adverbe nicatam disparaît en 2, 2.

114. Il faut souligner que les corrections impliquées finiraient aussi par rendre le texte édité peu lisible Rappelons que, comme les manuscrits, les inscriptions médiévales tamoules ne notent pas la longueur des voyelles o et e.

115. On constate ici l'incertitude où l'on est d'une norme de référence pour des textes particuliers qu'illustre le caractère parfois très hybride de la langue utilisée, mêlant sanskrit et tamoul en des termes pour lesquels il est impossible de rétablir une " orthographe ». Connaissant presque autant de graphies que d'occurrences différentes, l'adverbe signifiant « aussi longtemps que la lune et le soleil » est un bon exemple de sanskrit " tamoulisé », qu'accompagne ici des mélanges d'alphabets grantha et tamoul, du cantirätittaval de 1, 3; 3, 4 et 18,22-23 (cantirätitta[val]), à canträdiccaval de 8,3 , cantiräticcaval de 10,8-9, canträtittavar de 15,89, candiratitavat de 16,35 , candirātittaval de 18,12 , cantrādi $[t a v a] l$ de 20,4 et, enfin, cantirādittaval de 21,10 ). Le terme dérive du sanskrit candrádityavat et l'on peut supposer que la graphie flottante tente de se rapprocher d'une notation de la langue parlée.

116. On trouve toutes sortes de graphies pour ce terme, comme pannmarkku en 10, 2 . 
Certaines fautes d'orthographe sont si fréquentes qu'elles semblent constituer sinon une norme du moins une graphie habituelle, comme pakallum pour pakalum $(1,3 ; 3,4 ; 8,2 \text {, etc. })^{117}$, nonta pour nantā dans nantāvilakku $(1,3 ; 3,4 ; 8$, 3, etc.). Il semble qu'il existe une certaine confusion entre $\underline{n}$ et $n$, illustrée par le nicatam pour nicatam de 1,1 et le $\underline{n} \bar{a} n$ pour $n \bar{a} n$, de 3, 5. La consonne n'est pas toujours doublée devant une voyelle (samdhi irrégulier ?) : ainsi dans ivicenta pour ivvicainta $(1,7)$.

Dans la traduction, nous rétablissons l'orthographe conventionnelle lorsque nous utilisons les mots tamouls, notamment pour les toponymes afin de les rendre plus lisibles. Les conventions de lecture utilisées sont les suivantes :

Les lettres soulignées sont écrites en alphabet grantha.

[...] : restitution d'akșara dont on voit une trace sur la pierre, ou pour lequel il y a du moins la place nécessaire ; on a donc affaire soit à la restitution conjecturale, soit à une hypothèse de lecture.

(...) akșara fautifs ou supplémentaires; lorsque des crochets droits suivent une parenthèse, on a affaire à la correction orthographique d'un terme qui a paru trop connu par ailleurs (un terme géographique par exemple), ou impossible à reconnaître sans la correction; cependant, lorsque la correction est trop importante, elle est reportée en note pour ne pas gêner la lisibilité du texte, comme, par exemple, en 15,13 pour la séquence écrite ningrotu, que nous restituons ningr $(u) \bar{o} t u$ (où le samdhi fait disparaître le $u$ bref en finale).

[...*] : restitution d'akșara qui n'ont jamais été écrits (correction des termes);

[...] : restitution faite à partir d'un transcrit ou une publication antérieure. On ne lit plus rien aujourd'hui sur la pierre.

Dans le texte, un point . correspond à un aksara manquant, en cas de lacune.

Dans la traduction, les points qui se suivent signalent les lacunes inférieures ou égales à cinq aksara, reproduisant le système du texte selon lequel un point . représente un akșara manquant ; au-delà de cinq akșara manquants, la lacune est ainsi signalée : [lacune].

Un $\mathrm{S}$ correspond à un symbole numérique, dans le texte et la traduction.

117. Peut-être s'agit-il là encore d'un phénomène de samdhi lorsqu'on rattache -um considéré comme une particule indépendante à l'adverbe pakal. 

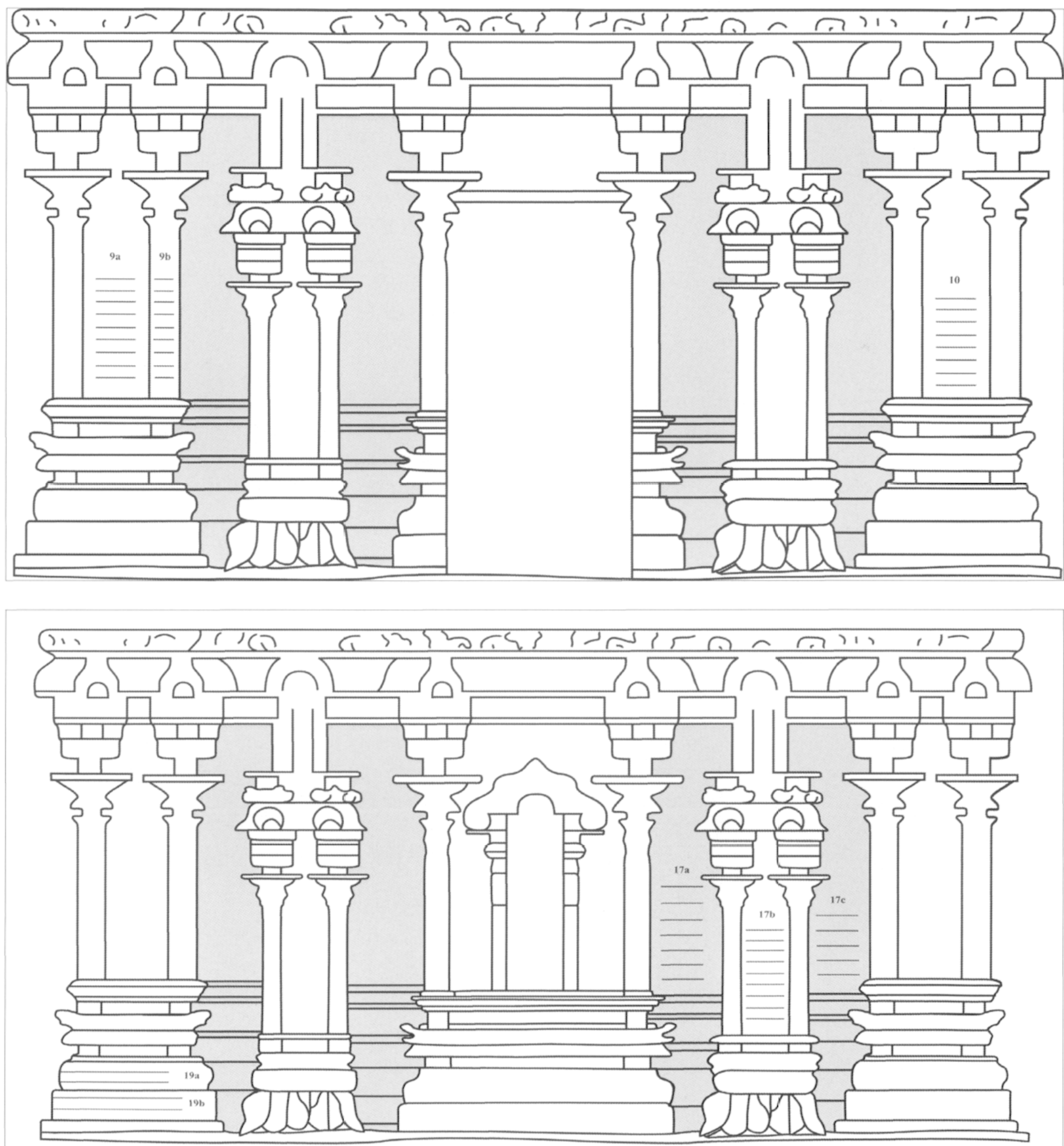

Fig. 55 : Localisation des inscriptions sur les faces est et ouest du temple. Dessin : N. RamaswamyE. Francis. 

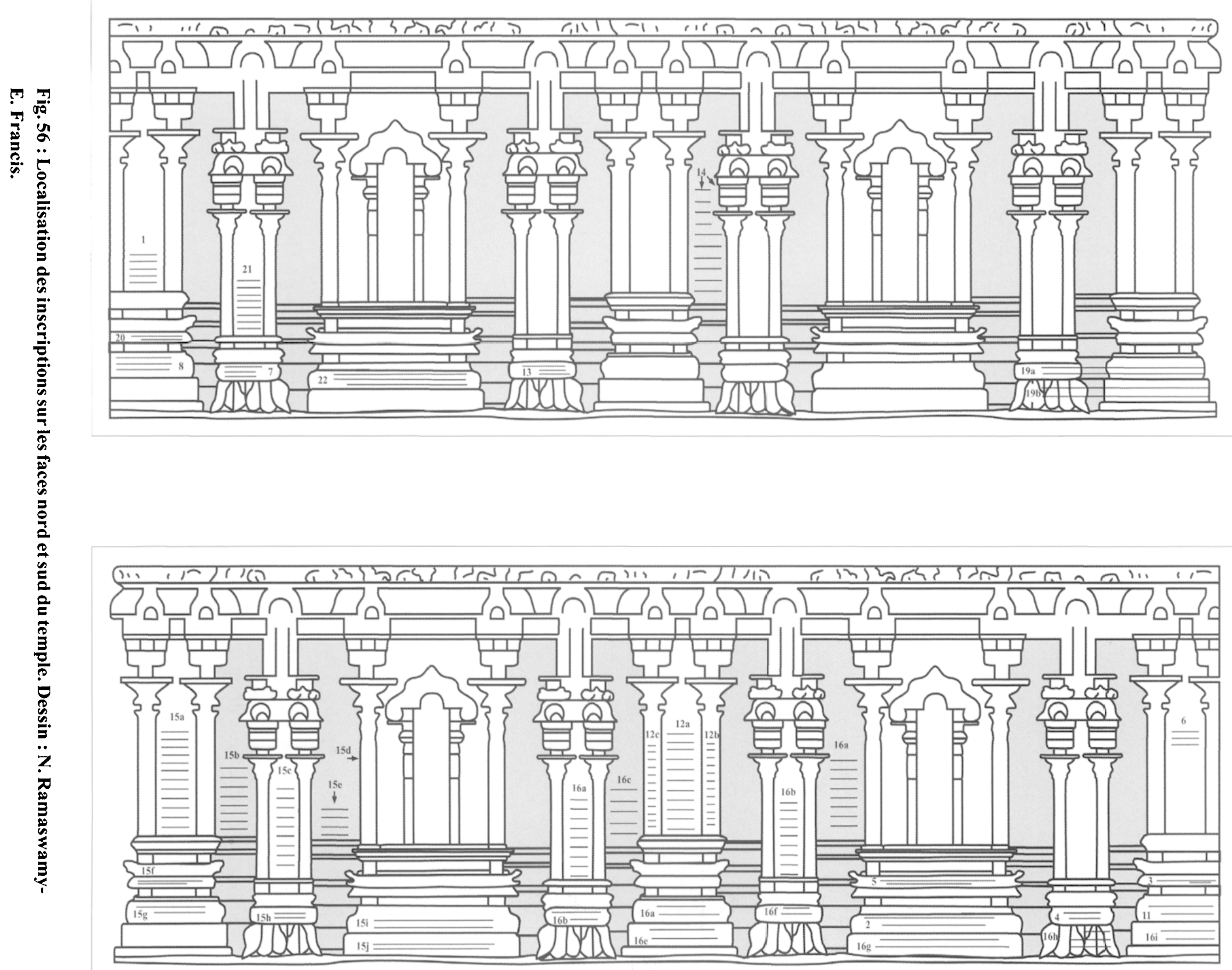


\section{CORPUS}

\section{1}

Mandapa, face nord, naissance du mur ; Parāntaka I ${ }^{\mathrm{er}}, 5,912$; AR n ${ }^{\circ}$ 546/1921 ; SII

XIX, $\mathrm{n}^{\circ} 138$; Mahalingam 1992, $\mathrm{n}^{\circ} 2298$.

\section{Texte}

1. [sva] ${ }^{118}$ sti śrī kopparakecari panmakku ${ }^{119}$ yāṇṭu añcāvatu kilāār kūrrat

2. [tu bra]hmadeyam puḷa(ñam)[mañ]kalattu tiruvālanturai mahade[var*]kku nicatam ula

3. [kke] ${ }^{120}$ ṇnaiyāl iravum pakallum oru nontāvilakku cantrādica

4. [v]al erivatāka mātalañakkancāmi ku[țu]tta nilam pañrikuli irạ̣

5. [tu] . mukkāṇikku ellai uṭciruvā[y*]kkālukku mekkum kaviciyān

6. . $\underline{n}^{121}$ an pataiyan nilattukku vatakkum tānan nilattukku kilak

7. [kum] vā[y*]kkal(l) ${ }^{122} \mathrm{uku}$ tekkum āka ivic(et)[ain]ta peru[nā]nkkellaik

$[8 . \mathrm{ku}]$

\section{Traduction}

Que la prospérité soit ! En la cinquième année de Kōpparakēcaripan̄mar, le Roi-[qui est]-lion-pour-ses-ennemis ${ }^{123}$, au grand dieu du [lieu] sacré Ālanturai à Puḷ!amañkalam, un brahmadeya de Kilāan Kūrram, pour que brûle, jour et nuit, quotidiennement, tant que durent la lune et le soleil, avec un $u l a k k u^{124} \mathrm{~d}$ 'huile, une lampe qui ne s'éteint pas, Mātalanakkancāmi a donné une terre : les limites relèvent de deux . et trois du [territoire] de statut kāni [dépendant de] Pañrikuli : à l'ouest du petit canal intérieur, au nord de la terre de Kaviciyān . nnan Pațaiyan, à l'est de la

118. Le début de cette inscription est recouvert par une construction ultérieure ; il semble qu'il manque un akara et demi environ au début de chaque ligne. Ils sont ici restitués dans les lignes 1 à 5 , ce qui n'a été fait ni dans le transcrit disponible à Mysore ni dans la publication de SII XIX.

119. Selon SII XIX, il faut lire pana[ $\left.{ }^{*} r\right] k k u$; le m sous le n est cependant bien lisible sous l'inscription.

120. Le $k$ est lisible, mais pas l'akṣara marquant le son [e].

121. SII XIX propose de restituer un $t$ à cet endroit ; mais sur la pierre, le $\underline{n}$ est net.

122. On voit que la graphie est flottante ; le même terme est orthographié de façon différente à la ligne 5 .

123. Nous conservons la graphie tamoule pour le terme kécari, et donc, également, pour - varman, transcrit panmar en tamoul. L'expression «le Roi-qui-est-lion-pour ses ennemis» traduit le titre Kōpparakēcari, dans lequel on reconnaît le sanskrit para-kesarin, le lion pour ses ennemis. Face à ses ennemis, le roi est le lion qui combat et domine. On peut aussi faire remarquer que, Kesarin étant, littéralement, le Chevelu, l'un des noms d'Agni et l'un des noms de Kṛ̣na, dont les cheveux libres représentent, toujours dans le cas d'Agni et parfois dans celui de Kṛnna, les flammes qui dévorent l'oblation sacrificielle (dont le combat guerrier peut être un équivalent), ces deux divinités ne sont peut-être pas étrangères à ce choix du titre royal.

124. L'ulakku est une mesure de contenance, toujours associée à l'huile et au beurre fondu. 
terre de Tānan, au sud du canal, telles sont les quatre grandes limites entre lesquelles elle se trouve.

2

Maṇdapa, face sud, base du temple ; Parāntaka I ${ }^{\mathrm{er}}, 6,913$; AR $\mathrm{n}^{\circ} 559 / 1921$; SII

XIX, $\mathrm{n}^{\circ} 168$; Mahalingam 1992, $\mathrm{n}^{\circ} 2299$.

\section{Texte}

1. svasti śrīi ${ }^{125}$ kopparakecaripanñmakku yāntu ārāvatu kilāar kūrnattu

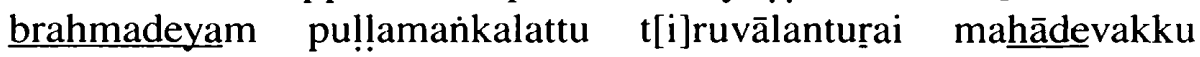
[c]e[m]piyan ma

2. gậvali vāṇarāyar ciṛu kālai santikku iru ñāli ariciyālum araippiṭi neyyamirtālum nicatamum tiru[va]mitu ${ }^{126}$ ce[y*]vatar(ru)[ku] vilaikku e ... kututta

3. nilam śrīkanțamañkalattu pūrati iran[tu] varavaiyum ${ }^{127}$ uḷppata ānaraikāl ${ }^{128}$ iva[n canti]puramāka vilaik(a)[u][kuṭut*]ta nilam

4. nalūr ceri kilur [sa]ma

\section{Traduction}

Que la prospérité soit ! En la sixième année de Kōpparakēcaripanmar, le Roi[qui est]-lion-pour-ses-ennemis, Cempiyan Magāvali Vānarāyar a donné au grand dieu du [lieu] sacré Ālanturai à Pullamañkalam, un brahmadeya de Kị̄ār Kūrram, une terre ... [pour laquelle il a versé un] prix, pour qu'elle produise une nourriture sacrée quotidienne [consistant en] deux nāli de riz et une demi-poignée de ghē [à offrir] au service du petit matin : [il s'agit de] ānaraikkāl ${ }^{129}$, se trouvant inclus dans deux varavai compris dans ${ }^{130}$ le saint village de Kantamańkalam; la terre [pour laquelle il a versé un] prix, pour le service qui a lieu au petit matin se trouve à Nallūr Cēri Kīlūr.

125. La graphie de cette inscription est particulière : la forme de «tu » dans kurrattu de la première ligne est inhabituelle ; à la ligne 2, on ne reconnaît pas vraiment le g grantha qui est utilisé et on lit ru lorsque ce devrait être $k u$ dans la séquence vatarku. Peut-être le scribe n'était-il pas très habile.

126. Les aksara correspondant à vami ne sont plus visibles sur la pierre; nous reprenons la lecture de SII XIX.

127. L'éditeur de SII XIX lit varajaiyum, qui ne fait pas sens.

128. Après ce terme, l'inscription est gravée moins profondément et se présente sous un aspect différent : il est possible que ce qui suit, qui fait difficilement sens et dont l'écriture est maladroite, ait été ajouté ultérieurement.

129. Le terme ānaraikkāl, qui semble au pluriel et dans lequel on est tenté de reconnaitre arai, un demi, correspond à une unité de mesure de la terre, qu'on ne connaît pas exactement. De même le terme varavai, autre unité de mesure de terre, n'est pas traduit parce qu'on ignore à quoi il correspond.

130. Le terme purati est peu clair dans ce contexte; nous faisons l'hypothèse d'une relation géographique entre Kaṇtamańkalam et la terre dont il est question. 
3

Mandapa, face sud, base du temple ; Parāntaka Ir, 8, 915 ; Varaläru vol. III, $\mathrm{n}^{\circ} 9.1$.

\section{Texte}

1. [sva]sti [śrī] ko[ppa]rakecari panmakku ${ }^{131}$ yāṇtu 8 . [āvat]u va . va ${ }^{132}$ ki[1]]ār kūrrat [tu] $]^{133}$

2. brahmadeya pullamańkalattu tiruvāla[nturai ma]hādeva[kku]

3. cāvāñti [cu]varan ${ }^{134}$ tatta nnicatam ulakku eṇnaiyāl [iravu]

4. m pakallum oru nontā vilakku cantrā[ti]ttaval eriva[tāka]

5. kuṭuttanilam śrī kaṇtamańkalat[tu] ālaicce[y] ñān [mā]

\section{Traduction}

Que la prospérité soit! Dans la huitième année de Kōpparakēcaripanmar, le Roi[qui est]-lion-pour-ses-ennemis, . ainsi . . . au grand dieu du [lieu] sacré Āla[nturai] de Puḷamankalam, un brahmadeya de Kilāar Kūrram, pour que brûle, tant que durent la lune et le soleil, jour et nuit, quotidiennement, avec un ulakku d'huile, une lampe qui ne s'éteint pas, Cavānnti Cuvaran Tattan a donné une terre : elle fait quatre $m \bar{a}$ de [statut] älaiccey du [territoire dépendant du lieu] sacré Kaṇtamañkalam.

\section{4}

Maṇdapa, face sud, base du temple ; Parāntaka I I ${ }^{\mathrm{er}}, 11 / 31,918 ; \mathrm{n}^{\mathrm{c}}$ 558/1921 ; Mahalingam 1992, n 2284.

\section{Texte}

1. svasti śrī matiraikoṇta kopparakecari panmakku yāṇṭu 11/31 135 āvatu kilāan kūrrat

2. tup piramateyam puḷamankkalattu tiruvālañturai mahādevakku ivvūr ma [hā sa]

3. bhaiyār kuṭutta nilam śrīkaṇtaman̉kalattu kilāâil tị̣alin tēnnmelai kulac

4. ceyyāña ellaikk(ā) [u] cey tiruvālanturai mahādevakku ațtikku

5. țutto[m] mahāsabhai[yom] ${ }^{136} \mathrm{i}[\mathrm{tu}]$ tiruvikoka vikkumāka /tilli . lko ${ }^{137}$

131. L'édition de Varalāru commence ici.

132. Les deux aksara va sont clairement lisibles, mais pas ce qui les entoure ; ils ne font pas sens. Les espaces sur la pierre indiquent qu'il ne peut s'agir dans aucun des deux cas du « va » de āvatu.

133. L'extrémité droite de l'inscription est aujourd'hui éclaboussée de ciment. L'équipe a dégagé certaines de ces éclaboussures mais nous devons compléter la lecture de la fin des lignes, entre grands crochets droits, avec le texte édité dans Varalāru (III, 1994 : 23), qui propose également, entre crochets, le terme âvatu, à la première ligne de cette inscription.

134. L'édition de Varalānu donne « vănatattan » comme nom de donateur ; mais la lecture est claire.

135. Il ne nous paraît pas possible de lire avec certitude la date. L'édition précédente donne 11 , mais il nous semble bien qu'il s'agit de 31 .

136. La fin de la première période d'existence de l'inscription se situe sans doute là : ce n'est pas la même main qui écrivit les lettres après ce mot et les termes qui suivent ne font pas sens.

137. La ligne s'achève par des mots gravés les uns au-dessus des autres. 


\section{Traduction}

Que la prospérité soit ! En la onzième/trente-et-unième année de Kōpparakēcaripanmar, le Roi-[qui est]-lion-pour-ses-ennemis, lui qui prit Madurai, les membres de la grande assemblée de ce village, au grand dieu du [lieu] sacré d'Ālanturai de Puḷamañkalam, un brahmadeya de Kị̄ār Kūrram, ont donné une terre : d'un cey, [la terre] que nous, la grande assemblée, avons consacrée au grand dieu du [lieu] sacré d'Ālanturai [se situe] quant au bornage de ce cey, du réservoir, au sud-ouest de l'espace ouvert [dit] Kilāār ${ }^{138}$ du saint Kaṇtamańkalam [...].

\section{5}

Maṇ̣apa, face sud, base du temple ; Parāntaka I'r $, 11,918^{139}$; Varalāru vol. II, $\mathbf{n}^{\circ}$ 16.2.

\section{Texte}

1. svasti śrī matirai koṇta koppara[ke]cari panmakku yān

2. tu 11 ãvatu tiruvi[lañ] ${ }^{140}$ koyil kanapperumakkal

3. tānkal eluntaruḷvitta kūtta [pe]rumālukku ti

4. ruvamirtukku sabhāyārițai [v]ilaikku konṭu tanta

5. nilam śrī kaṇṭama[n]]ka[la]ttu kil̄ārin teñva . . māvarai

\section{Traduction}

Que la prospérité soit ! En la onzième année de Kōpparakecaripañmar, le roi-[qui est]-lion-pour-ses-ennemis, lui qui prit Madurai, la terre donnée une fois achetée à l'assemblée ${ }^{141}$, pour une [offrande] de nourriture sacrée au grand dieu qui danse, qu'ont fait la grâce d'installer ceux qui sont un groupe des notables du temple provisoire $^{142}$ fait . . māa et un demi, au sud de Kil̄ār du saint Kaṇtamañkalam.

\section{6}

Mandapa, face sud, en haut du mur; Parāntaka I ${ }^{\mathrm{er}}, 18,925$; $A R \mathrm{n}^{\circ}$ 555/1921 ; ni l'estampage, ni le transcrit ne sont plus disponibles à Mysore. L'inscription est publiée dans The Early Chọlas-History, Art and Culture, S. Swaminathan, Sharada Publishing House, Delhi 1998 : 223 ; Mahalingam 1992, n² 2287 ; fig. 44.

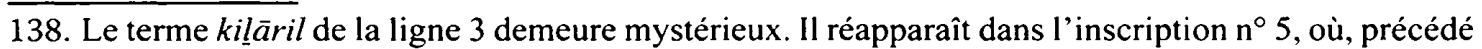
de même par le toponyme śrí kanțamankalam et suivi de ten, il ne peut renvoyer à une position à l'est. Dans ces deux inscriptions, nous l'avons interprété comme un simple toponyme, Kilār. Un toponyme Kilāar apparaît dans la composition de Kilāan Kurram, une unité territoriale qui revient à plusieurs reprises dans le corpus.

139. L'édition de Varaläru donne le chiffre 16 mais le 11 est très clair.

140. La restitution proposée s'appuie sur la séquence tiruvilankoyil de l'inscription 16 (ligne 8).

141. Il s’agit sans doute de l'assemblée de Puḷamañkalam.

142. L'expression " temple provisoire " traduit ilankoyil ; mais il est aussi possible que ce terme soit un toponyme, et qu'il faille comprendre : « un groupe des notables d'Ilańkōyil ». Le terme ne porte pas de marque de cas et on peut aussi le considérer comme un locatif se rapportant à l'installation de l'image : le groupe des notables a fait installer le grand dieu qui danse dans le temple provisoire. 


\section{Texte}

1. svasti śrī matirai koṇta kopparakesa

2. ri panmarki yāṇtu 18 āvatu para

3. keșari panm(m)ar kilāar kūrrattu pirama

4. teyam puḷamańkalattu tiruvā

5. lanturai mahādevakku kuți nikkiya

6. tevatānam ākak kuṭutta nilam vața

7. karai miraik kūrrattut tāvāman vāṭa

8. kkai nilam 3282 aiñcey kāle arai

9. mā araik kāniyālum nellu 500

10. aiñnūrruk kalam pon $5 \mathrm{~S}^{143}$ ainkala

11. ñcum

\section{Traduction}

Que la prospérité soit ! En la $18^{\mathrm{e}}$ année de Kōpparakēcaripanmar, le Roi-[qui est]lion-pour-ses-ennemis, lui qui prit Madurai, au grand dieu du [lieu] sacré Ālanturai, de Puḷamañkalam un brahmadeya de Kilāar Kūrram, Lui [qui est]-lion-pour-sesennemis donna une terre, ses métaiyers expulsés, en tant que devadāna: sur la rive nord [de la Kāvēri], la terre du district Tāvāman de Mirai Kūrram, [qui est de ] 3282 cey et demi, un kāla (un quart), un demi-mā, un demi-kāni [produisant par an] 500 kalam de riz, le tout [d'une valeur de] 5 kalañcu d'or.

\section{7}

Manclapa, face nord, base du temple ; Parāntaka I I, $2 \mathrm{~S}^{144}$; $A R \mathrm{n}^{\circ} 551 / 1921$; SII

XIX, $\mathrm{n}^{\circ} 188$; Mahalingam 1992, $\mathrm{n}^{\circ} 2300$.

\section{Texte}

1. svasti śrī kopparakecari parmakku yā[n.]tu [irupa āva] tu tiru

2. vālañturai mahādevakku āritan ma[a]ranāāāyaṇan tiruvilak

3. kku atṭina nilam panañce[y] oru māvarai kalam connra[rai*] pon pul

4. lamankkalattu mahāsabhaiyom koṇtu itt(u)[a] $\left\lfloor r^{*}\right\rfloor k a ̄ k a$ d[e*]vakku

5. țutta nilam pañrikkuḷi cenaikulattin vațavā[y] orumāva[r]ai

\section{Traduction}

Que la prospérité soit ! En la $2 \mathrm{~S}^{\mathrm{e}}$ année de Kōpparakēcaripanmar, le Roi-[qui est]-lion-pour-ses-ennemis, au grand dieu du [lieu] sacré d'Ālanturaiai, Āritan Māran Nārāyaṇan a consacré une terre pour une lampe sacrée ; la terre donnée à ce dieu

143. Un aksara illisible, peut-être un chiffre ; le nombre est ensuite écrit en lettres.

144. Dans le rapport publié, la date donnée est 7 ; mais on lit clairement un 2 et un chiffre indiquant les dizaines, suivis d'un autre aksara, que nous n'arrivons pas à déchiffrer. La date est donc comprise entre 20 et 29. 
important ${ }^{145}$, une fois qu'un kalañcu et demi d'or nous a été donné, à nous qui sommes la grande assemblée de Pullamankalam, [fait] un $m \bar{a}$ et demi [de la terre] de Panancey, au nord de Cenaikulam, dans Pañikkuli.

\section{8}

Mandapa, face nord, base du temple ; Parāntaka I'r ?, 31, $938^{146}$; première édition.

\section{Texte}

1. . . . . pa[ñ]makku ${ }^{147}$ yāṇtu muppattonnrāvatu kilāāk kūrֵrattu brahmadeyam pu-

2. [!̣lamañkalattu tiruvālan]turai mahādevak[ku] varākkiyan ilan mātavan irāmatevapaț̣anani. . .

3. [o]ru nontāvilakku iravum pakallum cantrādiccaval eriva[tāka] .

4. [nal]lurceri tennnūr kuppankkātṭu vākkāñkarai mūṇru mā

\section{Traduction}

En l'an 31 de [lacune], au grand dieu du lieu sacré d' [Ālan]turai de Pu[!llamańkalam], un brahmadeya de Kil̄ār Kūrram, Varākiyan Ilan Mātavan Irāmatēvapațanani ... [a voué] pour faire brûler une lampe qui ne s'éteint jamais, jour et nuit, tant que durent la lune et le soleil, ... trois $m \bar{a}$ [sur] la rive du canal de Kupañkam, à Tennnūr de [Nal]lūrcēri.

\section{9}

Maṇ̂apa, face est, à gauche de l'entrée du temple ; Parāntaka I'r, 39, 946 ; première édition.

\section{Texte}

1. svasti śrī matiraikonta

2. [ko]parakesari panmakka

3. yānțu 39 āvatu kil

4. ār kūrrattu pul!̣[ma]ńka[la*]t

5. [tu] mahāsabhaiyom

6. nānkal virrukkuṭutta ni

7. lam . . āppāl śrī nā

8. ranamańkalattu kāl ce

9. . . ellai kilāril ti

$10 . .$. kku mekkum itti

11. . . . . . . vāna

$12 . \ldots \ldots .1 \ldots$

145. C'est le terme itturku que nous avons traduit par un démonstratif et un adjectif, en l'interprétant comme un ittärku mal orthographié.

146. Le chiffre élevé de l'année de règne et la localisation de l'inscription, sur le soubassement du temple, inclinent à penser qu'il s'agit d'une inscription datée dans le règne de Parāntaka I Ir.

147. La partie gauche des deux premières lignes de l'inscription sont recouvertes par des constructions ultérieures. Il manque six ou sept aksara. 


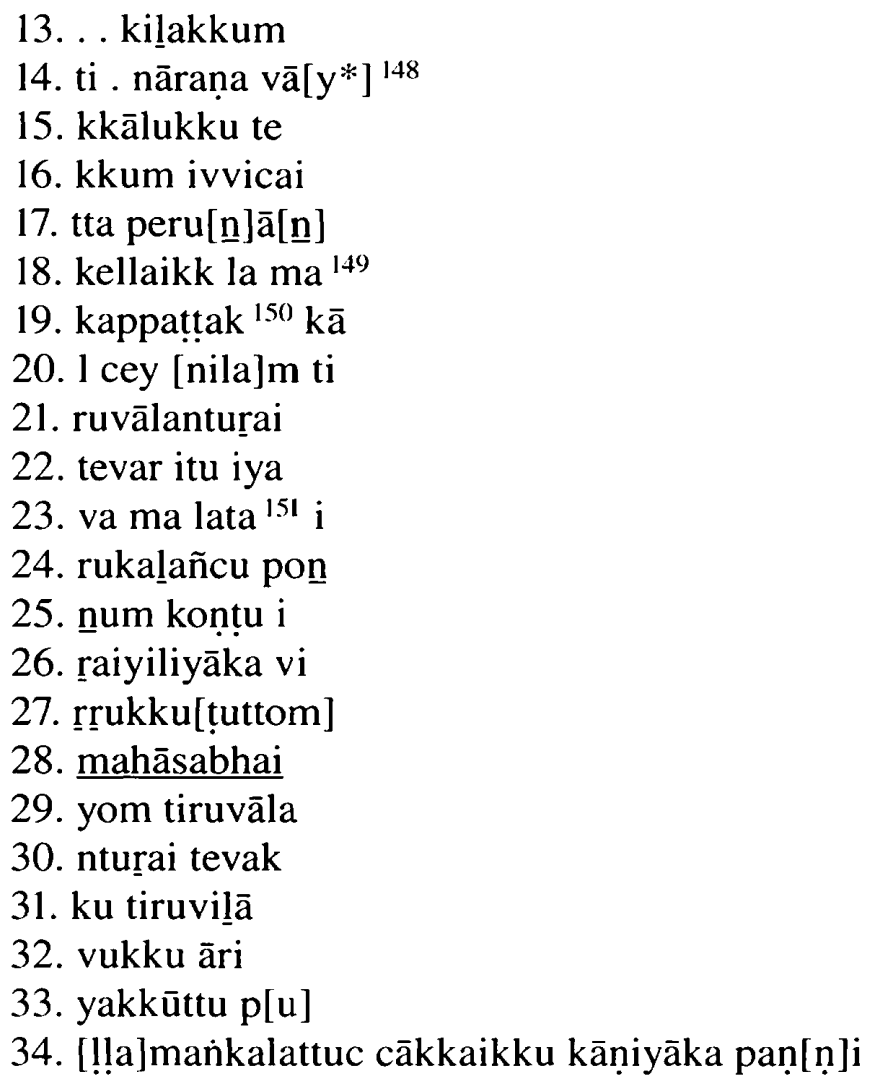

\section{Traduction}

Que la prospérité soit ! En la $39^{\mathrm{e}}$ année de Kōpparakecaripanmar, le Roi-[qui est]-lion-pour-ses-ennemis, lui qui prit Madurai, nous la grande assemblée de Puḷamañkalam de Kilāar Kūrram, nous avons donné une terre [qui était] à vendre : la terre [est constituée] d'un quart de cey du saint Naranamańkalam [qui se trouve] du côté de . .; [ce] quart de cey se trouve à l'intérieur de ces quatre grandes limites : [de $l a$ d'un $m a]^{152}$ les frontières passent à l'ouest de Ti . . à Kilāâr, et à l'est de [lacune] vāna [lacune] itti, et au sud du canal de Ti . nāraṇa ; voilà ce qui appartient au dieu du lieu sacré Ālanturai ; les iya va ma lata [de terre] ${ }^{153}$, avec deux kalañcu d'or, nous les membres de la grande assemblée [les] avons donnés une fois vendus, exempts de taxes, pour l'acteur de Pul! amanikalam responsable de la performance d'āriyakkuttu, dédiée au dieu du lieu sacré d'Ālanturai ; [la terre] est de statut kāṇi, Paṇni...

148. Nous rétablissons une syllabe ay pour la compréhension du terme, mais il faut remarquer que le terme qui apparaît en 1, 5 et 7 ne la comporte pas non plus.

149. La fin de la ligne est peu lisible ; des aksara se chevauchent.

150. Nous lisons makutpatta (un $a$ fautif à remplacer par un $u$ et un $t$ à suppléer antre le $u$ et le premier $p$ ).

151. Ces aksara qui ne font pas sens notent sans doute des mesures de terre.

152. Nous ne comprenons pas bien ce passage. Il semble s'agir de mesures.

153. Voir la note précédente. 
10

Mandapa, face est. sur le mur à droite de l'entrée ; Parāntaka I ${ }^{\mathrm{er}}, 39,946$ : Varalārạ

vol. II, $\mathrm{n}^{\circ} 16.1$.

\section{Texte}

1. svasti śrī matirai koṇta

2. kopparakecari pannmarkku

3. yāṇtu 39 āvatu piramate

4. yam pullamankalattu

5. mahasabhaiyom enkal

6. mañ ța]kapurattu ettu mā

7. ce[y*] pullamańkalattu tiruvāla

8. ' nturai mahādevakku cantirāticcava

9. 1 ira[v]um pakallum erivatā

10. ka nicatam uriy eṇnaiyāl

11. iraṇtu nontā viḷakku(kku)

12. kututtom mahasabhaiyo

13. $\mathrm{m}$ iv(v)ai panmāheśvara ra

14. kṣai

\section{Traduction}

Que la prospérité soit ! En la $39^{\mathfrak{e}}$ année de Kōpparakēcaripanmar, le Roi-[qui est]-lion-pour-ses-ennemis, lui qui prit Madurai, nous les membres de la grande assemblée de Puḷamankalam, un brahmadeya, huit $m \bar{a}$ de Maṇtakapuram ${ }^{154}$, au grand dieu du lieu sacré Tiruvālanturai, pour faire brûler jour et nuit, tant que durent la lune et le soleil, sans interruption, avec de l'huile, deux lampes qui ne s'éteignent pas, c'est nous les membres de la grande assemblée qui les avons donnés; cette [injonction] est protégée par les Panmāheśvara.

\section{1}

Maṇdapa, face sud, base du temple ; Parantaka $\mathrm{I}^{\mathrm{Er}}, 3 \mathrm{~S}^{155}$; première édition.

\section{Texte}

1. svastiśrī tiruvā[la*]ñurai mahādeva utai .

2. vum śrī parakeșari [pañ*] makku yāntu mupp

3. arula tiruvālantu[r] ai [ma]hādevark[ku]

4. ic ceyo[taica] ...

5. tiruvamirtu[ku] .......m .

6. lum karu yamā tu kumm. . . [u] ${ }^{156}$

154. Dans cette traduction, «mantakapuram » est considéré comme un toponyme ; mais il pourrait aussi s'agir d'un terme technique désignant les terres dont le revenu permet d'entretenir le mandapa.

155. Il est impossible de lire avec certitude le chiffre dénotant les unités. L'inscription est donc comprise entre la $31^{\mathrm{c}}$ et la $39^{\mathrm{e}}$ année du règne.

156. Cet $u$ est initial. Cette dernière ligne est trop lacunaire pour tenter une traduction. 


\section{Traduction}

Que la prospérité soit ! Au grand dieu d'Alanturai, dans la $3 \mathrm{~S}^{\mathrm{e}}$ année de Kōpparakēcaripanmar, le Roi-[qui est]-lion-pour-ses-ennemis, pour le gracieux (?) ${ }^{157}$ grand dieu d'Ālanturai ; pour une offrande de nourriture sacrée [lacune] ${ }^{158}$.

\section{2}

Prāsāda, face sud, au centre d'une niche sans images, puis sur les pilastres de celle-ci ; Āditya II, 5, 969 ; Mahalingam 1992, nº 2288.

(L'enregistrement de cette inscription est problématique. Elle fait peut-être l'objet du rapport 556/1921 mais qui aurait confondu une partie de son contenu avec le $n^{\circ}$ 554/1921 : le rapport 556/1921 évoque une donation de 72 moutons, qui n'apparaît nulle part ici mais qu'on trouve dans le rapport 554/1921 (qui correspond dans notre corpus à l'inscription 18). Le texte du transcrit 556/1921 n'est pas disponible et il est donc impossible de procéder à la vérification de cette hypothèse. T. V. Mahalingam reprend en tout cas ce rapport en indiquant une inscription rapportant un don de 72 moutons pour faire brûler trois-quarts de lampe ; fig. 51.)

Texte

1. pāṇtiyanai talai

2. konța koppara

3. kesari panmarku yā

4. nțu 5 àvatu tiruvālan

5. turai tirumanimantapattu ${ }^{159}$

6. svasti śrī kālāpitārikku tiru

7. amitukku ... . olocca

8. nānuūṛ[ru]van nān̄ūrrúu

9. van ūrkilāan kalaiyan

10. oloccan kātan̄ān̄ūrruvan

157. C'est le terme arula qui est traduit par l'adjectif gracieux ; mais il ne s'agit que d'un essai de traduction, le terme ne faisant pas vraiment sens ici.

158. À la suite de cette lacune viennent des termes qui ne font pas sens ; peut-être encore des termes de mesure car on remarque un $m \bar{a}$ parmi eux.

159. Les cinq premières lignes de cette inscription présentent une discontinuité avec la partie débutant à la ligne 6. L'écriture en est différente; à la ligne 6, les lettres sont grandes et bien formées, tandis que celles des lignes 1 à 5 sont bien plus petites et serrées. La ligne 6 commence par un svasti śrí qui ne se trouve pas à la ligne 1 .

Plusieurs hypothèses peuvent être formulées. La forme des lettres étant finalement la même dans ces deux parties de l'inscription, il est possible que les lignes 1 à 5 constituent un morceau ajouté après avoir inscrit les lignes 6 à 76. L'ajout aurait été motivé par le manque de certains renseignements indispensables, dont la date. La mention du tirumanimandapa qui apparaît dans l'inscription 14 rapportant une donation faite à la déesse met en relation ces deux inscriptions. Peut-être les lignes 1 à 5 de cette inscription 12 ont-elles été écrites après la gravure de l'inscription 14.

Les noms propres dont cette inscription est, pour l'essentiel, composée, ne sont pas faciles à distinguer : il n'est pas possible de décider avec certitude si une nasale constitue une fin de mot ou une simple consonne intérieure. 

11. kulakani ${ }^{160}$ rāyamallan
12. kūttāli kâțan cāttankuțti
13. nākarāyan muttān̄ānan ac
14. cān vāṇapperaiyan
15. arańkan comatitattan
16. mārañat tattan mallaiyan
17. murukkan collairri co
18. llairrri kuruntan tāyan
19. . rutan kariyānicakkațikan
20. tokan perumāti kātanto

21. kan pūtakkuṭaiyān kantan

22. vańkați kūttan kaṇnańko

23. yil ${ }^{161}$ nampan kecuvan nakka

24. nāāyiravan nakkan cellūran

25. kecuvan cataiyan pāṇtan

26. koyil nāraṇanāāccan vaikunt

27. taniñcan vikkiraman kariyān śrī

28. dharan cakaran kecuvanākan ka

29. ntayan arañkan kilavan śrī

30. mātavan kumāratevan tattan ilai

31. yānīlakaṇtan vaikunta nakkan

32. accaran kạtan tirunāṇan mutti

33. āliyān centan ūran kecuvan

(Sur le pilastre, à gauche de la niche)

34. malappāti na

35. kka[n] kāma

36. $\underline{n}$ kecuvan

37. madhyastan

38. orriyuüran

39. keśavan

40. madhyastan

41. kāri tiruve

42. nkkātța

43. tika!

44. tāyan

45. nakkan

46. tāyanam

47. pannārā

48. yan kārāyi

49. l cāttakut

50. ți eluvāti

51. yān comatị

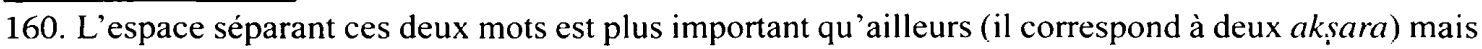
ne semble pas avoir été gravé.

161. On remarque un pulli au-dessus du $l$ final. 
52. perumān

(Sur le côté gauche du pilastre, à la perpendiculaire de l'emplacement précédent)

53. cen[ta]n

54. kāḷ vațu

55. kan pā

56.

57. kãman cāttan

58. tatta nārana

59. $\underline{\mathrm{n}}$

(Sur le pilastre à droite de la niche)

60. kūttāḷi

61. anayattan

62. kecuvanā

63. ccan kan

64. nan pirā

65. ntakan ci

66. lavānāāc

67. can tamma

68. ti arankan

69. kunaccirai

70. ańki ēn̄à

71. ti pāṇtan

72. kumanākati

73. kańkutaiyān

74. cūrri kumāra

75. tevan cāt

76. ta kutti

\section{Traduction}

Dans la $5^{\mathrm{e}}$ année de Kōpparakēcaripannmar, le Roi-[qui est]-lion-pour-sesennemis, lui qui prit le chef des Pāntiya, dans le maṇdapa beau et sacré du [lieu] sacré Ālanturai, que la prospérité soit, à Śrī Kālāpitạāi, pour une offrande de nourriture sacrée... ${ }^{162}$.

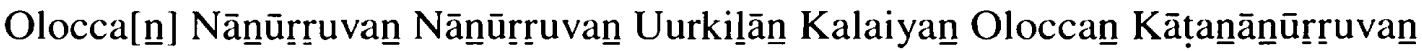
Kulakanirāyamallan Kūttāli Kạțan Cāttankuț̣i Nākarāyan Muttānāṇan Acānn Vānapperaiyan Arañkan Comattattan Māran Tattanmallaiyan Murukkan Collairrni Co llairrri Kuruntan Tāyan Ātan Kariyānicakkatikan Tokan Perumātikātan Tokan Pūtakkutaiyān Tanțan Vin̉kati Kūttan Kaṇnañkōyil Nampan Kecuvan Nakkanāāyiravan Nakkan Cellūran Kecuvan Caṭaiyan Pạṇtan Kōyil Nāraṇanāâccan Vaikunttaniñcan Vikkiraman Kariyān Śrīdharan Cakaran Kecuvanāanan Kaṇtayan Arañkan Kilavan Śrīmātavan Kumāratevan Tattanillai Yānīlakaṇtan Vaikunta Nakkan Accaran Kātan Tirunāṇan Mutti Āliyān Cēntan Üran Kecuvan Malappāṭi Nakka[ñ] Kāmañ Kecuvan

162. On peut aussi traduire, «à la Kālāpitāari du beau mandapa... », etc ; les noms propres qui suivent sont découpés le moins arbitrairement possible. Mais d'autres découpages auraient souvent pu être choisis. 
Madhyastan Orriyūran Keśavan Madhyastan Kāri Tiruveṇkāttatikal Tāyan Nakkan Tāyanam Pan Nārāyan Kārāyil Cāttakuțti Elıuvātiyān Comaṭi Perumāñ Centan Kāḷi Vatukan Pā [lacune] Kaman Cāttan Tattanāraṇan Kūttāli Aṇadhattan Kecuvanāccan Kạ̣ṇan Pirāntakan Cīlavān̄āccan Tammaṭi Arañkan Kuṇaccirai Añki Ēnāti Pāṇtann Kumanāākați Kañkuṭaiyān Cūrni Kumaratevan Cāttakuț̣i.

\section{3}

Maṇdapa, face nord, base du mur; Cuntara Cōla, dit Parāntaka II ; $A R$ $\mathrm{n}^{\circ}$ 548/1921; SII XIII, n 257 ; Mahalingam 1992, n 2289.

\section{Texte ${ }^{163}$}

1. koirācakecaripañmarkku yāṇtu 15 ā[vatu] tiruvāla[n]

2. turai maha[ade] varkku vīraśikhāmani-p-pa[. . . . . .]ya[r] $]^{164}$ vai $[\mathrm{t}]$ ta no

3. ntā vilakkin̄āl cāvā mūvā perāțu [ni]catam u[ḷak]ku neyyāl

4. erivatāka kuṭutta ātu 90

\section{Traduction}

En la quinzic̀me annćc de Kōpparakēcaripanmar, le Roi-[qui est]-lion-pour-sesennemis, au grand dieu du [lieu] sacré Ālanturai, Vīraśikhāmanippa[ḷuvēttarai]yar a donné des moutons, qui ne vieillissent et ne meurent jamais, pour faire brûler quotidiennement une lampe qui ne s'éteint jamais : 90 moutons.

\section{4}

Mandapa et prāsāda, face nord, mur ; Uttama Cola, 2+1, 973 ; AR n ${ }^{\circ} 549 / 1921$; SII XIX, n 63 ; Mahalingam 1992, $\mathrm{n}^{\circ} 2297$.

\section{Texte}

1. svasti śrī kopparakecaripanma

2. r̂ki yāṇtu 2 āvatin etirāmā

3. ntu kilāâr kūrrattu brahmadeya

4. m puḷ!amańkalattu mahāsabhai

5. yom ivvāṇtu minanāyarru

6. c cevvāykkilamai perra avi[țta]

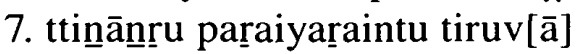

8. lan[turai] mu[ñpil] vācal mā[ța]

9. tte kūtiy iruntu sabhaiyom

10. [vi] rrrukkuțutta nilam v[i]lai[yā]

11. vaṇam ivvūr națuvirceri tiruma

163. Cette inscription est particulièrement mal gravée. Elle ne comporte pas de svasti śrī et sa syntaxe est désordonnée (par exemple, emploi de l'instrumental pour désigner l'objet du verbe brûler, objet de la donation en quelque sorte) : un manque de soin particulier se remarque ici.

164. SII XIII propose de restituer pa[lla]va[rai]yar; la proposition faite dans la traduction s'appuie sur le lien, attesté sur le site de Ciruppaḷuvūr, entre les Paluvēṭtaraiyar et le dieu d’Ālanturaia. On ne lit plus un aksara va que semble lire l'éditeur de SII XIII. 
12. [ṇi] maṇtakamuṭaiya kaḷā pițār[ikku] nā

13. ṅkal virrukkuṭtta nilam āvatu ivvū

14. rppāl brahmadeyam śrī kaṇtamañkala

15. ttu nānkal virrra nila[ttu]kku[k kīl]pāanke

16. llai vațukan vāykku mekkum kaṇnāanru

17. kku vațakkum āritan kecuvan pa[r]

18. nilattukku kil lakkum [pārtti]van panpanā

19. m nilattukkum kāpiyan co[t]tan mā

20. tevanilattukku terk $[\mathrm{k}] \mathrm{u} \ldots \ldots \ldots$. .

21. immuñu māvil ivvūr madhyasta

22. [tiruven] katțatikalāna 754 vanu

23. m tampimārum kāvitikkāṇiyal pirantutai

24. ya immuñu māvile $S$ S ceyyum ip

25. pițāriyārkku virrru kuṭutta paricāvatu i

26. v velunūrrrr[aim]pattu nālvan itan mun

27. nai . . . ivvūrkkaṇakkuc ceyvān . . . cu[n]

28. tara co[l]a muttai]rayārān pirā[nta]muttarai[yar*]kku

29. . . r rrukkala nellu ivvūr mela

30. tuttuvar[um ñ]ellil āyiratirunurra

(Sur la paroi perpendiculaire, à droite)

31. mpatin kala nellukku sabhai

32. yom panittuk kututta va

33. raiyum marrum ūril veḷ̣ā

34. laraiyum brāhmanaraiyun

35. kkātṭi iṭvicca kācum paya

36. rum ippayarum nellum

37. kācum mutale cilavu kāttu

38. kaveñru tannai alai[p]pittu

39. c cellakkātṭa tān vantu ka

40. nakkuk kātțāvițta kurrattā

41. lum tampimārmun ñingru

42. paṇi ceyya vițta kurrattā

43. lum tańkal 34 cceyyum

44. 25 iḷalakkācukku kị̄um iraiyi

45. li ātanmeyal melum irai

46. yili āka virru-k-kututtom ma

47. hāsabhaiyom innila

48. ttukku ituve ${ }^{165}$ āvanamum

49. porul māvaritip poruḷ cila

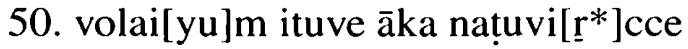

51. rik kanattāritai ivvirupattañcu

52. kācun koṇtu iv vorumā

53. varaic ceyyum virrukku

165. Le terme comporterait en tamoul classique un $\bar{e}$; de même à la ligne 50 . 
54. [ṭu]ttom bhi/āa ${ }^{166}$ tāariyārkku mahāsabhai

55. yom paṇiyāl madhyastan akka

56. [n]tāyañāna 700 vaneluttu

57. ippați yariviven kālāyan

58. vatakan tāyanen ippați ya

59. riven āritan patmanābhan ma

60. naranan ..........

61. ippati a

62. riven vā

63. kkiyan pā

64. nțan ke

65. cuvanen

66. ippati ya

67. riven $\mathrm{k} \overline{\mathrm{a}}$

68. ppiyan

69. cottan

70. comanen

71. ippati a

72. riven cāva

73. anti nārāya

74. ṇan māra

75. nen ip

76. pati arive

77. ㅁ cāvān

78. ti bhattan śrī

79. dharan tat

80. tanen

\section{Traduction}

Que vive la Prospérité !

Dans l'année qui suivit la deuxième année de Kōpparakēcaripanmar le Roi[qui est]-lion-pour-ses-ennemis, nous la grande assemblée de Pullamankkalam, un brahmadeya de Kilāar Kūrram, cette année-là, dans le mois du poisson, un mardi, alors que s'était levée [l'étoile] Aviț̣am, après avoir fait battre les tambours, une fois réunie l'assemblée que nous sommes dans le hall de la porte devant [le temple] de Tiruvālanturai, nous avons donné une terre après l'avoir vendue ; [voici] l'acte de vente de la terre que nous avons donnée après sa vente à Kạāpitāini, maîtresse du sacré et beau maṇdapa, à Națuvirccēri dans ce village, voici ce qu'il en est de [cette terre] : la terre que nous avons vendue [est une] terre de Śrī Kanțamańkalam, un brahmadeya voisin de ce village de [Pullamankalam]; en voici les quatre frontières : à l'ouest du canal de Vațukan (l'homme du Nord), au nord de Kaṇnāraranan, à l'est de la terre de Parpanāpan Kovan Āritan et au sud de la terre de Pārttivan Parpanān et aussi de la terre de Kāpiyan Cottan Mātevan [lacune] ; sur ces trois $m \bar{a}$ [de terre], qui sont la propriété de naissance selon le droit de possession du sol [dit] Kāviti de

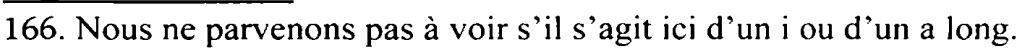


Tiruveṇkațtatikaḷạn Elunūrriampattu Nālvan de ce village et de ses frères, sur ces trois $m \bar{a}$ [donc], c'est [34] cey qui ont été donnés, après vente, à cette [déesse] Pițāri, de la façon suivante :

auparavant, . . . cet Eḷunūrriampattu Nālvan, . . . agissant en qualité de comptable du village [a donné] à Pirāntakamuttaraiyan Cuntara Coḷac . . . . ${ }^{167} \mathrm{kalam}$ de riz ;

sur ce riz, venu de ce qui a été rassemblé sous la juridiction de ce village, 1250 kalam de riz ont été fixés [comme taxe ?] sur notre ordre, nous qui sommes l'assemblée ; ensuite, au nom ${ }^{168}$ des Veḷālar et des brahmanes du village, $k \bar{a} c u$ et céréales, furent donnés ; [mais] étant donné la faute [commise] de ne pas présenter des comptes nets, puisque, après qu'on a fait venir cet [Elunūrriampattu Nālvañ] en [lui] demandant de montrer les dépenses afférentes aux $k \bar{a} c u$, au riz et aux céréales [donnés] auparavant, celui-ci vint sans montrer [comment] elles progressaient, et étant donné une autre faute [commise, à savoir] d'avoir permis à ses frères de prendre le contrôle des opérations, la grande assemblée que nous sommes a donné après vente, ces 34 cey, valant 25 monnaies de Ceylan, qui étaient auparavant d'un statut sans taxes, et qui sont aussi dorénavant d'un statut sans taxes ; voici l'acte de vente pour cette terre :

après avoir fixé le prix des $m \bar{a}$ comme étant précisément aussi ce qui se trouve consigné comme la dépense sur l'ôle, avec ces $25 k a ̄ c u$ [prix fixć], reçus des notables de Natuvirccēri, la grande assemblée que nous sommes, à Bhițāri, a donné après vente, un $m \bar{a}$ et un demi-cey.

Sur l'ordre de la grande assemblée, ce Kantāyan, le madhyasta, l'a écrit : c'est de cette façon que je le connais moi, Kālāyan Vațakan Tāvan, de cette façon que je le connais moi, Āritan Patpanābhan Manarananan [lacune] de cette façon que je le connais, moi Vākkiyan Pāṇtan Kecuvan, de cette façon que je le connais, moi Kāppiyan Cottan Comañ, de cette façon que je le connais, moi, Cāvanti Nārāyaṇan Māran, de cette façon que je le connais, moi Cāvānti Bhattan Śrīdharan tattan.

15

Prāsāda, face sud, mur puis base du temple; Rājarāja I Ir, 12, $996^{169}$; $A R$ $\mathrm{n}^{\circ} 553 / 1921$; Mahalingam 1992, $\mathrm{n}^{\circ} 2290$; cet auteur précise que la date donnée correspond au 28 décembre 996 ; fig. 47 et 48 .

\section{Texte}

1. $\underline{\text { svasti śrī }}$

2. cālai kalamarutta

3. kovirājarājarājake-

4. caripañmakku yāṇtu 1

167. Les akșara manquants et ceux qu'on lit encore (à savoir rru) pourraient constituer des symboles numériques.

168. Katti signifie littéralement en montrant, après avoir montré ; on l'interprète comme désignant les personnes au nom desquels l'action est faite. Les brahmanes et les Velḷallars sont montrés comme étant ceux dont viennent les $k a ̈ c u$ et les céréales.

169. On aurait pu calculer 997 ; mais nous nous fions ici à la date calculée par T. V. Mahalingam. 
5. $2^{170}$ āvatu kilāar [kū]rrattu

6. brahmadeyam pullaman-

7. kalattu mahāsabhaiyom

8. iv(v)ātțai makaranāyarru tińkal ki-

9. lamai perra pūcattin nāñru

10. mahāsabhaiyom iv vūr ārita

11. n mañran cuvaran ${ }^{171}$ akatte

12. y dha(r)mmi tațti)[a]li kotṭi kālam

13. ūti mahāsabhai kūti iruntu ivūr ningrotu ${ }^{172}$

14. cattarkal șāmavetikalukkum ${ }^{173}$ rgg[veti]kalukkum ${ }^{174}$ àka ca

15. țta bhokam āy ninrotu cattarkaluk[k] ${ }^{175} \mathrm{u}$ [kuṭu]tta nilam $\bar{a}$

16. vatu iv (v)ūrppāl brahmadeyam nilamańka[la . . tiya c]e[n]ta

17. nvāy nilam utaiya alai . .

18. yūr varākiyan nakkan kāḷ perumāḷa[lu $] k k u{ }^{176}$. . n

19. katavanāy kalii(ñci)[nta]tí pin̄pu perumāl śrīmukam

20. sabhaiyomukku inta nakkan kāḷi nilamum ivan

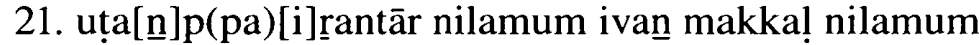

22. ivan brahmanimār perkkī kițanta nilamum

23. virru pāṇtikulācani mārāyar taṇtarulattu ${ }^{177}$ i

24. tuka enru śrīmukam vara innakkan kāli per kīl kita

(Sur le panneau à droite)

25. n[ta n]ilam ivvūr

26. ivan nilam iv

27. vūrppāl brahmadeya

170. On trouve après ce chiffre, un espace correspondant à un akșara; peut-être la formule marquant le début de l'inscription, que l'on retrouve dans l'inscription $n^{\circ} 16$, était-elle gravée avant la date ? Dans ce cas, les deux inscriptions 15 et 16 pourraient avoir été gravées simultanément. L'inscription 17 qui se réfère à cette inscription 15 , ne comporte pas la même formule mais un véritable éloge royal. Peut-être cette formule fut-elle utilisée par l'assemblée de Pullamańkai pour invoquer l'autorité d'un roi qui n'intervenait pas réellement alors, au contraire de l'inscription 17 où le roi se manifeste en personne.

171. Des traits verticaux sont gravés au-dessus des $\underline{n}$ de cette ligne. Il y en a aussi un au-dessus de celui de la ligne 4 . Il est difficile de les interpréter car ils ne correspondent pas à la fin d'un mot, et donc ne peuvent guère être des virama.

172. Nous lisons ningrōtu, c'est-à-dire ningru ōtu ; passim.

173. Le début de ce terme $\underline{s} \bar{a} m a v e t-$ est une transcription en alphabet tamoul du sanskrit sāmaveda, auquel on a ajouté une terminaison tamoule; on a affaire encore ici à une forme d'hybride épigraphique

174. Comme le précédent, ce terme est une combinaison graphique et linguistique de sanskrit et de tamoul. La lecture [ $t i]$ s'inspire du terme précédent. Au Rgveda sanskrit, écrit partie en grantha (le r et les deux $g$ ), partie en alphabet tamoul (le ve), on ajoute une terminaison tamoule.

175. On ne voit pas l'aksara $k$ mais la suite du $u$.

176. Ce terme peut se lire de trois manières différentes. Nous choisissons celle qui nous paraît correspondre à la forme que l'on retrouve à la ligne 18 ; on peut aussi lire, perumālarukku et perumāllukku.

177. Ce terme peut aussi se lire tantatălattu; on le retrouve à la ligne 84 de cette inscription. 
28. m [n]i[la]mankkalattu miya

29. centanvāy tati ira

30. nțāy nila[m*] 1 [ve]liyil

31. onpatu[m] . k k̄ị pār

32. kkellai varākkiyan vi

33. nācakan moțanum uța

34. p(a)[i]rantārum nilattukku me

35. kku tennpārkke[llai]

36. ivvināâakan moțanum

37. u[țapirantār]um ni[la]ttukk[um]

38. vațakku melpārkkellai vā[y]kkāa

39. luk[k]u kilakku vațapārkellai vā

40. ykkālukkey terkkum

41. āka innānnkellaiyi

42. lum națuvu[t* $t^{*}$ patta $S S S$ in

43. key itin melai S S mā

44. vukku kīlpārkkellai vāykkā

(À l'intérieur du pañjara, à droite)

45. lukku me

46. rkkum ten

47. pārkkellai aka

48. limańkalattu $\bar{u}$

49. rellaikku vațakkum

50. melpārkkellai [a]

51. kalimańkala[ttu e]

52. llaikkey kilakku

53. m vațapārkkellai

54. vāykkālukku ter

55. kkum āka ivvicai

56. tta perunānkellai

57. yilum națuvu[t*]pața ni $S$

58. S S āka(k) 1 tati iran

59. țāy 1 [ve]li in nilam

60 . veliyum ivan e

61. teya iva[n per]kīl

62. kițanta tottapara ${ }^{178}(\mathrm{t})[\mathrm{p}]$

63. tikku kīlpārkke

64. llai tāvānti nā

(Sur le côté, perpendiculaire, de la niche de Dakșināmūrti, à droite)

65. rāyanan śrīdharanum uțap

66. para[ntār]um nilattukku merkum

67. te[n̄pār] kkellai iva[r*]kal nila

68. ttukkey vațakkum [mel]pārkke

69. llai o[lu]kkaiykku kilakkum va

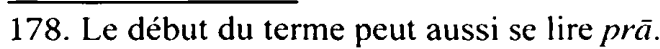


70. țapārkkellai oluk[kai]kkey

71 . . m āka innatuvu ... .

72. . . . . . . nnān . . . .

73. tiyum mun cutța[t]ppatța $S$ [ve]li ve

74. licceyyum ittotta pāti ${ }^{179}$

75. nānūrum innilañkal $j(\bar{a})$

76. ti sāmantar dhanikar munpu ni

(Sur le pan de mur à gauche de la niche et se poursuivant sur le plan perpendiculaire de la niche elle-même)

77. . nn ${ }^{180}$. kolvār i . . . . . . jāti sāmantar dhanikaraik kā

78. . mā . . viṭa nīńkạ innila[m] koṇțu ik kācu vaikkaven

79. . . pāṇtikulācañimārāyar sabhaiyomai koceyya ...

80 . . . kalukku varicaikkuttina varicaikkī innilam [vēl] ik

81. kum varicai vitṭa kācu 80 it toțtattār varicai vițta kācu $10 \mathrm{~m}$

82. āka toṇnūuru] kācum sabhai[yom] . . [pā]ṇțikulācani mārā

83. yan tanțatālattu vaittu ip paricu e[nka]! sabhaiyomi

84. [țai]y [i]runta in nilam v[êe]liyum it toțta $p\left[r^{*}\right] a \bar{t} t t i$ nānūrum mahā

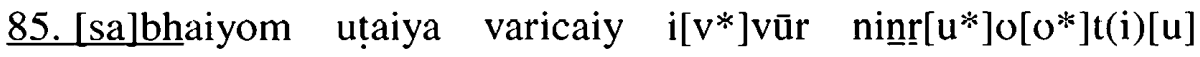
cațta[r*]kal sāma

(Retourner sous le premier pan de mur, sur la base du temple, tout à gauche de la face sud du prāsāda)

86. vetikalukkum [rggi] ${ }^{181}$ vetikalukkum catțabhoga

87. mmākac ceytu [kuṭut]tom mahāsabhaiyom

88. in nilam 1 veli[yum] it toțtap[r*]ātti nā

(Descendre plus bas sur la base du temple)

89. nūrum ic caț̣aperumakkaḷkku cantrātittavar iraiyili āka kuṭuttom pu

90. lḷamañkalattu mahāsabhaiyom ip paricu cațtaperumakkalukku kuțukka panittār

(Aller sur la base du temple, à droite)

91. tāvānti bhatṭa nārāyaṇan tāy pirān bhațta comāciyārum kāppiya

92. $\mathrm{n}$ bhatțan cottam paraṇanum tāvinti parameśvara nakkīran bha

93. țṭanum pālāśriyan bhaț̣an nārāyaṇan nārāyaṇanum (t)[ca]avān

(À droite, sur la base du temple, correspondant ici à la base de la niche du Dakṣināmūirti)

94. nti n[ārā]yaṇan tāyannum kāppi[ya]ṇ mācenn ankiyum kāppiyan . śsīdhā[ra]bhaț[țan] . . . n n ti[r*]yampakanum ipparicu paṇi

95. yițāar cattapperumakkalukku cattabhogamākap panittuk kuṭuttom mahāsa[bhai]yom ippa[ricu] . . . . . . r rur tiruvāṇai maruttar tanța

179. Nous lisons prāpti.

180. Cet aksara peut aussi se lire $!$.

181. La pierre est ici cassée ; la lecture proposée s'inspire des termes en usage à la ligne 14 de l'inscription. 
(Descendre plus bas sur la base du temple)

96. ppațuvatāka vyavastai ceytu el uti kuṭuttom mahāsabhaiyom ip

paricu paṇiyāl iv vūr madyastan nārāyaṇan utaiyativākaranāna

97. alan̉kārapriyanen ivai en el

\section{Traduction}

Longue vie! Prospérité !

Dans la $12^{\mathrm{e}}$ année du règne de Kōvīrājarājarājakēcaripannmar, qui distribua des mesures [de nourriture] dans l'hospice, nous la grande assemblée de Pullamańkalam, un brahmadeya de Kilāar Kūrrạam, cette année-là, dans le mois solaire du makara, un lundi, alors que s'était levée [l'étoile] Pușya ${ }^{182}$, dans la maison de Cuvaran Mañran Āritan de ce village ${ }^{183}$, cependant qu'après avoir [soufflé] dans les conques, battu les tambours et fait résonner les cornes, la grande assemblée s'était réunie, pour les lettrés qui récitent continûment, elle donna une terre avec le statut de cațabhoga pour des lettrés qui récitent continûment le Sāmaveda et le Rgveda ; voici comment :

Une fois le délai expiré pour Nakkan Kāli Varākiyan Perumāḷạ du village d'Alai... yūr, possesseur d'une terre située à Centan, $\mathrm{S} S$ à Nilamańkalam, un brahmadeya proche de ce village, [qui agissait] en tant que responsable (katavan), il y eut un ordre royal du roi ; un ordre royal élail [en effet] arrivé, adresssé nous qui sommes l'assemblée, disant :

«La terre de ce Nakkan Kāli, et la terre de ses frères, et la terre de ses fils, et la terre qui est au nom des femmes de sa famille, qu'elles soient vendues pour se trouver sous la férule ${ }^{184}$ de Pānțikulācani »;

[voici quelle était] la terre placée sous la dépendance de ce Nakkan Kāli ; la terre de cet homme dans ce village est une terre de 1 [ve]li, faisant deux tat $i$, située à Miyacentan, dans Nilamańkalam, un brahmadeya proche de ce village, [elle est constituée comme suit] :

- une terre de 9 dans $1 \mathrm{li}$. .; elle se trouve [incluse entre les quatre frontières suivantes] : la limite est se trouve à l'ouest de la terre de Varākkiyan Vinācakan Motan et de ses frères, la limite sud, au nord de la terre de ce Vinācakan Motan et de ses frères, la limite ouest, à l'est du canal et la limite nord, au sud du canal ; cette terre de S S S se trouve au milieu de ces quatre frontières;

- en ce qui concerne les $S \mathrm{~S} m \bar{a}$ de l'ouest de cette terre, ils se [trouvent inclus entre les quatre frontières suivantes] : la limite est se trouve à l'ouest du canal, la limite sud, au nord de la limite du village d'Akalimañkalam ${ }^{185}$, la limite ouest, à l'est de la limite d'Akalimańkalam, la limite nord, au sud du canal ; c'est dans ces quatre grandes limites que se trouve cette terre de S S S.

Voilà ce qu'il en est cette terre de $1 l i$, constituée de ces deux tati

182. Il s'agit du huitième nakṣatra.

183. Sur l'utilisation de l'expression iv viür, supra note 51.

184. C'est le terme tantal signalant l'autorité exercée que nous traduisons par « férule ». Il s'agit d'un dérivé du sanskrit danda. Le terme revient dans l'inscription 17, ligne 13.

185. Sur les deux termes qui se succèdent Akalimańkalam, un toponyme désignant un brahmadeya, et ür censé désigner une unité villageoise, supra note 51. 
Ce [Nakkan Kali] avait aussi [1] veli de terre utilisée comme jardin placée sous son nom : sa limite est [se trouve] à l'ouest de la terre de Tāvānti Nārāyaṇan Śrīdharan et de ses frères, sa limite sud, au nord de la terre de ceux-ci, sa limite ouest, à l'est d'Olukkai et sa la limite nord au . . d'Olukkai,

c'est dans ce terrain [lacune] nnān [lacune]

[terres] déterminées plus haut, un li, veli et les cey utilisés comme jardin, qui sont au nombre de quatre cents, en présence des personnes de la même caste, des voisins et des riches . $\underline{n}$. « que, une fois [lacune] ceux qui prennent, . . [i.e. ?] les personnes de même caste, les voisins et les riches, vous, prenant cette terre, remettiez les $k \bar{a} c u$ y afférant ${ }^{186}$ », déclara Pāṇtikulācañi Mārān après fait usage de son autorité sur l'assemblée que nous sommes:

une fois fixé le varicai ${ }^{187}$ pour [lacune] cette terre placée sous varicai, [c'est-àdire pour le 1] li, le varicai est fixé à $80 \mathrm{ka} c u$, et le varicai est fixé à $10 \mathrm{ka} c u$ pour les propriétaires de la terre de jardin, le tout faisant $90 \mathrm{k} \bar{c} c u$, [ces $90 \mathrm{ka} c u$ ] sont placés sous la férule de Paṇtikulācañi Mārāyan de la façon suivante : . nous l'assemblée, cette terre de [1] veli constituée de deux tati et de ces quatre cents utilisés comme jardin, nous l'assemblée qui avons droit de [fixer] le varicai en avons fait don, avec le statut de cattabhoga, aux lettrés connaissant le Rgveda et le Sāmaveda, qui récitent dans ce village; nous la grande assemblée avons donné cette terre de 1 veli et les quatre cents utilisés comme jardin à ces importants lettrés, comme [terre] exempte de taxes aussi longtemps que durent la lune et le soleil ; qu'elle soit donnée sur notre ordre à nous l'assemblée de Pull lamankkalam, pour ces importants lettrés de la façon définie ci-dessus, sur l'ordre de Cāvanti Bhaț̣a Nārāyaṇan Tāy Pirān Bhaț̣a Comāciyār, Kāppiyan Bhaț̣an Cottam Paraṇan, Cāvānti Parameśvara Nakkīran Bhațtan, Pālāśriyan Bhaț̣an Nārāyaṇan Nārāyaṇan, Cāvānti Nārāyaṇan Tāyan, Kāppiyan Mācenañki, Kāppiyan Śrīdharabhaț̣an . . . n n Triyampakan, c'est ainsi que l'ordre est donné, c'est sur notre ordre qu'est donnée [la terre] de cette façon pour les importants lettrés, avec le statut de cattabhoga; nous la grande assemblée avons fait un don de la façon suivante : [lacune] après avoir fait écrire que ceux qui désobéissent à l'ordre royal payeront une amende, c'est de cette façon que, sur ordre [de l'assemblée], moi qui suis Nārāyaṇan Utaiyativākaran aussi connu comme Alankarapriyan, le madhyasta de ce village, je l'ai écrit.

16

Maṇ̣apa, mur sud ; Rājarāja $\mathrm{I}^{\mathrm{er}}, 12,997$; $A R \mathrm{n}^{\circ} 557 / 1921$; Mahalingam 1992, $\mathrm{n}^{\circ} 2291$; fig. 52 et 53 .

Texte

(L'inscription est gravée sur le pilastre de gauche, sur son revers pour quelques lignes, puis sur l'espace disponible au centre du pañjara pour s'achever sur le pilastre de droite)

1. svasti śrī cālai kalam arutta ko

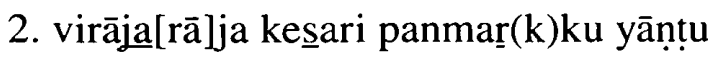

186. Littéralement «ces $k \bar{a} c u$ », c'est-à-dire les $k \bar{a} c u$ qui se rapportent à cette terre qui vient d'être nommée.

187. Le varicai est le montant des taxes dues par le village. 
3. 12 āvatu kilāār kūrrattu brahmadeyam pu!

4. lamańkalattu mahasabhaiyom iv vūr ārita

5. n mañan cuvaranukku nānkal ampalappura

6. māka [m]arruk kuṭutta p(ā)rattikku kīlnpārkellai

7. peruvalikku merkum tenpā[r]kellai tiru

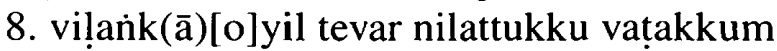

9. melpārnkellai cāvānti vīran māranum

10. uṭappirantārum nilattukkum tānañcan

11. nārāyañan cantiracekaranum uțappirantārum

12. nilattukkum cāvānti jādavetanāyan ni

13. lattukkum kilakkum vațapārkellai karuppūrutai

14. yān pat

(Descendre dessous, sur la base du temple)

15. țālakan colaiyum paț̣ālakan puvanavanum nilattukkum terkkum āka ivvicait

16. ta perunānnkellai SSSS[rum] națuvu[t]]pațta $p(\bar{a})$ ratti $8 \mathrm{~S} \mathrm{~S}$ ip $\mathrm{p}(\bar{a})$ ratti eṇnūụum

17. iv āritan mañan cuvarañukku nāńkal emmilicainta vilaipporulukku

(Sur le pan de mur disponible, à droite en remontant)

18. nānkal . . . . . . iva

19. $\underline{n}$ sabhaiyomitai vilai

20. kontutuaiyanāy irunta ip prātti

21. eṇuūurum ivanum ivātṭai

22. rșabha n[āya]rru [t]inkațkilamai

23. perra [mūlatti]n̄āñu

24. somagrahanam parri

25. na potu iv vūr $\mathrm{t}^{188}$ iruvālantu

26. rai paramesvarar koyilin

27. mun ip pullamañkalattu

(Descendre sur la base du temple, sous ce pan de mur)

28. maha[a*]sabhai kūti irukka [i] āritan mañran cuvaran muncutțapatta nālellaiyil

29. tirumaṇtakat[t*]e dhanmi ceytu pullamañkalattu mahā[sa]bhai kuțtak kuraivara [kūti] irukka i āritan

30. manran cuvaran muncuttappatṭa nālellaikkum naṭuv[ut]patṭa pra[a*]tti ${ }^{189} 8 \mathrm{SS}$ eṇṇūrum nān ețu

(Aller juste en dessous, sur la base du temple)

31. ppicca ampalattukkum currukkallūrikkum toțtikkum kiṇarril ni[i*]r iraippānukkum ampalam melukuvā

188. Le $t$ est bizarrement gravé.

189. Ce «prāpti » est écrit en faisant suivre directement un aksara pa, puis un aksara ra; il est difficile de savoir si on a noté para ou pra. Il en est de même pour d'autres occurrences de ce terme dans cette inscription, et à la différence de son occurrence à la ligne 20 par exemple, où les deux aksara sont liés. 
32. nukkum ampalam alivu colavum putukkavum tạnn[i*]ir ātțavum ipprātti eṇụurum sabhaiyom

33. muñpe ampalappuramāka ni[i*]roṭu ațti ippātti eṇnūrum irai ilicci taraventum entru

(Poursuivre sur la base, à droite)

34. sabhaiyomukku dravyantara sabhaiyomum ivan tanta idravyam

35. koṇtu ip[prā]tti eṇnūurum candiratitavat iraiy iliyākap panic

36. cu i[rai ili] ccik kututtom pul!̣amankalattu mahāsabhaiyom

(Poursuivre sur la base, à droite, on se trouve alors sur la base de la niche du Ganeśa)

37. ipparicu ippon kontu irai ilikkap paṇiccu tiruvālaṇturai śrī koyilil kalmel vețtiviccuk koḷ̣apperuvān nākap paṇiccār cāvānti parameśvaran akkipi

38. rān bhatțannum cāvāndi bhattan nārāyaṇan tāyac comāciyārum cāvānti civapaț̣ālakan kecuvannum cāvānti vāsutevan tāyanum vākkiyan kēśavan pāṇtanum varākki

39. yan nārāyaṇan jādavetanum varākkiyan tatan tivākara $\mathrm{sa}[\mathrm{r}] \mathrm{v}(\mathrm{r})$ akratukkaḷum kāppiyan bhatțan cottan pāța[ñum] vācciyan tāyan davacomāciyārum cāṭtiyan turutti tāya

(Poursuivre sur la base, à droite)

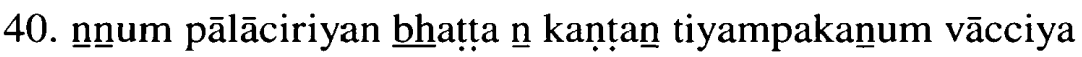

41. ñ vatukan cītaranum vāciyan kaṇtan tāmotaranum cāvānti

42. śruvata șānākāyaccomāciyāru[m*] vākkiyan pāṇtanāāāyaṇan

(Poursuivre sur la base, à droite)

43. pālācari bhatțan nārāyaṇan nārāyaṇan . . . [eḷu] ${ }^{190}$

44. tinen ivvur ma[dhya]stan nārāyaṇa karu . . .

45. n eluttu $^{191}$

\section{Traduction}

Longue vie ! Prospérité !

Dans la $12^{\mathrm{e}}$ année du règne de Kovirājarājarājakēcari, qui distribua des mesures [de nourriture] à l'hospice, nous la grande assemblée de Puḷamańkalam, un brahmadeya de Kil̄ār Kürram, à Āritan Mañran Cuvaran de ce village, nous donnons [une terre] en tant que terre pour le grand hall (ampalam); en ce qui concerne [ce] lot, ses limites est se trouvent à l'ouest de la grand-route, et ses limites sud, au nord de la terre du dieu de Tiruvilańkōyil, et ses limites ouest à l'est de la terre de Cāvānti Jādavetanāyan et de la terre de Tānanāācan Nārāyaṇan Candiracekaran et frères, et de la terre de Cāvānti Vīran Māran et frères, et ses frontières nord, au sud de la terre de Pūvaṇavan Pațtālakan et de Karuppūruṭaiyān Paț̣ālakan Colai : c'est entre ces grandes frontières que se trouve le lot de 800 , huit cents ; à cet Āritan Mañan Cuvaran, après avoir fixé entre nous le prix de la vente, nous [lacune]

190. La fin de ces deux lignes 43 et 44 s'achève sous le ciment d'une construction plus récente.

191. Deux petites barres verticales suivies de deux traits aux extrémités marquées de petits traits verticaux marquent la fin de l'inscription. 
C'est ainsi que cet [Āritan Mañran Cuvaran]], recevant de nous qui sommes l'assemblée le prix [convenu], est devenu possesseur de ce lot de huit cents : dans cette [même] année, au mois de Rsabha, un lundi, alors que s'était levée [l'étoile] Mūlam, cependant qu'une éclipse de lune se produisait, une fois réunie la grande assemblée de ce Pullamanakalam devant le temple du seigneur suprême du [lieu] sacré d'Ālanturai de ce village, Āritan Mannan Cuvaran [est devenu possesseur du lot compris] dans les quatre frontières indiquées plus haut, après qu'on a soufflé dans les cornes dans le mandapa sacré ; lors de cette réunion plénière de la grande assemblée de Puḷamańkalam, le lot de 800, huit cents, compris dans les quatre limites indiquées plus haut, Āritan Manran Cuvaran [en est devenu possesseur] ; pour [l'entretien de] l'ampalam que nous avons érigé, pour [son] enceinte, [sa] citerne, celui qui amènera l'eau dans le puits, celui qui polira le sol, pour les dépenses qu'occasionnent les dommages, rénovation et apport d'eau fraîche, ce lot de huit cents, [a été donné], devant nous l'assemblée, en tant que terre pour l'ampalam, en versant de l'eau, et avec la précision selon laquelle il était exempt de taxes; et le paiement fut donné à nous l'assemblée ; et, nous l'assemblée, lui avons donné cet argent à lui [Āritan Mañan Cuvaran] et nous la grande assemblée de Puḷamanikalam [lui] avons donné ce lot de huit cents exempt de taxes aussi longtemps que durent la lune et le soleil, ayant ordonné qu'il soit sans taxes.

C'est de cette façon, une fois donné cet or, et une fois ordonné qu'il y ait exemption de taxes, qu'ont ordonné qu'il soit celui qui a le droit de faire graver dans la pierre du saint temple du lieu sacré d'Ālanturai, Cāvanti Parameśvaran Akkipirān $\underline{B}$ hatṭan et Cāvandi Bhatṭan Nārāyaṇa Tāyan Comāciyār et Cāvānti Civapattālakan Kēcuvan et Cāvānti Vāsutevan Tāyan et Vākiyan Keśavan Pāṇtan et Varākkiyan Nārāyaṇan Jādavetan et Varākkiyan Tatan Tivākara Sarvakratukka! et Kāppiyan Bhaț̣n Cottan Pāțan et Vācciyan Tāyan Davacomāciyār et Cạtṭiyan Turutti Tāyan et Pālāciriyan Bhațtan Kaṇtan Tiyampakan et Vācciyan Vaṭukan Cītaran et Vāciyan Kaṇtan Tāmotaran et Cāvānti Sruvata Sānākāyaccomāciyār et Vākkiyan Pāṇtanāāāyaṇan Pālācari Bhațtan Nārāyaṇan . . ., je l'ai écrit, Nārāyaṇa Karu . . . ñ, le madhyasta de ce village a écrit.

\section{7}

Prāsāda, face ouest, sur le mur ; Rājarāja I ${ }^{\mathrm{er}}, 21,1006$; Varaläru vol.III, n 9.2 ;

fig. 49.

Texte

1. tiru makal pola[p peru nila] ccelviyum tana ${ }^{192}$

2. kkeyurimai pu[ntamai]mank [o]la kkā[n talu]

3. rccālai ka[lamaruttaru]!̣[i] venkai [n]ā[țu]n̉kan

4. ka pātiyu[m nulamp pātiyum]tatikai [p]ā[tiy]um kuta

5. lamum kalin(k)kamun en țicaip pukaltarura

6. ilaman[ța]la[mu]m ilața [pa] ți elarai ilakkamum

7. ti[n tiral vennrit tanțār koṇta*] tacc elil

192. C'est à la fin de cette ligne que se trouve gravé le $e$ du kkeyurimai du début de la deuxième ligne. 
8. vi e [oliiyum ellā yāṇtum to*]mū e . llu ${ }^{193}$ vilan̉ku[m]

9. yāṇ[tē celiyarait tēcukol**] śrī kovirājarāja

10. keșariva[ñma nāña śrī] d d[e]varkku yāṇtu 21 āvatu

11. nitta[vino]ta-vala[n]ātṭuk kilāākūrrattu

12. brahmadeyam puḷamañkalattu mahāsabhaiyo

13. mum ivvū[r] tanțaluṭaiya atavattūr uṭaiyāru

(Aller à droite de ce panneau, au centre du pañjara)

14. m kūti yiruntu sa

15. bhaiyom ${ }^{194}$ panitta pa

16. [ricāvatu] mun sabhaiyo

17. m na .... . [ni]lamañ

18. kalattu mutțattu alai

19. yūr nakkan kāḷi kāṇi vi

20. lai koṇtu sabhaiyo

21. mitāy sabhaip potu

22. vāy iru(t)[n]ta nilam it te ${ }^{195}$

23. varkku yāṇtu 12 āva

24. tu i nilamañkalattu sa

25. bhaiyomitāna oñre

26. nānnku nila[t*]taiyum iv

27. vur catța[r] ningru otuvārkku

28. irai iliyākap pani

29. ttu irai kollapata

30. perāāin nilattāl en

31. ru tiruvānai $\mathrm{k}\left[\mathrm{u}^{*}\right]$ uri kalli[1*]

32. vetți kita[n*]ta nilam nilava

33. tu cațtarāy otuvāru min

34. ri irai ilayāna nilam

35. kal irai erri kolka

36. venru napamai utaiya

(Troisième partie de l'inscription, gravée à droite du pañjara)

37. cak[ravarttikal] śrī rājarāja tevar[kku] yāṇ

38. [țu] 21 [āvatu] ......

39. mēyal innilamum irai kolla

40. ka tiruvāṇai k[ūr] i ittiruvāṇ[ai] kūrru sabhai

41. yomey viț̣u tiruvãy mo[ḷin]tapați . [ye] . . 196

42. lam irai kolvatāka panitt[om]

43. mahāsabhaiyom ${ }^{197}$

193. Tout ce passage, très abîmé, présente des termes illisibles même quand on reconnaît les akșara.

194. Le ai de sabhaivom est gravé en fin de la ligne 14.

195. Le deuxième $t$ est gravé au début de la ligne 23 .

196. L'édition de Varalāru indique « ini » à la fin de la ligne, mais nous ne voyons rien de ce genre.

197. La fin de l'inscription est marquée par deux petits traits verticaux, suivis d'un trait horizontal. 


\section{Traduction}

(Les lignes 1 à 9 sont très abîmées; elles constituent une version de l'éloge royal (meykkīrtti) de Rājarāja I'r, bien connu par ailleurs. Nous nous sommes basés sur les versions connues de cet éloge pour reconstituer le texte, mais les portions demeurant illisibles découragent les essais de traduction. Nous renvoyons donc aux traductions publiées du meykkīrtti de Rājarāja I'r comme celle qu'on trouve dans SII II, 1. Signalons cependant l'erreur faite par ces publications anciennes qui voyaient dans cālai kalam arutta une allusion à une bataille navale.)

En la $21^{\mathrm{e}}$ année du roi Rājarājakesariv[arman] ${ }^{198}$, nous la grande assemblée de Pullamañkalam, un brahmadeya de Kilāar Kurram [situé dans la région] de Nitta(vinōta)-valanāttu, et le maître d'Atavattūr, qui est aussi possesseur de [l'autorité que confère] la férule sur ce village, nous nous sommes rencontrés, et nous l'assemblée avons ordonné ce qui suit . . . . ; auparavant, nous, l'assemblée, avons versé un prix pour la terre de statut kāṇi de Nakkan Kāḷi d'Aḷaiyūr de Muțtam de Nilamańkalam, [terre] devenant commune à l'assemblée ; en l'année 12 de ce roi, cette terre commune à l'assemblée de un [veli] et quatre [cents de terre utilisés comme jardin], nous avions donné l'ordre qu'elle soit exempte de taxes, pour les lettrés de ce village qui récitent en continu, après avoir fait graver sur la pierre l'ordre royal ordonnant qu'on n'obtienne pas de taxcs sur cette terre ; voici ce qu'il en est de la terre : comme il n'y a pas de lettrés récitants, que l'on impose les taxes et qu'on les collecte sur [ces] terres qui étaient [auparavant] sans taxes, c'est là ce qui fut dit, dans la $21^{\mathrm{e}}$ année de notre seigneur le cakravartin Śrī Rājarājadeva...

(lacune)

l'ordre royal de collecter les taxes sur cette terre aussi fut proclamé ; une fois que nous qui sommes l'assemblée avons proclamé cet ordre royal, en accord avec la parole [venant] de la bouche du roi ${ }^{199}$.. nous la grande assemblée avons ordonné que l'on collecte les taxes sur cette terre.

\section{8}

Maṇapa, face sud. sur le mur ; Vikrama Cōla, 1/ 9, $1119 / 1127$; $A R \mathrm{n}^{\circ} 554 / 1921$

(le transcrit s'arrête à la ligne 17); Mahalingam 1992, $n^{\circ} 2292^{2(\kappa)}$; fig. : 45 et 46.

1. svasti śrī vikkirama cola te-

2. varku yānțu 1 āvatu ruttavinota-

3. vaḷanāttuk kil̄ārk kūrrattu brahmadeya

4. m puḷ!amankalattut tiruvālanturai mahādevar ko-

198. L'akșara $v$ étant encore visible on peut penser que le terme utilisait la graphie sanskrite -varman.

199. L'expression tiruvāy molintapati signifie l'accord avec l'ordre royal donné ; la variation de la traduction cherche à rendre les variations du vocabulaire tamoul qui utilise plusieurs termes différents pour évoquer un ordre royal décidément bien présent.

200. Étant donné le caractère difficile de cette inscription, nous donnons ici le résumé qu'en fait T. V. Mahalingam (1992: 524) : " the Palli-Ponni-Nadalvan and Vanarayap-poyan, two watchmen (kaval) attached to the temple of Tiruvalandurai-Mahadeva had a quarrel and as Kuppai Perumāl, the son of the former, fell at the hands in the affray, a gift of 72 sheep was made. » 
5. yil kầvaluṭaiya paḷi ponnnināțālvānnum kāa

6. valuțaiya vānarāyappera[raiya* ${ }^{*}$ num iv viruvarum tan

7. kalil pakaicata eytatattu ponnintāâlvān ${ }^{201}$

8. makan kuppai perumān vānarāyappera[rai]yan kai

9. kkeyațattu avanukkut talai māru perpaṭa ku

10. țāmaikku ta[n்]kalil upaiyam vantu ik kuppai

11. perumānnac cārtti it tiruvālanturai māhāatevarkku

12. catarātittaval eriyakkațavatāka vaitta tirununtāvila

13. [kku*] ta mukālātu $\underline{1}^{202}$ [viṭ.]ta ățu 72 ivātu elupa

14. tta . . me kali ukarāl ak kațaikkātan pakkal niñña

15. ātu elupattirantu ivvātu el elupattirantum

16. [ik koyilil kā] ${ }^{203}$ ṇi uṭ [ai]ya cila brāhmanari

(Sur le rebord inférieur marquant la fin du mur, invisible lorsqu'on est en face de

l'inscription)

17. loccan nā . . n tiruccirrampalam

(À l'intérieur du pañjara à gauche)

18. . . y.ānuum ikkuṭi sūriyan

19. cāttapirānum ikkuṭi tiruve

20. kampan porkātanum im

21. mūvom ivvātu e(p)[1] $]$ u[pa*]ttira

22. ntum kaikkontu canti

23. rātitta[val] erikka . . māña

24. tirunontāvilakku mukkāl im

25. mukkā(lu)m ikkoyilil kucci kai

26. țeranatu paniceyyak

27. kața[vāre] erippatāvatu

28. itu panmāheśvara rakṣai

\section{Traduction}

Que la prospérité soit ! En l'an 1 de Vikramacōladeva, entre le gardien du temple du grand dieu du lieu sacré Ālanturai de Pullamañkalam, un brahmadeya de Kilāâr Kūrram, de Nittavinōtavaḷanam, le pa!lli Ponnni Nātāạlvān, et le gardien Vānarāyappera(rai)yan, entre ces deux-là donc, une dispute s'étant élevée, et Vānarāyapperaiyan en étant venu aux mains avec Kuppai Perumān, fils de Ponnni Nātālvan, un accord fut passé entre ces [deux gardiens] pour une compensation concernant ce [Kuppai Perumānn] : au nom de ce Kuppai Perumānn, pour qu'on fasse brûler pour le grand dieu de ce lieu sacré Ālanturai, trois quarts d'une lampe perpétuelle sacrée, tant que durent lune et soleil, ces 72 moutons, qui sont des moutons consacrés, qui ne vieillissent pas, sont placés . . ces 72 moutons sont 72 moutons se trouvant avec Kaliukarālakkațaikkāțan ; les Civa brāhmaṇari qui possède le kāni de ce temple, ...

201. Sans doute s'agit-il du même terme qu'à la ligne 5, mais il est orthographié légèrement différemment.

202. On lit un $\underline{l}$, mais il pourrait aussi s'agir d'un $m$.

203. Cette lecture est basée sur le transcrit de Mysore : on ne voit plus rien sur la pierre. 
Loccan nā . . n de Tiruccirrrampalam, . . y yāñ Ikkuṭi Sūriyañ, Cāttapirān Ikkuṭi Tiruvekampan Porkātan, ces trois-là ont donné de leur main ces 72 moutons, pour faire brûler tant que durent lune et soleil, trois-quarts d'une lampe sacrée perpétuelle étant . . . ; ces trois-quarts, dans ce temple, que les fassent brûler ceux qui ont obligation des services religieux ; cette [injonction] est placée sous la protection des Panmāheśvara.

\section{9}

Prāsāda, faces nord et ouest, base du temple; Kulōttunka III ? ${ }^{204}$; $A R$ $n^{\circ} 552 / 1921$; Mahalingam 1992, n² 296.

\section{Texte}

$\underline{\text { 1. svasti śrín }}^{205}$ : maturai tribhuvanac cak(k)aravattikal maturai konțu pāṇtiyan muṭittalaiyum [ko]ṇțaruliya śrī kulo[ottunika*] . . rạla . e . . . . . . . nittavi[no ${ }^{206}$ ta] . . . . . . k kilāark kū

2. rrattu brahmadecam puḷamańkalattu tiruvāla(t)[n]turaiyuțaiya mahād[e]var ${ }^{207}$ tiruñāmattuk . . . . m ūrnattamum . . . . . . . . . kku me[lai mutarka] ${ }^{208}$ ṇnāarrru]kku merkku mel

3. pārkellai pavititaramāṇikkapuravatikkuk kilakku
iraṇtāñkaṇnāanrukkuk kilakku tenp[ [*ā]rkellai uṭciruvāykālukku vațakku kāveri yārrril națuvura innān̄kellaikkuṭpaț̣a tirunāmattuk kāniyāna nanceyum mā

4. vațai punpayir kațamaiyum paṭukai kūraikkațaimai tari irai cekkirai taț̣oli tatțārappātṭamum āyavarkamum cāraṭai kuḷa[va*]ṭai mațuvațai pācippāṭ̣am

\section{Traduction}

Que la prospérité soit! Le cakravartin des trois mondes ${ }^{209}$, qui après avoir pris Maturai, fit la grâce de s'emparer de la tête couronnée du Pānțiya, Śrī Kulo[ttuñka], ... et une terre d'habitation au nom du grand dieu de Tiruvalālanturai à Puḷlamańkalam, un brahmadeśa de Kilāar Kūrram, à Nittavinota... ; [les frontières est et nord...], se situent à l'ouest du canal ouest, les frontières ouest, à l'est du deuxième canal qui se

204. Aucun élément ne permet de dater l'inscription en choisissant le règne d'un des trois Kulōttunka, qui utilisent tous les trois le même embryon de meykkirtti, voir $S I I$ XVII, n 451, 630, 631, etc.

205. Le visarga $h$ est exceptionnel; sa présence correspond à la datation, plus tardive que la majorité des autres inscriptions, dans le règne d'un Kulōttunkka.

206. Le $e$ correspondant à la première partie de la graphie du $\bar{o}$ se trouve sur là pierre.

207. À partir du tiru qui suit, la gravure de l'inscription est différente. Les lettres sont plus petites et moins profondément gravées. La paléographie n'en est pas pour autant modifiée; peut-être a-t-on changé de scribe, ou bien le scribe s'était-il arrêté dans son travail pour le reprendre ensuite. La gravure de l'inscription 12 est, comme celle-ci, différente en certains endroits sans qu'il s'agisse pour autant nécessairement d'ajouts ou d'inscriptions complétées ultérieurement.

208. Cette lecture entre grands crochets droits est celle du transcrit disponible à Mysore. Sur la pierre plus aucun aksara n'est lisible à cet endroit.

209. Le premier « Maturai » de l'inscription semble une interpolation; il est difficile de lui donner un sens. 
trouve à l'est de la route de Pavitramānikkapuram, les frontières sud au nord du petit canal intérieur ; c'est entre ces quatre frontières, situées dans le pays de la rivière Kāvēri, que se trouvent l'ensemble des quatre cey de terre mise au nom du dieu ; les taxes provenant du revenu tiré des animaux et des terrains cultivés à sec, les taxes sur les réservoirs ${ }^{210}$ et sur les vêtements, les taxes sur les métiers à tisser, les taxes sur les presses à huile, les taxes sur les terrains cultivés et les taxes sur les forgerons ainsi que les taxes mineures, celles [qu'on prélève] à la saison des pluies [sur les terrains], celles des citernes, celles du bétail, celles de la pêche.

\section{0}

Manḍapa, face nord, sur la base du temple ; cōla ; AR $\mathrm{n}^{\circ}$ 547/1921; Mahalingam 1992, 2301; Varalāru, vol. II, n 16.3.

\section{Texte}

1. svasti śrī pullamañkalattu tiruvālanturai

2. [ma]hādevakku vācciyan nārāyana [ñ $\left.{ }^{*}\right]$ kātan ulakken

3. [ṇai]yāl oru no[n*]tāvilakku iravum pakallum cantrādi

4. [ttava]l erivatarku ku[tu]tta nilam . [ndha]mamkala

5. [ttu ${ }^{211}$ kīl] kulattu ira[ṇtu] [māvum] ${ }^{212}$ vallavākkanka[rai ${ }^{213}$

6. [orumā $\left.{ }^{214} \mathrm{vu}\right] \mathrm{m}$ āka nilam [mūnnñu mā] ${ }^{215}$

\section{Traduction}

Que la prospérité soit ! Au grand dieu du [lieu] sacré Ālanturai de Pullamañkalam, Vācciyan Nārāyaṇan Kātan, a donné une terre pour faire brûler, avec une mesure d'huile, une lampe qui ne s'éteint jamais, jour et nuit, tant que durent la lune et le soleil ; la terre [fait] trois $m \bar{a}^{216}$ : deux $m \bar{a}$ de Kịlar Kulattu et un $m \bar{a}$ de Vall lavākkankarai.

210. On ne sait pas exactement de quelle taxe il s'agit ; ce pourrait aussi être un impôt concernant les terres situées sur des rives. En ce qui concerne les taxes énumérées ici, qu'il est souvent difficile de déterminer, voir l'étude de N. Karashima (2001:69-158) qui donne les références qu'on trouve dans les inscriptions publiées à toutes les taxes ici mentionnées.

211. tu apparaît sur le transcrit de Mysore et [ttu] sur l'édition de Varālāru (1994, 2 : 36).

212. Les termes entre grands crochets gras sont une conjecture faite par le transcrit 547/1921 de Mysore et qui n'a pas été reprise par l'édition de Varalāru (ibid.). Sur la pierre, on ne voit rien aujourd'hui.

213. La conjecture est faite sur la base du toponyme apparaissant en 8,4 .

214. Le transcrit 547/1921 porte rumāvum et Varalāru . māvum.

215. La conjecture entre crochets est la lecture du transcrit de 547/1921; sur la pierre, on ne voit plus rien.

216. La traduction se base sur la lecture du transcrit. 
21

Maṇapa, face nord, au centre d'un pañjara ; cōla ; Varaläru, vol. III, nº 9.3.

\section{Texte}

1. tā .

2. kai ne ..... ([a]ñ

3. c)[aint]u nontā vilak

4. kukku eṇnai [yal ni]

5. cat(i)[a]m aivulakkin̄ā

6. l àtțai viț[ta] ne

7. [1]lukka ... . [1] am

8. innel ...

9. [a]ñcu nontā $[v] \mathrm{i}$

10. lakku cantirādittaval

11. [i]ravum pakallum e

12. rivatākavum ipparicu

13. paniccuk kututtom pu

14. ḷamankkalattu mahāsa

15. bhaiyom ivai māheśvara rakșai 217

\section{Traduction}

... pour cinq lampes qui ne s'éteignent pas, cinq mesures d'huile, quotidiennement, [venant du revenu produit par] le riz d'une année . . ${ }^{218}$, ce riz, pour faire brûler [ces] cinq lampes qui ne s'éteignent pas, tant que durent la lune et le soleil, nuit et jour, de cette façon, nous la grande assemblée de Pullamañkalam nous avons ordonné de donner ; cette [injonction] est protégée par les Māheśvara.

\section{2}

Maṇapa, face nord, sur la base du temple, sous la niche de la déesse ; $c \bar{l} \underline{l} a ; A R$ $\mathrm{n}^{\circ}$ 550/1921 (le transcrit s'arrête à la ligne 6); Mahalingam 1992, n² 2302 ; fig. 54.

\section{Texte}

1. svasti śrī tirukkoyilluṭaiyarkal arccanābho [kammāna nilamum

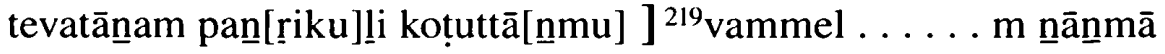
2. varaiyum kīle mūñru māv(u)um kaṇtikai mu[ [kattu]muk[kāni]yum nallūrceri[te]ñūr] . . . . kk . [ru] . m k . . . ttu a

217. La fin de l'inscription est marquée par un signe similaire à ceux de l'inscription $16:$ deux traits verticaux suivis par un trait horizontal.

218. La traduction est peu sûre, le texte étant trop lacunaire.

219. Les parties entre grands crochets gras correspondent à ce qui se trouvent sur le transcrit de Mysore uniquement, tout le centre de l'inscription étant dorénavant recouvert par un bloc de ciment. 
3. rimala vākkālin vațakarai mukkāṇiyum [ [āka i] ...... raikkāllum arccanābhokam svasti śrī puḷ!a]mañkalattu cākkaikku nicatikkuruni i

4. ruñāli nellāka orāttai nellu muppa[ti [ne]lu . . . tūṇippatakku nellukku . . . varicaiyāl] . . . . . n nilam elumāvaraiyāl

5. nilam nallūr cerinūr nāṇmāv $(u) u m$ i $[\tan$ ten . . . . oru mā varaiyum [pāticceyirattu] iraṇṭu] . . [mā]v(u)um . . ${ }^{220} \mathrm{~m} \ldots \mathrm{m}$. [e]lumāvarai um

6. kilāaril melai kāl(1)um uḷata āka ni[lamaraiye[raikkā]llum kontu[eluntu] tuvatāka ...... . . . . . . . . nicata

7. palantevatānatte orupakala vilak . . . . . . . . . la araimāvum kīlpulattu tenvā

8. kkālan ${ }^{221}$ ikkalañi mukāṇayum tiran kuṭi kkālan̄ārrakkalan mukkāṇiyum āka nilam ñā

9. nnkumā mukkāṇi

\section{Traduction}

Que la prospérité soit ! en tant qu'arcānabhoga pour le Maître du saint temple, en tant que devadānam, Pañrikuli ${ }^{222}$ a donné une terre : [cllc fait] ... quatre $m \bar{a}$ et demi et trois $m \bar{a}$ à l'est, $3 / 4$ de $k \bar{a} n i$ de Kantikaimukam et trois $m \bar{a}$ de Nallūrcēritenūr, un quart et un demi ... correspondant à $3 / 4$ de kāni sur la rive nord du canal d'Arimala de ... , [voilà ce qui est] arcanabhoga ${ }^{223}$; que la prospérité soit ! pour l'acteur de Puḷamańkalam, une terre [dont le] varicai [est défini comme étant] trente-sept tūni patakku $u^{224}$ de riz pour une année ... c'est-à-dire deux nāl $i$ de riz quotidiens, terre de sept $m \bar{a}$ et demi :

quatre $m \bar{a}$ du village de Nallūr Ceri, ... un $m \bar{a}$ et demi ... deux $m \bar{a}$ de Pāticceyiram, [voilà ces] sept $m \bar{a}$ et demi de terre; et la terre étant à l'intérieur pour un quart, [du terrain] à l'ouest de Kiḷār, avec araikkāl ... un demi-mā de Palantevatānam ... Tenvākkalan de Kīlpulam ..., 3/4 de käni Tîran Kuṭi, ... [tels] sont les quatre $m \bar{a}$ en $3 / 4$ de kāni.

220. Il est difficile d'évaluer s'il manque un ou deux akșara à cet endroit.

221. Ce terme est curieux ; peut-être faut-il le considérer comme une autre version du terme kalan $i$ qui suit.

222. Il s'agit de la seule occurrence de ce corpus où le village est en position de donateur ; on pourrait penser que le toponyme correspond à de la terre donnée. Mais alors on ne sait pas où est le donateur... peut-être sous le ciment qui recouvre le centre de la ligne, après kotutta[n] .

223. Une fois encore, on ne peut ici que proposer un essai de traduction : le style télégraphique, l'emploi d'unités de mesure dont on ne sait pas toujours à quoi elles correspondent et les lacunes ne permettent pas de dresser un tableau clair du territoire en question.

224. Il s'agit de termes de mesure. 


\section{BIBLIOGRAPHIE}

\section{Textes}

Annual Report on Indian Epigraphy (1887-1905), The Director General, Archaeological Survey of India, New Delhi, réimpr. 1986.

Annual Report on Indian Epigraphy (1918-1921), The Director General, Archaeological Survey of India, New Delhi, réimpr. 1986.

Annual Report on Indian Epigraphy (1922-1925), The Director General, Archaeological Survey of India, New Delhi, réimpr. 1986.

Annual Report on Indian Epigraphy (1926-1929), The Director General, Archaeological Survey of India, New Delhi, réimpr. 1986.

\section{Bhāgavatapurāna}

1844-1884, Le Bhāgavata-purāṇa ou histoire poétique de Krichna, traduit par M. Eugène Burnouf, 4. vol, Paris, Imprimerie Royale.

\section{Cilappatikāram}

Cilappatikkāram, (ed. non accr.), Tirunelveli \& Chennai, Śaiva Siddhanta Press, 1942.

Digital Tēvāram: an Electronic Edition of the English Translation of Tēvāram by the late Subrahmanya Ayyar, Accompagnied by a Full Concordance of the Tamil Text and Various Maps and Other Informations, edited by J.-L. Chevillard and SAS Sarma, coll. « Indologie » $\mathrm{n}^{\circ}$ 103, Pondichéry, EFEO/IFP, 2007.

Epigraphia Indica, vol. IV, Calcutta/Delhi, Archaeological Survey of India. Epigraphia Indica, vol. XIII, Calcutta/Delhi, Archaeological Survey of India. Epigraphia Indica, vol. XXVI, Calcutta/Delhi, Archaeological Survey of India.

\section{Divyaprabandham}

Nalayira tivyap piranpantam, The Sacred Book of Four Thousand, by Dr. S. Jagathratchagam, English Rendered from The Sacred book by Sri Rama Bharati, Chennai, Ālvārkal Āyavumaiyum, 1993, réimpr. 2002.

\section{Harivamśa [HV]}

Harivamśa, éd. cr. P. L. Vaidya, vol. I, Introduction, critical text and notes, vol. II, Appendices, Poona, Bhandarkar Oriental Institute, 1969-1971; voir aussi A. Couture, 1991.

\section{Mahābhārata [MBh]}

Mahābhārata, éd. cr. V. S. Sukthankar, Poona, Bhandarkar Oriental Institute, 19331963. 
Manimēkalai,

Mạnimēkalai, Cāminātaiyar nul nilaiyam, Chennai, 1998.

Pattupattu,

Pattupattu, Ten Tamil Idylls, Tamil verses with English Translation, Translated by J. V. Chelliah M.A.,Thanjavur, Tamil University Reprint, Tamil University, 1985.

Pondicherry Inscriptions, Part I, Introduction and Texts with Notes, compiled by Bahour S. Kuppusamy, edited by G. Vijayavenugopal and with an Introduction by Leslie Orr, coll. «Indologie » n 83. 1, Pondichéry, EFEO/IFP, 2006.

Rāmāyaṇa

The Rāmāyana of Vālmīki, with the commentary of Rāma, Paṇsíkar (Wasudev Laxmaṇ Śāstrī) dir., IVe édition, Bombay, The Nirnayasagar Press, 1930.

The Vãlmīki Rāmāyaṇa, Bhatt G. H. dir., vol. I-VII, Baroda, Oriental Institute, 19601973.

Six Long Poems from Sangam Tamil, Translated into English verse, by N. Raghunathan, Madras - Bangalore, Vighneswara Publishing House, 1978.

South Indian Inscriptions, vol. II, part I, Madras, Archaeological Survey of India, 1891.

South Indian Inscriptions, vol. II, part II, Madras, Archaeological Survey of India, 1892.

South Indian Inscriptions, vol. II, part IV, Madras, Archaeological Survey of India, 1913.

South Indian Inscriptions, vol. III, part III, Madras, Archaeological Survey of India, 1920.

South Indian Inscriptions, vol. VI, Madras, Archaeological Survey of India, 1928.

South Indian Inscriptions, vol. VIII, Madras, Archaeological Survey of India, 1937, réimpr. 1986 (Delhi).

South Indian Inscriptions, vol. XII, Madras, Archaeological Survey of India, 1943, réimpr. 1986 (Delhi).

South Indian Inscriptions, vol. XIII, Madras, Archaeological Survey of India, 1952, réimpr. 1986 (Delhi).

South Indian Inscriptions, vol. XIX, Madras, Archaeological Survey of India, 1967, réimpr. 1988 (Delhi).

South Indian Inscriptions, vol. XXIII, Delhi, Archaeological Survey of India, 1979.

Tirupati Devasthanam Inscriptions, 1931.

Early Inscriptions translated and edited with introduction, vol. I, by S. Subrahmanya Sastry, Madras, 1931 (seconde édition : Sri Satguru Publications, Delhi, 1984).

\section{Viṣnupurāna}

The Critical Edition of the Viṣnupurānam, vol. I et II, critically edited by M. M. Pathak, Baroda, Oriental Institute of Baroda, 1997-1999; voir aussi H. H. Wilson, 1840. 


\section{Études}

BAKKER, Hans

2004 "At the Right Side of the Teacher: Imagination, Imagery, and Image in Vedic and Saiva Initiation ", dans Phyllis Granoff et Koichi Shinohara (éd.), Images in Asian Religions. Texts and Contexts, Vancouver - Toronto, University of British Columbia Press, p. 117-148.

Balasubrahmanyam, S. R.

1963 Four Chola Temples, sponsored by the Bhulabhai Memorial Institute, Bombay, N.M. Tripathi Private Ltd.

1964 «Three Tirumayam Sculptures (7th century A.D.)», Journal of Indian Museums, XVII-XX, p. 27-33.

1966 Early Chola Art, Part I, Bombay - New York, Asia Publishing House.

1967a «Three Dated Early Chola Sculptures of Erumbur », Lalit Kalā, 13, p. 16-20.

$1967 b$ "The Sculptures of the Koranganātha Temple, Srinivasanallur », Lalit Kalā, 13, p. 21-25.

1969 «Dadapuram, Śri Kari-varada Perumāl Temple», Lalit Kalā, 14, p. 43-45.

1971 Early Chola Temples. Parāntaka I to Rajaraja I (A.D. 907-985), Bombay - Calcutta - New Delhi - Madras, Orient Longman.

BARRETT, Douglas

1974 Early Chola Architecture and Sculpture (866-1014 A.D.), Londres, Faber \& Faber.

BoOTHALINGAM, M.

1969 Movement in Stone. A Study of Some Chola Temples, New Delhi, Soumani Publications Ltd. (P).

BrunNer-Lachaux, Hélène

1990 «L'image divine dans le culte agamique de Śiva. Rapport entre l'image mentale et le support concret du culte ", dans André PAdoux (éd.), L'image divine. Culte et méditation dans l'hindouisme, Paris, Éditions du CNRS, p. 9-29.

1992 «Jñana and Kriyā. Relation between Theory and Practice in the Śaivāgamas », dans Teun GoUdRIĀN (éd.), Ritual and Speculation in Early Tantrism. Studies in Honor of André Padoux, Albanie, State University of New York Press, p. 1-59.

Champakalakshmi, R.

2001 «Reappraisal of a Brahmanical Institution. The Brahmadēya and its Ramifications in Early Medieval South India ", dans Kenneth R. HALL (éd.), Structure and Society in Early South India. Essays in Honour of Noboru Karashima, New Delhi, Oxford University Press, p. 59-84.

Chevillard, Jean-Luc

2000 « Le Têvāram au xx siècle », BEFEO, 87[2], p. 729-740.

Colas, Gérard

1986 Le temple selon Marici, coll. «Publications de l'Institut Français d'Indologie $» n^{\circ} 71$, Pondichéry, Institut Français d'Indologie. 
CuTLer, Norman

2003 «Three Moments in Tamil Literary Culture », dans Sheldon Pollock (éd.), Literary Cultures in History. Reconstructions from South Asia, Berkeley (Cal.) - Londres, University of California Press, p. 271-322.

Davis, Richard H.

2000 Worshipping Śiva in Medieval India. Ritual in an Oscillating Universe, Delhi, Motilal Banarsidass.

Dehejia, V. et Tartakov, Gary Michaël

1984 «Sharing, Intrusion and Influence. The Vidya Mahișamardinī Imagery of the Calukyas and the Pallavas », Artibus Asiae, 45, p. 287-345.

DHAKY, M. A.

1971 «Cōla Sculptures », dans Karl J. Khandalavala, Anand Krishna et Chandramani Singh (éd.), Chhavi. Golden Jubilee Volume. Bharat Kala Bhavan (1920-1970), Bénarès, p. 263-289.

Filliozat, Jean

1967 «L'abandon de la vie par le sage et les suicides du criminel et du héros dans la tradition indienne ", Arts Asiatiques, 15, p. 65-88.

Filliozat, Pierre-Sylvain

2004 «Dc la conscience ct de la divinité des arbres dans la culture sanskrite », dans Eugen Ciurtin (éd.), Du corps humain, au carrefour de plusieurs savoirs en Inde. Mélanges offerts à Arion Rosu par ses collègues et amis à l'occasion de son $80^{\circ}$ anniversaire, vol. 4 (2003) et 5 (2004) de la revue Studia Asiatica, Bucarest-Paris, Université de Bucarest (Centre d'histoire des religions) - Éditions De Boccard, p. 85-103.

FRANCIS, Emmanuel

[en cours] Le discours royal. Inscriptions et monuments pallava, thèse de doctorat, en préparation à l'Institut orientaliste de l'Université Catholique de Louvain.

GILLET, Valérie

2006 L'invention d'une iconographie shivaïte. Les manifestations du dieu dans les temples construits pallava, thèse de doctorat soutenue à l'université Paris III.

GOPAL IYER, T. V.

1984 Tēvāram, Hymnes śivaïtes du pays tamoul, édition établie par T. V. Gopal IYER sous la direction de François Gros, vol. I : Nanacampantar, coll. «Publications de l'Institut Français d'Indologie» $\mathrm{n}^{\circ} 68.1$, Pondichéry, Institut Français d'Indologie.

GranOFF, Phyllis

1997 "Ganeśa as Metaphor: the Mudgala Purāna », dans Robert L. Brown (éd.), Ganesh, Studies of an Asian God, Delhi, Sri Satguru publication

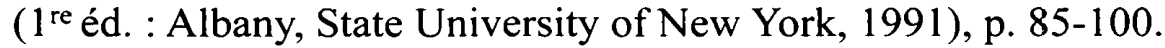

Gros, François, et Nagaswamy R.

1970 Uttaramērūr. Légendes, histoire, monuments, avec le Pañcavaradakșetra māhātmya édité par K. SRINIVASACHARYA, coll. " Publications de l'Institut Français d'Indologie $» n^{\circ} 39$, Pondichéry, Institut Français d'Indologie. 
Harle, James C.

1958 The Brahmāpurisvara Temple at Pullamangai, Bombay, Bhulabhai Memorial Institute.

1963 « Durgā, Goddess of Victory », Artibus Asiae, 26, p. 237-246.

Hoekveld-Meijer, Gerda

1982 Koyils in the Colamandalam: Typology and Development of Early Cola Temples. An art-historical study based on geographical principles, Amsterdam, Krips Repro.

Kaimal, Padma

1996 «Early Cōla Kings and "Early Cōla Temples". Art and the Evolution of Kingship ", Artibus Asiae, 58, p. 33-66.

2003 «A Man's World? Gender, Family and Architectural Patronage in Medieval India ", Archives of Asian Art, 2002-2003, p. 26-52.

Karashima, Noburu

2001a History and Society in South India. The Cholas to Vijayanagar, Delhi, Oxford University Press.

$2001 \mathrm{~b}$ « Whispering of Inscriptions », dans Kenneth R. Hall (éd.), Structure and Society in Early South India. Essays in Honour of Noboru Karashima, New Delhi, Oxford University Press, p. 44-58.

Krishna SASTRI, H.

1974 South Indian Images of Gods and Goddesses, Delhi, Bhartiya Publishing House (1 $1^{\text {re }}$ éd. Madras, Government Press, 1916).

KupPusamy \& ViJayaVENUGOPAL

Voir Pondicherry Inscriptions, Part I dans la section Textes.

LEGRAND, Blandine

1987 Külaiyūr-Mēlappaluvūr. Épanouissement d'une dynastie princière en Inde à l'époque cōla, coll. « Recherche sur les Civilisations Paris » $\mathrm{n}^{\circ} 71$, éditions du CNRS.

L'Hernault, Françoise

1978 L'iconographie de Subrahmanya au Tamilnad, coll. "Publications de l'Institut Français d'Indologie " $n^{\circ} 59$, Pondichéry, Institut Français d'Indologie.

2002 The Iconography of the Brhadiśvara Temple, ed. Lalit M. GuJRAL, New Delhi - Pondichéry, Indira Gandhi National Centre for the Arts - EFEO - Aryan Books International.

LONG, Bruce

1971 «Śiva as Promulgator of Traditional Learning and Patron deity of the Fine Arts ", Annals of the Bhandarkar Research Institute, 52, p. 67-80.

MaHALINGAM, T. V.

1988 A Topographical List of Inscriptions in the Tamil Nadu and Kerala States, Vol. I, Indian Council of Historical Research, New Delhi, S. Chand \& Company Ltd.

1992 A Topographical List of Inscriptions in the Tamil Nadu and Kerala States, Volume Seven Thanjavur District, Indian Council of Historical Research, New Delhi, S. Chand \& Company Ltd.

Meister, Michael W., et DhaKy, M. A.

1983 Encyclopaedia of Indian Temple Architecture, South India, Lower Drāvidadéśa, edited by Michael W. MeIsTER, coordinated by M. A. DHAKY, New Delhi/Philadelphia, American Institute of Indian Studies/University of Pennsylvania Press. 
Mousset \& DupuIs

1938 Dictionnaire tamoul-français, Pondichéry, Imprimerie de la Mission.

Narayanan, Vasudha

2000 «The Ramayana and its Muslim Interpreters », dans Paula Richman (éd.), Questioning Ramayanas, A South Asian Tradition, New Delhi, Oxford University Press, p. 265-281.

Nagaswamy, R.

1977 «A Note on Niśumbhasudani installed by Vijalaya Chola in Tañjore », Lalit Kalā, 18, p. 39.

Nilakanta Sastri, K. N.

1955 Cōlas, Madras, University of Madras (réimpr. : 2000, Chennai).

OrR, Leslie

2005 «Identity and Divinity: Boundary-crossing Goddesses in Medieval South India », Journal of the American Academy of Religion, 2005, vol. 73, $\mathrm{n}^{\circ} 1$, p. 9-43.

Palaniappan, S.

2004 « Ālvār or Nāyanār: The Role of Sound Variation, Hypercorrection and Folk Etymology in Interpreting the Nature of Vaisnava Saint-Poets ", dans Jean-Luc CHEviLLARD \& Eva WILDEN (éd.), with the collaboration of A. Murugayan, South Indian Horizons, Felicitation Volume for François Gros on the occasion of this $70^{\text {th }}$ birthday, , coll. « Publications de l'Institut Français d'Indologie » $n^{\circ}$ 94, Pondichéry, EFEO - IFP, p. 63-84.

Pichard, Pierre

1994 Vingt ans après Tanjavur, Gangaikondacholapuram, coll. " Mémoires Archéologiques » $\mathrm{n}^{\circ} 20$, Paris, EFEO.

1995 Tanjavur Brhadīśvara, An Architectural Study, New Delhi/Pondicherry, Indira Gandhi National Centre for the Arts - EFEO.

Pollock, Sheldon I.

1996 "The Sanskrit Cosmopolis, 300-1300: Transculturation, Vernacularization, and the Question of Ideology ", The Ideology and Status of Sanskrit in South and Southeast Asia: Contributions to the History of the Sanskrit Language, Leiden, E. J. Brill, p. 197-247.

SANDERSON, Alexis

1990 "The Visualisation of the Deities of the Trika », dans L'image divine, culte et méditation dans l'hindouisme, études rassemblées par André Padoux, Paris, éditions du CNRS, p. 31-88.

SANFORD, David Theron

1974 Early Temples Bearing Rāmāyana Relief Cycles in the Chola Area: A Comparative Study, Los Angeles, University of California, PhD Dissertation.

1987 «Miniature Relief Sculptures at the Pullamangai Siva Temple, with Special Reference to the Ramayana Sequence », Kusumãñjali, vol. II, M. S. Nagaraja Rao éd., Delhi, Agam Kalam Prakashan, p. 277-292.

SCHMID, Charlotte

2002 «Aventures divines de Krṣna : la lìlā et les traditions narratives cōla », Arts Asiatiques, 57, p. 33-50.

2004a « $\mathrm{A}$ propos des premières images de la Tueuse de buffle : déesses et krishnaïsme ancien », BEFEO, 90-91, p. 7-67. 
2004b « Le sanglier qui danse : étude iconographique d'un avatar de Viṣnu », dans Eugen CIURTIN (éd.), Du corps humain, au carrefour de plusieurs savoirs en Inde. Mélanges offerts à Arion Roşu par ses collègues et amis à l'occasion de son $80^{\circ}$ anniversaire, vol. 4 (2003) et 5 (2004) de la revue Studia Asiatica, Bucarest-Paris, Université de Bucarest (Centre d'histoire des religions) - Éditions De Boccard, p. 579-610.

2005 "Mahabalipuram, la Prospérité aux deux visages », Journal Asiatique, 293. 2, (2005), p. 459-528.

[à paraître] «Déesses indiennes entre rituel et mythe : meurtre et sacrifice du buffle du Nord au Sud».

Sethuraman, G.

1994 "The Artistic Significance of the Galapāda Motifs of Brahmāpurīśvara Temple, Pullamangai », Käla, 1, p. 33-38.

Stein, Burton

1999 Peasant State and Society in Medieval South India, Oxford University Press, Delhi (première édition : 1980).

SubBarayalu, Y.

1973 Political Geography of the Chola Country, Tamil Nadu, State Department of Archaeology, Government of Tamil Nadu.

Subrahmaniam, T. N.

1958 «Chōḷa Jaina Copper - Plate Grant», Transactions of the Archaeological Society of South India, 1957-1958, p. 84-110.

Swaminathan, S.

1998 The Early Chōlas - History, Art and Culture, Delhi Sharada Publishing House.

ANNEXE

Les séries narratives

Cette annexe présente la liste des panneaux des deux séries, désignées par les lettres $a$ et $b$ pour chacun des soixante-quatre emplacements théoriquement disponibles, décorant la base du temple, avec les scènes représentées quand elles sont identifiées. Les références afférentes des épisodes krishnaïtes et de ceux qu'inspire le Rāmāyaṇa sont données à la suite de l'identification. Les références des épisodes krishnaites sont celles des éditions critiques du Harivamśa [HV] (Poona, Bhandarkar Institute) et du Visnupurāna [VP] (Baroda, Oriental Institute), et celles de l'édition d'Emile Burnouf (1844-1884) du Bhāgavatapurāṇa [BhP]. La première référence du Rāmāyana renvoie à l'édition de la Nirnayasagar Press du Rāmāyana de Vālmiki ; la deuxième à l'édition critique du même texte par l'Oriental Institute de Baroda.

Les panneaux recouverts sont indiqués comme tels, les panneaux comportant des feuillages également et ceux dont l'identification est problématique, brièvement décrits. Les éventuelles illustrations sont signalées. 


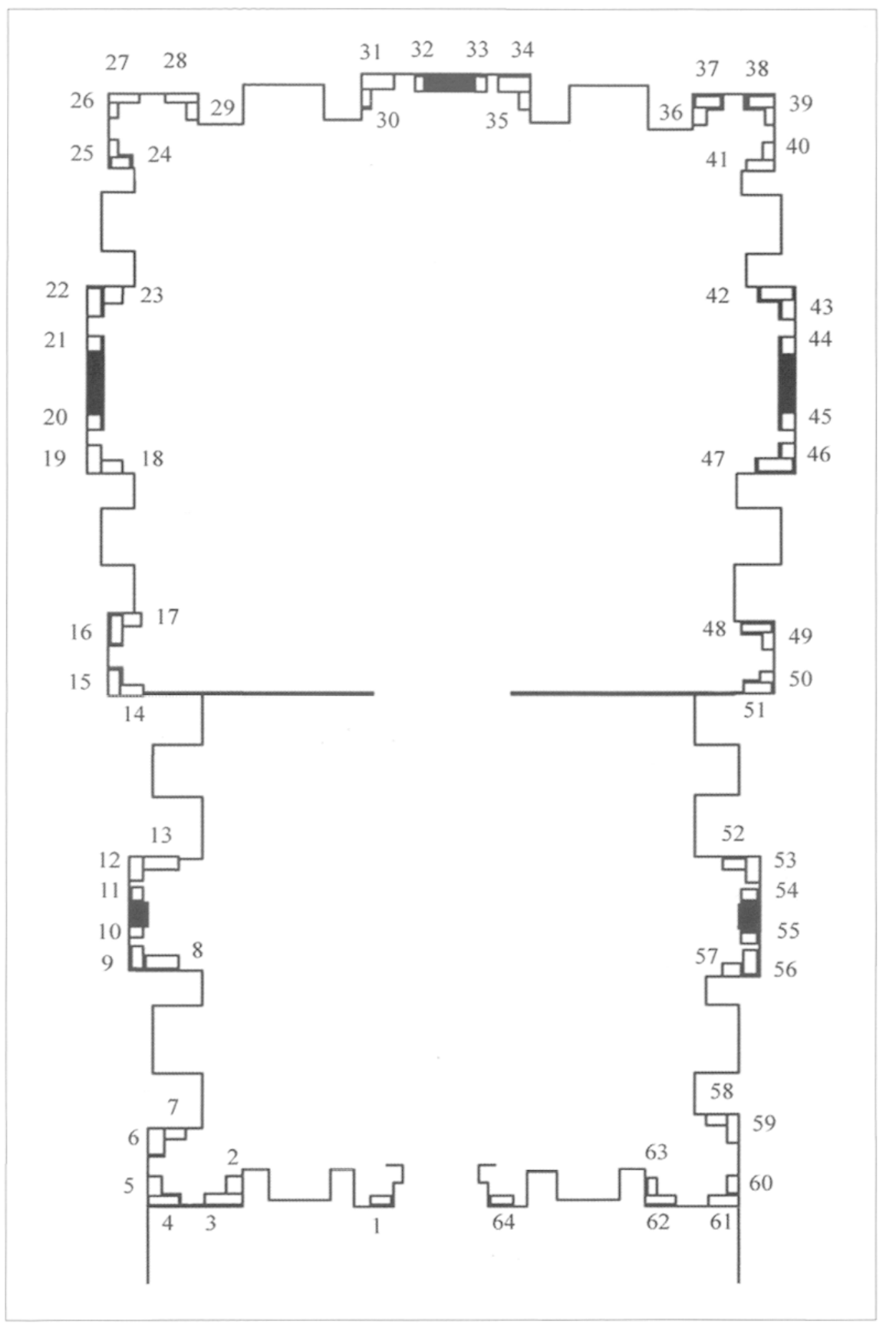

Fig. 57 : Schéma du temple, avec les numéros des panneaux correspondant aux séries 1 (a) et 2 (b).

1, a : recouvert.

1, b : Rāma, Lakṣmaṇa et Sītā sur un char à cheval, accompagnés de plusieurs personnages, dont un personnage barbu qui prend place dans le char. Ce panneau a été dégagé par les soins de l'équipe et avec la bénédiction de M. Kumar, prêtre actuel du temple. Étant donné que la traversée du Gange est le panneau identifiable qui suit, nous proposons de l'identifier comme le départ pour la forêt dans le char de Sumantra ; Ayodhyākāṇda 40. 17-22 ; Ayodhyākāṇda 35. 14-19.

$2, \mathrm{a}:$ recouvert.

$2, \mathrm{~b}:$ recouvert.

3 , a : recouvert.

3 , b : recouvert. 
4, a : recouvert.

$4, b$ : recouvert.

5, a : feuillage.

5, b : la traversée du Gange ; Ayodhyākāṇụa 55. 74-92 ; Ayodhyākāṇḍa 46. 61-74.

6, a : le combat entre Arjuna et le Kirāta.

6, b : l'arrivée à l'ermitage de Bharadvāja ; Ayodhyākāṇ̣̣a 54. 8-20; Ayodhyākāṇ̣̣a 48. 8-18.

7 , a : feuillage.

7, b : la traversée de la Yamunā ; Ayodhyākāṇ̣a 55. 13-22 ; Ayodhyākāṇụa 49. 9-11 ; fig. 21.

8, a : feuillage.

$8, \mathrm{~b}:$ feuillage.

9, a : la mort de Virādha ; Āranyakānda 3. 21-26 ; Āranyakānda 3. 14-16ac ; $11 . .$.

9, b : le départ de l'armée de Bharata ; Ayodhyākāṇụa 55. 13-22 ; Ayodhyākāṇ̣̣a 49. 9-11.

10, a : Harihara.

10, b : l'arrivée à l'ermitage d'Atri (1) : Rāma, Sītā et Lakṣmaṇa ; Ayodhyākāṇ̣a 117. 3-8 ; Ayodhyākāṇ̣ạa 109. 3-8.

11, a : Ardhanārīisvara.

11, b : l'arrivée à l'ermitage d'Atri (2) : Atri et les sages ; Ayodhyākāṇụa 117. 3-8 ; Ayodhyākāṇda 109. 3-8.

12, a : Narasimha.

12, b : l'apparition de Virādha ; Āraṇyakāṇ̣̣a 2. 4-8ab ; Āranyakāṇ̣̣a 2. 4-8ab ; fig. 33.

13 , a : feuillage.

$13, \mathrm{~b}$ : feuillage.

14, a : Pralambavadha ; HV 58, 50-52 ; VP V, 9. 34-38 ; BhP X, 18. 24-29.

14, b : la mort de Virādha ; Āranyakāṇụa 3. 21-26 ; Āranyakāṇḍa 3. 14-16ac ; fig. 34.

15, a : Śiva dansant ; fig. 39.

15, b : l'arrivée de Sūrpaṇakhā ; Āraṇyakāṇụa 17. 1 - 18 ; Āraṇyakāṇ̣̣a 16. 3-18.

16, a : Śiva mendiant (bhikșātanamūrti) ; fig. 35.

16, b : la lutte de Lakșmana et de Śūrpanakha ; Āranyakānda 18. 14-21 ; Āranyakāṇda 17. 14-21.

17, a : feuillage.

17, b : Śūrpaṇakha se plaint à Khara et à Triśiras ; Āraṇakāṇụa 18. 24-26 ; 19. 1-20 ; Āranyakāṇḍa 17. $25-26 ; 18.1-16$.

18, a : trois gana dansant (motif d'acrobate).

18, b : le combat de Rāma contre l'armée de Khara ; Āraṇyakāṇ̣a 20. 3-21 ; Āraṇyakāṇ̣a 19. 3-22.

19 , a : recouvert.

$19, \mathrm{~b}:$ recouvert.

20, a : recouvert.

$20, \mathrm{~b}:$ recouvert.

21, a : recouvert.

$21, \mathrm{~b}:$ recouvert. 
22 , a : recouvert.

$22, \mathrm{~b}$ : recouvert.

23, a : Gan̉gādhara.

23, b : Śūrpanakha se plaint à Rāvaṇa ; Āranyakāṇḍa 32. 22-25 ; 33 et 34 (entier) ; Āraṇakāṇḍa 30. 4-23, 31 et 32 (entier).

24 , a : feuillage.

24, b : l'entrevue de Rãvaṇa et de Mārīca ; Āraṇyakāṇ̣a 35. 37-42, 36, 1 ; Āraṇyakāṇụa 33. 36-38 ; 34. 1 .

25, a : une déesse échevelée plongeant son trident dans le corps du démon qu'elle domine ; fig. 40 .

25, b : trois scènes sont représentées dans ce panneau : (1) Rāma à la poursuite du daim Mārīca (Āranyakānda 44. 1-12 ; Āranyakāṇ̣a 42. 1-9) ; (2) Rāma tirant une flèche sur Mārīca (Āraṇyakāṇda 44. 13-16 ; Ȧranyakāṇda 42. 10-12) ; (3) Mārīca retrouvant sa forme humaine (Āraṇyakāṇạa 44. 17-21 ; Āraṇyakāṇụa 42. 13-16); fig. 41.

26, a : Śiva tue le démon éléphant (gajasaṃharamūrti) ; fig. 36.

26, b : l'enlèvement de Sītā ; Āranyakāṇụa 52. 13-18 ; Āraṇyakāṇụa 50. 12-17.

27, a : homme combattant un lion.

27, b : le combat de Jaṭāyus et de Rāvaṇa ; Āraṇyakāṇụa 51. 37-42 ; Āraṇyakāṇ̣̣a 49. 34-37.

28, a : Viṣnu et Śiva.

28, b : la rencontre de Rāma et Lakṣmaṇa avec Jaṭāyus ; Āraṇyakāṇḍa 67.14-28 ; Āranyakāṇda 63. $13-25$.

29 , a : vide.

$29, \mathrm{~b}$ : feuillage.

30, a : feuillage.

30, b : le combat contre Kabandha ; Āraṇyakāṇ̣̣a 69. 27, 35-36 ; 70. 8-9. ; Āraṇyakāṇụa 65. 15, $22-23 ; 66.5-6$.

31, a : Siva porteur de son linga.

31, b : les dieux vont chercher conseil auprès de Brahmā ; Bālakāṇụa 15. 4-15 ; Bālakāṇ̣a 14. 515 ; fig. 25.

32, a : feuillage.

32, b : Brahmā et les dieux vont demander à Viṣnu de s'incarner (1) : Brahmā et les dieux se tournent vers Viṣṇu ; Bālakāṇ̣̣a 15. 16-21, 16. 1-8 ; Bālakāṇ̣̣a 14. 16-21, 15. 1-7 ; fig. 26.

33, a : feuillage.

33, b : Brahmā et les dieux vont demander à Viṣṇu de s'incarner (2) : Viṣnu accueille Brahmā et les dieux, appuyé sur Garựa ; Bālakāṇụa 15. 16-21, 16. 1-8 ; Bālakāṇụa 14. 16-21, 15. 1-7 ; fíg. 27.

34, a : Siva couronnant Caṇ̣eśa.

34, b : Viṣnu couché sur le serpent : symbole du processus d’incarnation ; fig. 28.

35, a : feuillage.

35, b : l'apparition dans le feu du personnage donnant le payasam à Daśaratha ; Bālakāṇda 16.11 24 ; Bālakāṇụa 15. 7-22 ; fig. 29.

36, a : gana assis sur une guirlande.

36, b : le payasam est distribué aux épouses de Daśaratha ; Bālakāṇụa 16. 25-30 ; Bālakāṇḍa 15. 23-28. 
37, a : Kāmāntaka.

37, b : le choix des noms des enfants ; Bālakāṇụa 18. 21-24ab ; Bālakāṇ̣̣a 17. 10-12.

38, a : la scène n'est pas identifiée ; Śiva assis semblant consoler Pārvatī (peut-être une suite de la scène précédente).

38, b : l'enseignement de la science de l'arc ; Bālakāṇ̣a 18. 36cd-37ab ; Bālakāṇ̣a 17. 513 *, 514 *, 1. $38-43$; fig. $42^{225}$.

39, a : la mort de Vali ; Kiṣkindhākāṇḍa 22. 1-3, 24-31 ; Kiṣkindhākāṇụa 16. 13-24 ${ }^{226}$.

39, b : l'entrevue de Viśvāmitra et de Daśaratha ; Bālakāṇ̣a 18. 49b-59; $19 ; 20 ; 21$; Bālakāṇ̣a 17. $31-39 ; 18 ; 19$.

40, a : Varāha.

40, b : le combat de Rāma et de Tāṭaka ; Bālakāṇụa 26. 6-26ab ; Bālakāṇ̣a 25. 6-15.

41, a : déesse échevelée poursuivant deux démons avec son trident.

41, b : le panneau est trop abîmé pour tenter une identification.

42, a : une danseuse et une musicienne.

42, b : Rāma et Lakṣmaṇa gardiens du sacrifice de Viśvamitra : ils écoutent les mantra présidant au sacrifice ; Bālakāṇụa 30. 7-10 ; Bālakāṇụa 29. 7-9.

43, a : Śiva dansant; fig. 38.

43, b : Combat de Rāma contre Mārīca, Subāhu et autres démons ; Bālakāṇ̣a 30. 10-23 ; Bālakāṇ̣a 29. 10-20.

44, a : Dhenukavadha ; HV 57, 17-20 ; VP V, 8. 1-10 ; BhP X, 15. 29-32.

44, b : Viśvamitra, Rāma et Lakṣmaṇa se dirigeant vers l'ermitage de Gautama ; Bālakāṇụa 48. 11-12, 49. 11-12 ; Bālakāṇụa 47. 11, 48. 11-12.

45, a : le combat contre Keśin ; HV 67, 22-42; VP V, 16. 1-15 ; BhP X, 37. 1-8.

45, b : la libération d’Ahalyā ; Bālakāṇ̣̣a 49.13-16 ; Bālakāṇụa 48. 13-16.

46, a : Tripurāntaka, (supra note 43); fig. 37.

46, b : l'entrevue entre Viśvamitra et Janaka ; Bālakāṇụa 50. 10-25, 51, 1-4 ; Bālakāṇụa 49. 10-25, 50. $1-4$.

47, a : Śiva dansant.

47, b : Rārna brise l’arc de Rudra ; Bālakāṇ̣̣a 67. 13-19 ; Bālakāṇụa 66. 13-19.

225. Cette scène est très fréquente dans les représentations du cycle du Rāmãyana sur les bases des temples cōla et il est donc remarquable qu'elle ne corresponde pas aux textes connus. Dans l'édition de la Nirnayasagar Press, le thème de l'enseignement apparaît mais il n'est pas particulièrement axé sur un enseignement de l'art de l'arc, qui est ici représenté ; le thème même de l'instruction est rejeté en appendice dans l'édition critique de Baroda. Les représentations prouvent pourtant que ce thème était populaire en Inde du Sud, dès le $\mathrm{IX}^{\mathrm{e}}$ siècle sans doute. Si l'on considère le Rāmāyaña avant tout sous l'angle de l'enseignement qu'il contient, et donc sa représentation comme participant de la transmission d'un enseignement, la portée du thème dont on a constaté l'importance dans ce temple (supra: 57-61) se comprend aisément. Son rejet par l'édition critique pose des questions nouvelles. Les représentations et les textes conservés par l'intermédiaire des manuscrits relevaient-ils de domaines où le même texte était utilisé différemment? Plaisir esthétique, valeurs morales, langue... on peut mettre l'accent sur tel ou tel aspect du texte ; ou alors, faut-il supposer des textes dont on n'a conservé aucune autre trace que ces représentations?

226. Cette scène est souvent représentée ; il est ici remarquable qu'elle apparaisse dans la série 1, alors qu'elle n'apparaît pas dans la série 2. 
48, a : feuillage avec un gana décoratif.

48, b : le mariage de Sītā et de Rāma ; Bālakāṇ̣a 73. 24-29 ; Bālakāṇụa 72. 16-17.

49, a : Rājamannār.

49, b : le mariage de Lakṣmaṇa et d'Uurmilā ; Bālakāṇḍa 73. 30-31 ; Bālakāṇḍa 72.18.

50, a : Mahișamardin̄̄ ; fig. 30.

50, b : le mariage de Māṇụāi et de Bharata, et celui de Śatrughna et de Śrutakīrti ; Bālakāṇda 73. 32-36 ; Bālakāṇ̣̣a 72. 19-20.

51, a : la mort de Pūtanā ; HV 50, 20-33 ; VP V, 5. 57-11; BhP X, 6. 8-18ab.

51, b : Daśaratha retourne à Ayodhyā ; Bālakāṇ̣̣a 74. 7cd-8ab ; Bālakāṇ̣̣a 73. 7cd-8ab.

52 , a : feuillage.

$52, \mathrm{~b}:$ feuillage.

53, a : Trivikrama.

53, b : Rāma tend l'arc de Paraśurāma ; Bālakāṇụa 76. 4-12, 19-24 ; Bālakāṇụa 75. 4-12, 21 -33.

54, a : recouvert.

54, b : le départ de Bharata et de Śatrughna accompagné de Yudhajit ; Bālakāṇụa 18. 21-24ab ; Bālakāṇ̣a 17. 10-12.

55 , a : recouvert.

55 , b : le panneau est très abîmé ; plusieurs personnages prennent des poses complexes : combat, danse?

56, a : l'apparition de Virādha.

$56, \mathrm{~b}$ : quatre personnages, dont au moins un féminin, dans un char ; la scène n'est pas identifiée.

À partir de ce panneau, les scènes de la deuxième série ne semblent pas assurer de continuité sur la face nord.

57, a : un cheval attaqué par un éléphant ; fig. 32.

$57, \mathrm{~b}$ : une femme enceinte marchant entre deux femmes ${ }^{227}$.

58 , a : feuillage.

$58, \mathrm{~b}$ : Daśaratha s'adresse à ses quatre fils ; la scène n'est pas identifiée plus précisément.

59, a : la première plainte de Śūrpanakhā.

$59, \mathrm{~b}$ : quatre femmes autour d'un gros récipient ${ }^{228}$.

60, a : recouvert.

$60, b$ : scène de harem : une femme allongée sur un lit, entourée de plusieurs femmes.

61, a : recouvert.

$61, \mathrm{~b}:$ recouvert.

62 , a : recouvert.

$62, \mathrm{~b}:$ recouvert.

227. Cette scène est représentée dans de nombreux temples, sur le soubassement comme ici, ou à d'autres emplacements secondaires, sans aucune relation avec le Rāmāyana.

228. Cette scène est représentée dans plusieurs autres temples, sans aucune relation avec le Rāmāyana ; elle est cependant moins courante que la scène de la femme enceinte (emplacement $57, \mathrm{~b}$ ). 
63 , a : recouvert.

$63, \mathrm{~b}:$ feuillage.

64 , a : recouvert.

$64, \mathrm{~b}$ : le panneau est très abîmé ; on distingue cinq silhouettes.

\section{Liste des figures}

\section{Un très grand merci à Emmanuel Francis et à G. Ravindran à qui l'article doit la plupart de ses illustrations.}

Fig. 1. Le temple derrière l'enceinte moderne, angle sud-ouest. Cliché : E. Francis.

Fig. 2. La face nord du temple, vue de l'extérieur de l'enceinte. Cliché : E. Francis.

Fig. 3. La face nord du temple, vue de l'intérieur de l'enceinte. Cliché : E. Francis.

Fig. 4. Elément de décor sur un pilier intérieur. Cliché : E. Francis.

Fig. 5. Détail du décor d'un pilastre extérieur. Cliché : E. Francis.

Fig. 6. Un gana, ornant le bord du toit du mandapa, (face sud). Cliché : E. Francis.

Fig. 7. Krṇna luttant contre Keśin, décor de pilastre (face sud). Cliché : E. Francis.

Fig. 8. Temple en réduction carré marquant l'angle du mandapa (angle sud-est). Cliché : E. Francis.

Fig. 9. La facc sud du temple: Ganeśa et la succession des éléments de décor sur lés murs extérieurs. Cliché : E. Francis.

Fig. 10. Le temple, vu de l'angle sud-ouest : on voit se succéder les niches marquant le rythme des murs extérieurs. Cliché : E. Francis.

Fig. 11. Śiva en posture de méditation, premier étage du couronnement, face est. Cliché : E. Francis.

Fig. 12. Śiva Bhikșātana, premier étage du couronnement, face sud. Cliché : E. Francis.

Fig. 13. Viṣnu assis sur le serpent, premier étage du couronnement, face ouest. Cliché : E. Francis.

Fig. 14. Narasiṃha, deuxième étage du couronnement, face ouest. Cliché : E. Francis.

Fig. 15. Rāma et son arc, élément intermédiaire du couronnement, face nord. Cliché : E. Francis.

Fig. 16. La déesse de la face nord. Cliché : E. Francis.

Fig. 17. Un des adorateurs de la déesse, face nord. Cliché : E. Francis.

Fig. 18. Une des montures de la déesse de la face nord : l'antilope. Cliché : E. Francis.

Fig. 19. Brahmā, face nord du prāsāda. Cliché : E. Francis.

Fig. 20. Le soubassement portant les séries narratives. Cliché : G. Ravindran.

Fig. 21. La traversée de la Yamunā ; série 2, face sud (emplacement $n^{\circ} 7$ ). Cliché : G. Ravindran.

Fig. 22. Le dispositif iconographique de la face ouest. Cliché : E. Francis.

Fig. 23. Le Brahmā de la face ouest. Cliché : E. Francis.

Fig. 24. Le Viṣnu de la face ouest. Cliché : E. Francis.

Fig. 25. Brahmā assis sur le lotus ; série 2, face ouest (emplacement $n^{\circ} 31$ ). Cliché : G. Ravindran.

Fig. 26. La députation des dieux auprès de Visnu ; série 2, face ouest (emplacement $n^{\circ} 32$ ). Cliché : E. Francis.

Fig. 27. Viṣnu appuyé sur Garuḍa écoute les dieux; série 2, face ouest (emplacement $n^{\circ} 33$ ). Cliché : G. Ravindran.

Fig. 28. Visnu couché sur le serpent ; série 2, face ouest (emplacement $\left.n^{\circ} 34\right)$. Cliché : E. Francis.

Fig. 29. Le sacrifice de Daśaratha ; série 2, face ouest (emplacement $n^{\circ} 35$ ). Cliché : G. Ravindran.

Fig. 30. Mahișamardin̄ ; série 1 , face nord (emplacement $n^{\circ} 50$ ). Cliché : G. Ravindran.

Fig. 31. La mort de Virādha ; série 1, face sud (emplacement $n^{\circ}$ 9). Cliché : G. Ravindran.

Fig. 32. Le combat d'un éléphant et d'un cheval ; série 1, face nord (emplacement $n^{\circ} 57$ ). Cliché : E. Francis.

Fig. 33. L'apparition de Virādha ; série 2, face sud (emplacement $n^{\circ} 12$ ). Cliché : G. Ravindran.

Fig. 34. La mort de Virādha ; série 2, face sud (emplacement $n^{\circ} 14$ ). Cliché : G. Ravindran.

Fig. 35. Śiva mendiant ; série 1, face sud (emplacement $\left.n^{\circ} 16\right)$. Cliché : E. Francis.

Fig. 36. Śiva tue le démon éléphant; série 1, face sud (emplacement $\left.\mathrm{n}^{\circ} 26\right)$. Cliché : E. Francis.

Fig. 37. Siva Tripurāntaka ; série 1, face nord (emplacement $\left.n^{\circ} 46\right)$. Cliché : E. Francis.

Fig. 38. Śiva dansant ; série 1, face nord (emplacement $n^{\circ} 43$ ). Cliché : E. Francis.

Fig. 39. Śiva dansant; série 1, face sud (emplacement $n^{\circ} 15$ ). Cliché : G. Ravindran.

Fig. 40. Déesse échevelée plongeant son trident dans le corps d'un démon; série 1, face sud (emplacement $\left.n^{\circ} 25\right)$.

Cliché : G. Ravindran. 
Fig. 41. Le panneau consacré à la poursuite de Mārīca ; série 2, face sud (emplacement $\left.n^{\circ} 25\right)$. Cliché : G. Ravindran. Fig. 42. L'enseignement de la science de l'arc; série 2, face nord (emplacement $n^{\circ} 38$ ). Cliché : E. Francis.

Fig. 43. Inscription $n^{\circ} 16,1.34-36$. Cliché : E. Francis.

Fig. 44. Inscription $n^{\circ}$ 6. Cliché : G. Ravindran.

Fig. 45. Inscription $n^{\circ} 18$. Cliché : E. Francis.

Fig. 46. Détail de l'inscription $n^{\circ} 18:$ « les lettres invisibles ». Cliché : E. Francis.

Fig. 47. Inscription $n^{\circ} 15$. Cliché : Ch. Schmid.

Fig. 48. Inscription $n^{\circ} 15$, détail : fin de l'inscription. Cliché : E. Francis.

Fig. 49. Inscription $n^{\circ} 17$. Cliché : Ch. Schmid.

Fig. 50. Inscription $n^{\circ} 19$, détail : début de l'inscription. Cliché : E. Francis.

Fig. 51. Inscription $n^{\circ} 12$, début de l'inscription. Cliché : E. Francis.

Fig. 52. Inscription $n^{\circ} 16$, détail : début de l'inscription. Cliché : E. Francis.

Fig. 53. Inscription $n^{\circ} 16$, détail. Cliché : E. Francis.

Fig. 54. Inscription $n^{\circ} 22$, détail : l’inscription est en partie prise sous le ciment. Cliché : E. Francis.

Fig. 55 : Localisation des inscriptions sur les faces est et ouest du temple. Dessin : N. Ramaswamy-E. Francis. Fig. 56 : Localisation des inscriptions sur les faces nord et sud du temple. Dessin : N. Ramaswamy-E. Francis.

Fig. 57 : Schéma du temple, avec les numéros des panneaux correspondant aux séries 1 (a) et 2 (b). 